

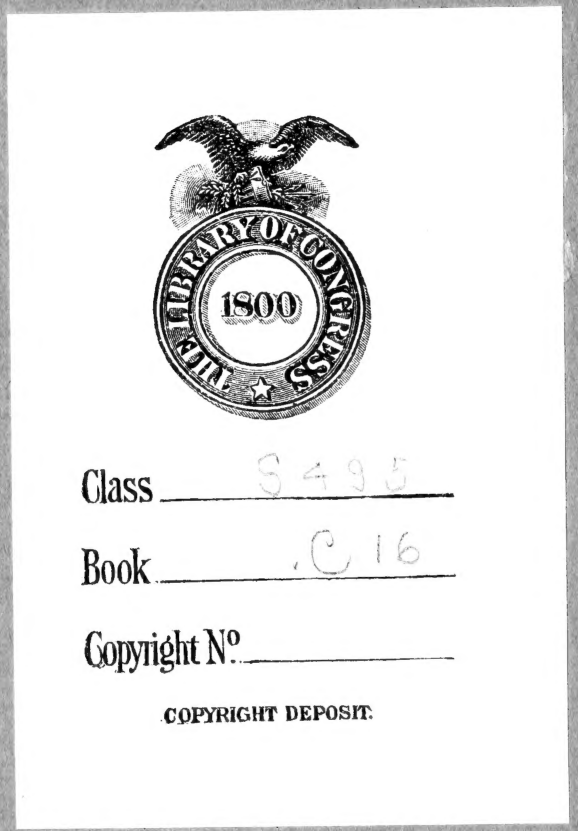




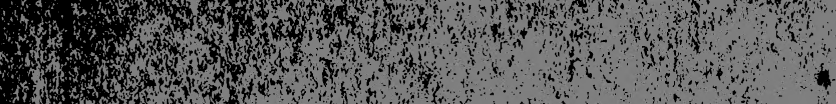

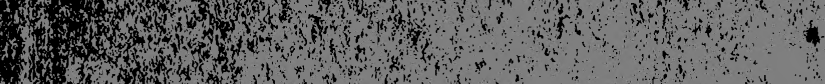

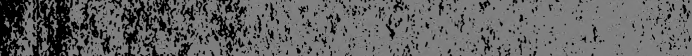

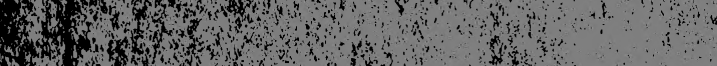

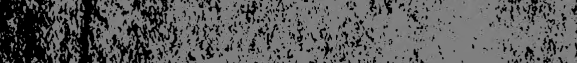

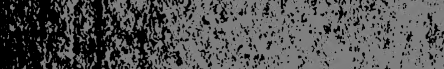

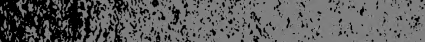

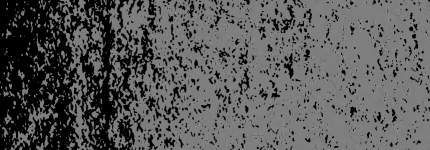

Wo

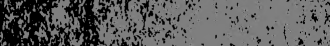

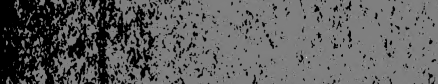

Hento

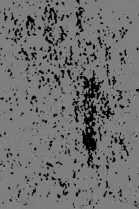

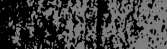

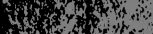

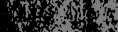

(n)

wos

(w) $x+2$,

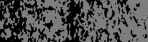

(3)

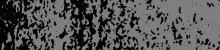

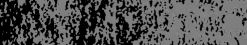

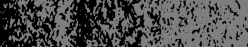

W

(4)
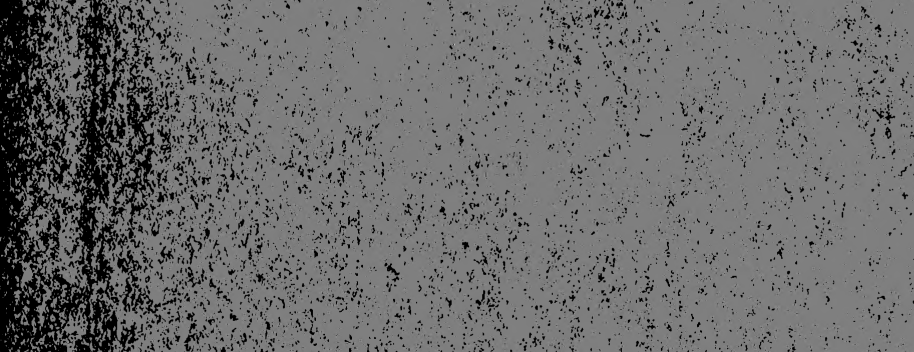
$+3+\infty$
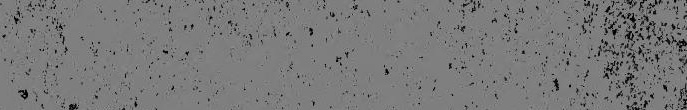

$\therefore \quad \therefore$ is

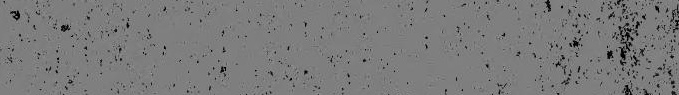

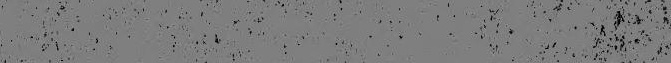

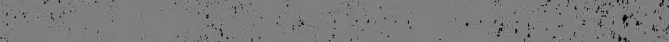

$=$
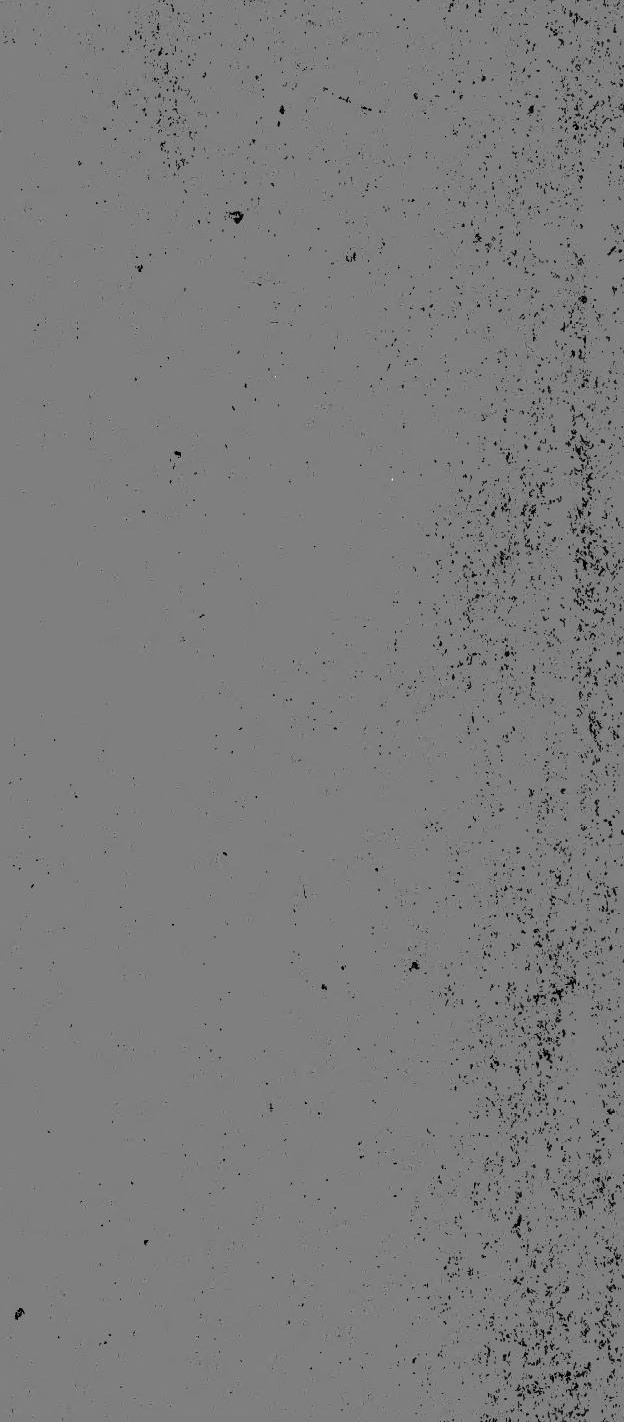


\section{A LABORATORY MANUAL OF AGRICULTURE FOR SECONDARY SCHOOLS}




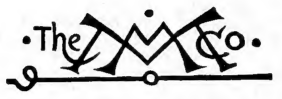

\section{THE MACMILLAN COMPANY \\ NEW YORK - BOSTON - CHICAGO \\ DALLAS - SAN FRANCISCO \\ MACMILLAN \& CO., LIMITED \\ LONDON - BOMBAY - CALCUTTA \\ MELBOURNE}

THE MACMILLAN CO. OF CANADA, Ltd. TORONTO 


\section{A LABORATORY}

\section{MANUAL OF AGRICULTURE}

\section{FOR SECONDARY SCHOOLS}

BY

LELAND E. CAALL, M.S.

ASSOCIATE PROFESSOR OF SOILS IN THE KANSAS

STATE AGRICULTURAL COLLEGE

AND

E. G. SCHAFER, M.S.

INSTRUCTOR IN FARM CROPS IN THE KANSAS

STATE AGRICULTURAL COLLEGE

XYeor 洫ark

THE MACMILLAN COMPANY

1912 


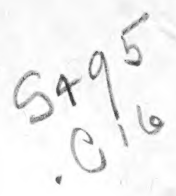

Coprright, 1912,

BY THE MACMILLAN COMPANY.

Set up and electrotyped. Published October, I9i2.

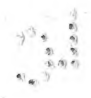

Norwoot 据ress

J. S. Cushing Co. - Berwick \& Smith Co.

Norwood, Mass., U.S.A. 


\section{PREFACE}

As population increases, society is demanding greater efficiency on the part of the producers - the men and women who feed, clothe, and shelter society. This demand can be met only by giving the producers an education that will function in greater social and vocational efficiency. During the last decade there has been an increasing interest in agricultural education for the secondary schools.

The greatest danger to agriculture as a subject for a course of study in high schools has resulted from attempting to make it conform to the organizing ideas of that kind of education that has for its controlling motive formal discipline, instead of making it strictly vocational. The result is that agriculture is being taught as a textbook subject in too many of the high schools. This is due largely, no doubt, to the fact that there have been no laboratory and field guides in agriculture adapted to high schools. The controlling motive in the organization of a course in agriculture should be vocational efficiency.

The authors of this manual are experts in agriculture. Both of them have spent much time in studying how agriculture can be adapted to the needs of secondary education. Their training and experience in teaching the subject have admirably fitted them to prepare a workable manual for 
the high schools. I have examined carefully every lesson in the manual and have seen many of them worked out in the laboratory and field, and I am firmly convinced that it meets an urgent need in the high schools to-day. It is scientific, systematic, and, above everything else, it is a workable manual. It can be adapted to the needs of the small and the large high schools.

In writing this valuable manual the authors have done credit to themselves and have rendered a great service to the high schools.

Edwin L. Holton.

Department of Rural Education,

Kansas State Agricultural College. 


\section{ACKNOWLEDGMENTS}

IN the preparation of this manual the authors have used freely every available source of information. They are indebted to Pres. H. J. Waters, Prof. E. L. Holton, Prof. Albert Dickens, Prof. J. W. Searson, Prof. H. L. Kent, Prof. G. H. Hine, Mr. C. F. Chase, and Mr. W. T. McCampbell, of Kansas State Agriculture College, for suggestions and assistance in the preparation of this manual.

They are also indebted to the Animal Husbandry Department of Purdue University for illustrations Nos. 15, 21, 22, and 23 ; to the Animal Husbandry Department of Kansas State Agricultural College for illustrations Nos. 18 and 20; to the Dairy Department of Kansas State Agricultural College for illustration No. 19 ; and to Mr. H. Yuasa for assistance in the preparation of drawings.

Material taken from other sources has been properly credited where it appears in the manual. 



\section{CONTENTS}

\section{EXERCISES FOR SEPTEMBER}

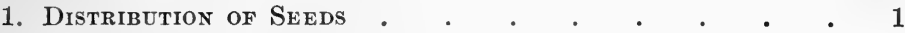

2. A Field Lesson on the Study of Corn . . . . 5

3. A Study of Soil Particles . . . . . . . . . 8

4. A Field Lesson in Soils . . . . . . . . 14

5. The Influence of Vegetation on Soll Temperature $\quad 19$

6. A Soll Moisture Study . . . . . . . . . 23

\section{EXERCISES FOR OCTOBER}

7. A Soll Moisture Study (Continued) . . . . . 23

8. The Rise of Capillary Water in Solls . . . . 30

9. The Percolation of Water in Solls . . . . . 34

10. The Weight of Soll per Cubic Foot . . . . . 40

11. Capacity of Solls to hold Moisture . . . . . 44

12. Soll Drainage . . . . . . . • • . 49

13. Soll Mulches /. . . . . . . . . . . . . 53

14. The Effect of Undecayed Organic Matter on the Rise of Soll Moisture.

15. Collecting Material for Starting Plants (Field Lesson). 63

\section{EXERCISES FOR NOVEMBER}

16. The Early Developient of the Wheat Plant . • . 66

17. The Early Development of the Rye Plant . • . 71

18. The Early Development of the Corn Plant . . . 75

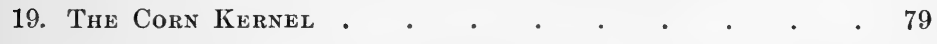




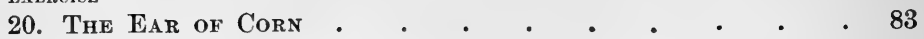

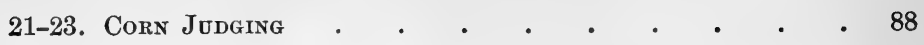

EXERCISES FOR DECEMBER

24. A Study of Shelled Corn . . . . . . . 100

25. A Study of the Wheat Head . . . . . . 105

26. A Study of the Rye Head . . . . . . . 111

27-28. A Study of Wheat . . . . . . . . 116

29. A Study of Rye . . . . . . . . . . 121

30. A Study of the Barley Head . . . . . . . 124

EXERCISES FOR JANUARY

31. A Study of the OAt Head . . . . . . . . . 129

32. A Study of Barley . . . . . . . . . 133

33. A Study of OAts . . . . . . . . . . . 137

34. A Study of the Sorghum Head . . . . . . . 141

35. A Study of Sorghum Seed . . . . . . . . . 144

36. A Study of Cowpeas or Soy Beans . . . . . 148

37. The Capacity of Grain to absorb Moisture • . . 151

38. Factors affecting the Germination of Seeds • . . 154

\section{EXERCISES FOR FEBRUARY}

39. A Germination Test of Clover or Grass Seed . • 159

40. A Study of Grass Seed . . . . . . . . . 162

41. A Study of Alfalfa Seed . . . . . . . . 165

42. A Study of the Plow . . . . . . . . . . 168

43. A Study of the Grain Grader or Fanning Mill • 171

44. The Corn Grader . . . . . . . . . 175

45. The Corn Planter. . . . . . . . . . 178

46. Accuracy of Drop of the Corn Planter . . . 182 


\section{EXERCISES FOR MARCH}

EXERCISE

47. Treatment of Seed Oats for Siut . • • • • 185

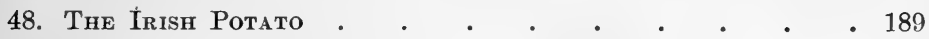

49-50. Planning the Home Garden . . . . . . 193

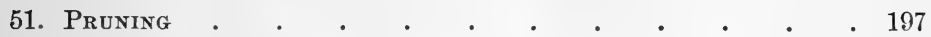

52-53. ВАвсоск ТеST . . . . . . . . 200

54. Mixing Spray Material . . • • • • . . 205

55. GRAfTING . . . . . . . . . . . . 209

EXERCISES FOR APRIL

56-57. Germination Test of Seed Corn . . . . . 213

58. The Early Development of the Barley Plant . . 218

59. The Early Development of the Oat Plant . . . 222

60. Judging Draft Horses . . . . . . . . 226

61. Judging Light Horses . . . . . . . . . . 236

62. Comparative Judging of Horses . . . . . . 244

63. Judging Dairy Cattle . . . . . . . . . . . 249

EXERCISES FOR MAY

64. Judging Beef Cattle . . . . . . . . . 257

65. Comparative Judging of Cattle . . . . . . 263

66. Judging Fat Hogs . . . . . . . . . .

67. JUdging Mutton Sheep . . . . . . . . 274

68-69. JUdGING A FARM . . . . . . . . . 280

70. Planning the Home Farm . . . . . . 287

71. The Arrangement of Farm Buildings and Plantings • 291

EXTRA EXERCISES

72. The Geographical Distribution of Corn . . . . 295

73. The Geographical Distribution of Wheat . . . 299 
74. The Geographical Distribution of Oats . . . . 303

75. The Geographical Distribution of Potatoes . . . 307

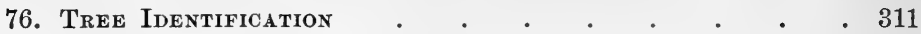

77. Starting Plants by Cuttings . . . . . . . 315

78. Potting Plants . . . . . . . . . 317

79. The Dairy Herd Record . . . . . . . 320

80. A Study of the EGG . . . . . • • • . 325

81. A Study of the Rice Head . . . . . . . . 330

\section{EXTRA FOR ARBOR DAY}

82. Tree Planting. . . . . . . . . . . . . 334

\section{APPENDIX}

Section I. Equipment . . . . . . . . . . 337

Section II. Suggestions to Teachers $\quad . \quad \ldots \quad . \quad . \quad . \quad 341$ 


\section{ILLUSTRATIONS}

FIGURE

1. A SoIl AUger

2. A Torsion Balance . . . . . . . . . . 24

3. Equipment Suitable for demonstrating Percolation OF W ATER IN SoILS . . . . . . . . . . 35

4. A Soll Mulch Cylinder . . . . . . 54

5. Young Wheat Plants . . . . . . . 67

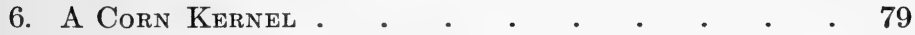

7. Ears of Corn that approach the Ideal Type . $\quad 89$

8. A Head of Wheat and its Parts . . . . 106

9. A Head of Rre . . . . . . . . . . . 112

10. A Head of Six-rowed Barlex • • • • • 125

11. A Head of OAts. • . • • • • • . 130

12. Root Grafting . . . . . . . . . . 210

13. Cleft Grafting . . . . . . . . . 210

14. A Seed Corn Tester. . . . . . . . . 214

15. A Draft Horse, showing Location of Parts • • 228

16. Rear View of Hind Legs of Horses . • • . 230

17. Side View of Hind Legs of Horses . • • . 231

18. A Driving Horse, showing Location of Parts. • 238

19. A Dairy Cow, showing Location of Parts • . 251

20. A Beff Steer, showing Location of Parts • 259

21. A Fat Hog, showing Location of Parts • • 269 
22-23. A Mutton Sheep, showing Location of Parts .

24. Map of the United States, showing the DistribuTION OF CORN • • • . . . . . . . 298

25. Map of the United States, showing the DistribuTION OF WHEAT • • . • . . . . 302

26. Map of the United States, showing the DistribuTION OF OATS . . . . . . . . . . . 306

27. Map of the United States, showing the Distribution of Potatoes .

28. Section of AN EGG • • • • • • • • • 326

29. A Head of Rice . . . . . . . . . . 330 


\section{A LABORATORY MANUAL OF AGRICULTURE FOR SECONDARY SCHOOLS}





\section{LABORATORY MANUAL OF AGRICULTURE}

\section{EXERCISE 1}

\section{DISTRIBUTION OF SEEDS}

Object. - To study natural methods of seed distribution.

Explanation. - It is an advantage for plants to have their seeds distributed as widely as possible. There is severe competition among plants for existence. Only a few of the many seeds produced from year to year find favorable conditions for growth.

There are four important common methods by which the seeds of plants are distributed: distribution by wind; distribution by birds; forceful expulsion from the pod; distribution by animals other than birds. There are two general kinds of seed transported by the wind. Some have wings, as the ash and maple. Others have feathery projections and float long distances in the air. The dandelion and thistle are examples of these.

Seeds of berries and small fruits are often carried long distances by birds. The pulp of the fruit is digested, but the seed is uninjured and may be dropped along fence rows or other places where it may grow. The fleshy part of the fruit is the attraction that favors distribution. 
Some seeds produced in pods are thrown out with considerable violence when the pods burst open. The common pea and locust are examples of this method of distribution.

Many seeds, known as burrs, bear small hooks or spines which adhere to the hair of animals and to the clothing of man. Such seeds are sometimes carried long distances before they are removed. The sand burr and cockle burr afford good illustrations of this method of distribution.

Directions. - Make a journey into the fields, visiting, if possible, a cultivated field, a pasture, a hillside, a wood lot, a creek bank, and a roadside. Collect as many kinds of seeds as can be found growing in these places. Make a list of the names of the seeds that have been gathered. Record in the accompanying outline form the name, the locality where collected, and the means that the plant uses for distributing its seeds. 


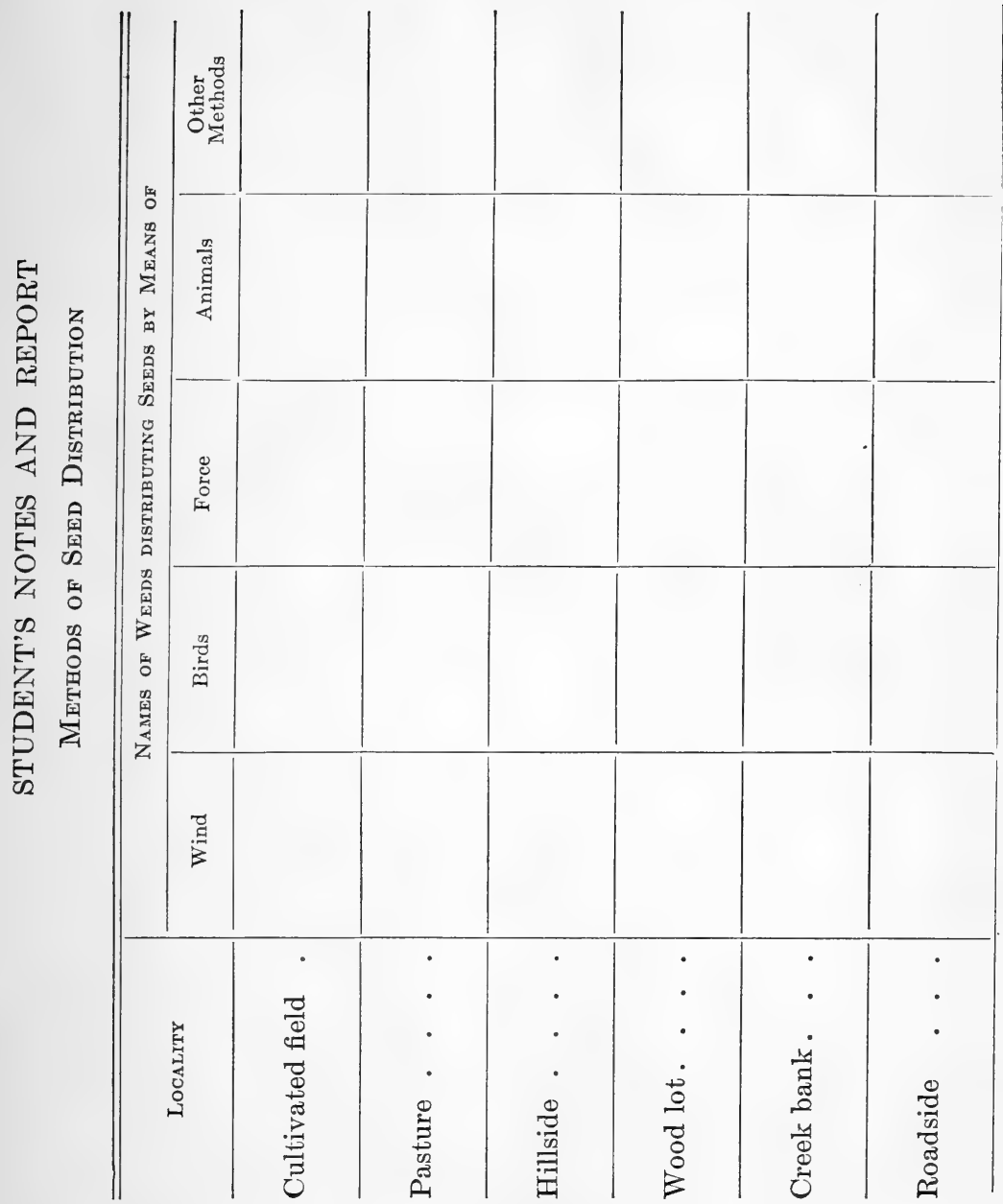




\section{EXERCISE 2}

\section{A FIELD LESSON ON THE STUDY OF CORN}

Object. - To observe field conditions that affect yield of corn.

Explanation. - There is a wide range in the yield of corn to the acre, not only in different states and counties, but in fields adjacent to each other. Close observation in the field shows that in many case the stand of corn is not good; that is, there are many vacant places, and the corn is unevenly distributed. If corn is planted in drills, - one kernel to the place, - the plants should be from twelve to thirty inches apart in the row. If checkrowed, two to four kernels of corn should be planted to the hill, depending upon the richness of the soil, rainfall, and other climatic conditions, and the variety of corn.

The ears on the different stalks vary in size. Some are large and well-shaped, others, commonly known as nubbins, are smaller, and many stalks fail to produce ears at all. It will be easily understood that the number of plants for a given area, the per cent of stalks producing ears, and the size of the ears are all important factors influencing the acre yield. In this exercise one stalk for each twenty-one inches will be considered a perfect stand when drilled, and three stalks to the hill when checkrowed. 
Equipment. - 1. A hundred-foot tape line.

2. Spring balance.

3. Half bushel basket.

Directions. - Go to a neighboring field or patch of corn. Select an area representing the average of the field. Measure off a row one hundreth of an acre in area. (A row 125 feet long and $3 \frac{1}{2}$ feet wide is one hundreth part of an acre.) Determine the number of stalks that should be in the row if the stand were perfect. Count the number of stalks actually in the row. Count the number of stalks producing ears. Husk and weigh the corn in the row. Count the total number of ears. Determine the average weight of the ears. Record all results in the accompanying outline form. Make the calculations necessary to fill in the form. 


\section{STUDENT'S NOTES AND REPORT}

Number of stalks for perfect stand . . . . . . .

Actual number of stalks

Number of ear-producing stalks

Weight of corn for the plot

Total number of ears

Average weight of ears

From the above determine the following:

The per cent of a perfect stand .

The per cent of stalk-producing ears .

The plot yield in bushels

The acre yield in bushels

The possible acre yield for a perfect stand, each stalk to produce an average-size ear

The possible acre yield for a perfect stand, each stalk to produce a twelve-ounce ear

(In reducing pounds to bushels count seventy pounds equivalent to one bushel.) 


\section{EXERCISE 3}

\section{A STUDY OF SOIL PARTICLES}

Object. - To study the size, shape, color, and character of the soil particles in different types of soil.

Explanation. - The earth is supposed at one time to have been solid rock. The soil that now covers the earth was formed by the breaking up of this rock material. Mixed with the rock material of the soil is a small amount of plant material or organic matter.

In the beginning of soil formation the rocks that composed the earth were undoubtedly not all of one kind; some were soft and others were hard. The soft rocks gave way easily to the forces of nature and were soon ground into very small particles. The hard rocks have resisted this action, consequently they have been broken up very slowly, and they form the larger particles of the soil.

Some of these particles are so large that they hinder plowing and cultivating. These are called stones. Other particles smaller than these are called gravel, and still smaller particles are called sand. Thus it is possible to take a soil, and, by examining it closely, see that it is made up of a countless number of particles of many different sizes. These particles representing different sizes have been given different names, as follows: 
1. Stones: particles of soil so large that they interfere with tillage operations.

2. Gravel: particles smaller than stones but larger than one twenty-fifth of an inch in diameter.

3. Coarse sand: one twenty-fifth to one fiftieth of an inch in diameter.

4. Medium sand: one fiftieth to one hundredth of an inch in diameter.

5. Fine sand: one hundredth to one two hundredth of an inch in diameter.

6. Very fine sand: one two-hundredth to one five-hundredth of an inch in diameter.

7. Silt: one five-hundredth to one five-thousandth of an inch in diameter.

8. Clay: one five-thousandth to one two-hundred-fiftythousandth of an inch in diameter.

These different-sized particles of soil are spoken of as soil components or physical soil constituents. All soils do not contain all of these components. Some of the most fertile soils do not contain stones or gravel, yet all of the fertile soils contain the three other constituents, sand, silt, and clay.

While all soils contain most of the different soil constituents, very few soils contain these constituents in exactly the same amount. One soil will have the sand particles predominating, another soil the silt particles, and a third soil the clay particles. Thus there will be different types of farm soils produced as the amounts of these different soil constituents vary. The leading types of farm soils formed by varying amounts of these different soil constituents are given in the following list: 
1. Sandy soils. - Made up chiefly of the soil constituents of the sand size.

2. Clay soils. - Soils that contain over one third clay and a large amount of silt.

3. Loam soils. - Soils made up of about one half sand of the various grades and the other half silt and clay.

The soil particles vary in color and shape as well as in size. The color of the soil particles has but little influence on the color of the soil. The color is due to organic matter and other coloring material found in the soil.

Equipment. - 1. Microscope magnifying to low power.

2. Microscope slides.

3. Four large test tubes.

4. A few grams of the following soils: gravel, sand, loam, clay.

Directions. - Place a few grains of the gravel on a piece of white paper and examine with reference to color.

Estimate the per cent of particles that are white, gray, brown, black. Record your results in the accompanying outline form.

Study the shape of the particles and determine the per cent that are angular and rounded. Record your observations.

Study the condition of the particles. Are they single or compound? Record the percentage of each.

Divide the particles into groups as to size. Record the per cent that are coarse, medium, and fine.

Place a few grains of sand on a microscope slide and study under the microscope, making the observations required in studying gravel. Study in the same way the sample of 
loam and clay. Record all observations in the outline form. Wet a small amount of each of the soils and compare them as to stickiness; as to feel, whether gritty or smooth when rubbed between the fingers. Record your observations.

Examine the different soils as to color. Is the color the same as the color of the largest per cent of the soil particles? Record your observations.

Put a small amount of each kind of soil in a test tube, fill the tube two thirds full of water, and shake thoroughly. Set aside and observe the rapidity with which the particles in each soil settle. Which settles the most rapidly? the most slowly? Is there any relation between the size of the particles and the rapidity with which they settle? Record your observations. 


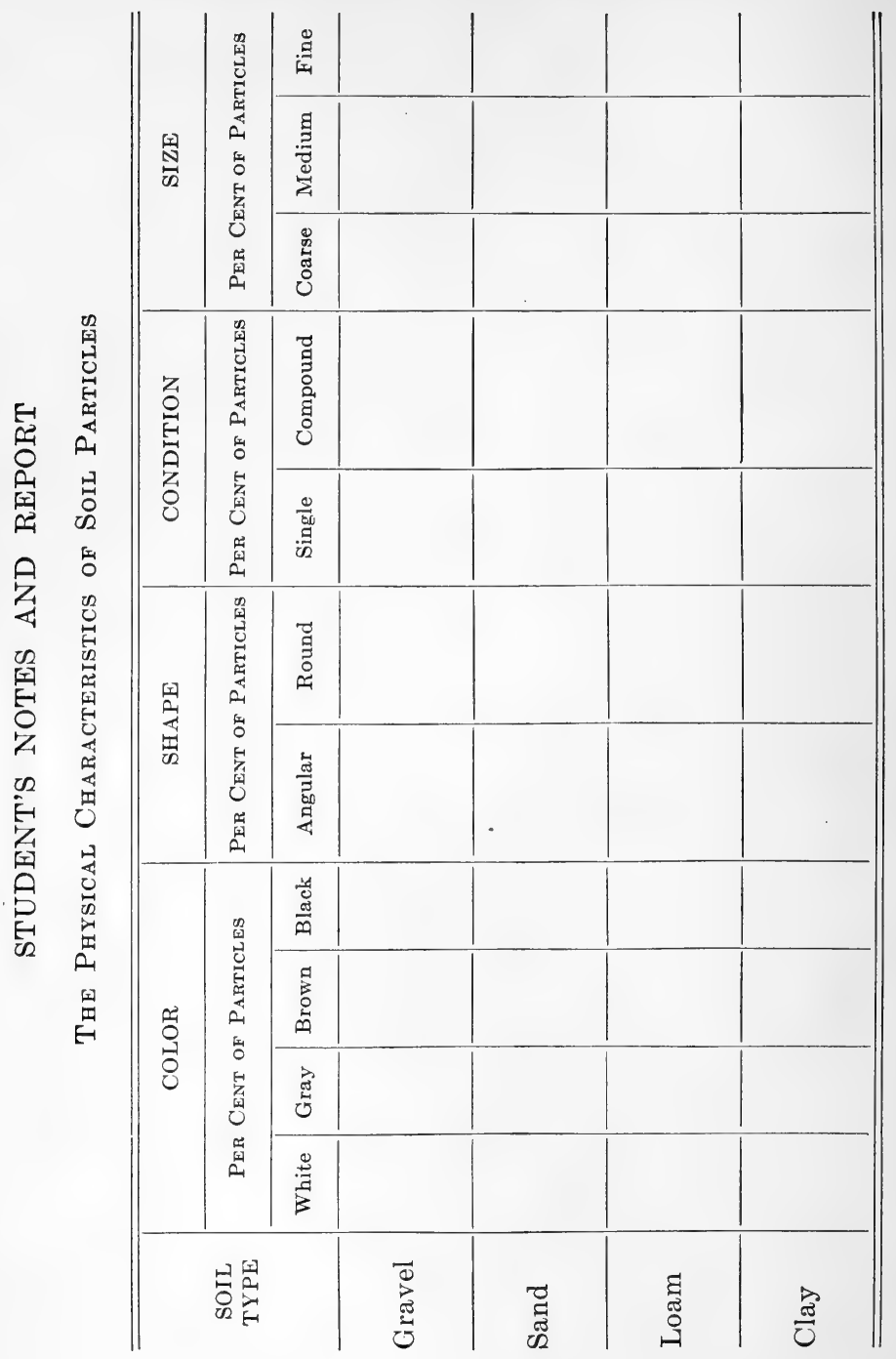




\section{STUDENT'S NOTES AND REPORT}




\section{EXERCISE 4}

\section{A FIELD LESSON IN SOILS}

Object. - To study the formation of soils and the effect of location and cultivation upon their depth and value.

Explanation. - A soil can usually be separated into three distinct layers: first, the surface soil; second, the subsurface; and third, the subsoil. The surface soil is the top soil and varies in depth with location and manner of formation. It is distinguished from the subsurface soil by color, the subsurface soil being lighter in color. The subsoil lies immediately below the subsurface soil and is also distinguished from the subsurface soil by having a lighter color. The subsurface soil is intermediate between the soil and subsoil in both location and color.

The different layers of the soil differ in texture, that is, in the size of the soil particles. Usually the surface soil has a slightly coarser texture than the subsurface or subsoil.

Equipment. - 1. A soil auger.

2. A piece of oilcloth eighteen inches square.

Directions. - Go to a near-by field in which there is a hill. Examine the soil on the level land at the top of the hill, on a steep slope, and in the valley at the bottom of the slope. Make an examination of the soil in each place as follows: 
Select the exact spot to be examined and clear the surface of the ground of grass and other vegetation.

Place the auger over the spot to be examined and give it a few turns, forcing it into the ground four or five inches. Remove the auger with the soil. In pulling the auger a slight backward turn will enable the auger to be pulled with greater ease, and prevent the caving in of the soil around the auger hole.

Remove the soil from the auger and place it in a pile on the oilcloth provided for the purpose.

Repeat this operation, forcing the auger down a few inches at a time until the subsurface is reached. This may be determined by the change in color.

Determine the depth of the surface soil by the distance the auger was sunk into the ground at the time the subsurface soil was struck.

Remove a sample of the subsurface soil in the same way that the surface soil was obtained and pile it on the oilcloth by itself.

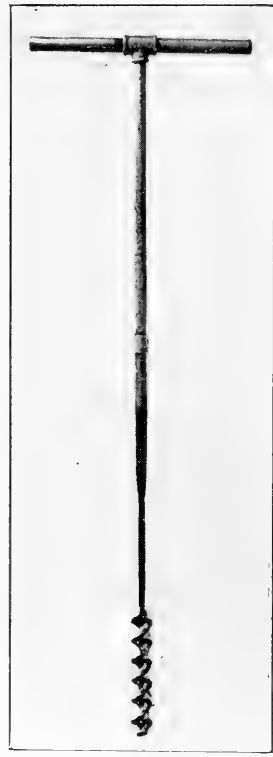

Fig. 1. - A soil auger made by welding a $\frac{3}{8}$-inch gas pipe to a $1 \frac{1}{4}$-inch wood auger.

Determine the depth of the subsurface soil.

Remove a sample of the subsoil to a depth of three feet. Place the subsoil in a pile on the oilcloth beside the surface and subsurface soil.

Examine carefully each layer of soil and record the differ- 
ence in color, texture, stickiness, and amount of moisture and organic matter present. Record your observations in the accompanying outline.

Examine the soil on a steep slope and in the valley in the same manner, recording depth of surface, subsurface and subsoil. Also record difference in color, texture, stickiness, and amount of moisture and organic matter present. Record the data in the outline form.

Examine the surface soil of an old cultivated field and the surface soil of the adjoining fence row. Make careful notes of any differences observed.

\section{QUESTIONS}

1. How do you account for the difference in color between the surface, subsurface, and subsoil at the top of the hill? How do you account for the difference in stickiness? For the difference in amount of organic matter present?

2. Explain the cause of the difference in depth of the surface soil on the hilltop, the hill slope, and in the valley.

3. Explain the difference in color as found in the three places.

4. Which do you think would grow the better crop, the hillside or the bottom? Why? Can you state from your knowledge of crops whether this is generally true?

5. What differences did you observe between the soil in the cultivated field and the soil in the fence row? How do you account for these differences?

6. Was the soil all over the cultivated field originally like the soil in the fence row? What has been the cause of the change brought about by cultivating the soil ?

7. What ean the farmer do to make his cultivated land as mellow and black as the soil in the fence row?

8. What are the uses of humus or organic matter in the soil?

\section{REFERENCES}

1. Elements of Agriculture, Warren, pp. 95-96, 109-110.

2. First Principles of Soil Fertility, Vivian, pp. 98-104. 


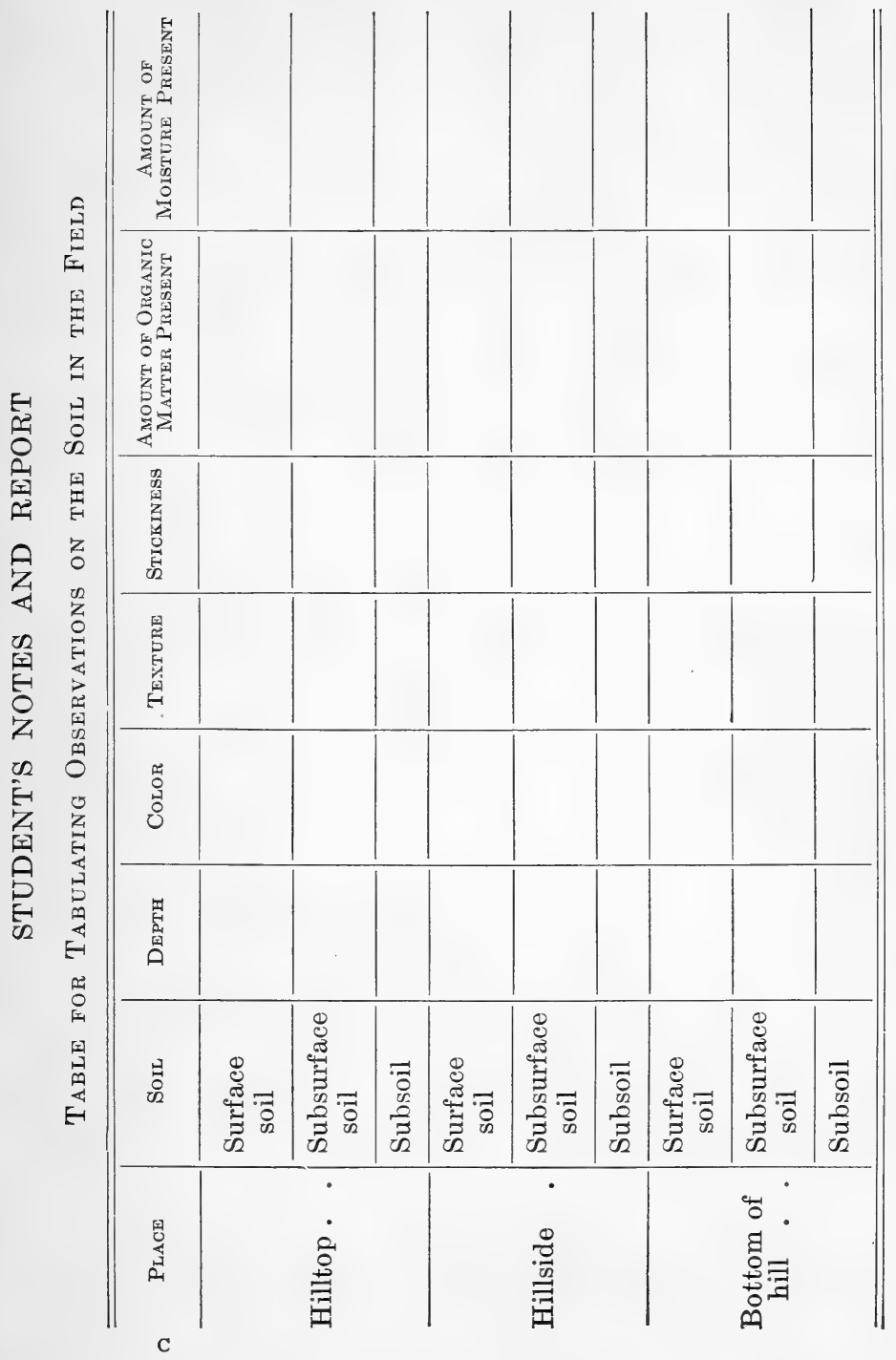


STUDENT'S NOTES AND REPORT 


\section{EXERCISE 5}

\section{THE INFLUENCE OF VEGETATION ON SOIL TEM- PERATURE}

Object. - To determine the difference in temperature between a soil covered with a growing crop and a bare soil exposed to the direct sunshine.

Explanation. - The temperature of the soil is influenced by its color, topography, moisture content, and the vegetation growing on the soil. The amount of moisture that the soil contains is the principal factor affecting the temperature. With soils of the same moisture content the soil upon which there is a growing crop will be cooler than the one without vegetation.

Equipment: - 1. A soil auger.

2. Eleven chemical thermometers.

3. Fifteen feet of picture wire.

Directions. - Go to a garden or field where there is cultivated ground and also ground growing a crop such as grass, alfalfa, clover, or any other dense-growing crop that shades the ground thoroughly.

With the soil auger make holes in both the cultivated and the cropped ground to a depth of 3 inches, 6 inches, 1 foot, 2 feet, and 3 feet. In choosing a location for the holes care should be taken to place them where the ground has the same general direction of slope and the same angle of slope. 
Place a thermometer in each hole. The thermometers should be lowered into the holes that are two and three feet deep by means of picture wire attached to the thermometer and held at the top by being fastened to a short stick. It is advisable to wrap with paper the bulbs of the thermometers used in taking temperatures at a depth of two and three feet. The paper wrapped around the bulb serves as an insulation, and thus prevents sudden changes in the reading of the thermometer. This makes it possible to remove the thermometer from the hole and read it before the reading changes. If wet paper is used in wrapping the bulbs, it should be allowed to dry thoroughly before the thermometers are used.

Take the temperature of the air four feet above the surface of the ground and also of the soil in each field at the depths indicated. Make temperature readings fifteen minutes after the thermometers are placed, and each succeeding fifteen minutes for one hour. Record the readings in the accompanying outline.

Discuss fully the results of the exercise and account as fully as possible for the facts observed.

\section{QUESTIONS}

1. Why should the slope of the fields be the same upon which the temperature of the soil is taken?

2. What effect has the slope of the land upon the temperature of the soil?

3. Is the effect of the slope of the land upon the temperature of the soil ever of practical importance? When?

4. Why should not thermometers be used that have the bulbs wrapped in wet paper?

5. What effect has growing vegetation upon the temperature of the soil? 


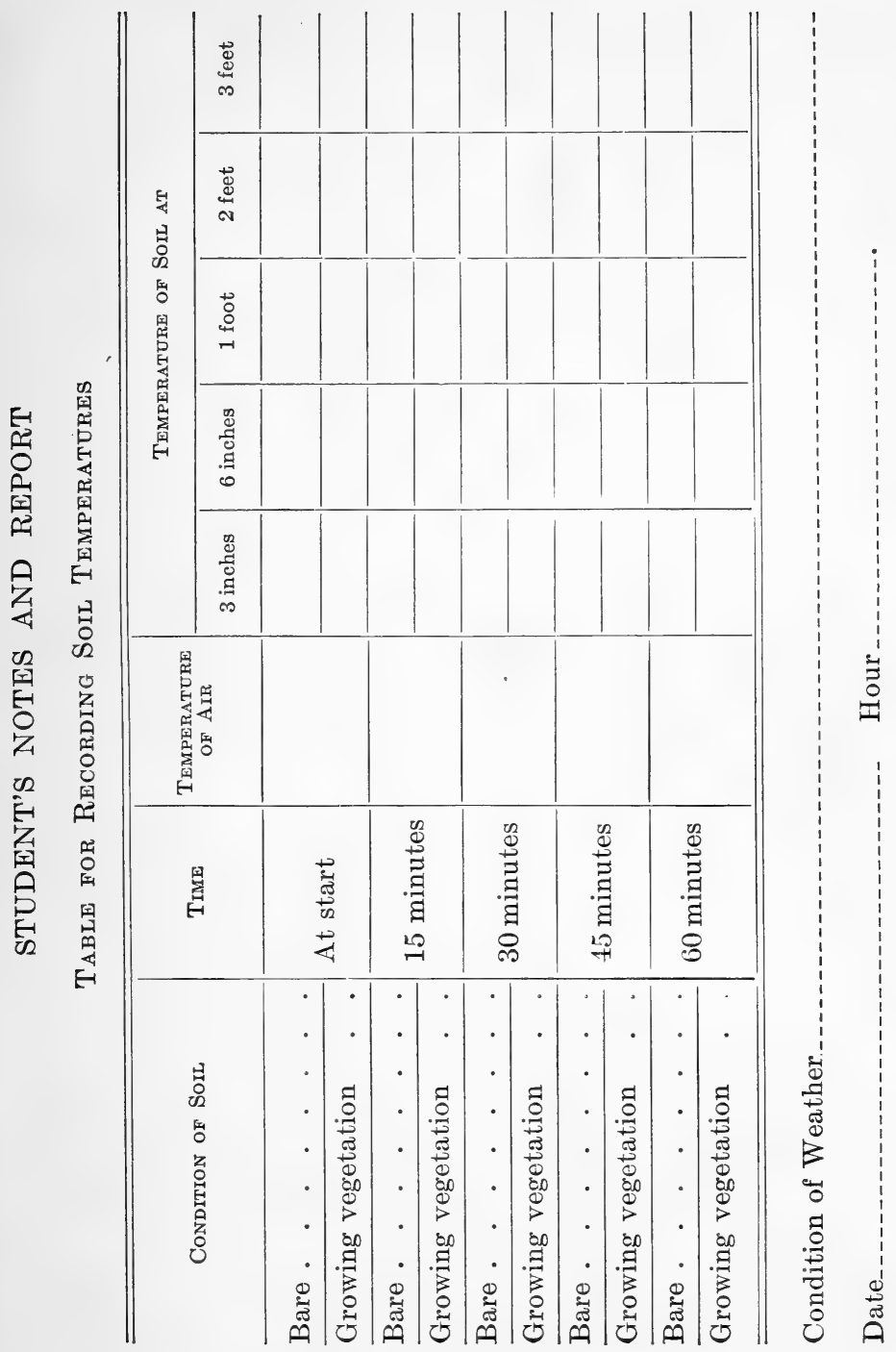




\section{EXERCISES 6 AND 7}

\section{A SOIL MOISTURE STUDY}

Object. - To determine the amount of capillary water in a cultivated and in an uncultivated soil.

Explanation. - Capillary soil water is the water in the soil that may be used by plants. It is held in the soil as a thin film surrounding the soil particles. It is free to move by the force of capillarity from a moist to a drier portion of the soil. All capillary water evaporates from the soil when it is thoroughly dried in the air.

Equipment. - 1. Soil auger 3 feet in length.

2. Six one-quart mason jars.

3. A piece of oilcloth 18 inches square.

4. Twelve tin pie pans 6 inches in diameter.

5. Balances weighing to half a gram.

Directions. - Secure a sample of soil from a garden or field where the ground has been kept cultivated all summer, and another sample from the edge of the garden or edge of the field where the ground has not been cultivated, and where the weeds and grass have been allowed to grow.

Clear the surface soil of all trash and vegetation, and where the ground has been cultivated, brush back the loosest of the surface soil so that it will not roll down into the auger hole while removing the sample. 


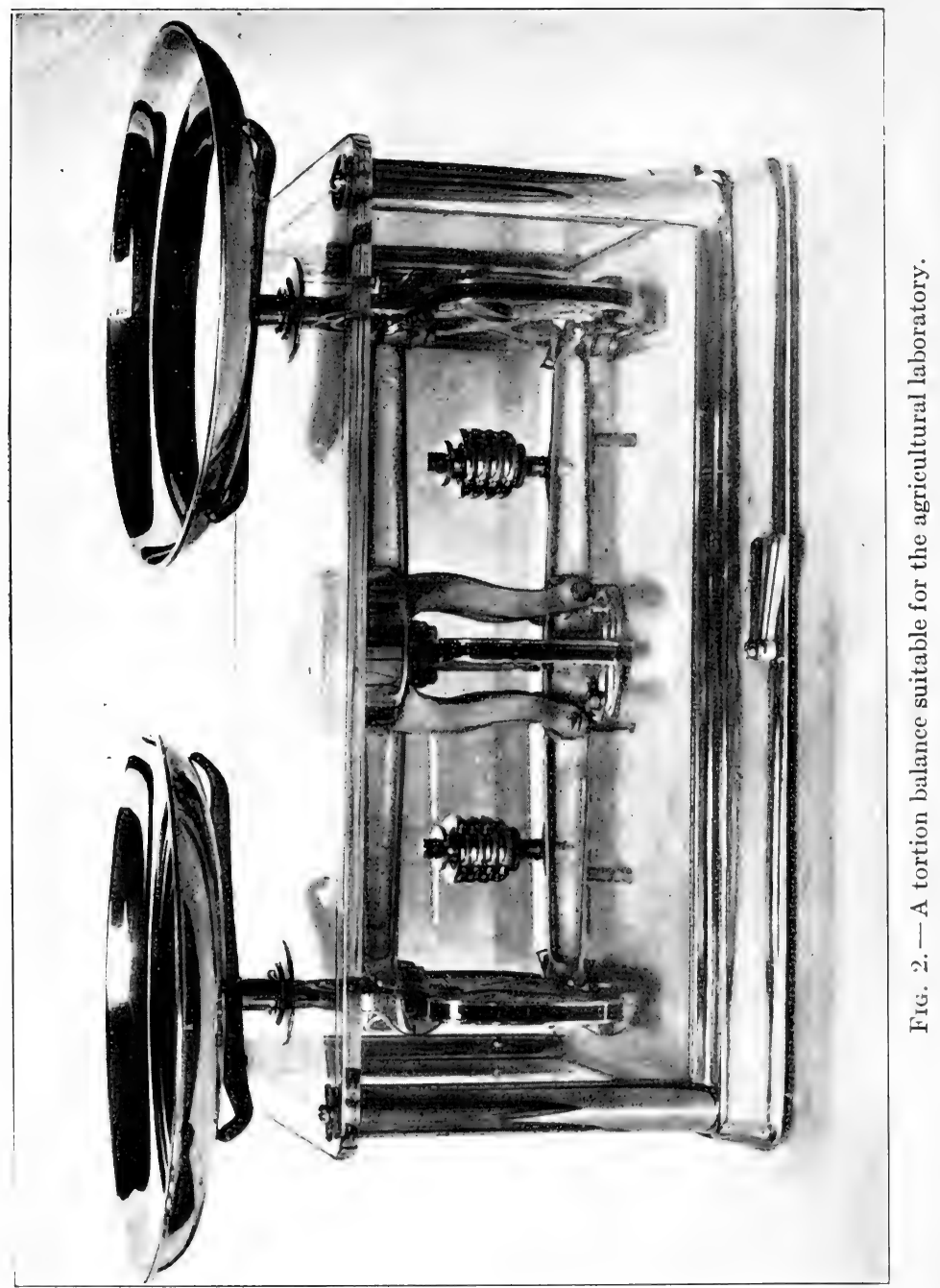


Force the auger into the soil by turning until it has entered three or four inches.

Remove the auger by pulling with a backward twisting motion. This enables the auger to be pulled more easily and prevents the breaking off of the soil around the sample hole.

When the auger has been withdrawn, remove the soil to the oilcloth provided for this purpose and transfer it immediately to a quart mason jar.

Repeat this operation, forcing the auger into the ground three or four inches at a time, until the sample is secured to a depth of twelve inches.

Cap the mason jar tightly and mark with a label that gives the treatment of the soil, its character, and depth, and the date.

Place the auger in the hole and move it up and down several times, turning it slightly for the purpose of cleaning the walls of the hole so that the samples of the second and third feet may be removed without coming in contact with the surface soil.

Remove the soil loosened in enlarging the hole by sinking the auger just to the depth reached in taking the first foot sample. Discard the soil removed in this operation.

Secure a sample of the soil of the second foot (12 to 24 inches) in the same manner as described for the firs ${ }^{\perp}$ foot. Care should be taken to remove any surface soil that may adhere to the second foot sample as it is removed from the hole.

After the second foot sample has been placed in a mason jar and properly labeled, secure a sample of the third foot (24 to 36 inches) by sinking the auger an additional 12 
inches in the same manner as that described in taking the first and the second foot samples.

Samples from at least three holes on both the cultivated and the uncultivated fields should be secured. The soil from each of the three holes for the first foot of the cultivated field should be placed in the same mason jar. A second mason jar should be used for the three samples from the second foot, and a third mason jar for the three samples from the third foot.

On the uncultivated field three samples from the first foot should be placed in one mason jar, three samples from the second foot in another jar, and the three samples from the third foot in a third jar. Thus for the two fields six jars will be required, and each jar will contain a composite of three soil samples.

See that all jars are properly labeled, and that the tops are screwed on tightly, so that no soil moisture can escape by evaporation.

Take the samples into the laboratory and set them aside for the next laboratory period.

At the next laboratory period determine the moisture in duplicate for each sample of soil secured. Before the jars are opened to take the samples for the moisture determinations, the contents should be thoroughly mixed by shaking. The shaking cannot be done too thoroughly.

Number a drying pan to correspond with the sample of soil to be studied. Weigh this pan and record the weight. Weigh into the pan 200 grams of the soil. In the same manner weigh out another 200-gram sample of the same soil as a duplicate. 
Weigh out two 200-gram lots of each of the other samples to be studied.

Spread the soil out over the bottom of the weighing pan in a thin layer and put in some convenient place to dry. After four days drying weigh each sample and record weight. Repeat the drying and weighing each day until a constant weight is obtained. The loss in weight represents the capillary water content of the soil.

Determine the percentage of capillary moisture computed on the weight of the air-dry soil. Tabulate the results in the accompanying outline.

\section{QUESTIONS}

1. Which foot contains the largest amount of water?

2. Which soil contains the most water, the cultivated or the uncultivated?

3. Discuss the reasons for the difference in moisture formerly in the two soils.

4. From the moisture determination, figure the number of pounds of water there would be in the acre three feet of soil in the cultivated and uncultivated field, weight of soil the acre foot 3,500,000 pounds. 


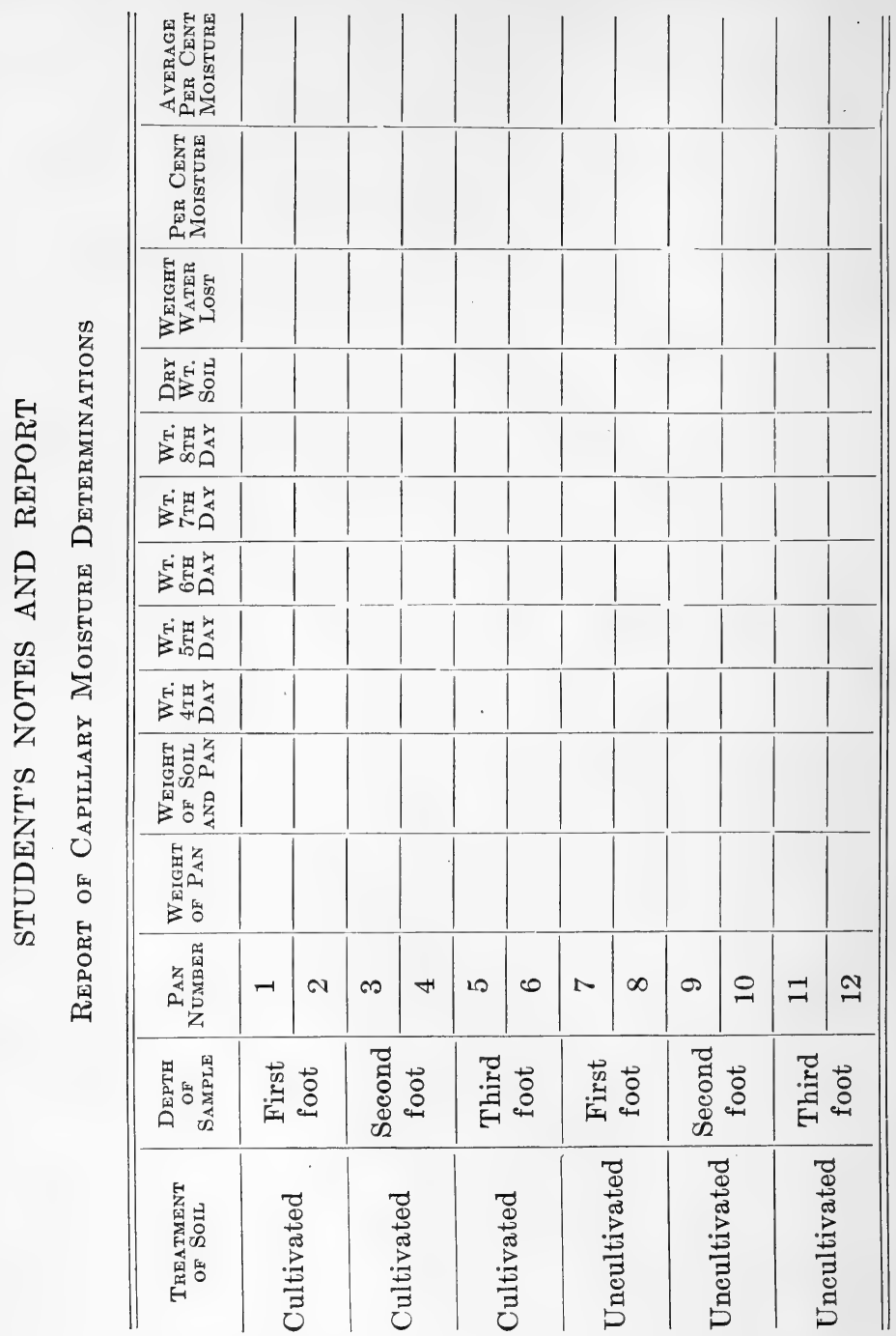


STUDENT'S NOTES AND REPORT 


\section{EXERCISE 8}

\section{THE RISE OF CAPILLARY WATER IN SOILS}

Object. - To compare the rate of the rise of capillary water in soils of different texture.

Explanation. - Capillary water is held in the soil as a thin film surrounding the soil particles. It moves by the force of capillarity from a moist to a drier part of the soil. Capillary water will move upward through the soil if the soil above is drier than the soil below. The height to which capillary water will rise in the soil depends upon the soil texture. In a coarse-grained soil it rises very rapidly, but for only a short distance. In a fine-grained soil it rises slowly, but to a greater height. Capillary water rises in the soil until the force of capillarity is overcome by the force of gravity.

Equipment. - 1. Four glass tubes 3 feet long and 1 inch in diameter.

2. A tube rack for holding the tubes.

3. A pan for water in which to immerse the bottom of the tubes.

4. Cheesecloth.

5. String.

6. One-foot rule.

7. Air-dry soil: gravel, sand, loam, and clay. 
Directions. - Tie pieces of cheesecloth over one end of each of the four glass tubes.

Fill each tube with a different type of air-dry soil. In filling, the tubes should be placed upon the floor with the end tied with cheesecloth down. The soil may be poured into the tube, using a tin funnel or a paper funnel made from a sheet of paper.

Place the tubes in the tube rack in such a manner that the ends are in the pan.

When all the tubes are in position, fill the pan with water to a depth of two inches. Take the exact time when the water is added.

Make readings of the height to which the water has risen in the soil at the end of 5 minutes, 15 minutes, 30 minutes, 45 minutes, 1 hour, 2 hours, 1 day, 2 days, 3 days, 4 days, 5 days, and 6 days.

Record your measurements in the accompanying outline form.

\section{QUESTIONS}

1. In which soil was the rise of water the most rapid?

2. In which soil was the rise of water the highest?

3. Is the fact that water can rise from a wetter to a drier soil of any value to growing crops? When?

4. Which of the soils used would make the best subsoil? Why?

5. What effect would a layer of gravel two feet in thickness in the upper subsoil have upon growing crops in a period of dry weather? Why? 


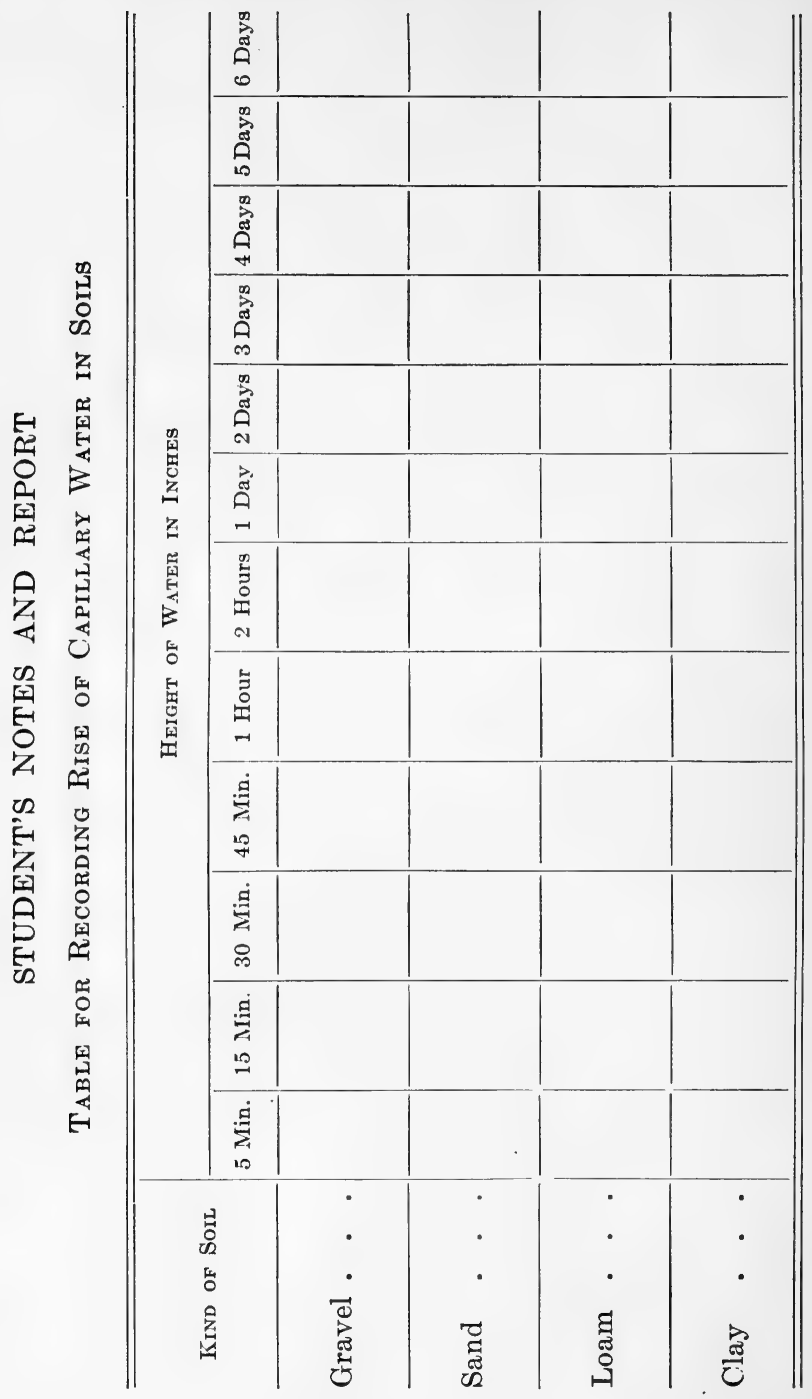




\section{STUDENT'S NOTES AND REPORT}




\section{EXERCISE 9}

\section{THE PERCOLATION OF WATER IN SOILS}

Object. - To compare the rate of percolation of water through soils of different texture.

Explanation. - The capacity of soils to absorb water that falls as rain depends upon its texture, or the size of the soil particles. A coarse-textured soil absorbs moisture rapidly, but in such a soil the water percolates through it quickly, and thus a large part of the rain that is absorbed is lost from the soil as percolating water. A fine-grained soil absorbs rain water slowly, but holds in the soil a larger portion of the water that is absorbed. An ideal soil is one that is coarse enough to absorb moisture with fair rapidity, yet fine enough to retain a large portion of the moisture absorbed.

The condition of the surface of the soil also affects the capacity of a soil to absorb moisture. A soil that is hard and compact at the surface will absorb moisture much more slowly than one that is loose and open. Thus, plowing the ground when it is compact or cultivating it when it is crusted, favors the absorption and percolation of moisture into the soil.

Equipment. - 1. Six percolation cylinders with rack and supply tank.

2. Six beakers 400 or 500 c.c. 


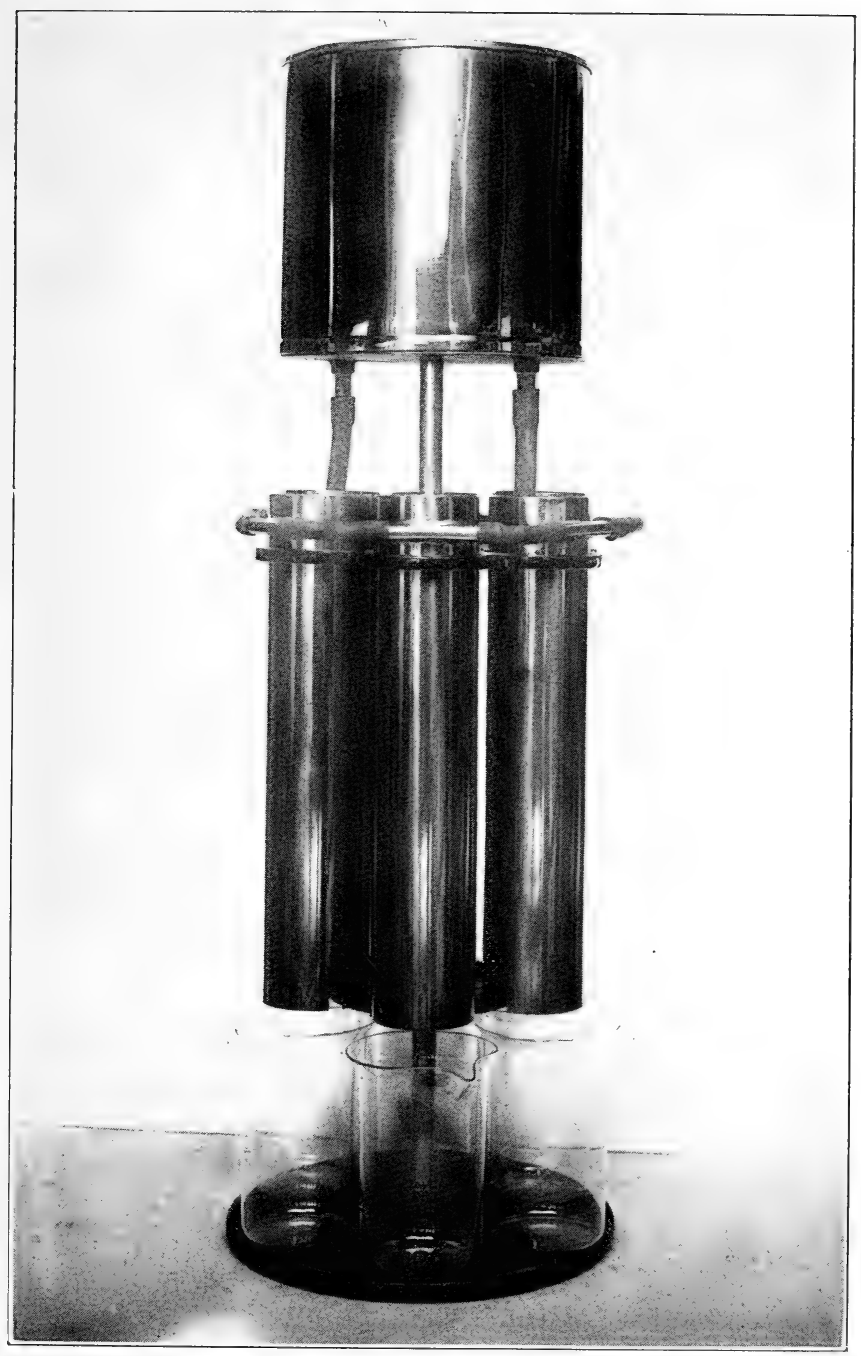

FIG. 3. - Equipment suitable for demonstrating percolation of water in soils. 
3. Graduated cylinders 100 c.c.

4. Cheesecloth.

5. Shears.

6. Eighteen inches rubber tubing $\frac{1}{4}$-inch diameter.

7. Three soils: sand, loam, and clay.

Directions. - Cut a disk of cheesecloth just large enough to cover the bottom of each tube. Place the cheesecloth in the bottom of each tube. Fill with soil the tubes provided for the purpose within one inch of the overflow pipes. Fill two tubes with sand, two with loam, and two with clay. Place a half-inch layer of gravel on the surface of each to prevent displacement of the soil by running water. Place the tubes in the rack and connect the overflow pipes with short pieces of rubber tubing.

Fill the supply tank with water and invert it in place over the soil tubes. The supply tank will maintain a water level automatically.

Note the time at which water was applied.

Place beakers under each tube to catch the drip water. Note the time at which the water starts to flow from each tube.

When the flow becomes constant, which will be ten or fifteen minutes after the flow starts, collect the water which percolates through each soil in fifteen minutes. Measure the water carefully and record the amount in the accompanying outline form.

Repeat the process of percolation and measurements twice. Record the amount of water percolating for each fifteenminute period in the outline form. 


\section{QUESTIONS}

1. In which soil was percolation the most rapid? The slowest?

2. Will a soil that is coarse and sandy absorb rain rapidly? Will it hold the water well?

3. Which soil would be the best farm soil? Give your reasons.

4. Would plant roots, earthworms, molds, and other animals help water to percolate in loam and clay soil?

5. Would alfalfa be a good crop to plant on loam or clay soil to assist percolation? 


\section{STUDENT'S NOTES AND REPORT}

The Percolation of Water in Solls

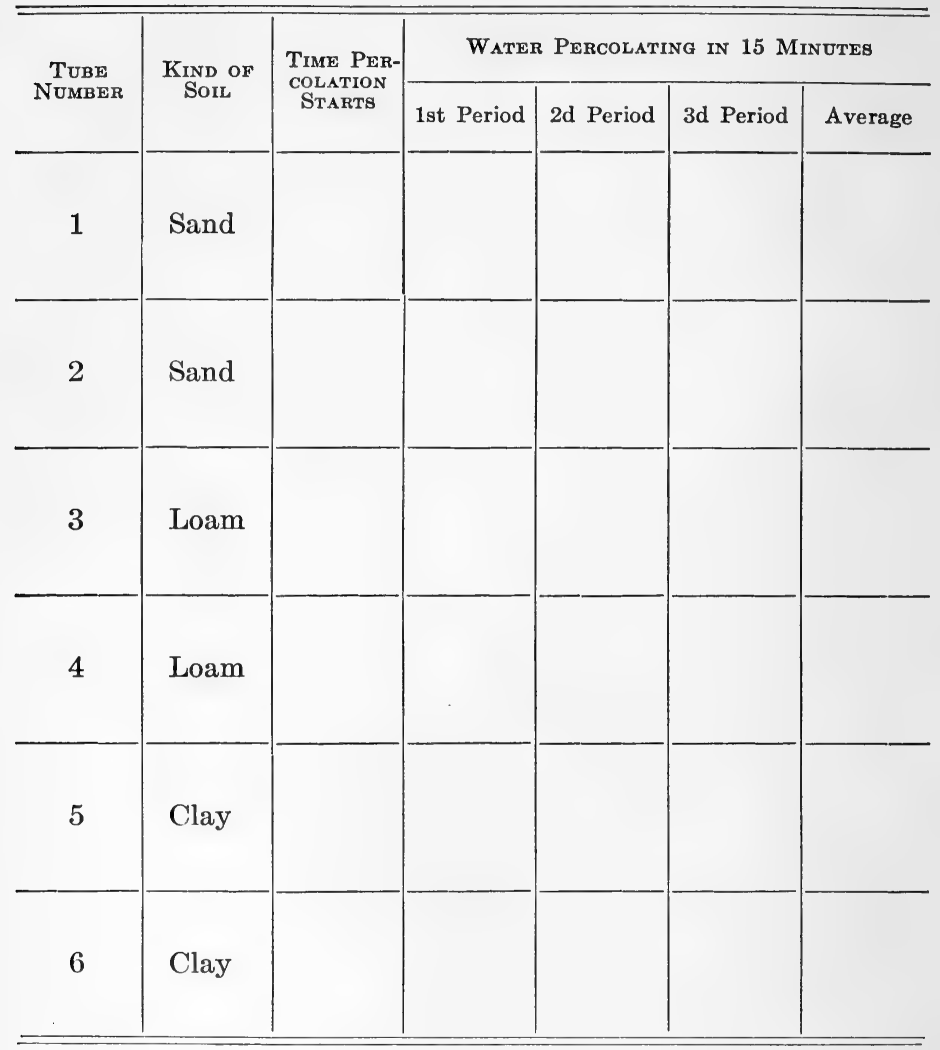




\section{STUDENT'S NOTES AND REPORT}




\section{EXERCISE 10}

\section{THE WEIGHT OF SOIL PER CUBIC FOOT}

Object. - To determine the weight of soil per cubic foot.

Explanation. - The weight of soil depends upon the weight of the material of which the soil is composed and the amount of open space or pore space in the soil. If a cubic foot of soil contained no pore space and were composed entirely of rock particles, it would weigh a little more than two and one half times as much as a cubic foot of water, or about 165 pounds per cubic foot. A cubic foot of soil never weighs this much. A soil always contains some pore space, and this reduces its weight. A soil also contains some organic matter, and since organic matter is lighter than the rock particles, the more organic matter it contains the less it weighs. Thus the weight of soil per cubic foot varies with its organic matter content and the amount of pore space in the soil.

Equipment. - 1. Four soil tubes, like those used in Ex. 9.

2. Cheesecloth.

3. Shears.

4. Torsion balances weighing to half a gram.

5. Four soils: gravel, sand, loam, and clay. 
Directions. - Cut disks of cheesecloth to cover the openings in the bottom of the tubes. Place the cheesecloth in position in the tubes. Number and weigh the tubes. Record weight in accompanying outline form.

Fill the four tubes level full with air-dried gravel, sand, loam, and clay, respectively. Compact the soils in each tube by holding the filled tube three inches above a book and letting the tube drop bottom downward on the book. Compact the contents of each tube by letting it drop from a height of three inches three times.

After compacting, again fill the tubes level full and stroke with a straight edge.

Weigh and record weight of tube and soil.

Empty the tubes, refill with the same soil, and weigh again as a duplicate determination.

Record duplicate weighings.

Measure the diameter and height of the tubes and compute the number of cubic inches of soil contained in each.

Calculate the weight of the soil per cubic foot.

Calculate the weight of an acre of the different soils to a depth of one foot.

Tabulate all weighings and calculations in the following outline form. 


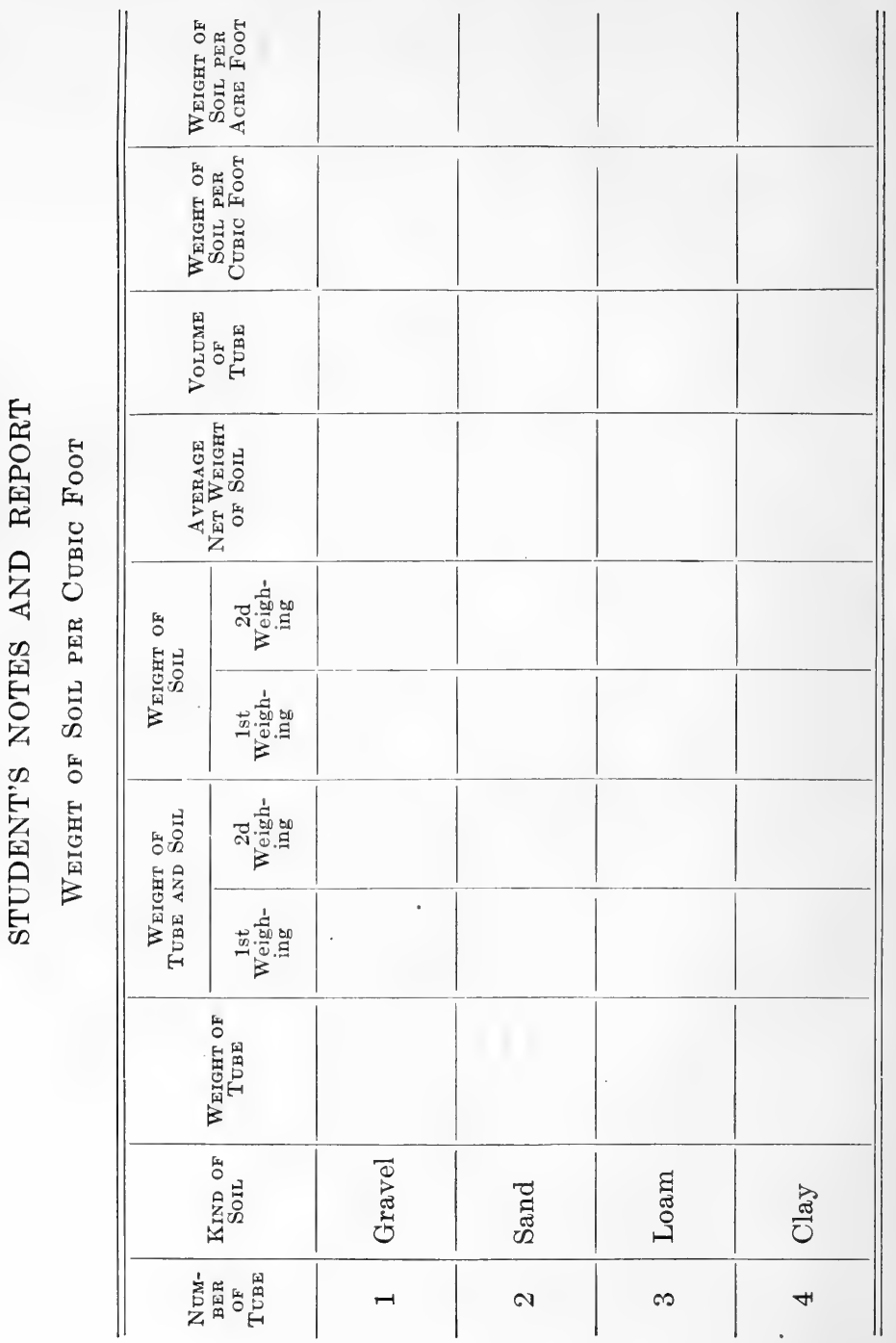


STUDENT'S NOTES AND REPORT 


\section{EXERCISE 11}

\section{CAPACITY OF SOILS TO HOLD MOISTURE}

Object. - To determine the capacity of different types of soils to hold moisture and to study the effect of organic matter on the moisture-holding capacity of the soil.

Explanation. - Soil water is held in the soil partly as a thin film surrounding the soil particles and partly as an accumulation of water in the pore spaces of the soil. If a soil is saturated with water, all its pore space will be filled, and the capacity of a soil to absorb water will be determined by the amount of its total pore space. If the water is allowed to drain away from the saturated soil, the free water will escape. After the free water has percolated away, the water which remains will represent the amount of film water that the soil will hold.

Different types of soils differ in the amount of pore space they contain and in the amount of surface exposed around the soil particles, and therefore in the amount of free and film water that they can hold. Other things being equal, the soil having the smallest-sized particles will have the greatest amount of pore space and will hold the most water.

Organic matter affects the water-holding capacity of the soil. Those soils of the same texture supplied with the most organic matter will absorb and hold the most water. Or- 
ganic matter holds the soil particles apart, gives a greater amount of pore space, and thus increases the total waterabsorbing power of the soil. Well-decayed organic matter is spongy in nature. It has great ability to absorb and hold water itself, just as a sponge holds water. Therefore, it greatly increases the water-retaining power of the soil.

Equipment. - 1. Four soil tubes, the same as used in Ex. 8.

2. A four-gallon crock.

3. Balances weighing to half a gram.

4. Cheesecloth.

5. Pair of shears.

6. Wash pan.

7. Four pieces of glass three inches square.

8. Well-decayed barnyard manure.

9. Three soils: sand, loam, and clay.

Directions. - Cut disks of cheesecloth to cover the openings in the bottom of the tubes. Place the cheesecloth in position in the tubes.

Number and weigh the four tubes; record weight in accompanying outline form.

Fill the tubes to within one inch of the top with the following soils :

No. 1. Sand No. 3. Clay

No. 2. Loam No. 4. Sand and manure.

Prepare the sand and manure for tube No. 4 by mixing ten parts of sand with one part of manure. Proportions determined by weight. Weigh and record weight of all tubes filled with soil.

Place the tubes in the four-gallon crock provided for the 
purpose. Fill the crock with water until the water stands about level with the top of the soil in the tubes.

Take the time that the water was added. Note the time that the first moisture appears on the top of the soil in each tube. Record time required for water to appear in each case.

Allow the tubes to remain in the water until the soil is thoroughly saturated. This will be about ten minutes after water appears on the surface of the last soil.

Remove the tubes one at a time, wipe off the excess water with a towel, and quickly weigh. Record weights.

Place the tubes on a draining shelf and cover with glass plates to prevent evaporation of water at the surface of the soil.

Weigh after standing 15 minutes, 30 minutes, 1 day, 2 days, 3 days, 4 days, 5 days, 6 days. Wipe excess water from bottom of the tube each time before weighing. Record each weight in the outline form.

\section{QUESTIONS}

1. What is a saturated soil?

2. What effect has organic matter upon the water-holding power of the soil?

3. Calculate the per cent of water held by each soil the sixth day.

4. Calculate the number of pounds of water retained per cubic foot of dry soil. 


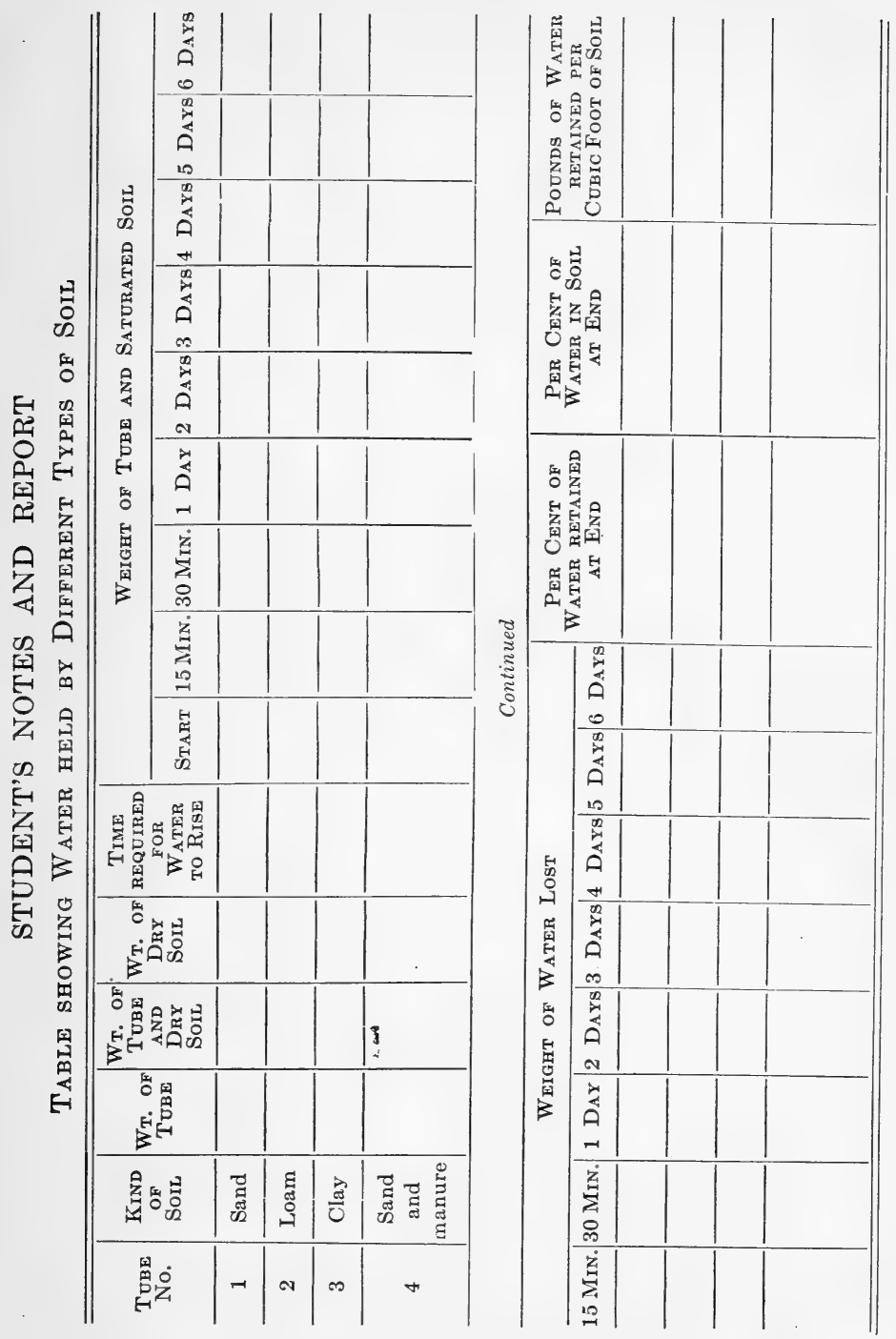




\section{EXERCISE 12}

\section{SOIL DRAINAGE}

Object. - To study the effect of standing water in the soil upon the growth of plants.

Explanation. - A plant, to develop properly, must be grown in a soil supplied with both air and water in proper proportions. When the soil contains too much water, all the spaces between the soil particles are filled, and there is no room for air. A plant growing in a soil in this condition will not thrive because its roots will not receive sufficient air. The water must be removed from a saturated soil so that air can enter before crops will grow well. This can best be accomplished by means of tile drainage.

Equipment. - 1. Two chemical thermometers.

2. Two one-gallon flower pots.

3. A pound of paraffin.

4. A two-quart saucepan in which to melt paraffin.

5. A one-foot rule.

6. Graduated cylinder, 100 c.c.

7. A few grains of corn.

8. Loam soil, and a small amount of gravel.

Directions. - Melt the paraffin and dip one flower pot so that it is covered with a thin coating of paraffin. Allow the paraffin to cool and solidify slightly. While 
the paraffin is still soft, plug up the hole in the bottom of the pot.

Place an inch of gravel in the bottom of the second pot to insure good drainage and see that the hole in the bottom of the pot remains open.

Fill both pots to within one inch of the top with loam soil.

Add water slowly by means of the graduated measure to the soil in the paraffined pot until it has absorbed all that it will. This will require twenty or thirty minutes. Record the amount of water added. Add the same amount of water to the unparaffined pot, allowing any water that will to escape at the bottom of the pot through the drain. Place the two pots in the window of the laboratory where they will receive sunlight.

Let the pots stand two days. At the end of two days plant three grains of corn in each pot at a depth of two inches.

Place a thermometer in each pot with the bulb two inches below the surface soil and record the temperature of the soil at the time the corn was planted. Take the temperature every two days for thirty days. Record data in the accompanying outline form.

Add enough water every three days to the pot with good drainage to keep the corn growing well. Add the same amount of water to the poorly drained paraffined pot.

Measure the height of growth of plants when temperature of the soil is taken.

At the end of thirty days remove the plants from both pots and examine the root growth. 


\section{QUESTIONS}

1. In which pot did the plants make the best growth?

2. How do you account for the difference in growth?

3. Was there any difference in the color of the plants in the two pots? How do you account for this difference?

4. What was the difference in temperature of the soil in the two pots? How do you account for this difference?

5. Would this difference in temperature have any effect on the growth of the plants?

6. In which pot did the roots go the deeper? Why?

7. Can a farmer expect the best growth of corn on a field poorly drained?

8. How can the farmer improve the drainage of a poorly drained field?

\section{STUDENT'S NOTES AND REPORT}

Table for Recording Temperature of Soll and Growth of Plants in Poor and Well Drained Soll

\begin{tabular}{|c|c|c|c|c|c|c|c|c|c|c|c|c|c|c|c|c|}
\hline \multirow{2}{*}{ SoIL } & \multirow{2}{*}{ OBSERVATION } & \multicolumn{15}{|c|}{$\begin{array}{l}\text { Temperature of SoIl in Degrees F. } \\
\text { Growth of Plants in Inches }\end{array}$} \\
\hline & & 2 & 4 & 6 & 8 & 10 & 12 & 14 & 16 & 18 & 20 & 22 & 24 & 26 & 28 & 30 \\
\hline \multirow{2}{*}{$\begin{array}{c}\text { Well } \\
\text { Drained }\end{array}$} & Temperature & & & & & & & & & & & & & & & \\
\hline & Plant growth & & & & & & & & & & & & & & & \\
\hline \multirow{2}{*}{$\begin{array}{l}\text { Poorly } \\
\text { Drained }\end{array}$} & Temperature & & & & & & & & & & & & & & & \\
\hline & Plant growth & & & & & & & & & & & & & & & \\
\hline
\end{tabular}


52

LABORATORY MANUAL OF AGRICULTURE

STUDENT'S NOTES AND REPORT 


\section{EXERCISE 13}

\section{SOIL MULCHES}

Object. - To determine the amount of water that evaporates from the soil when cultivated at different depths and when covered with different material.

Explanation. - A soil mulch is any covering placed upon the soil that prevents the evaporation of moisture. There are two kinds of soil mulches, natural soil mulches and artificial soil mulches. An artificial soil mulch is any material such as straw, sawdust, or stones placed upon the soil to prevent evaporation, while a natural soil mulch is the loosened surface of the soil itself produced by cultivation. Natural soil mulches are the most practical because they can usually be produced at the smallest cost. Any implement of cultivation that leaves the surface soil loose and mellow will produce a good natural soil mulch.

Equipment. - 1. Four evaporation cylinders.

2. A wash pan.

3. A long-bladed knife or spatula.

4. Scales weighing to one quarter of a pound and having a capacity of fifty pounds.

5. A small amount of cut straw.

Directions. - Fill the four evaporation cylinders to within one inch of the top with fine air-dried loam soil.

Fill the water-supply tubes on the cylinders with water. 


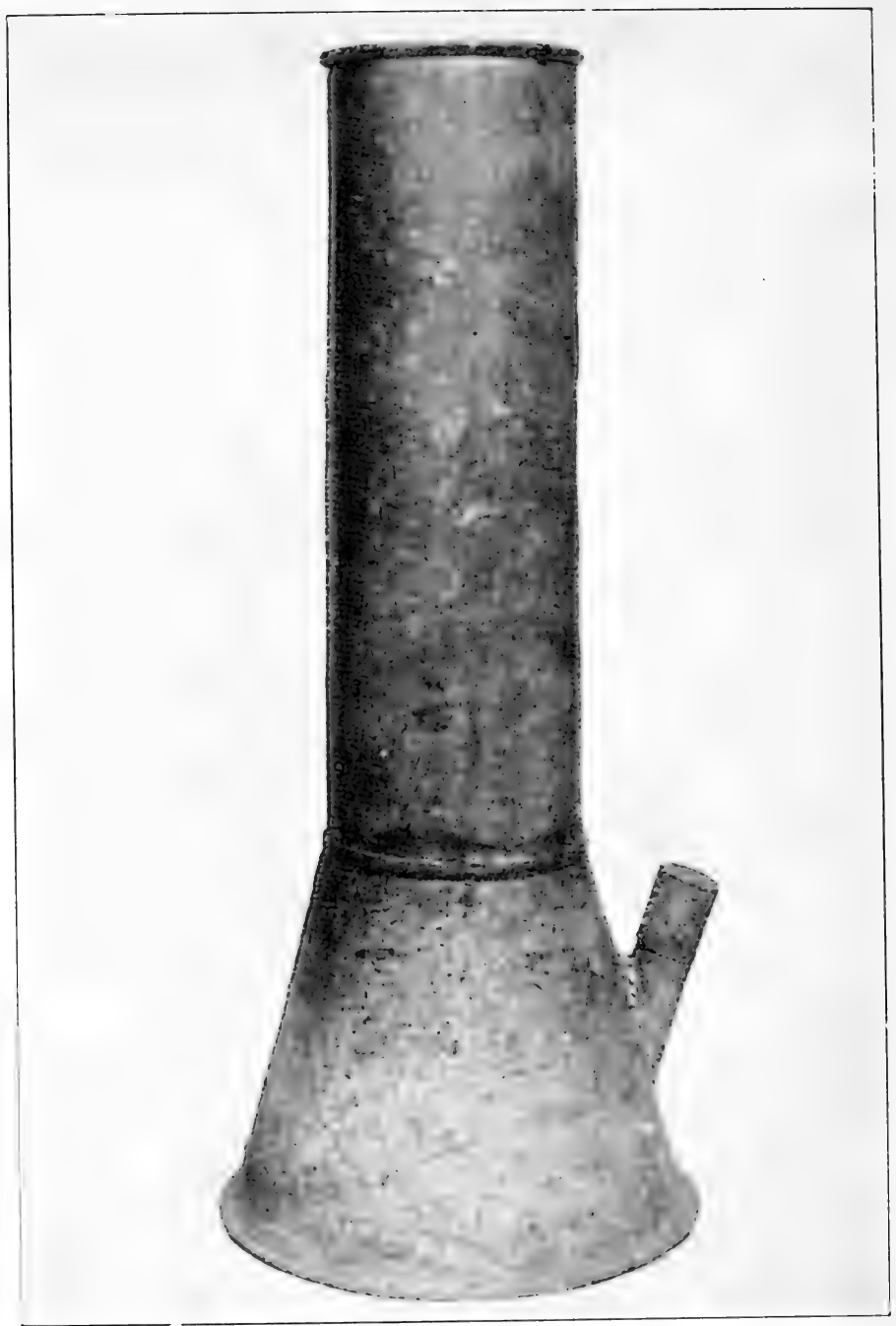

FIG. 4. - A cylinder suitable for demonstrating the effect of mulches on erilporation of water foum soils. Made of galvanized iron. Dimensions of cylinder eighteen inches long and four in diameter. The bottom of the cylinder is incased in a water jacket. The water in the jacket enters the soil by means of perforations near the bottom of cylinder. 
Let the cylinders stand until the soil appears damp at the surface in all the cylinders. This may require several hours, and it may be necessary to replenish the water in the supply tubes during this period of time.

After capillary water appears at the top of the soil on all the cylinders they should be treated as follows: ${ }^{1}$

No. 1. No treatment.

No. 2. Cultivated one inch deep.

No. 3. Cultivated three inches deep.

No. 4. Covered with two inches of cut straw.

Cylinders 2 and 3 should be cultivated by removing the soil to the required depth into a wash pan by means of a long-bladed knife. Thoroughly mix the soil and return it in a loose condition to the cylinder. Just sufficient soil should be returned to the cylinder to bring it to within one inch of the surface. Discard any surplus soil.

Cylinder 4, on which the cut straw is used as a mulch, should be prepared by removing two inches of the soil and replacing the soil with two inches of finely cut straw.

When the mulches are in place, fill the supply tubes to the same level with water. Cork the tubes to prevent evaporation. Weigh the cylinders and record the weight in the accompanying outline form.

Repeat the weighings each day for six days.

Determine the surface area of the cylinders and compute the number of tons of water evaporated per acre in each case during a period of one week.

Tabulate your results in the accompanying outline form.

1 The eylinders may be filled at one laboratory period and the mulches placed in the cylinders at the next period. 


\section{QUESTIONS}

1. Which was the best mulch?

2. Which depth of cultivation saved the most moisture?

3. Was there any difference in the amount of water evaporated from day to day? Can you account for this difference?

4. Does the farmer ever use soil mulches? When?

5. How often should the farmer cultivate his fields to keep a good soil mulch? 


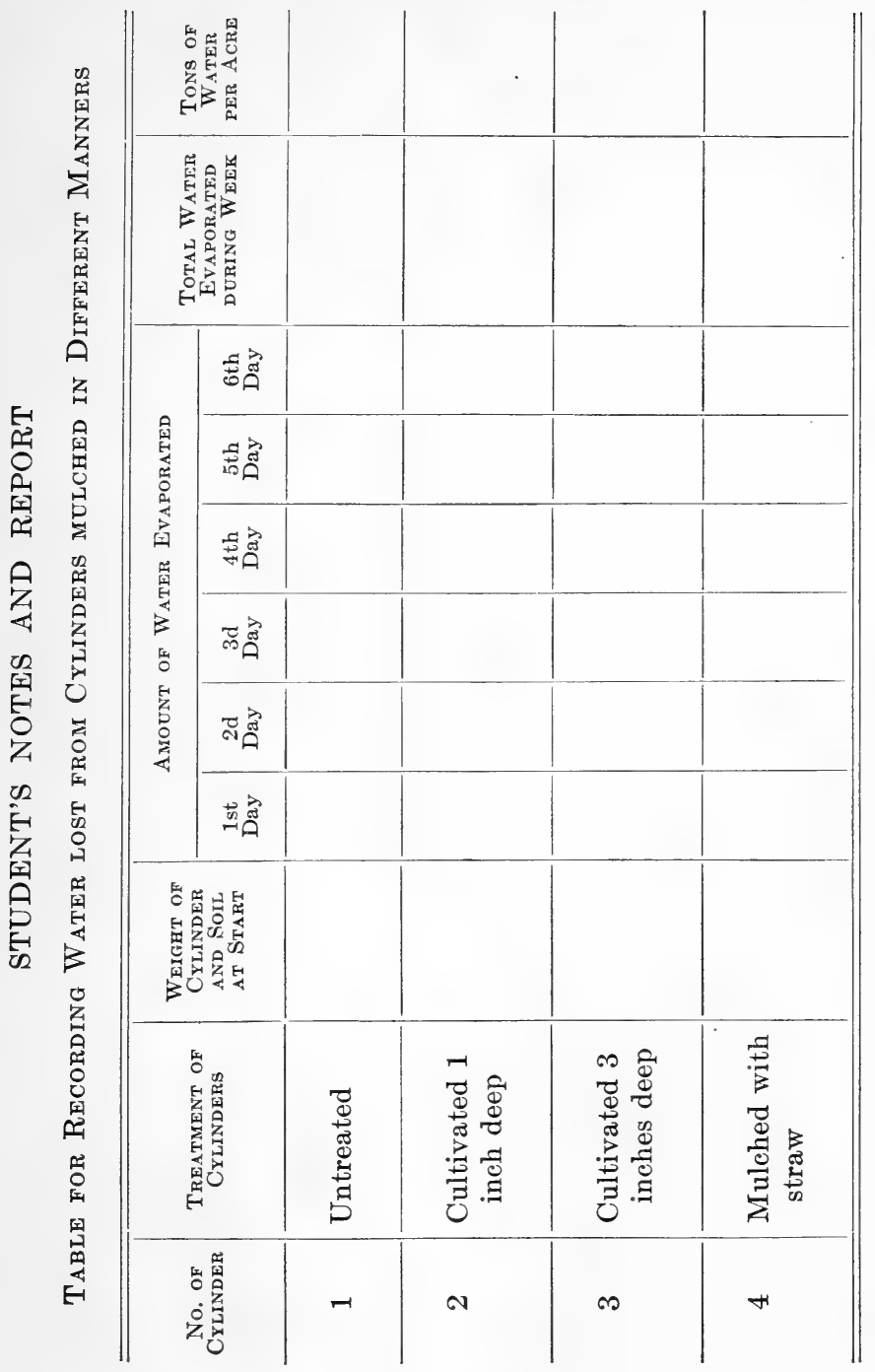




\section{EXERCISE 14}

\section{THE EFFECT OF UNDECAYED ORGANIC MATTER ON THE RISE OF SOIL MOISTURE}

Object. - To study the effect of plowing under undecayed organic matter on the rise of soil moisture.

Explanation - Moisture moves from a wetter to a drier portion of the soil by means of capillarity. In order that capillary movement of moisture may take place the soil particles must be in close contact. If the soil particles are not in close contact, capillary movement of moisture cannot take place. When large amounts of barnyard manure or rank growths of green plant material are plowed under in the soil, the soil particles are held apart by this layer of material and the capillary rise of water cannot take place in the surface soil. If a crop is planted on a soil in this condition, it will be unable to secure moisture from the lower soil in its early stages of growth, and if the season is dry, will suffer greatly for water. It is, therefore, undesirable to plow under barnyard manure, straw, or green manure just before planting a crop. If manure is to be used just before planting, it should be applied lightly as a top dressing.

Equipment. - 1. Three glass tubes, rack, and pan, like those used in Ex. 8.

2. Cheesecloth. 
3. Shears.

4. String.

5. Loam soil.

6. A small amount of green grass.

7. A small amount of manure.

Directions. - Tie a piece of cheesecloth over the end of each of the glass tubes.

Fill the tubes with soil to a height of twelve inches. In filling, the tubes may be placcd on the desk or floor with the end tied with cheesecloth down.

Place the tubes in the tube rack in such a manner that the lower ends are in the pan which is to be used later as a container for water.

Number the tubes. Treat the tubes as follows:

No. 1. Place two inches of green grass cut into small pieces in the tube over the top of the soil and fill the tube to the top with loam soil.

No. 2. Place two inches of finely pulverized barnyard manure in the tube over the top of the soil and fill the tube to the top with loam soil.

No. 3. Fill with loam soil as a check.

When all the tubes are filled and in position, fill the pan with water to a depth of two inches. Take the exact time of adding the water.

Make readings of the height to which the water has risen in each tube at the end of 15 minutes, 30 minutes, 1 hour, 1 day, 2 days, 3 days, 4 days, 5 days, and 6 days.

Record your measurements in the accompanying outline form. Describe fully the lesson that you have learned from conducting this exercise. 


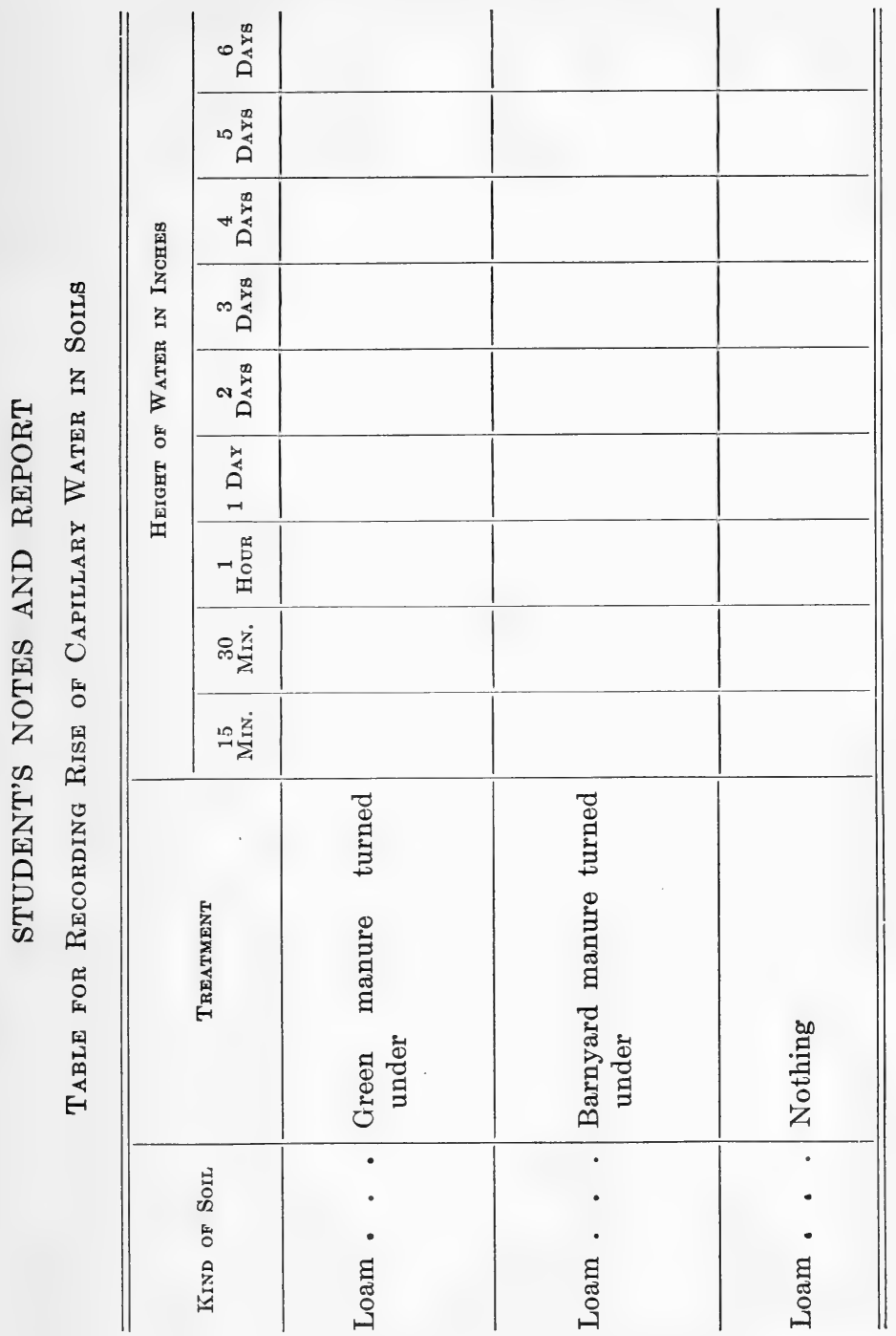




\section{EXERCISE 15}

COLLECTING MATERIAL FOR STARTING PLANTS

Object. - To collect and store material to be used for grafting and making cuttings.

Explanation. - Twigs and branches for grafting and cuttings must be collected when they are in a dormant stage. This can usually be best accomplished in the fall soon after the leaves have fallen. They should be stored in a cellar where they will not freeze and where they will remain moist.

Equipment. - 1. A sharp knife.

2. A barrel or box for storing cuttings.

Directions. - Go into an orchard where the variety of the trees and quality of the apples are known. Collect twigs only from trees that are thrifty and that produce a good quality of apples. Use wood of the previous season's growth. Collect two hundred twigs, ranging in length from four to ten inches. Tie them in bundles of twenty-five each. Label each bundle with the name of the variety.

Go into a vineyard and select twigs from grapevines. Collect fifty twigs from grapevines that produce a good quality of grapes. These twigs should be from five to ten inches long. Label them with the name of the variety and tie them in bundles of twenty-five each.

Go into a wood lot and select twigs from willow or cotton- 
wood trees. Collect one hundred twigs of the previous season's growth. Tie them in bundles of twenty-five each.

Partly fill the barrel or box with sawdust, sand, or moss. Carefully place the bundles of twigs in the barrel or box and cover completely, filling in with the sawdust, sand, or moss. The material should be moistened and not allowed to dry out. The apple twigs collected in this exercise will be used in Ex. 55 for grafting, and the other material will be used in Ex. 77 for making cuttings. 


\section{STUDENT'S NOTES AND REPORT}




\section{EXERCISE 16}

\section{THE EARLY DEVELOPMENT OF THE WHEAT PLANT}

Object. - To study the germination of the wheat kernel and the early growth and development of the plant.

Explanation. - The kernel of wheat incloses a living plant in the dormant stage. The germ is the living part of the kernel from which the shoot and roots develop. When the kernel or seed is placed in the soil under proper conditions of moisture and temperature, it absorbs moisture and begins to grow. The food for the young plantlet is furnished by the endosperm.

When the kernel of wheat germinates, it sends out three temporary roots. As the plant continues to grow it sends out permanent roots. The depth at which the permanent roots occur depends upon the condition of the soil. If the wheat is seeded at a medium depth, the temporary and permanent root systems will develop at about the same place. If the wheat is seeded very deeply, the permanent roots will develop above the temporary roots and near the surface of the soil.

Equipment. - 1. Plants of wheat one, two, three, and four weeks old, seeded one inch deep.

2. Plants of wheat two and four weeks old, seeded three inches deep. 
Directions. - Dig up a number of small wheat plants for this study. Be careful not to break the roots in removing the plants from the soil. Remove the dirt which clings to the roots, by washing. Make a study of plants one week old, two weeks old, three weeks old, and four weeks old, seeded one inch deep. Also make a study of plants two weeks old and four weeks old, seeded three inches deep. (In determining age of plant count time from date of seeding.)

Make drawings of the plants at the different stages of growth and at the different depths of seeding indicated.

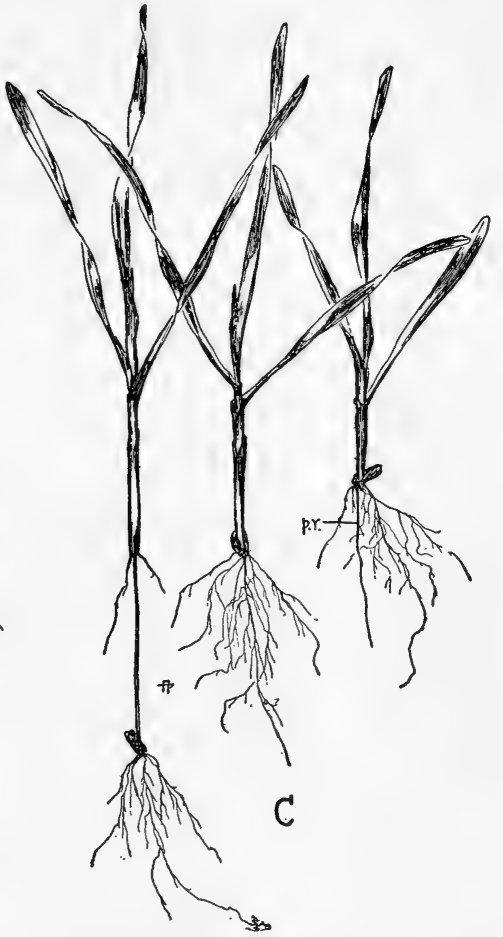

Fig. 5.- Young wheat plants. $A$, two days after planting; $B$, five days after planting; $C$, three plants the same age planted at different depths.

Show in the drawings the three temporary roots which develop first, and in other drawings show the permanent roots which develop somewhat later and are sent out in 
whorls from the nodes. Show how the distance between the temporary roots and the whorl of permanent roots depends upon the depth of planting. Show how the older plants begin to tiller, by sending up new stems. The drawings should include the root system, stems, and leaves and their arrangement. 


\section{STUDENT'S NOTES AND REPORT}




\section{EXERCISE 17}

\section{THE EARLY DEVELOPMENT OF THE RYE PLANT}

Object. - To study the germination of the rye kernel and the early growth and development of the rye plant.

Explanation. - The kernel of rye incloses a living plant in the dormant stage. The germ is the living part of the kernel from which the shoot and roots develop. When the kernel or seed is placed in the soil under proper conditions of moisture and temperature, it absorbs moisture and begins to grow. The food for the young plantlet is furnished by the endosperm.

When the kernel of rye germinates, it sends out four temporary roots. As the plant continues to grow it sends out permanent roots. The depth at which the permanent roots occur depends upon the condition of the soil. If the rye is seeded at a medium depth, the temporary and permanent root system will develop at about the same place. If the rye is seeded very deeply, the permanent roots will develop above the temporary roots and near the surface of the soil.

Equipment. - 1. Plants of rye one, two, three, and four weeks old, seeded one inch deep.

2. Plants of rye two and four weeks old, seeded three inches deep. 
Directions. - Dig up a number of small rye plants for this study. Be careful not to break the roots in removing the plants from the soil. Remove the dirt which clings to the roots, by washing. Make a study of plants one week old, two weeks old, three weeks old, and four weeks old, seeded one inch deep. Also make a study of plants two weeks old and four weeks old, seeded three inches deep. (In determining age of plant count time from date of seeding.)

Make drawings of the plants at the different stages of growth and at the different depths of seeding indicated. Show in the drawings the four temporary roots which develop first, and in other drawings show the permanent roots which develop somewhat later and are sent out in whorls from the nodes. Show how the distance between the temporary roots and the whorl of permanent roots depends upon the depth of planting. Show how the older plants begin to tiller, by sending up new stems. The drawings should include the root system, stems, and leaves and their arrangement. 
STUDENT'S NOTES AND REPORT 


\section{EXERCISE 18}

\section{THE EARLY DEVELOPMENT OF THE CORN PLANT}

Object. - To study the germination of the corn kernel and the early growth and development of the corn plant.

Explanation. - The kernel of corn incloses a living plant in the dormant stage. The germ is the living part of the kernel from which the shoot and roots develop. When the kernel or seed is placed in the soil under proper conditions of moisture and temperature, it absorbs moisture and begins to grow. The food for the young plantlet is furnished by the endosperm until the root system becomes established.

When the kernel of corn germinates, it sends out four temporary roots. The largest of the four roots grows directly out from the tip end of the germ. The other three roots grow out where the main root and shoot are attached to the kernel. Just above these three roots a little swelling appears, and from this point the permanent root system develops. The permanent root system develops about the same distance from the surface of the soil regardless of the depth of planting.

Equipment. - 1. Corn plants one, two, three, and four weeks old, seeded one inch deep. 
2. Corn plants two and four weeks old, seeded three inches deep.

Directions. - Dig up a number of small corn plants for this study. Be careful not to break the roots in removing the plant from the soil. Remove the dirt which clings to the roots, by washing. Make a study of plants seeded one inch deep, one week old, two weeks old, three weeks old, and four weeks old. Also plants seeded three inches deep two weeks old and four weeks old. (In determining age of plant count time from date of seeding.)

Make drawings of the plants at different stages of growth and at the different depths of seeding indicated. Show in the first drawing the four temporary roots which develop first, and in drawings of older plants the permanent root system which develops later. Show how the distance between the temporary roots and the permanent root system depends upon the depth of planting.

The drawings should include the root system, stalk, and leaves and their arrangement. 
STUDENT'S NOTES AND REPORT 
78

LABORATORY MANUAL OF AGRICULTURE

STUDENT'S NOTES AND REPORT 


\section{EXERCISE 19}

\section{THE CORN KERNEL}

Object. - To make a study of the physical parts of corn kernels. To show the differences in texture in the different parts of the same kernel. To show the location of color in yellow, white, and red kernels of dent corn.

Explanation. - There are six distinct types of corn: dent, flint, soft, sweet, pop, and pod. Dent corn is the type most generally grown.

There are four distinct parts of the corn kernel. They are the seed coat, aleurone layer, endosperm, and embryo. The seed coat or hull is a thin outer layer covering the entire kernel. It serves as a protection for other parts of the kernel and constitutes about 7 per cent of the kernel. The aleurone layer lies just

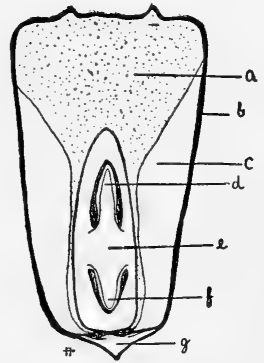

Fig. 6. - A corn kernel. $a$, crown starch; $b$, hull ; $c$, horny starch; $d$, shoot of embryo; $e$, germ; $f$, root of embryo; $g$, tip cup. under the seed coat and serves as a second covering for the kernel. It constitutes about 10 per cent of the corn kernel. The endosperm comprises the greatest part of the corn kernel. It is composed largely of starch and is a source of food supply for the young plant just after 
germination. The endosperm is composed of two distinct classes of material: the hard, corneous, and the white, starchy endosperm. About 73 per cent of the entire kernel is endosperm. The embryo, also called the germ, is the living part of the corn kernel. It is located near the center and upper side of the kernel. It contains a large percentage of protein and oil. About 10 per cent of the kernel is embryo.

Equipment. - 1. A wash basin.

2. Kernels of white, yellow, and red corn.

Directions. - Make a drawing showing the germ side of a kernel of corn. Make a drawing of a cross section and a longitudinal section of a kernel of corn. Show in the drawings the difference in structure of the different parts of the endosperm.

Remove the hulls of white, yellow, and red kernels of dent corn that have been soaked in water for one day. Observe the location of color.

Where is the white color located in white corn?

Where is the yellow color located in yellow corn?

Where is the red color located in red corn?

What is the color of the endosperm in red corn? 


\section{STUDENT'S NOTES AND REPORT}




\section{EXERCISE 20}

\section{THE EAR OF CORN}

Object. - To make a study in detail of an ear of corn.

Explanation. - Ears of corn vary in size, shape, number of rows, number of kernels per ear, and in their general appearance. This variation occurs in different types of corn, in different varieties of corn, and in different ears of corn of the same variety.

Equipment. - 1. Two ten-ear samples of corn of different varieties.

2. A foot rule.

3. A yard tape line.

4. A torsion balance, weighing to half a gram.

Directions. - Number the ears from one to ten. Use the blank outline below and fill in the following data for the two samples of corn. Record the length and circumference of each ear in inches. Record the weight of each ear in grams. Record the number of rows per ear, the number of kernels per row, and the number of kernels for each ear. Record the measurements for each individual ear and the average for the sample. 


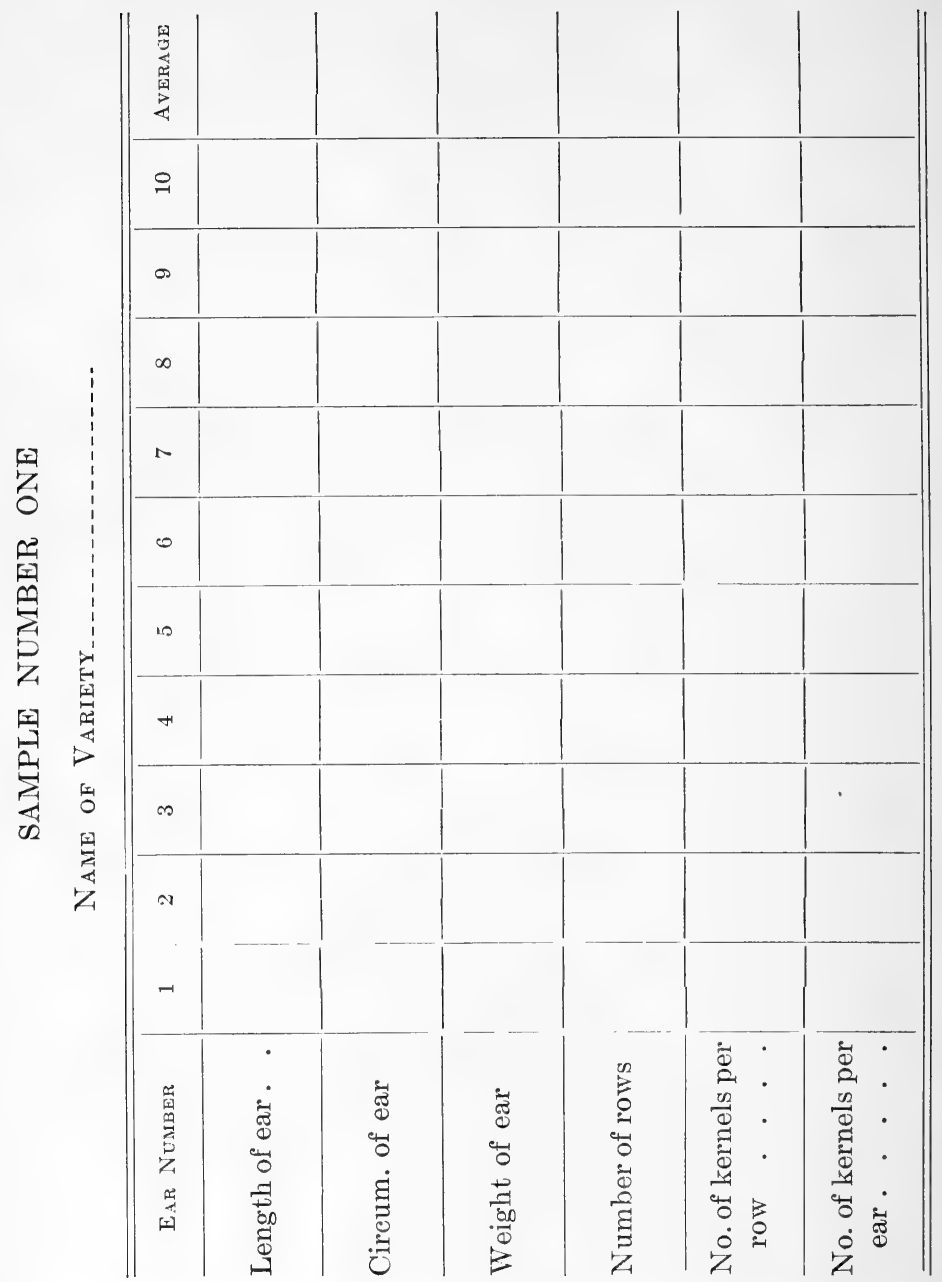

Counting seventy pounds to the bushel, how many average cars of the above sample are required for a bushel? 


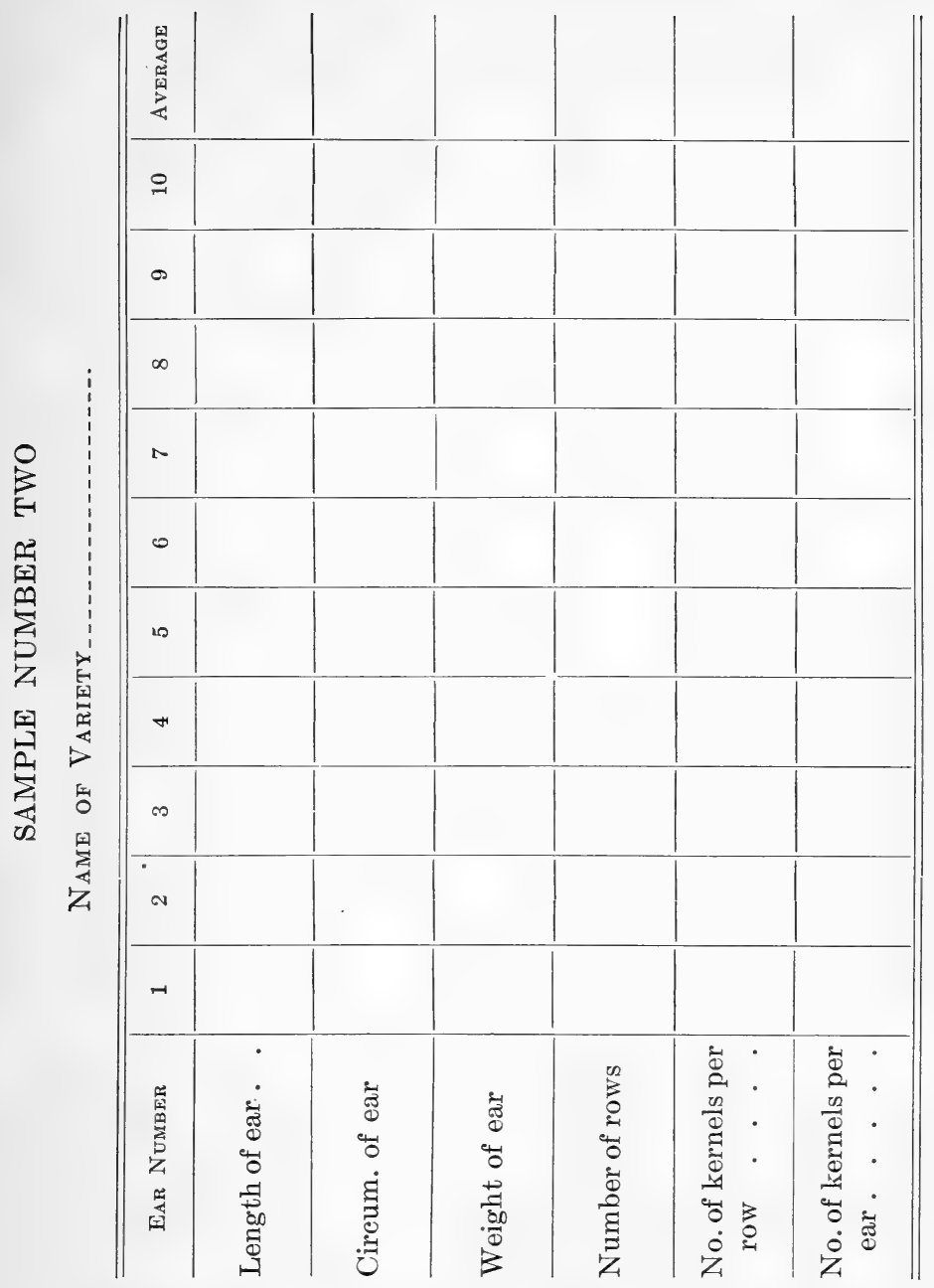

Counting seventy pounds to the bushel, how many average ears of the above sample are required for a bushel? 
Determine the per cent of shelled corn in at least two of the ears studied.

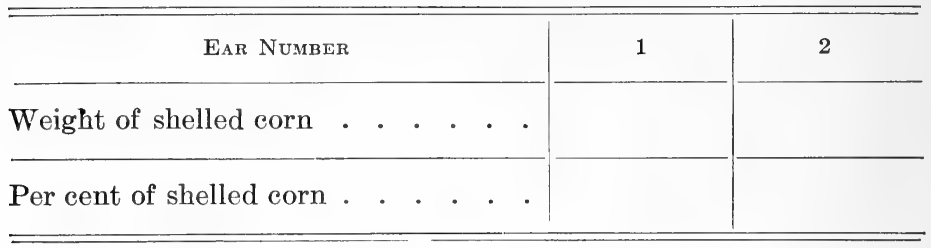


STUDENT'S NOTES AND REPORT 


\section{EXERCISES 21, 22, 23}

\section{CORN JUDGING}

Object. - To acquire skill and obtain practice in selecting seed ears of corn.

Explanation. - Corn judging is estimating the value of ears of corn for seed. It requires a knowledge of different parts of the ear of corn and an appreciation of quality in corn characters. Ears of corn are different in size, shape, and appearance. A good corn judge should be able to select those ears that are best suited for planting. The score card is used to designate the parts of an ear of corn and the relative value of these parts.

A good ear of corn should be nearly cylindrical, approximately 10 to 11 inches in length, and 7 to $7 \frac{1}{2}$ inches in circumference. The kernels and cob should each be of a uniform color. The ear should be sound, the kernels should be firm on the cob, and the butt and tip should be covered with well-shaped kernels. There should be from sixteen to twenty rows of corn on the ear, and the kernels should be deep and well shaped, with little space between the rows. The germ should be large and bright, and the ear should be well matured.

Different varieties of corn may differ in their standard of perfection. Early maturing varieties are usually smaller 


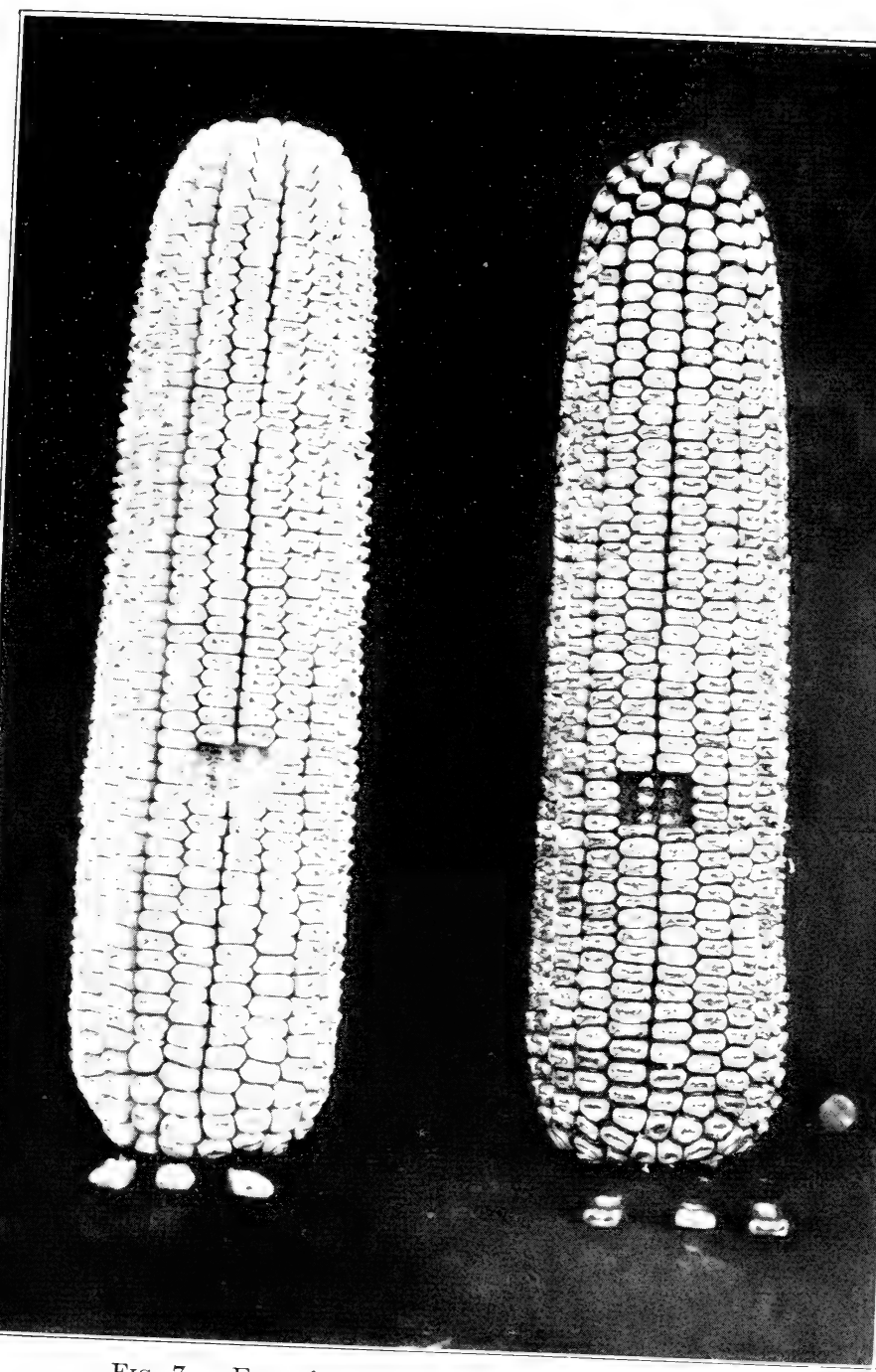

FIG. 7. - Ears of corn that approach the ideal type. 
than those maturing later, and corn growing in districts of light rainfall has a more shallow kernel and a smoother surface than varieties growing in districts with an abundance of rainfall. Varieties of corn may also differ in color, some being white, some yellow, and some red. The sample of corn used for judging should contain ten ears of the same variety.

Equipment. - 1. One ten-ear sample of corn for each member of the class.

2. A foot rule.

3. A tape line.

Directions. - Number the ears from one to ten. Commence with ear number one and place in the first vertical column of the score card the scores that the ear merits. Deduct from the perfect score for all deficiencies of the ear.

\section{Description of Points of the Score Card}

Shape of Ear. - A desirable type of ear should be nearly cylindrical. This will permit an equal number of rows from butt to tip of ear, with kernels quite uniform in size. The rows should run straight the entire length of the ear, and the ear should present a uniform shape. If the ear is poor in shape, the score for shape should be decreased.

Length of Ear. - The length of ear may be determined by measuring from the extreme butt to the extreme tip. If the ear is below the standard, it should be scored off according to the deficiency. If it is too long, it is likely to have broad and shallow kernels, with an inferior butt and tip, and the score should be reduced accordingly. 
Circumference of Ear. - The circumference of ear is determined by measuring the ear one third the distance from the butt to the tip. Small circumference of ear indicates a small amount of corn. Ears too large in circumference are likely to be immature, and are, therefore, of less value. For such deficiencies the score should be decreased.

Color of Kernel. - A uniform color, true to the variety, indicates purity. If there is a difference in color, or if there are grains that differ in color from that of the variety standard, a mixture is indicated, and the score should be reduced.

Color of Cob. - Usually yellow varieties of corn have red cobs, and white varieties have white cobs. If the cob is not correct in color, a mixture is indicated, and the score should be reduced.

Butt of Ear. - The butt of the ear should be well filled out with kernels of uniform shape.

Tip of Ear. - The rows of kernels should extend the full length of the ear, covering the tip with kernels of uniform size and shape.

Shape of Kernels. - Desirable kernels should be wedgeshaped; that is, they should be wider across the crown than at the tip of the kernel. The thickness should be about one half the width, and they should have a large, well-developed germ. The kernels on the different parts of the ear should be uniform in shape and size. This is essential to secure a uniform distribution in planting.

Depth of Kernels. - The amount of corn on an ear depends largely upon the depth of the kernels. From this point of view it would seem desirable to have as deep a kernel as possible. Experiments seem to indicate, however, that 
kernels of medium depth are preferable to deeper ones, and will perhaps produce a larger yield and better quality of corn.

Furrows between Rows. - If the crowns of the kernels are rounded off on top, there is likely to be space between the rows. This condition is usually associated with a shallow grain, and indicates a small per cent of corn.

Space between Kernels at Cob. - The kernels should be close together at the tips. Space between the tips of the kernels, next to the cob, indicates immaturity and weak vitality.

Composition and Feeding Value. - By far the largest part of the corn kernel is starch. It also contains protein and oil. The protein and oil are higher in feeding value than starch, and high content of these substances is indicated by a large per cent of the horny endosperm and large germ.

Vitality. - It is essential that corn used for seed should be of strong vitality. The ear should be well matured. The kernels should be sound and firm on the cob. The germ should be large. Small, wrinkled, or dull-colored germs indicate low vitality.

Soundness or Freedom from Injury. - Mold or fungous disease not only indicates decreased vitality, but it decreases the market value of the corn. Kernels that are cracked, or injured by various insects, are of less value, and should be scored against accordingly.

Careful examination should be made of the various parts of the ear as given on the score card. In examining the kernels, two or more kernels should be removed from near the center of the ear so that a better estimate may be formed of their worth. If an ear is very poor in some quality, it 
may be scored very low or even zero for that point. After a score is given for each point the column should be added. The sum is the score of the ear. It requires a very good ear to score higher than 85 per cent.

After the ears have been scored, place them in the order of their worth, placing the best ear first, the second-best ear second, etc., for the ten ears. 
是

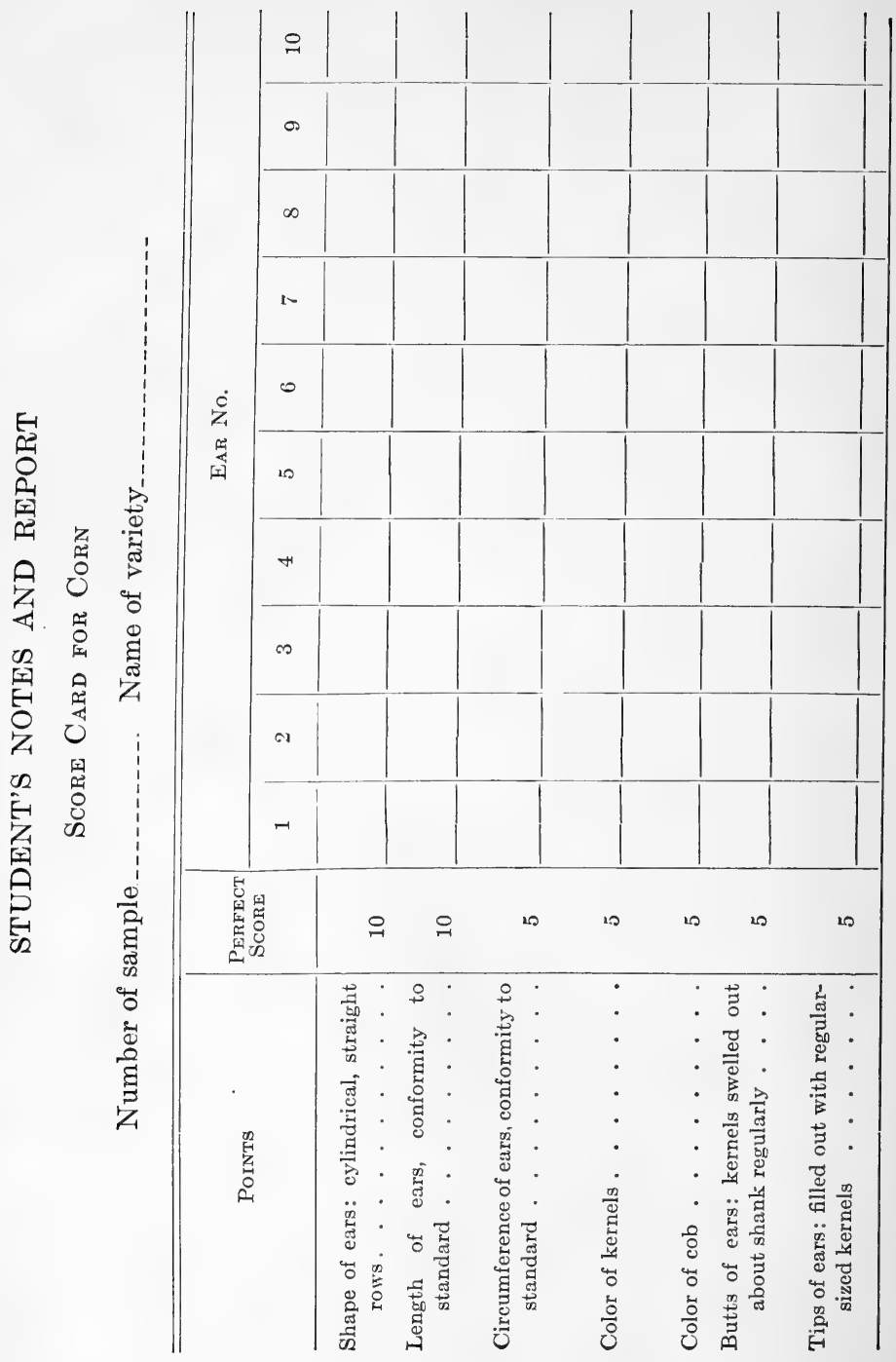




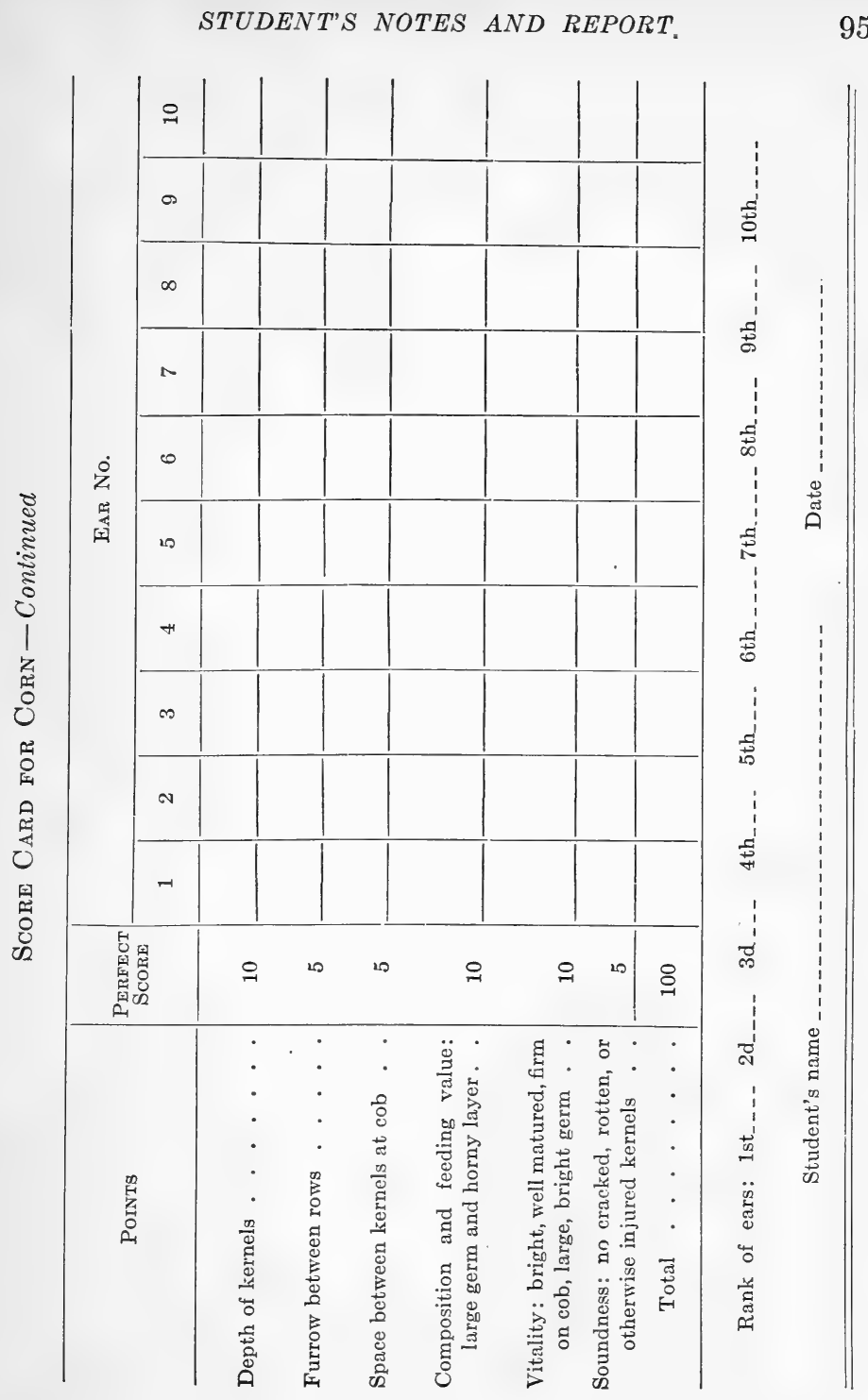



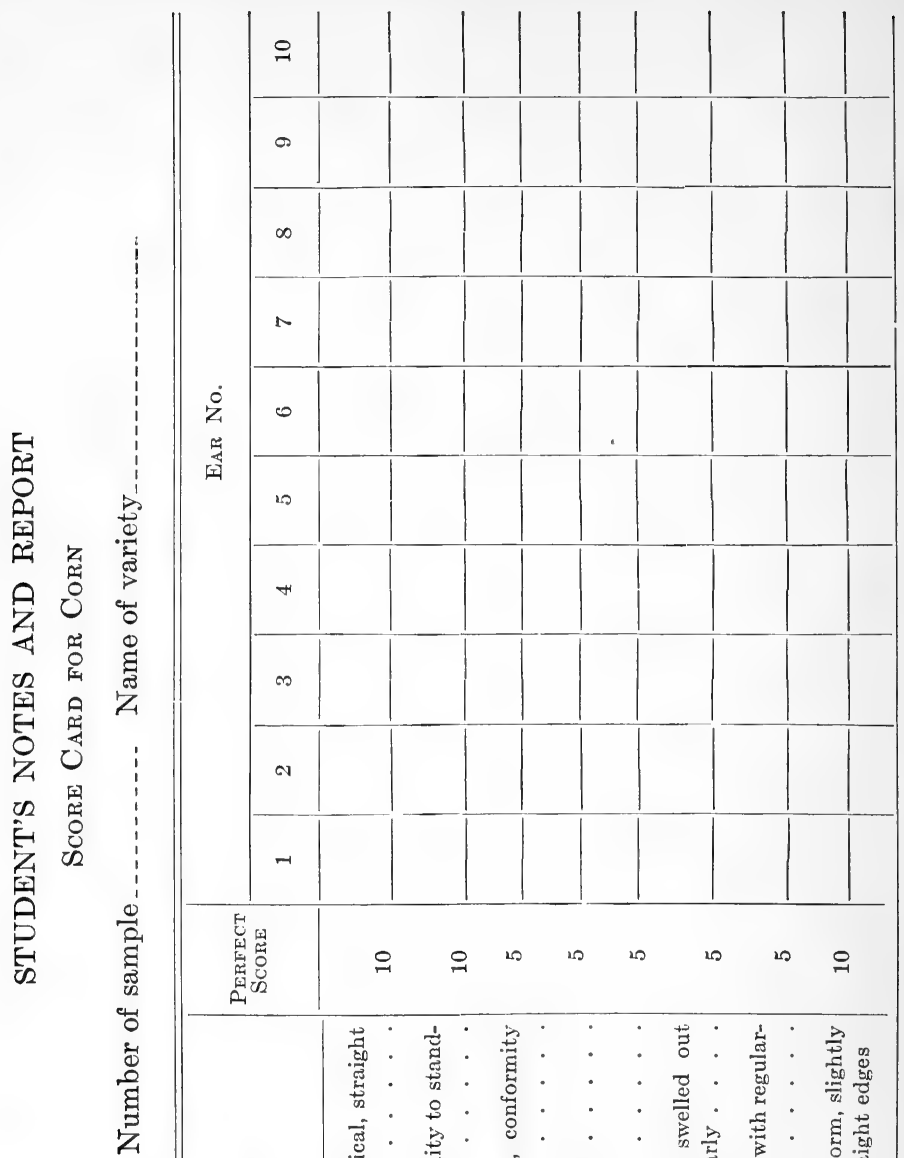

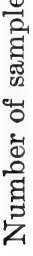

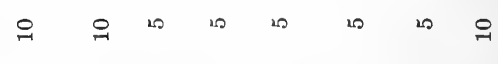

尝

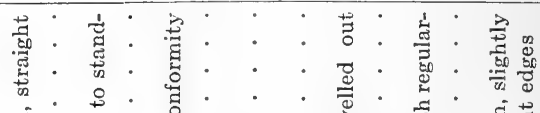

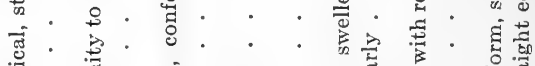

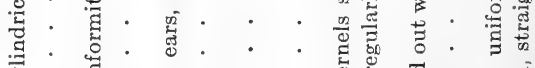

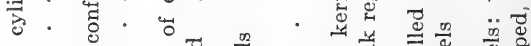

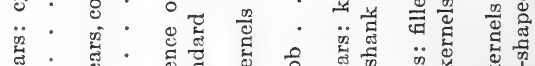

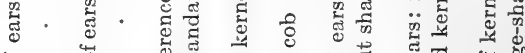

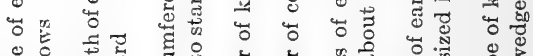

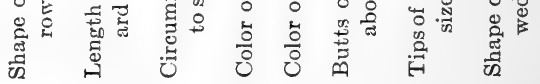




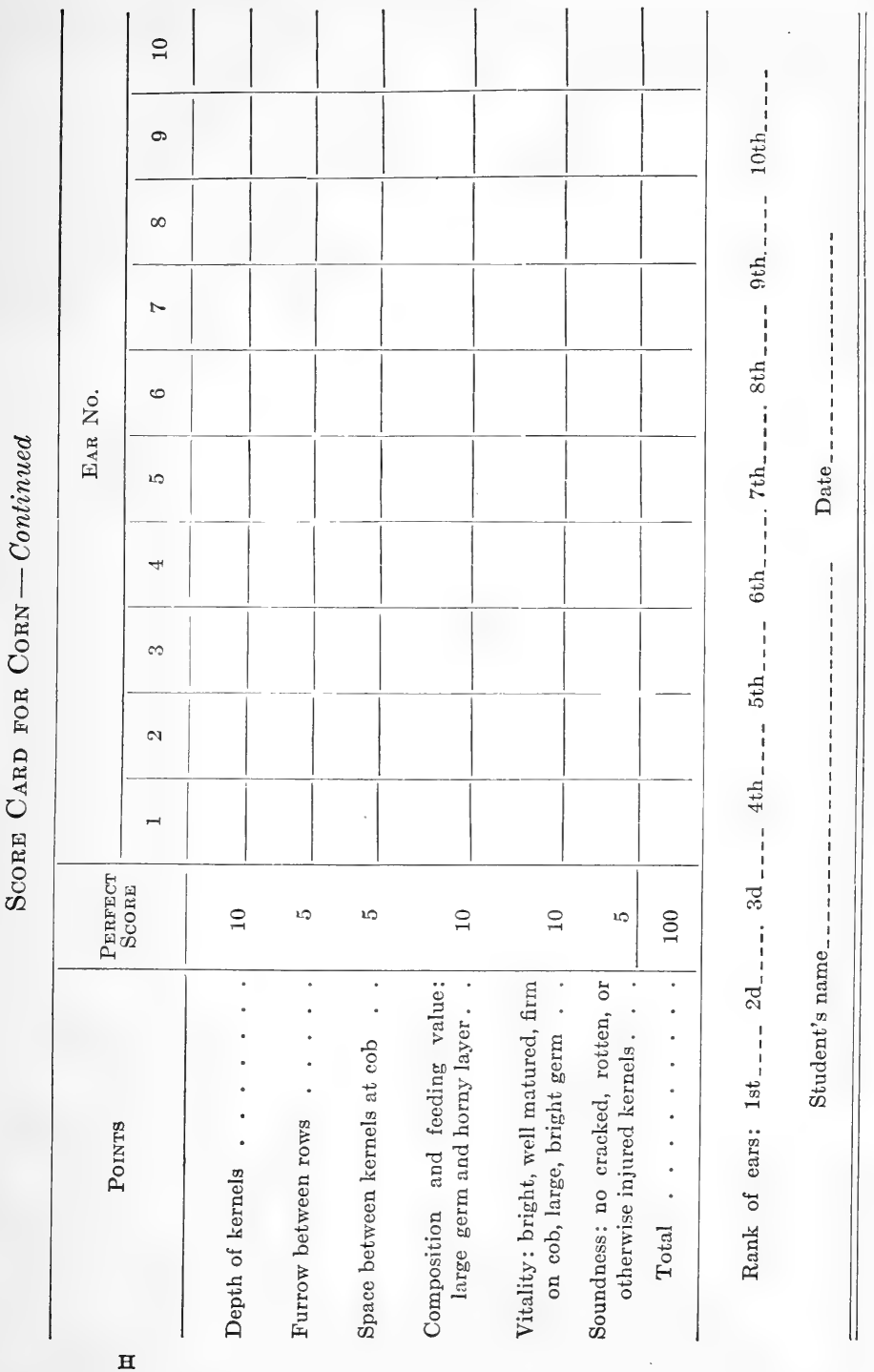




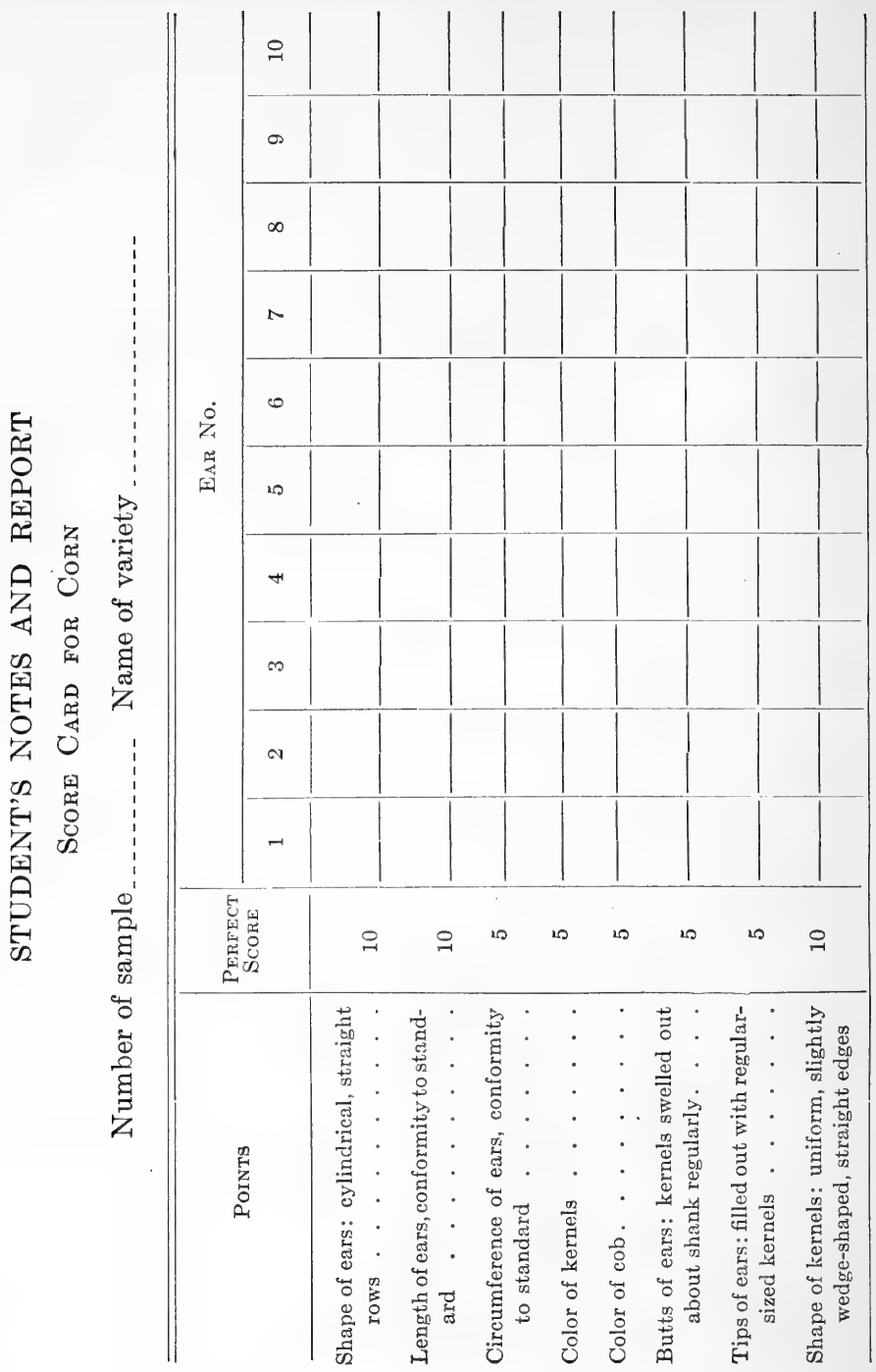




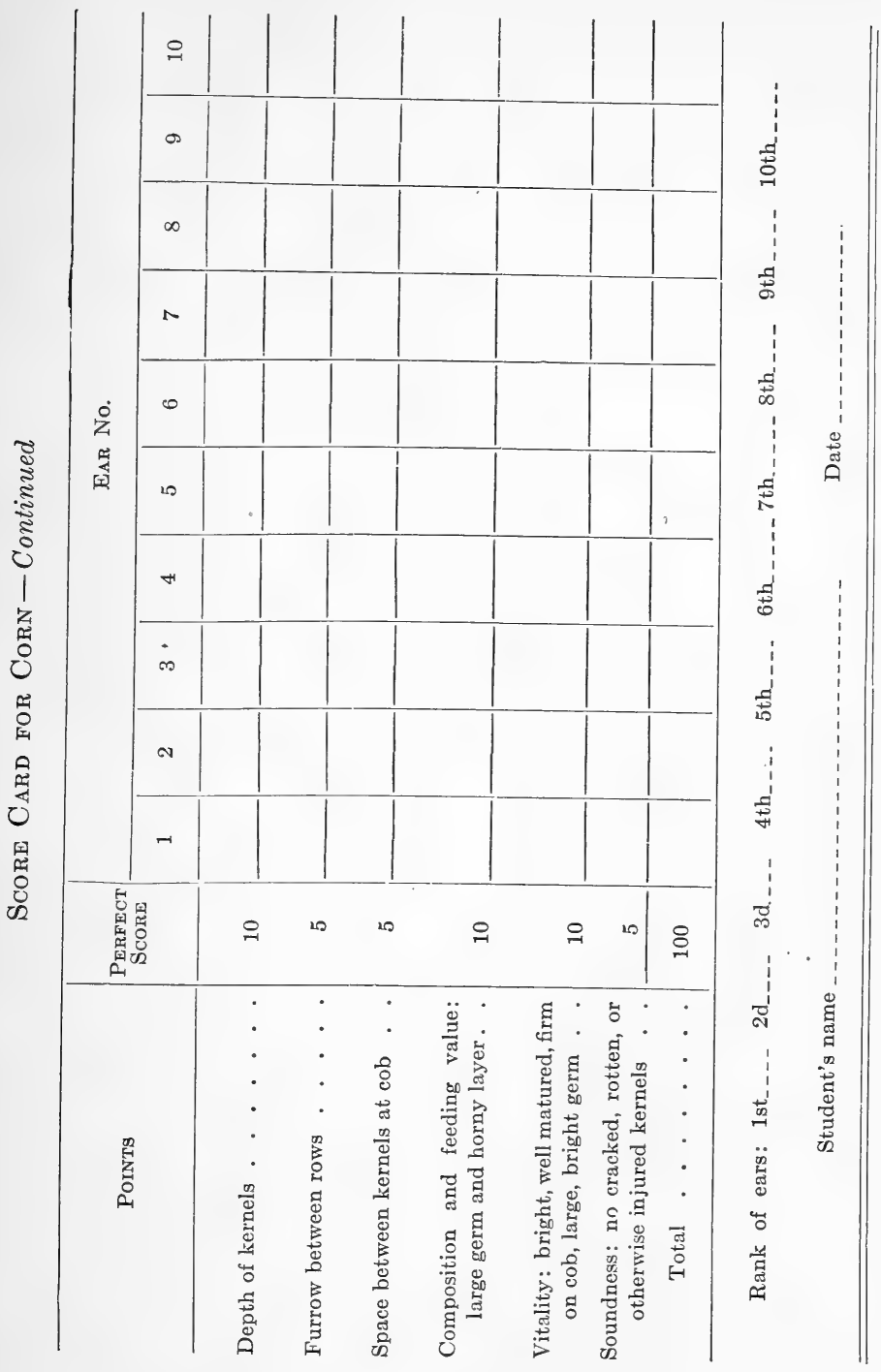




\section{EXERCISE 24}

\section{A STUDY OF SHELLED CORN}

Object. - To study corn with reference to its quality and commercial grade; and to become familiar with different classes and grades of corn.

Explanation. - Practically two thirds of the corn crop of the United States is produced in eight states: Illinois, Iowa, Kansas, Nebraska, Missouri, Indiana, Ohio, and Texas. Within these same eight states the live-stock industry has been developed to the greatest extent. While corn is used almost exclusively as a food for live stock, large quantities are sold on the commercial market before reaching final destination. For the proper classification of corn of varying quality it is necessary to have a system of grading. In determining quality it is necessary to consider purity, condition, color, and size of kernels.

Equipment. - 1. Four ten to twelve pound samples of corn representing different grades.

2. A weight-per-bushel tester.

3. A balance weighing to a half gram.

Directions. - Weigh out fifty grams of corn from one of the samples, and make a detailed study of it. Use the outline form "A Study of Shelled Corn" to record the results of the examination. Classify the sample of corn under ob100 
servation as yellow, white, or mixed, according to the rules governing the inspection and grading of corn that are included in this exercise. Record the class name in the column for that sample number for classification.

Spread the sample out on a blank piece of paper and make a detailed study for each of the divisions given below.

Purity. - Make a study of purity by separating the sample into the following groups: corn, other grains, foreign matter. Weigh each group and record its weight and percentage in the blank form in the column of the sample number. Weigh to one half of one gram. Quantities less than one half of one gram may be indicated as "trace." All the groups of the division should total 100 per cent for purity.

For the remainder of the determinations in the study of this exercise use twenty-five grams of the corn from which other grain and foreign matter have been removed.

Condition. - Make a study of condition by separating this sample into the following groups: sound kernels; cracked or broken kernels; rotten, decayed, or otherwise injured kernels. Weigh and record the weight and per cent of each group. The total for condition should be 100 per cent.

Color. - The predominating colors in corn are white and yellow. Other common colors are red, speckled, and blue. Corn of the latter colors are less likely to be pure in color in large lots, and are usually designated as mixed. Make a study of color by separating the sample into the following groups: white, yellow, and mixed. Weigh and record the weight and per cent in each group. The total for color should be 100 per cent. 
Size. - Separate the sample into the following groups for size: large kernels; medium-size kernels; small kernels. Weigh and record the weight and per cent of each group. The total for size should be 100 per cent.

Separate from the sample one hundred average-size kernels. Weigh them and record their weight. Compare the weight of one hundred average-size kernels in the different samples studied.

The weight per bushel may be determined by using the weight-per-bushel tester. Determine the weight per bushel of the sample by pouring the corn in very lightly over the top or side of the tester and without shaking or packing. Draw the bar or straight edge once across the top of the tester so that it will be filled just level with the top. Adjust the tester by moving the weight out on the bar until it just balances. The scale on the bar by the weight indicates the weight per bushel. Record weight per bushel of sample.

The commercial grade is determined by the foregoing factors, and a grade is given according to the quality of the sample. The grain inspection departments of the various states provide rules for the inspection and grading of corn. The following rules govern the inspection of corn in Kansas:

\section{White Corn}

No. 1. White Corn. - Shall be pure white corn and sweet.

No. 2. White Corn.- Shall be fifteen-sixteenths white and sweet.

No. 3. White Corn. - Shall be fifteen-sixteenths white and sweet. 
No. 4. White Corn. - Shall be fifteen-sixteenths white, but shall include tough, musty, and damaged corn.

(Mixed corn and yellow corn have separate rules, but the rules are the same other than color. In yellow, seveneighths is used instead of fifteen-sixteenths, as in white.)

The per cent of moisture contained in corn affects its quality. Corn with a high per cent of moisture is usually tough and is given a lower grade.

Corn to grade No. 1 is not allowed to have over 15 per cent of moisture; to grade No. 2 not over 16 per cent; to grade No. 3 not over 19 per cent; to grade No. 4 not over 22 per cent.

Make a study of as many samples as the time given permits, 


\section{STUDENT'S NOTES AND REPORT}

A Study of Shelled Corn

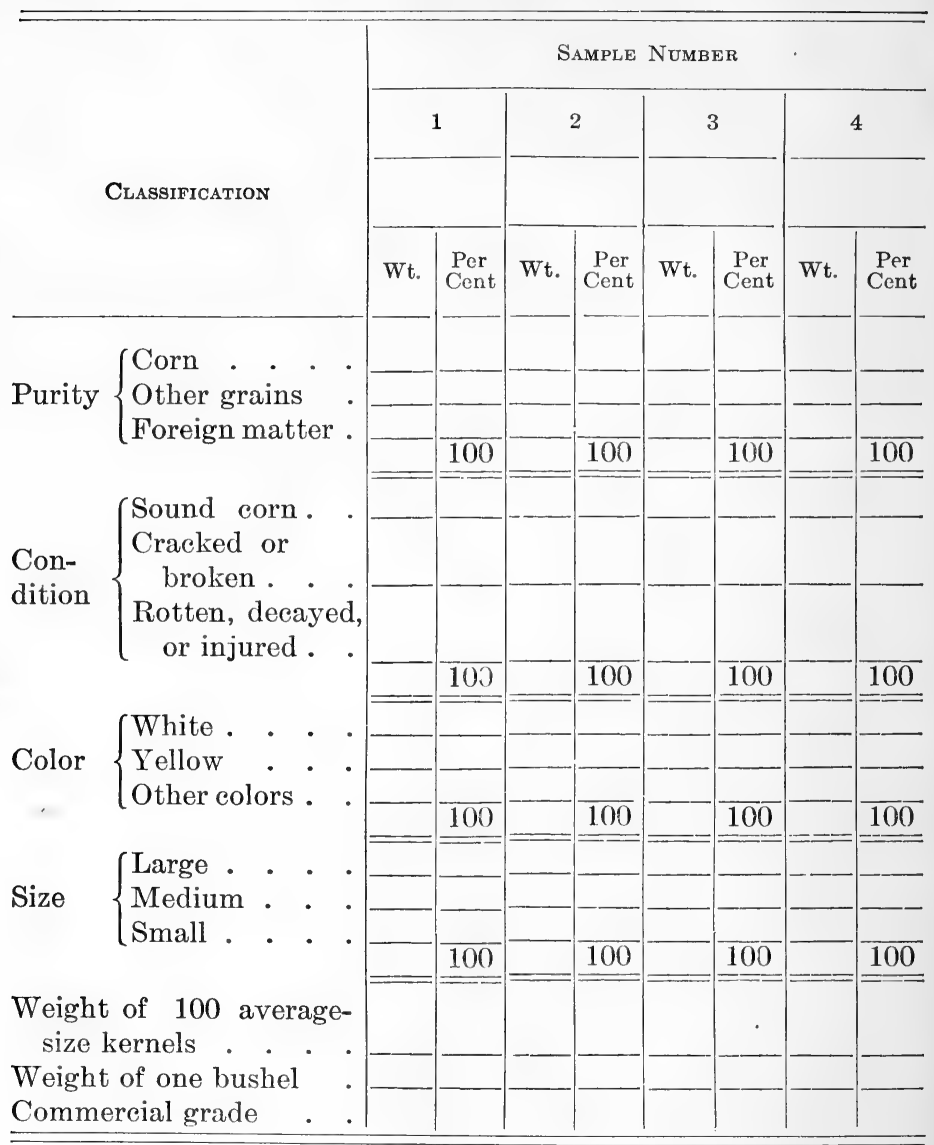

Date 


\section{EXERCISE 25}

\section{A STUdy OF THE WHEAT HEAD}

Object. - To examine the head of wheat and become familiar with the shape and arrangement of its different parts.

Explanation. - The head of wheat is commonly called a spike. It is made up of several parts, of which the grain is the most important. The head is composed of a single rachis and several spikelets. The spikelets are attached to the rachis. A fully developed spikelet has two or more kernels, usually only two. There is an outer glume, flowering glume, and a palea for each kernel, except when a third kernel develops. The third kernel of a spikelet does not have an outer glume. There is an undeveloped flower for each spikelet. Sometimes the spikelets near the base of the head fail to develop. The two divisions of a spikelet are similar in arrangement of parts. There is an outer glume on each side of the spikelet, and they partly inclose the flowering glumes. The uppermost part of the outer glume is called the beak. The notch just below the beak forms the shoulder, and the heavy line running from the beak to the base is called the keel. The flowering glume is just within the outer glume and bears the beard or awn. The kernel is inclosed by the flowering glume on the outside and by another husk called the palea 


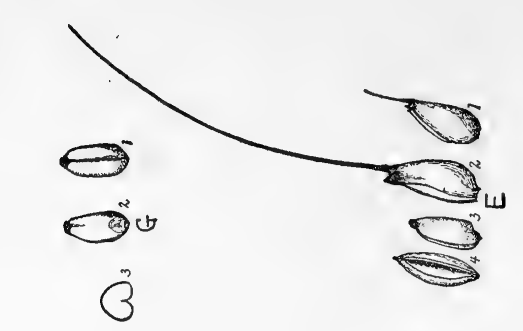

A.

.. 800

.0.

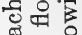

용

o क्षे क्ष

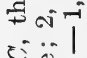

çö

ซ్

i

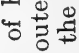

$\leq 4$

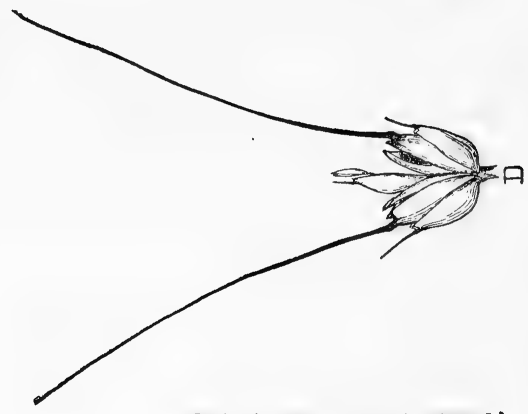

席获

$5 \pm$

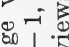

1

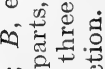

$\because$ क

で.

요

世.

언

i

$>$ สี

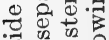

क in

过焉

$\nabla \overrightarrow{0}$

的政

गुं की

ॠू

का लाँ

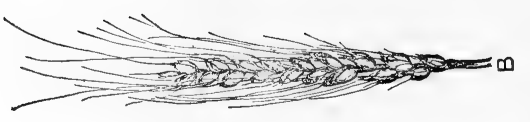

\pm 둥 0

두용

त.

तै 65

过焉

प‥ 可

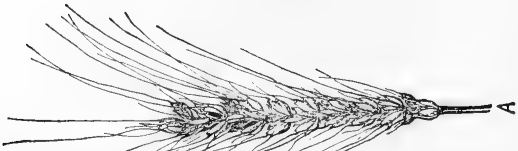

-

\%

ज्ञ ति

ব० ...

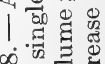

$\infty$ क

空 
on the inside. The germ of the kernel is at the base and it faces toward the outside. The crease is on the inside next to the palea. The brush end of the kernel extends upward. There is an undeveloped flower between the two divisions of the spikelet. The attachment of the spikelet to the rachis is called the rachilla. Figure 8 shows all the different parts of the spike.

Equipment. - Heads of wheat sufficient to supply all members of the class.

Directions. - Make two drawings of the entire head of wheat, one showing the side and one showing the edge view. Remove a single well-developed spikelet and make a drawing of it. Draw a single outer glume; a single flowering glume; and the palea. Make a drawing of the kernel showing the crease side, one showing the germ side, and one showing the cross section. Remove all the spikelets from the head and make a drawing of the rachis. Make all drawings at least four times the natural size except the head and rachis. Make them in careful detail and name all the different parts.

Fill out the following description for five average-size heads of wheat. 


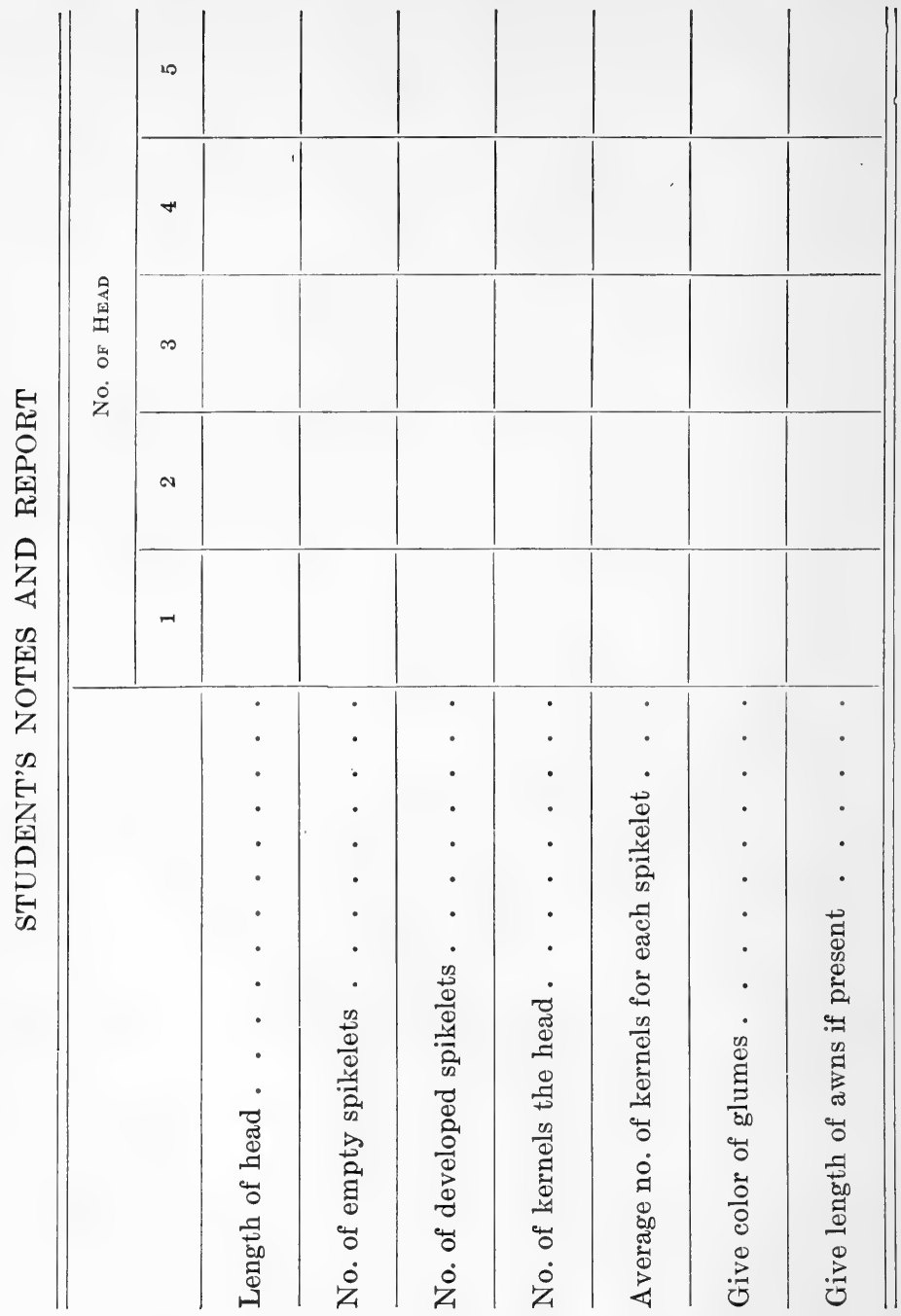




\section{STUDENT'S NOTES AND REPORT}


110 LABORATORY MANUAL OF AGRICULTURE

STUDENT'S NOTES AND REPORT 


\section{EXERCISE 26}

\section{A STUDY OF THE RYE HEAD}

Object. - To examine the head of rye and become familiar with the shape and arrangement of its different parts.

Explanation. - The head of rye is commonly called a spike. It is made up of several parts, of which the grain is the most important. The head is composed of a single rachis and several spikelets. The spikelets are attached to both sides of the rachis. There are two divisions of the spikelet, each division containing one kernel. There is an outer glume, a flowering glume, and a palea for each kernel. The kernel is inclosed by the flowering glume on the outside and the palea on the inside. The flowering glume does not entirely inclose the kernel, and a small portion of it is exposed. The outer glume is small and does not inclose the flowering glume. The rye kernel is similar to the kernel of wheat, though it is somewhat more slender, more pointed at the germ end, and the crease is not so deep. There are only two flowers in a spikelet, and both of them develop.

Equipment. - Heads of rye sufficient to supply all the members of the class.

Directions. - Make two drawings of the entire head of rye. Make a drawing showing the side view, then turn the head 


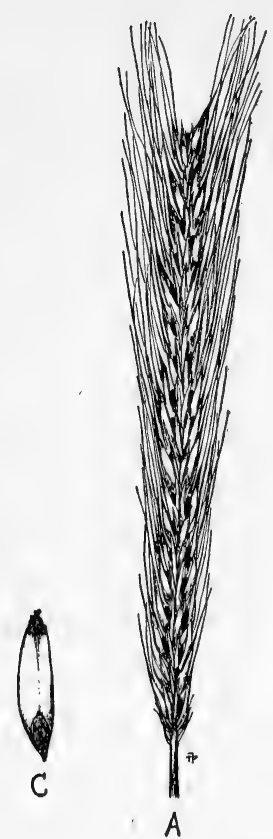

Fig. 9. $-A$, a head of rye; $B$, a single spikelet; $C$, a kernel of rye showing germ side. one fourth way around and make the second drawing. Remove a single welldeveloped spikelet and make a drawing of it. Draw a single outer glume, a single flowering glume, and the palea. Make a drawing showing the crease side, one showing the germ side, and one showing the cross section of the kernel. Remove all the spikelets from the head and make drawing of the rachis. Make all drawings at least four times their natural size, except those of the head and rachis. Make them in careful detail and name all the different parts. 
Fill out the accompanying outline for five average-size heads of rye.

\section{STUDENT'S NOTES AND REPORT}

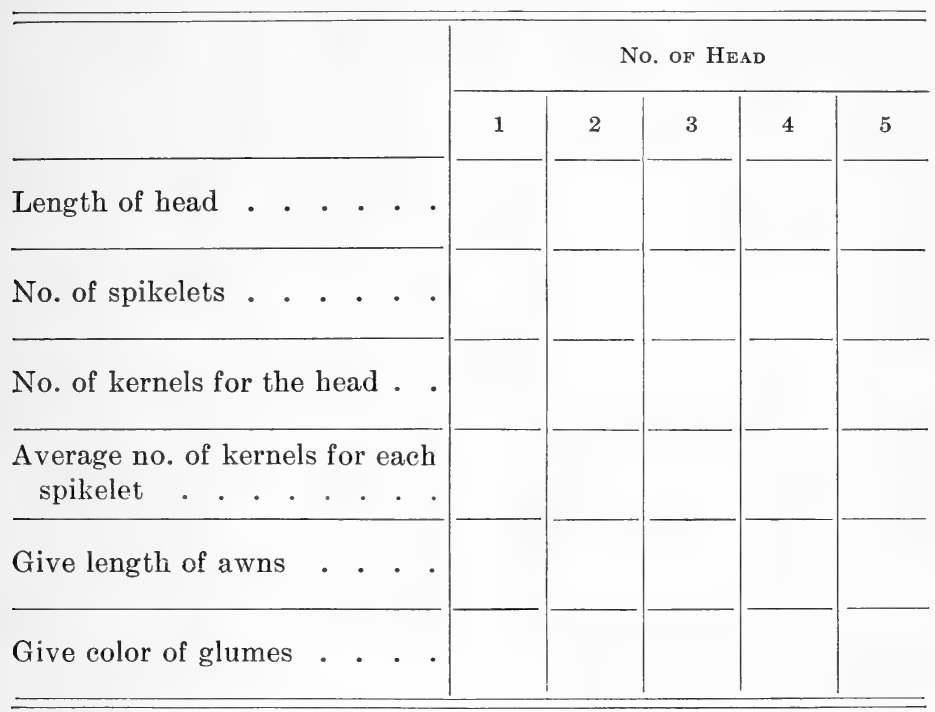


STUDENT'S NOTES AND REPORT 
STUDENT'S NOTES AND REPORT 


\section{EXERCISES 27 AND 28}

\section{A STUDY OF WHEAT}

Object. - To study samples of wheat with reference to their quality and commercial grade, and to become familiar with different classes and grades of wheat.

Explanation. - The principal use of wheat is for the production of flour. Wheats differ in their milling value, depending largely upon the quality. In determining quality it is necessary to consider purity, soundness, color, texture, size, and other conditions of the kernel. The student should become familiar with the quality of different classes of wheat, such as hard winter, soft winter, hard spring, durum, etc. Representative samples of different classes and grades of wheat are used in this study.

Equipment. - 1. Four ten-pound samples of wheat.

2. Type samples of wheat, showing color and class.

3. Balances weighing to one half of one gram.

4. A weight-per-bushel tester.

Directions. - Weigh out twenty grams of wheat from one of the samples, and make a detailed study of it. Use the outline form "A Study of Wheat" to record the results of the examination. Compare the sample of wheat under observation with named type sample for identification. Record the type name in the column for that sample number for classification. 
Spread the sample out on a blank piece of paper and make a detailed study of each of the divisions given below.

Purity. - Make a study of purity by separating the sample into the following groups: wheat of class; other wheats; other grains ; foreign matter. Weigh each group and record its weight and per cent of the sample in the blank form in the column of that sample number. Weigh to one half of one gram. Quantities less than one half gram may be indicated as "trace." All the groups of the division should total 100 per cent for purity.

For the remainder of the determinations in this exercise use ten grams of the wheat from which other grains and foreign matter have been removed. This includes "wheat of class " and "other wheats," as obtained by the first separation.

Soundness. - Make a study of soundness by separating the kernels of this sample into the following groups: sound; broken; shriveled; sprouted; heat damaged. Weigh and record the weight and per cent in each group. The total for soundness should be 100 per cent.

Color. - Color in wheat is represented by different colors and shades, as amber, dark amber, yellowish, and white. Kernels subjected to adverse weather conditions are likely to be discolored, and are known as bleached. The kernels should be compared with type samples representing the different colors found in wheat. Light amber is represented by durum wheat; amber by the common hard winter wheats; dark amber by hard winter wheats of a very dark color; yellowish includes those kernels which are yellow or have yellow sides, and are often found in the hard winter wheats. 
White wheats are represented by the very light colored wheats grown largely on the Pacific coast. Bleached wheat may be kernels of any color which have been badly discolored by adverse weather conditions. Make a study of the color by separating the sample into the following groups: light amber, amber, dark amber, yellow, white, and bleached. Weigh, and record the weight and per cent in each group. The total for color should be 100 per cent.

Texture. - Texture in wheat may be classed as hard, medium, and soft. Texture is closely associated with color. Amber-colored wheats are usually hard in texture. Wheats that have a tendency to become yellowish are usually of a medium texture. Wheats that are yellow or white are likely to be soft. Texture may also be determined by crushing typical kernels.

Make a study of the texture by separating the sample into the following groups : hard, medium, soft. Weigh, and record the weight and per cent in each group. The total for texture should be 100 per cent.

Size. - Divide the sample into the following groups: large kernels, medium kernels, and small kernels. Weigh and determine per cent of each group. Record weight and per cent in the blank form. The total for size should be 100 per cent.

Separate from the sample 100 average-size kernels. Weigh and record weight. Compare the weight of 100 average-size kernels in the different samples studied. The size of kernels differs in different classes of wheat.

The weight per bushel is determined by using the weightper-bushel tester. Determine the weight per bushel of the 
sample by pouring the wheat in lightly over the top or sides of the tester without shaking or packing. Draw the bar or straightedge once across the top of the tester so that it will be filled just level to the top. Adjust the tester by moving the weight out on the bar until it just balances. The scale on the bar by the weight indicates the weight per bushel. Record weight per bushel of the sample.

The commercial grade is determined by the foregoing factors, and a grade is given according to the quality of the sample. The grain inspection departments of the various states provide rules for the inspection and grading of wheat. The following rules govern the inspection of hard winter wheat for Kansas:

\section{Hard Winter Wheat}

No. 1. Dark Hard. - Shall be hard winter wheat of the dark variety, sound, sweet, dry, plump, and clean, and shall weigh not less than sixty-one pounds to the bushel.

No. 2. Dark Hard. - Shall be hard winter wheat of the dark variety, sound, sweet, dry, plump, and clean, and shall weigh not less than fifty-nine pounds to the bushel.

No. 3. Dark Hard. - Shall be hard winter wheat of the dark variety, sound, sweet, dry; some grains may be bleached; not clean or plump enough for No. 2 ; shall weigh not less than fifty-six pounds to the bushel.

No. 4. Dark Hard. - Shall be hard winter wheat of the dark variety, tough, sprouted, or from other causes so badly damaged as to render it unfit for No. 3.

Other classes of wheat are graded in a similar manner.

Make a study of as many other samples as the time permits. 


\section{STUDENT'S NOTES AND REPORT}

A Study of Wheat

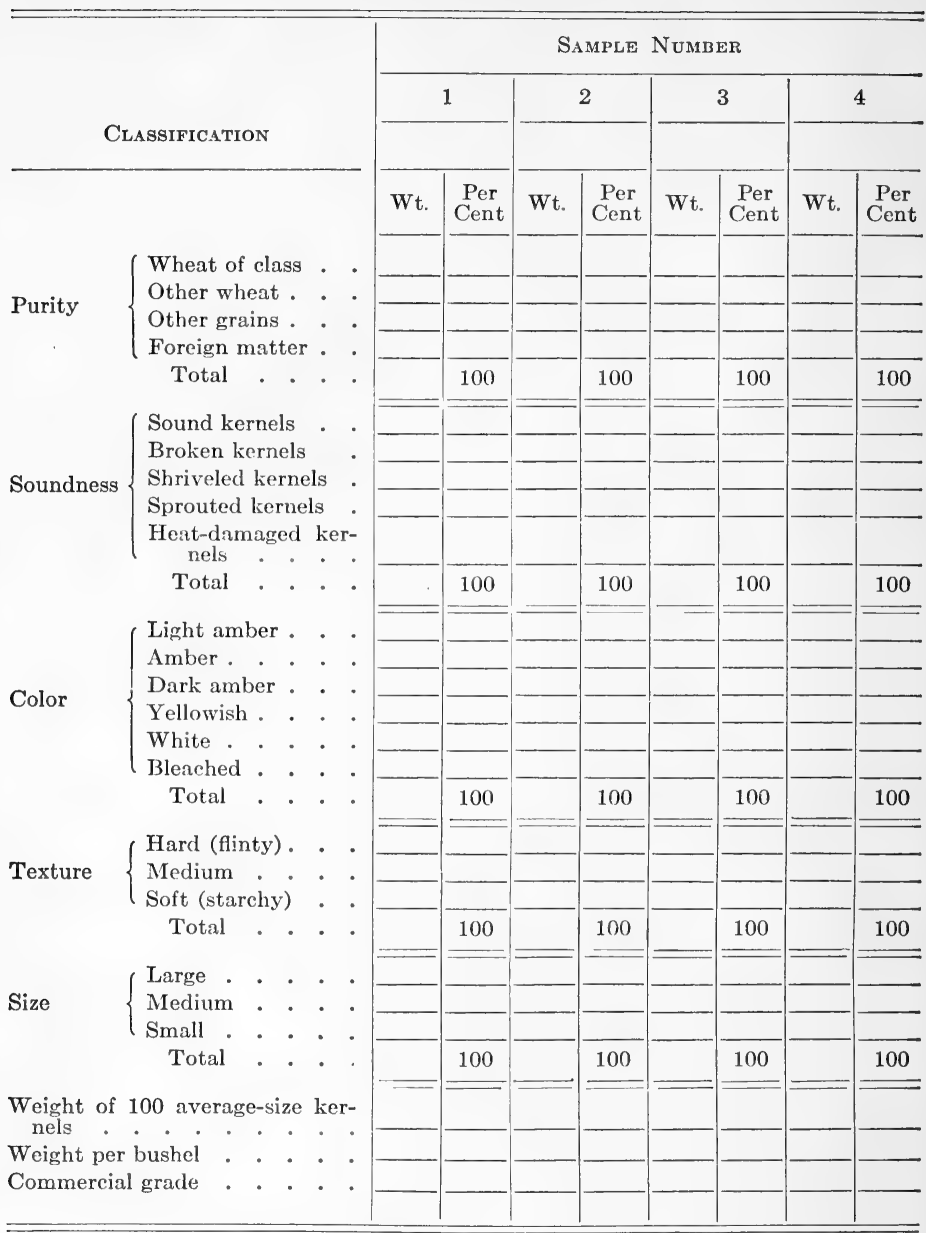

Date 


\section{EXERCISE 29}

\section{A STUDY OF RYE}

Object. - To study samples of rye with reference to their quality and commercial grade, and to become familiar with different grades of rye.

Explanation. - Rye is used for the production of flour for bread, for malting purposes, and to some extent for feed for live stock. Rye is not extensively grown in the United States. There are not as many varieties of rye as of wheat. There is a variation in texture and color, but it is not as important as in wheat. There is usually but one class of rye recognized on the commercial market. Different grades of rye are recognized, and the commercial grade given depends upon the quality. The student should become familiar with the different factors that affect the quality of rye. Representative samples of different grades of rye are used in this study.

Equipment. - 1. Four ten-pound samples of rye.

2. A weight-per-bushel tester.

3. A balance weighing to one half gram.

Directions. - Weigh out twenty grams of rye from one of the samples and make a careful study of it. Use the accompanying outline form "A Study of Rye," to record the results of the examination. 
Spread the sample out on a blank piece of paper and make a detailed study of each of the divisions given below.

Purity. - Make a study of purity by separating the sample into the following groups: rye; other grains; foreign matter. Weigh each group and record the weight and per cent. For the remainder of the determinations in this study use ten grams of rye from which other grains and foreign matter have been removed.

Soundness. - Make a study of soundness by separating the kernels of the sample into the following groups: sound, broken, shriveled; sprouted; heat damaged, or otherwise injured. Weigh, and record the weight and per cent in each group. The total for soundness should be 100 per cent.

Size. - Separate the sample into kernels of the following groups: large, medium, small. Weigh, and record weight and per cent of each group on the blank form. The total for size should be 100 per cent.

Separate from the sample 100 average-size kernels. Weigh and record the weight of the sample on the blank form in the column for that sample number. Quantities less than one tenth of one gram may be indicated as " trace."

The weight per bushel is determined by using the weight per bushel tester. Determine the weight per bushel of the sample as described in Ex. 27. All samples of rye are placed in the same class for commercial grading and given a commercial grade similar to wheat. Designate the commercial grade of the sample. 


\section{STUDENT'S NOTES AND REPORT}

\section{A Study of Rye}

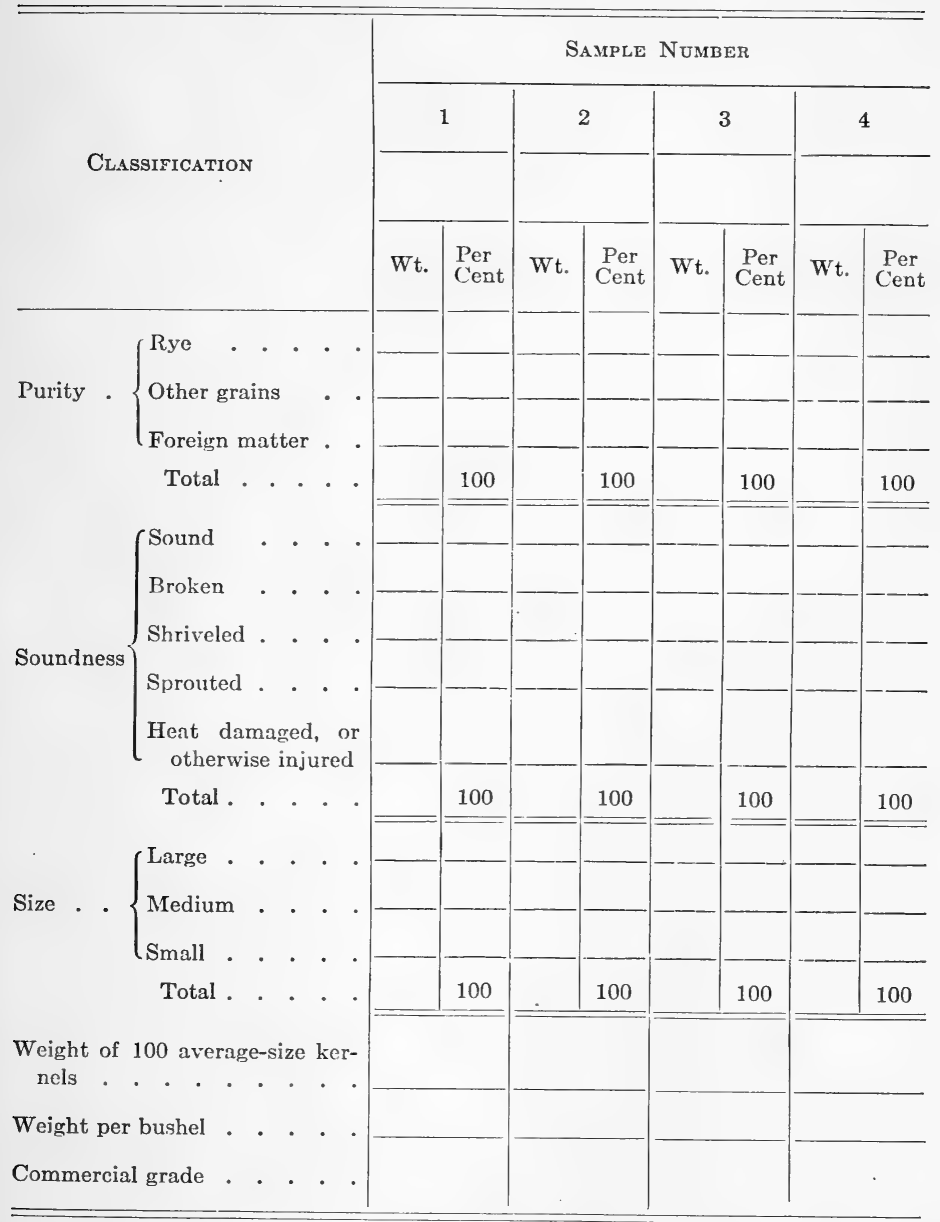

Dute

Student's Name 


\section{EXERCISE 30}

\section{A STUDY OF THE BARLEY HEAD}

Object. - To examine the head of barley and become familiar with the shape and arrangement of its different parts.

Explanation. - The head of barley is commonly called a spike. It is made up of several parts, of which the grain is the most important. The head of barley is composed of a single rachis and several spikelets. The spikelets bear the grain and are attached to the rachis. A spikelet of barley is made up of two outer glumes, a flowering glume, a kernel, and palea. The outer glumes are small and awl-shaped and do not inclose the flowering glume as in wheat and oats. The flowering glume bears the beard or awn when present and incloses the greater part of the kernel. The palea incloses the inner side of the kernel. In most barleys the flowering glume and palea adhere to the kernel when threshed. Some varieties of barley, however, are hull-less. In hull-less barleys the flowering glume and palea do not adhere to the kernel. The germ is at the base of the kernel, as in wheat, and faces outward. The crease is on the inside next to the palea. There are both two-rowed and six-rowed barleys.

In the six-rowed barleys the spikelets develop in groups of 
three on opposite sides of the rachis. In two-rowed barleys there is a single row of spikelets on each side of the rachis. There is an undeveloped spikelet on either side of the developed spikelet. Each developed spikelet contains but one kernel of barley. Figure 10 shows the different parts of the barley spike.

Equipment. - Heads of barley for each member of the class.

Directions. - Make two drawings of the entire head of a six-rowed barley, one showing the side and one showing the edge view. Make a drawing of a group of three spikelets. Make a drawing of a single spikelet, showing the flowering and outer glume. Make drawings of the kernel, one showing the germ side and one showing the cross section. Remove all the spikelets and make a draw-

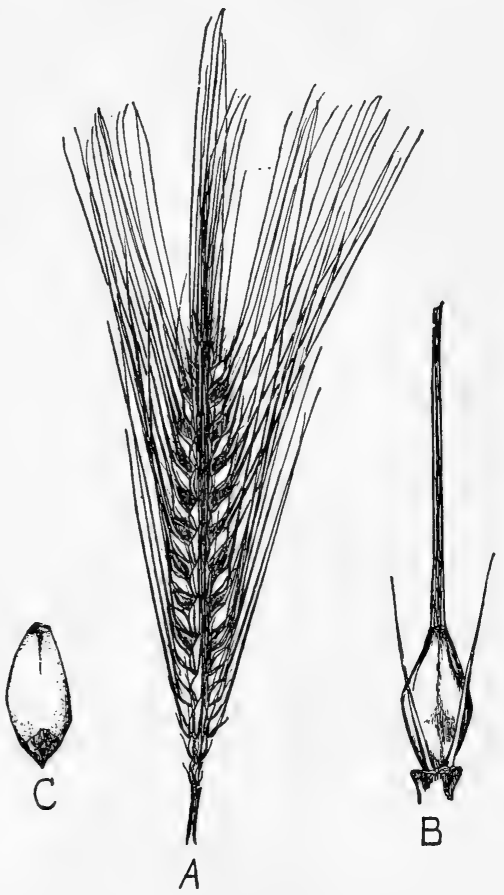

Fig. 10. $-A$, a head of six-rowed barley ; $B$, a single spikelet of barley; $C$, a kernel of barley with glumes and palea removed. ing of the rachis. Make all drawings at least four times the natural size, except the head and rachis. Make them in careful detail and name all the different parts. 
Fill out the following description for four heads of barley:

\begin{tabular}{|c|c|c|c|c|c|c|c|}
\hline Number of Head & & & & 1 & 2 & 3 & 4 \\
\hline Kind of barley . . . . & - & .. & . . & & & & \\
\hline Length of head . . . . & • & .. & - & & & & \\
\hline Number of kernels the head & & - & .. & & & & \\
\hline Length of awns if present & . & . . & . & , & & & \\
\hline
\end{tabular}




\section{STUDENT'S NOTES AND REPORT}




\section{EXERCISE 31}

\section{A STUDY OF THE OAT HEAD}

Object. - To examine the oat head and become familiar with the shape and arrangement of its different parts.

Explanation. - The head of oats is commonly called a panicle. It is made up of several parts, of which the oat grain is the most important. The head is composed of a branching stem and spikelets containing the grain. The branches of the panicle are attached in groups to the main stem. The spikelets are attached to these branches.

Each spikelet has two or more kernels, usually only two. Each kernel is inclosed within a flowering glume and palea. The kernel, together with the flowering glume and palea, is known as the grain, and is inclosed within the outer glume. When the oat grain has an awn or beard, it grows out from the back of the flowering glume. A sterile flower often develops near the base of the second kernel. The flowering glume and palea adhere tightly to the kernel and are not removed by threshing. One kernel is a little larger than the other. The smaller kernel develops near the base of the larger kernel and is sometimes almost inclosed within the flowering glume of the larger kernel. Figure 11 shows the parts of the oat panicle. 
Equipment. - Heads of oats for each member of the class.

Directions. - Make a drawing of the entire head of oats, showing the arrangement of the spikelets. Remove a single well-developed spikelet and make a drawing of it. Draw a single outer glume, a single flowering glume, and the palea.
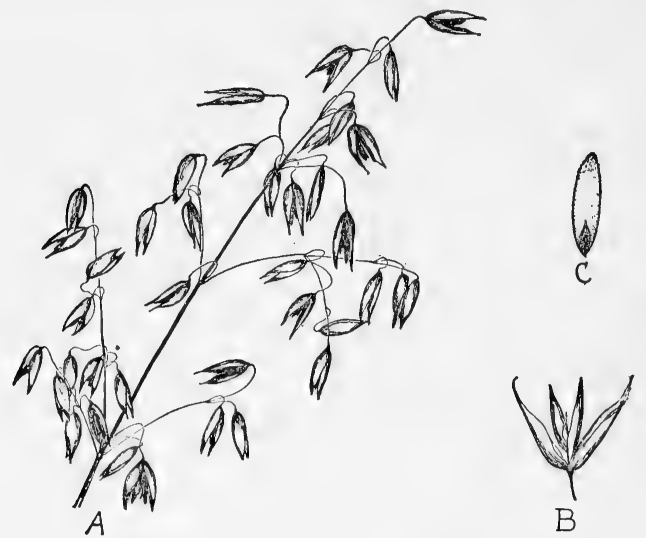

FIG. 11. $-A$, a head of oats; $B$, a single spikelet; $C$, the oat kernel with glumes and palea removed, showing the germ side.

Make a drawing of the kernel, showing the crease side, ne showing the germ side, and one showing the cross section. Make all the drawings at least four times the natural size, except the one of the panicle. Make them in careful detail and name the different parts. 


\section{STUDENT'S NOTES AND REPORT}




\section{STUDENT'S NOTES AND REPORT}




\section{EXERCISE 32}

\section{A STUDY OF BARLEY}

Object. - To study samples of barley with reference to their quality and commercial grade; and to become familiar with different classes and grades of barley.

Explanation. - A large amount of barley is used as a grain feed for live stock on farms where it is produced. Approximately one half of the barley produced is sold on the commercial market, where it is finally used either for brewing or feeding purposes. The value of barley depends largely upon the quality of the grain. In determining quality it is necessary to consider purity, soundness, color, texture, size, and other conditions of the grain. The student should become familiar with different classes and grades of barley.

Equipment. - 1. Four ten-pound samples of barley.

2. A weight-per-bushel tester.

3. A balance weighing to one half of one gram.

Directions. - Weigh out twenty grams of barley from one of the samples, and make a detailed study of it. Use the outline form "A Study of Barley" to record the results of the examination. Compare the sample of barley under observation with named type samples for identification. Record type name in the column for that sample number for classification. 
Spread the sample out on a blank piece of paper and make a detailed study of each of the divisions given below.

Purity. - Make a study of purity by separating the sample into the following groups: barley of class; other barleys; other grains ; foreign matter.

Weigh each group and record the weight and per cent of the sample in the blank form in the column of the sample number. Quantities less than one tenth of one gram may be indicated as "trace." All the groups of the division should total 100 per cent for purity.

For the remainder of the determinations in this study use ten grams of the barley from which other grains and foreign matter have been removed. This includes "barley of class" and "other barleys," as obtained by the first separation.

Soundness. - Make a study of soundness by separating the sample into the following groups: sound kernels; broken kernels ; shriveled kernels; sprouted kernels; other damaged kernels. Weigh and record the weight and per cent of each group. The total for soundness should be 100 per cent.

Color. - The color of barley may be injured by adverse weather conditions during harvesting. A bright light color is desirable. Make a study of color by separating the sample into the following groups: good color; slightly bleached; discolored. Weigh and record the weight and per cent in each group. The total for color should be 100 per cent.

Texture. - Texture in barley may be classed as hard and soft. The barleys of hard texture are more vitreous and contain a higher per cent of protein than others. The 
barleys that are soft are usually higher in starch content. Crush typical kernels and observe their hardness.

Size. - Separate the sample into the following groups for size: large, medium, small. Weigh and record the per cent of each group. The total for size should be 100 per cent.

Separate from the sampie 100 average-size kernels. Weigh them and record their weight. Compare the weight of 100 average-size kernels in the different samples studied. The size of kernels differs in different classes of barley. The weight per bushel is determined by using the weight-perbushel tester. Determine the weight per bushel of the sample.

The commercial grade is determined by the foregoing factors, and a grade is given according to the quality of the sample. The grain inspection departments of the various states provide rules for the inspection and grading of barley. The following rules govern the inspection of barley in Kansas:

\section{Barley}

No. 1. Barley. - Shall be sound, bright, sweet, clean, and free from other grain.

No. 2. Barley. - Shall be sound, dry, and of good color.

No. 3. Barley. - Shall include shrunken, stained, dry barley, unfit to grade No. 2.

No. 4. Barley. - Shall include tough, musty, dirty barley. Make a study of as many other samples as the time permits. 


\section{STUDENT'S NOTES AND REPORT}

\section{A Study of Barley}

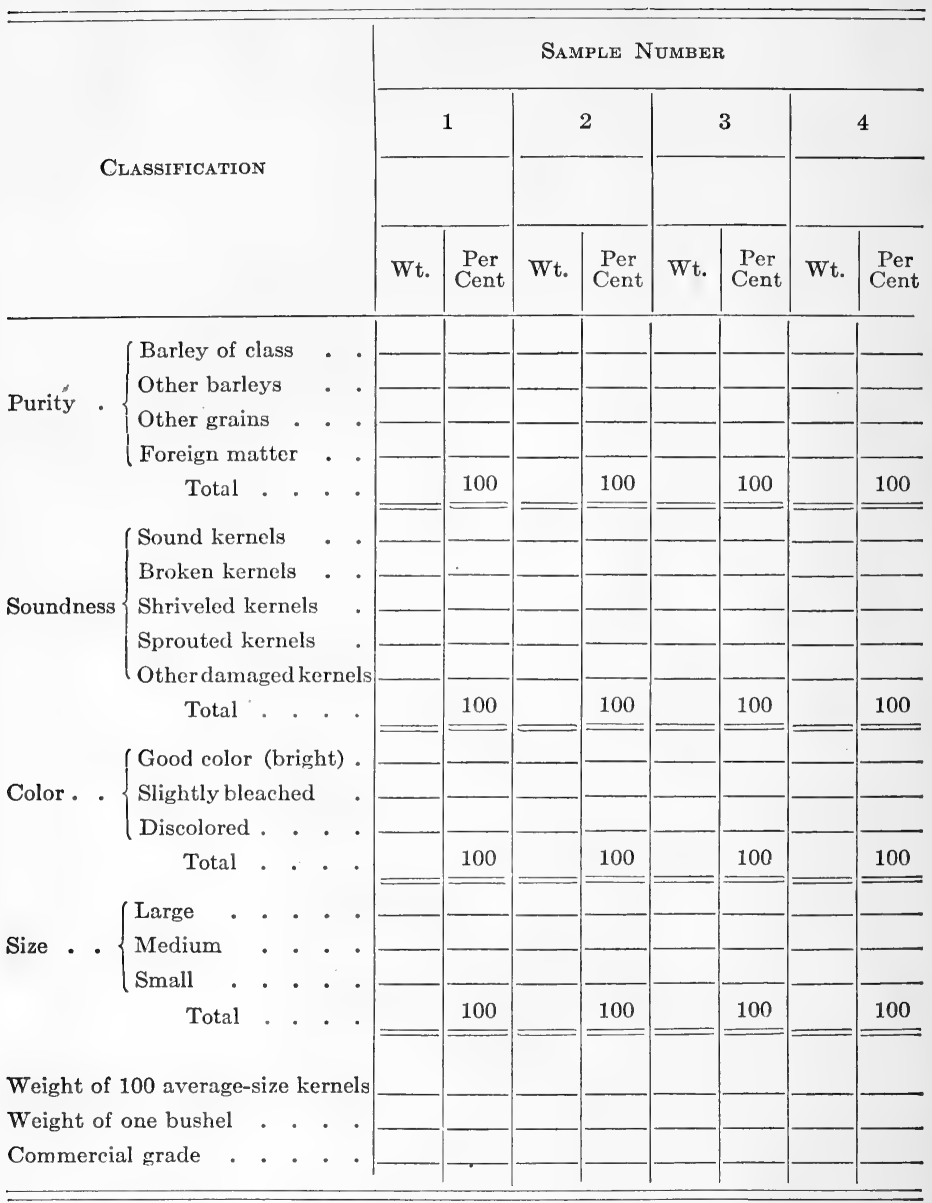

Date 


\section{EXERCISE 33}

\section{A STUDY OF OATS}

Object. - To study samples of oats with reference to their quality and commercial grade, and to become familiar with different classes and grades of oats.

Explanation. - A large proportion of the oats produced in the United States is used as grain for live stock on farms where grown. Some oats is sold on the commercial market, a part of it being used for cereal foods and for feeding purposes. The value of oats depends largely upon the quality of the grain. In determining value it is necessary to consider purity, soundness, color, size, and other conditions of the grain. The student should become familiar with different classes and grades of oats.

Equipment. - 1. Four ten-pound samples of oats.

2. Weight-per-bushel tester.

3. Balance weighing to one half gram.

4. Named type sample of oats.

Directions. - Weigh out twenty grams of oats from one of the samples and make a detailed study of it. Use the accompanying outline form "A Study of Oats" to record the results of the examination. Compare the sample of oats under observation with named type samples for identification. Record the type name in the column for that sample 
number under classification in the accompanying outline form.

Spread the sample out on a blank piece of paper and make a detailed study of each of the divisions given below :

Purity. - Make a study of purity by separating the sample into the following groups: oats of class; other oats; other grains; foreign matter. Weigh each group and record the weight and per cent of the sample in the blank form in the column of that sample number. Quantities less than one tenth of one gram may be indicated as "trace." All the groups of the division should total 100 per cent for purity.

For the remaining determinations in this study use ten grams of the oats from which other grains and foreign matter have been removed.

Soundness. - Make a study of soundness by separating this sample into the following groups: sound kernels; injured kernels. Weigh, and record the weight and per cent of each group. The total for soundness should be 100 per cent.

Color. - There is considerable variation in the color of oats, as white, yellowish, brownish, red, and black. Oats is sometimes discolored by adverse weather conditions, and the original color is obscure. Separate the sample into the different colors named above. Weigh, and record the weight and per cent in each group. The total for color should be 100 per cent.

Size. - Separate the sample into the following groups for size : large, medium, small. Weigh, and record the weight and per cent of each group. The total for size should be 100 per cent.

Separate from the sample 100 average-size kernels. Weigh 
them and record their weight. Compare the weight of 100 average-size kernels in the different samples studied. The size of kernels differs in the different classes of oats.

The weight per bushel is determined by using the weightper-bushel tester, as has been described in Ex. 27. Determine the weight per bushel of the sample.

The commercial grade is determined by the foregoing factors, and the grade is given according to the quality of the sample. The grain inspection department of the various states provide rules for the grading of oats. The following rules govern the inspection and grading of white oats in Kansas :

No. 1. White Oats. - Shall be pure white oats, dry, sweet, sound, clean, and free from other grain.

No. 2. White Oats. - Shall be seven-eighths white, sound, dry, and contain not more than 1 per cent each of dirt and foreign matter or 3 per cent of other grain.

No. 3. White Oats. - Shall be seven-eighths white, sound, dry, and not more than 3 per cent of dirt or foreign matter nor 5 per cent of other grain.

No. 4. White Oats. - Shall be seven-eighths white, tough, musty, or from any cause unfit for No. 3.

Make a study of as many other samples as the time permits. 


\section{STUDENT'S NOTES AND REPORT}

\section{A Study of Oats}

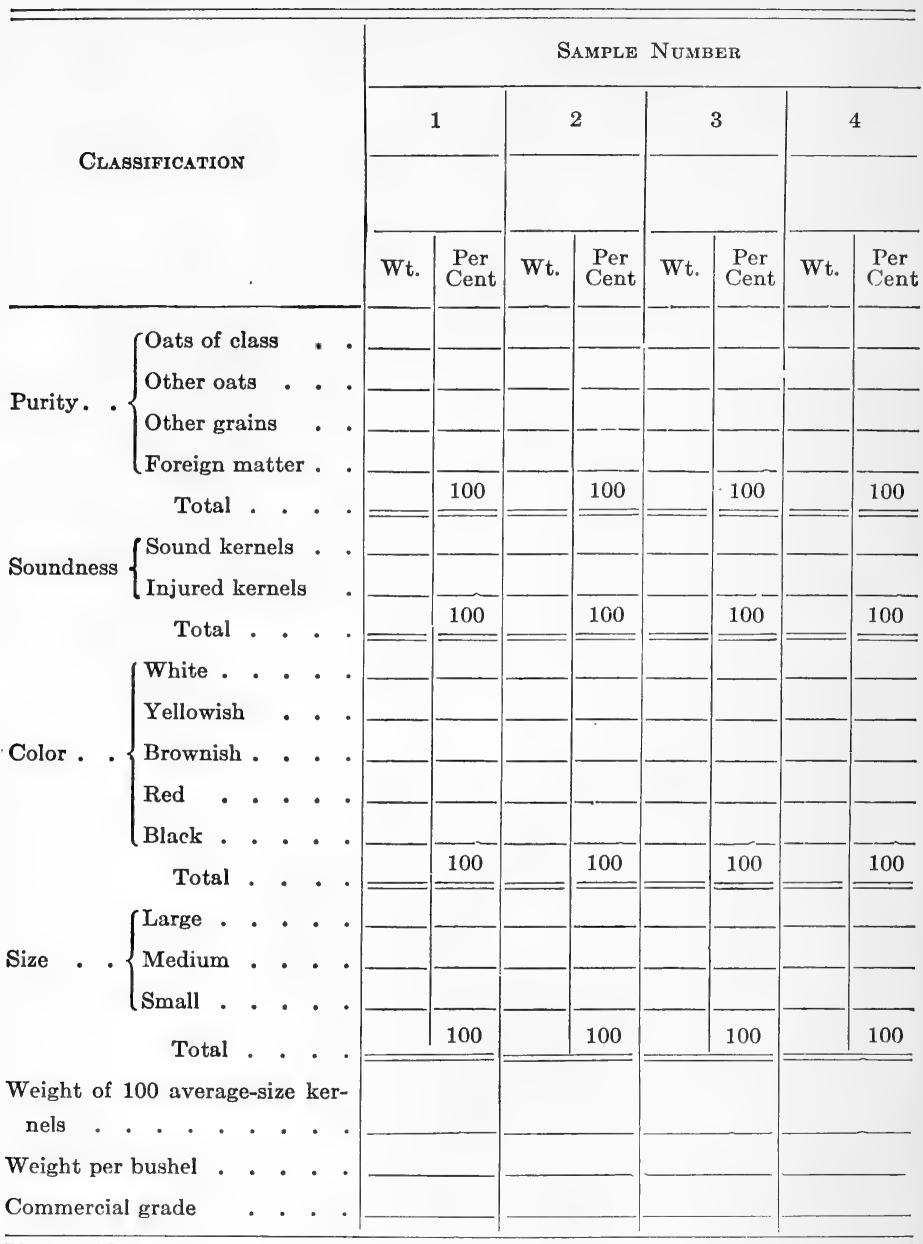

Date 


\section{EXERCISE 34}

\section{THE SORGHUM HEAD}

head.

Object. - To study the shape and structure of the sorghum

Explanation. - Sorghum resembles corn somewhat in its method of growth, but unlike corn the seed is produced in heads on the top of the plants. The heads of different types of sorghum vary in shape and appearance. Some are oval and compact; some are long and compact; and others are open and branching. The variety or kind of sorghum is most easily determined by a study of the head characters. The head of sorghum is called a panicle.

Equipment. - Typical heads of at least three types of sorghum, one each of kafir, milo, and a sweet sorghum for each member of the class.

Directions. - Make an outline drawing of a typical head of kafir. Split the head longitudinally through the center, so that the method of branching may be more easily observed. Study the branches of the panicle and their arrangement and make a drawing of the panicle. Make a similar study and drawings of the head of milo and of the head of sweet sorghums. Fill in the detail of these drawings as far as time permits. 
142 LABORATORY MANUAL OF AGRICULTURE STUDENT'S NOTES AND REPORT 


\section{STUDENT'S NOTES AND REPORT}




\section{EXERCISE 35}

\section{A STUDY OF SORGHUM SEED}

Object. - To study the purity and worth of sorghum seed. Explanation. - There are two general classes of sorghum, saccharine and nonsaccharine. Saccharine sorghum is used extensively for forage and for the production of sorghum sirup. The seed of saccharine sorghum has a bitter taste and is not generally used as feed for live stock. However, it has a commercial value as it is used extensively for planting. The nonsaccharine sorghums are used extensively for forage and their seed is used for feed.

Sorghum seed is more easily injured in handling than most of the other small grain cereals. The kernels crack easily in threshing, and their vitality is often reduced by improper storing. Sorghum seed of different varieties is often somewhat mixed.

Equipment. - 1. Four ten to twelve pound samples of sorghum seed representing the different types of sorghum.

2. A weight-per-bushel tester.

3. A balance weighing to one half gram.

4. Type samples of sorghum seed.

Directions. - Weigh out twenty grams of sorghum seed from one of the samples and make a detailed study of it. Use the outline form "A Study of Sorghum Seed " to record 
the results of the examination. Compare the sample under observation with named type samples for identification. Record the name in the column of that sample number for classification.

Spread the sample out on a blank piece of paper and make a detailed study of each of the divisions given below.

Purity. - Make a study of purity by separating the sample into the following groups : sorghum of class ; other sorghums ; other grains; foreign matter. Weigh each group and record its weight and per cent on the blank form in the column of that sample number. Weigh accurately to one half of one gram. Quantities less than one half of one gram may be indicated as "trace." All the groups of this division should total 100 per cent for purity.

For the remainder of the determinations in the study of this exercise use ten grams of sorghum seed which have been separated from other grains and foreign matter.

Condition. - Make a study of condition by separating the ten-grams sample into the following group: sound kernels; cracked or broken kernels; rotten, decayed, or otherwise injured kernels. Weigh and record the weight and per cent of each group. The total for condition should be 100 per cent.

Color. - The color of sorghum seed depends largely upon the type and variety. In a pure variety there should be little variation in color. Make a study of color by separating the sample into the following groups: white, yellow, red, brown, and tan. Use named type samples of color in determining color of sample. Weigh and record the weight and per cent of each color. The total for color should be 
100 per cent. Separate from the sample 100 averagesize sound kernels. Weigh them and record their weight. Determine weight per bushel of sample as described in Ex. 27. Record the weight per bushel on blank form. From the data recorded on blank form, compute the per cent of the sample that is sound seed. 


\section{STUDENT'S NOTES AND REPORT}

\section{A Study of Sorghum Seed}

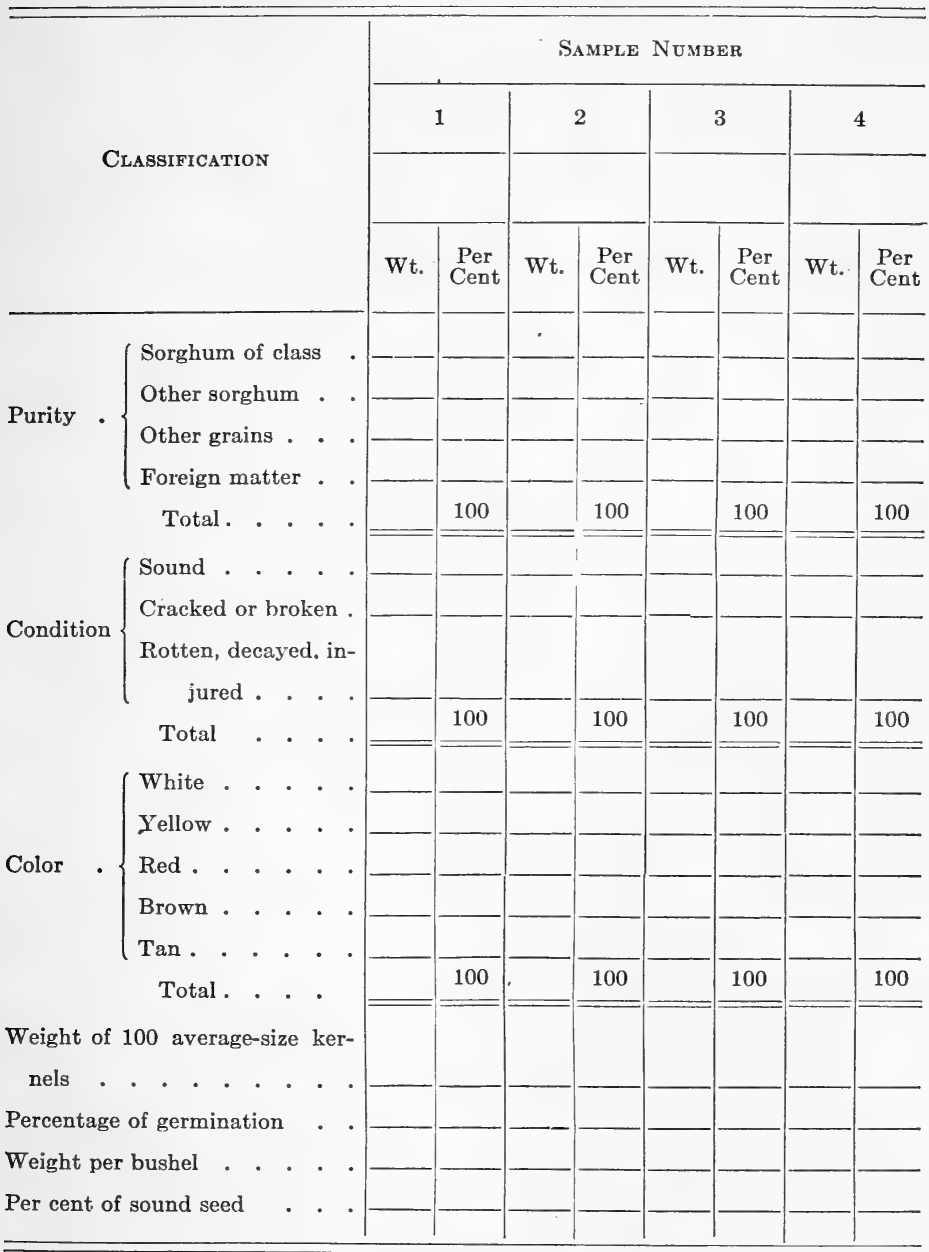




\section{EXERCISE 36}

\section{A STUDY OF COWPEAS *}

Object. - To study the purity, condition, and worth of cowpea seed.

Explanation. - Cowpeas make nutritious feed for live stock, but the value of the seed is greater for planting than for feed. The seed is seldom used for feed unless it is badly cracked or broken. Cowpeas are very easily broken by threshing, and commercial samples usually contain broken seed. The worth of cowpea seed depends largely upon its purity and condition.

Equipment. - 1. Two five to six pound samples representing different types of cowpeas.

2. A weight-per-bushel tester.

3. A balance weighing to one half of one gram.

4. Type samples of cowpea seed.

Directions. - Weigh out twenty grams of cowpeas from one of the samples and make a detailed study of it. Use the outline form "A Study of Cowpeas" to record the results of the examination. Compare the sample under observation with named type samples for identification. Record the name in the column of that sample number for classification.

* If soy beans are more commonly grown in your community than cowpeas, substitute soy beans for cowpeas in this exercise. 
Spread the sample out on a blank piece of paper and make a detailed study of it for each of the divisions given below.

Purity. - Make a study of purity by separating the sample into the following groups: cowpeas of variety class; cowpeas of other varieties; other seeds ; foreign matter. Weigh each group and record its weight and per cent on the blank form in the column of that sample number. Weigh accurately to one half of one gram. Quantities less than one half of one gram may be indicated as " trace." All the groups for this division should total 100 per cent for purity. For the remainder of the determinations of this study use ten grams of cowpea seed which has been separated from other grain and foreign matter.

Condition. - Make a study of condition by separating the ten-gram sample into the following groups: sound seed; cracked or broken seed; moldy and otherwise injured seed. Weigh, and record the weight and per cent of each group. The total for condition should be 100 per cent.

Color. - The color of cowpea seed depends largely upon the type and variety. There is little variation in color in a pure variety. Make a study of color by separating the sample into the following groups: white, light brown, dark brown, mottled, gray, black, white with black eye. Use named type samples of color in determining color of sample. Weigh, and record weight and per cent of each color. The total for color should be 100 per cent. Separate from the sample 100 average-size seeds. Weigh, and record their weight. Determine the weight per bushel of sample as described in Ex. 27. Record all data on blank form. 


\section{STUDENT'S NOTES AND REPORT}

A Study of Cowpeas

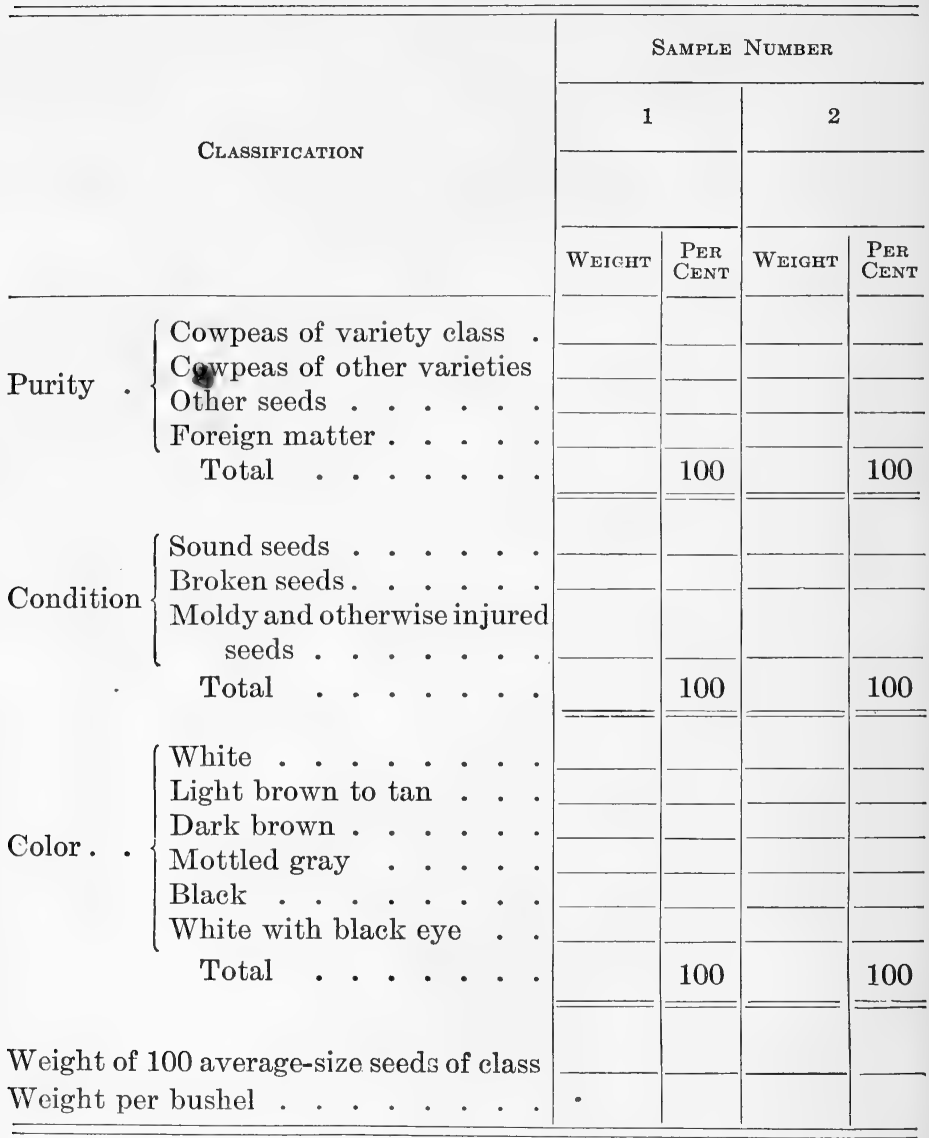

Date 


\section{EXERCISE 37}

\section{THE CAPACITY OF GRAIN TO ABSORB MOISTURE}

Object. - To determine the amount of moisture that corn and other grains will absorb when submerged in water; also the rate at which such absorption takes place.

Explanation. - The outside covering of the corn kernel and other grains is called the hull. It presents a smooth and somewhat glossy surface. The hull serves as a protection for the main portion of the kernel. Because of its smooth surface it is not likely to adhere to other material or absorb moisture readily from the atmosphere. When placed in water or damp earth; it immediately absorbs moisture. It is necessary for the kernel to absorb moisture before it will germinate.

Equipment. - 1. Four washpans.

2. A balance weighing accurately to one half of one gram.

3. A large blotter.

4. A small sample each of dent corn, sweet corn, wheat, and beans.

Directions. - Weigh out twenty-five grams each of dent corn, sweet corn, wheat, and beans. Place each sample in a washpan and pour in enough water to submerge the grain completely. Weigh each sample after it has soaked for 30 minutes, 1 hour, 2 hours, 1 day, and 2 days, respectively, 
and record the weights on the accompanying outline form. Before weighing, drain the water off and place the grain on the blotter for a few seconds to absorb excess moisture clinging to it. After each weighing replace sample in washpan and again submerge in water. 


\section{STUDENT'S NOTES AND REPORT}

Table for Recording the Moisture absorbed by Different Grains

\begin{tabular}{|c|c|c|c|c|c|c|c|c|c|}
\hline KIND & of $\mathrm{G}$ & AIN & & $\begin{array}{c}\text { 1st } \\
\text { WEIGHT }\end{array}$ & $\begin{array}{c}\text { WEIGHT } \\
\text { AFTER } \\
30 \text { Min. }\end{array}$ & $\begin{array}{c}\text { WEIGHT } \\
\text { AFTER } \\
1 \mathrm{HR} .\end{array}$ & $\begin{array}{c}\text { WEIGHT } \\
\text { AFTER } \\
2 \text { HRS. }\end{array}$ & $\begin{array}{c}\text { WEIGHT } \\
\text { AFTER } \\
1 \text { DAY }\end{array}$ & $\begin{array}{l}\text { WEIGHT } \\
\text { AFTER } \\
2 \text { DAYS }\end{array}$ \\
\hline Dent ce & orn & . & & $25 \mathrm{gms}$. & & & & & \\
\hline Sweet & corn & • & & $25 \mathrm{gms}$. & & & & & \\
\hline Wheat & - . & - & . & $25 \mathrm{gms}$. & & & & & \\
\hline Beans & . & 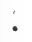 & - & 25 gms. & & & & & \\
\hline
\end{tabular}




\section{EXERCISE 38}

\section{FACTORS AFFECTING THE GERMINATION OF SEEDS}

Object. - To study the factors affecting the germination of seeds.

Explanation. - In order that a seed may grow it must be supplied with the proper amount of moisture, air, and heat. It is well known that seeds will not germinate if planted when the soil is too cold. The proper temperature for seeds to grow varies with the seed of different plants. Some seed, like oats and clover, will germinate when the soil is very cool, while other seeds, like pumpkin and tomato, require much higher temperatures for germinating. A temperature of $70^{\circ}$ to $80^{\circ} \mathrm{F}$. is sufficiently high to germinate the seeds of most farm crops.

Seeds will not germinate unless supplied with moisture in proper amounts. If the soil is too dry, the seeds will not germinate, while if it is too wet, the soil is often too cool for germination to take place. Oxygen or air is also necessary for germination. Seeds will not germinate well when the soil is badly crusted because they do not receive sufficient air.

Equipment. - 1. Six washpans.

2. A stick with blunt end for compacting the soil.

3. Two soils, sand and clay. 
4. One hundred and twenty kernels of corn of uniform size and known to be of strong vitality.

5. Balances weighing to one half gram.

6. Graduated cylinder, 100 c.c.

Directions. - Number the washpans from one to six. Put into the first three pans equal amounts by weight of airdry sand and into the last three equal amounts by weight of air-dry clay. The pans should be about two thirds full.

Add water slowly by measure to one pan containing sand until the soil, when thoroughly mixed, appears to contain the proper moisture content for the best growth of seeds. Add the same quantity of water to the second and third pan, mixing it well with the soil.

In the same way determine the proper amount of water to add to the clay soil for the best growth of plants. Make up all three pans containing clay to the same moisture content.

Smooth the surface of the soil in all the pans and plant twenty kernels of corn in each pan. Plant the kernels at a depth of one inch.

Treat the pans as follows:

1. Sand. No treatment. Set in a warm place to germinate.

2. Sand. Thoroughly saturate with water. Set in a warm place to germinate.

3. Sand. No treatment. Place where the temperature is cool, but not cold enough to freeze.

4. Clay. No treatment. Set in a warm place to germinate. 
5. Clay. Thoroughly pack the surface of the soil by compacting. Set in a warm place to germinate.

6. Clay. Thoroughly pack the surface of the soil by compacting and thoroughly saturate the soil. Set in a warm place to germinate.

It will usually be sufficiently warm behind the stove or in the furnace room of the school building to maintain the proper temperature for germination.

Pans 1, 3, 4, and 5 should be watered to maintain the proper moisture for the best growth of the seeds.

Pans 2 and 6 should be wet until water just stands on the surface and should be maintained in this condition by adding additional water each day.

Examine the pans each day for two weeks and count the number of seeds that have germinated.

Record your count in the following outline form. Discuss fully the cause for the difference in germination observed. 


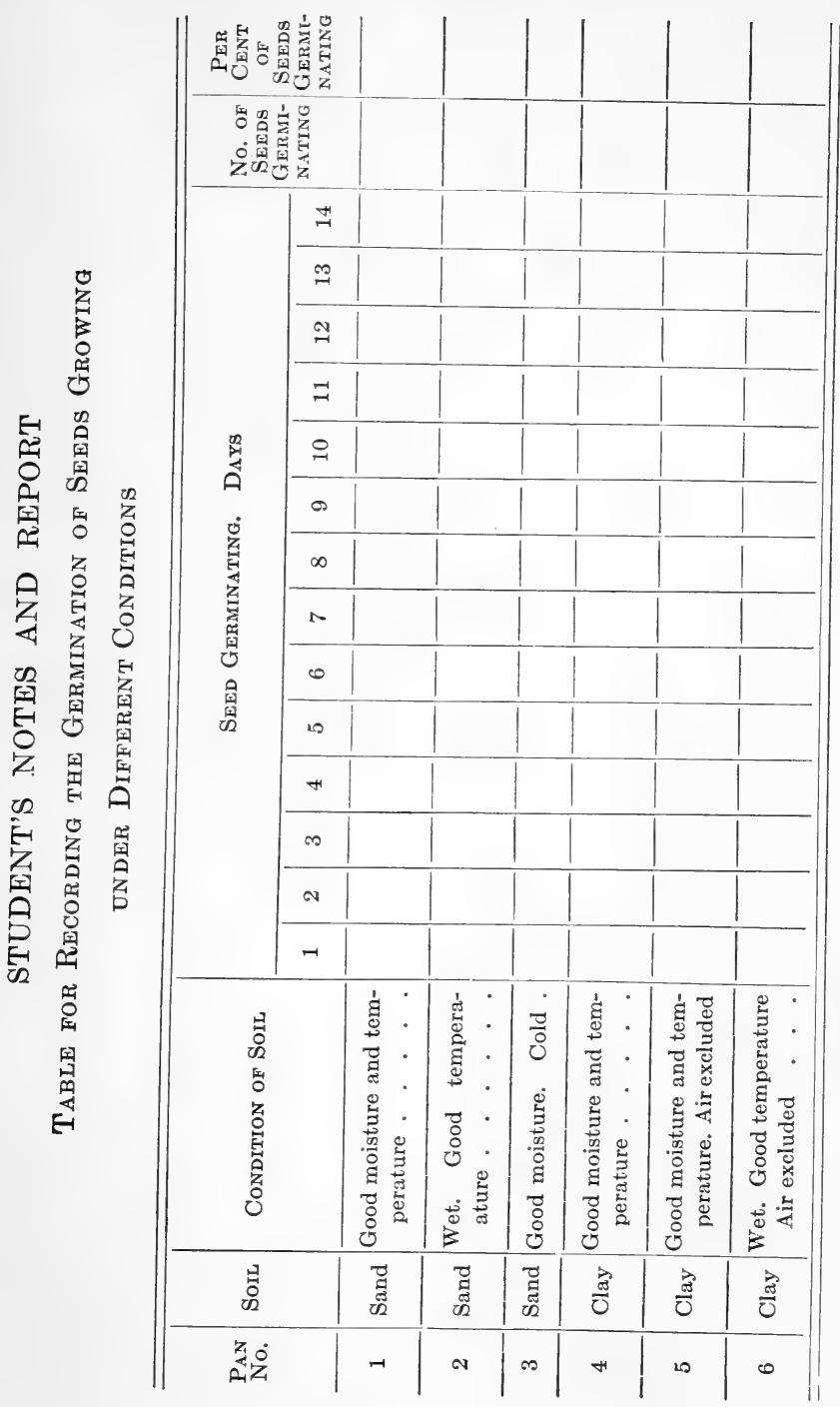




\section{STUDENT'S NOTES AND REPORT}




\section{EXERCISE 39}

\section{A GERMINATION TEST OF CLOVER OR GRASS SEED}

Object. - To test the vitality of clover or grass seed.

Explanation. - There are many factors affecting the quality of seed, and many commercial samples of clover and grass seed are low in vitality. The vitality of these seeds is more easily injured than the vitality of the seed of the common cereals. It is essential, therefore, before sowing clover or grass seed to make a germination test to determine its vitality.

In making germination tests the seeds should be kept moist and at a proper growing temperature. The most favorable temperature differs with different seeds. The clovers should germinate well at $60^{\circ}$ to $80^{\circ} \mathrm{F}$.

Equipment. - 1. A pound of red clover seed.

2. Two paper plates or pieces of blotting paper for each student.

3. A pair of forceps for each student.

Directions. - Count out 100 sound seeds. Place them between the paper plates or blotters, and moisten well. Keep at a temperature of $60^{\circ}$ to $80^{\circ} \mathrm{F}$. Examine the seed at the end of four days. Count and record the number of 
seeds that have produced sprouts. Carefully remove the sprouted seeds so that they will not interfere with later countings. Count and remove the additional seeds that germinate each second day for eight days. Record data in the outline form. 


\section{STUDENT'S NOTES AND REPORT}

Record of Germination

\begin{tabular}{|c|c|c|c|c|c|c|c|}
\hline \multirow{2}{*}{$\begin{array}{l}\text { NAME OF } \\
\text { SAMPLE }\end{array}$} & \multirow{2}{*}{$\begin{array}{l}\text { No. of } \\
\text { SEEDIS IN } \\
\text { SAMPLE }\end{array}$} & \multicolumn{5}{|c|}{ Number of Seeds Sprouted } & \multirow{2}{*}{$\begin{array}{c}\text { Total Per } \\
\text { Cent of } \\
\text { Seeds } \\
\text { Sprouted }\end{array}$} \\
\hline & & $\begin{array}{c}4 \\
\text { Days }\end{array}$ & $\begin{array}{c}6 \\
\text { Days }\end{array}$ & $\begin{array}{c}8 \\
\text { Days }\end{array}$ & $\begin{array}{c}10 \\
\text { Days }\end{array}$ & $\begin{array}{c}12 \\
\text { Days }\end{array}$ & \\
\hline & & & & & & & \\
\hline & & & & & & & \\
\hline & & & & & & & \\
\hline & & & & & & & \\
\hline & & & & & & & \\
\hline
\end{tabular}




\section{EXERCISE 40}

\section{A STUDY OF GRASS SEED}

Object. - To study the purity and worth of grass seed.

Explanation. - The perennial grasses include such grasses as timothy, Kentucky bluegrass, orchard grass, brome grass, and redtop. The seeds of different kinds of perennial grasses are not as generally known as are the seeds of cereal grains. They are not produced in such large quantities, commercial samples often contain seeds of other grasses, weed seeds, and foreign matter, and their vitality is often low because of unfavorable conditions during harvesting and storing. To insure good results in seeding grasses it is essential that the seed be free from other seed and foreign matter, and that its vitality be reasonably strong.

Equipment. - 1. A one-pound sample of timothy seed or other grass such as has been named under explanation.

2. A balance weighing to one tenth of one gram.

3. A pair of forceps.

4. A hand lens.

5. Type sample of grasses.

Directions. - Weigh out two grams of grass seed from the samples and make a detailed study of it. Use the outline form "A Study of Grass Seed" to record the results of the 
examination. Record the name of the grass in the column of that sample number for classification.

Spread the sample out on a blank piece of paper and make a study of it for purity. Separate the sample into the following groups: grass seed true to name; seed of other grasses; weed seeds; foreign matter. Weigh each group and record its weight and per cent on the blank form in the column for that sample number. Weigh accurately to one tenth of one gram. Quantities less than one tenth of one gram may be indicated as "trace." All the groups under purity should total 100 per cent.

Separate from the sample one hundred seeds true to name and make a germination test as described in Ex. 39. Record the data of the germination test in Ex. 39 . Record the per cent of germination on the blank form. From the data recorded on the blank form compute the per cent of the sample that will grow and that is true to name. 


\section{STUDENT'S NOTES AND REPORT}

A Study of Grass Seed

\begin{tabular}{|c|c|c|c|c|c|c|c|c|}
\hline \multirow{3}{*}{ Classification } & \multicolumn{8}{|c|}{ Samplee Number } \\
\hline & \multicolumn{2}{|c|}{1} & \multicolumn{2}{|c|}{2} & \multicolumn{2}{|c|}{3} & \multicolumn{2}{|c|}{4} \\
\hline & Wt. & $\begin{array}{c}\text { Per } \\
\text { Cent }\end{array}$ & Wt. & $\begin{array}{c}\text { Per } \\
\text { Cent }\end{array}$ & Wt. & $\begin{array}{l}\text { Per } \\
\text { Cent }\end{array}$ & Wt. & $\begin{array}{l}\text { Per } \\
\text { Cent }\end{array}$ \\
\hline \\
\hline \multicolumn{9}{|l|}{ Grass seed of other classes } \\
\hline \multirow{2}{*}{\multicolumn{9}{|c|}{ 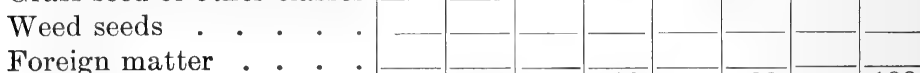 }} \\
\hline & & & & & & & & \\
\hline Total... & & 100 & & 100 & & 100 & & 100 \\
\hline Per cent of germination . & & & & & & & & \\
\hline $\begin{array}{l}\text { Per cent of seed of sample } \\
\text { that will grow }\end{array}$ & & & & & & & & \\
\hline
\end{tabular}

Date Student's Name 


\section{EXERCISE 41}

\section{A STUdy OF ALFAlfa SEED}

Object. - To study the purity and worth of alfalfa seed. Explanation. - Alfalfa is more likely to be adulterated with other material than the seed of cereals. Very often samples of alfalfa contain seed of obnoxious weeds, immature alfalfa seed, and trash. Such samples are of an inferior quality, and the man who procures alfalfa seed should guard against such impurities. To insure good results in seeding alfalfa, it is essential that the seed be free from other seeds and foreign matter and that its vitality be reasonably strong.

Equipment. - 1. A one-pound sample of alfalfa seed.

2. A balance weighing to one tenth of one gram.

3. A pair of forceps.

4. A hand lens.

Directions. - Weigh out two grams of alfalfa seed from the sample and make a detailed study of it. Use the outline form "A Study of Alfalfa Seed" to record the results of the examination. Record the sample, name, and source of the seed at the top of the vertical column for classification.

Spread the sample out on a blank piece of paper and make a study of it for purity. Separate the sample into the following groups: sound alfalfa seed; broken and immature alfalfa seed ; seed of clover and grasses ; weed seeds ; foreign 
matter. Weigh each group and record its weight and per cent on the blank form in the column for that sample number. Weigh accurately to one tenth of one gram. Quantities less than one tenth of one gram may be indicated as "trace." All the groups of the sample should total 100 per cent.

Separate from the sample one hundred sound seeds and make a germination test as described in Ex. 39. Record the data of the germination test in Ex. 39. Record the per cent of germination on the blank form. From the data recorded on the blank form compute the per cent of the sample that will grow and that is true to name. 


\section{STUDENT'S NOTES AND REPORT}

\section{A Study of Alfalfa Seed}

Crassification

Sound alfalfa seed

Broken and immature alfalfa seed. Seed of clover and grasses

Weed seeds

Foreign matter

Per cent of germination

Per cent, of seed of sample that will grow

Sample Number

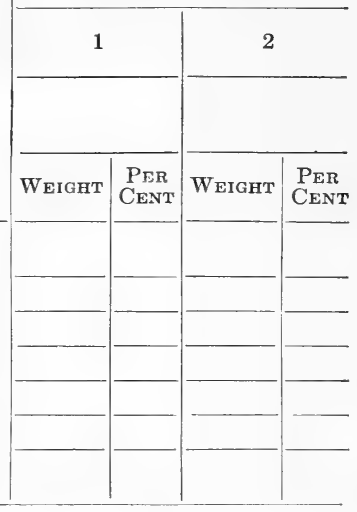

Date Student's Name 


\section{EXERCISE 42}

\section{A STUDY OF THE PLOW}

Object. - To study the structure of the plow and to become familiar with the different parts and their purpose.

Explanation. - The plow is the most generally used of all farm implements. The purpose of the plow is to invert and pulverize the soil and to turn under weeds and other vegetation. Its construction is not complex, and when properly adjusted, it is easy to operate. If improperly adjusted, the plow is often difficult to operate, and it does an inferior grade of work. The principal parts of a plow are the share, landside, and the moldboard.

Equipment. - 1. A walking plow.

2. A riding plow.

3. A three-foot rule.

4. A three-foot tape.

Directions. - Make the necessary measurements and observations to answer the following questions.

Record answers in the following outline form: 


\section{STUDENT'S NOTES AND REPORT \\ Walking Plow}

1. Give name of plow.

2. Give the manufacturer's name.

3. Give location of manufacturer.

4. Is the plow a stubble, sod, or landside plow?

5. Give size of plow.

6. Measure and record distance from point of share to center of hitch.

7. Measure and record distance from floor to highest point under beam. (Clearance.)

8. Measure and record distance from point of share to point on plow just below end of beam.

9. Measure and record distance that the end of beam extends outside of the line of the landside.

10. Why is the plow made with the end of the beam extending outside of the line of the landside?

11. Measure and record the suction of the plow.

12. What is the purpose of the suction of the plow?

13. What is the purpose of the high polish on the moldboard? 
14. How should the moldboard be protected when not in use so as to retain this high polish?

\section{Riding Plow}

1. Give the name of plow.

2. Give the manufacturer's name.

3. Give location of manufacturer.

4. Is the plow a single or a gang plow?

5. Give the size of plow.

6. Is the plow drawn from the beam or the frame?

7. Has the plow a foot lift?

8. Have the wheels hard oilers?

9. Are the wheels difficult to oil?

10. Place a straightedge along landside and measure and record distance from this line to furrow wheel.

11. Measure and record the height of hitch above plow with plow resting on the floor. 


\section{EXERCISE 43}

\section{A STUDY OF THE GRAIN GRADER OR FANNING MILL}

Object. - To study the structure of the grain grader, and test its efficiency for grading grain for planting.

Explanation. - Small grain as it comes from the threshing machine is usually unfit for planting. It contains small pieces of straw and chaff, which obstruct the grain drill in seeding, and make uniform seeding impossible. Besides straw and chaff, grain as it is threshed contains broken, shriveled, and small kernels. This material is unfit for planting, but will make valuable feed if separated from the seed grain.

It is estimated that twenty per cent of the grain as it comes from the thresher is unfit for planting, but suitable for feeding. By using the grain grader in preparing grain for seed, a more uniform stand of vigorous plants is obtained, and the broken and small kernels may be saved for feed.

Apparatus. - 1. A fanning mill.

2. A weight-per-bushel tester.

3. One bushel of uncleaned wheat as it comes from the thresher. 
4. Scales weighing one hundred pounds or more and weighing accurately to one half pound.

Directions. - Part I. Structure of Grain Grader. Make the necessary measurements and observations to answer the following questions. Record answers in the outline form on the following page. 


\section{STUDENT'S NOTES AND REPORT}

1. Give name of grader.

2. Give the manufacturer's name.

3. Give location of manufacturer.

4. Does the mill depend upon specific gravity or size of grain or both for separation?

5. Does the grader have sieves?

6. Are the sieves horizontal or sloping?

7. When the machine is in motion, do the sieves move vertically, horizontally, or lengthwise with the machine?

8. Can the length of the stroke of the sieves be varied?

9. How many sieves has the machine?

10. Give the purpose of each sieve.

11. Give size of mesh of each sieve (the number of holes for inch of length).

12. Does the grader have a bagger attachment?

13. What is the rated capacity of the grader? 
Part II. Test of Grain Grader. - Weigh out sixty pounds of uncleaned wheat. Use scales for weighing. Determine weight per bushel of wheat by using weight-per-bushel tester. Adjust the grain grader properly for grading wheat. Run the bushel of wheat through the grader, making three grades if possible. Weigh the amount of wheat in first grade and determine per cent. Determine the weight per bushel with weight-per-bushel tester. Determine per cent and weight per bushel of the second and third grades. Observe the difference in quality of the different grades of wheat.

Record data in the following outline:

\section{STUDENT'S NOTES AND REPORT}

Table showing Wheat as graded by the Grain Grader

\begin{tabular}{l|c|c|c}
\hline & Weight & Per Cent of Sample & Wt. Per Bushel \\
\cline { 1 - 3 } Bushel sample & 60 pounds & $100 \%$ & \\
\hline Best grade & & & \\
\hline Second grade . & & & \\
\hline \hline
\end{tabular}




\section{EXERCISE 44}

\section{THE CORN GRADER}

Object. - To study the construction of the corn grader and test its efficiency for grading corn.

Explanation - Even though seed corn is selected with considerable care, the ears will not be uniform and the kernels will not be of the same shape and size when shelled. It is necessary for seed corn to be uniform in shape and size for uniform distribution in planting. A good corn grader will remove those kernels that are very large, very small, or irregular in shape.

Equipment. - 1. A corn grader.

2. One half bushel of shelled corn.

3. A scale weighing one hundred pounds or more and weighing accurately to one half pound.

Directions. - Part I. Structure of the Grain Grader. Make the necessary measurements and observations to answer the following questions. Record answers in the following outline form : 


\section{STUDENT'S NOTES AND REPORT \\ The Corn Grader}

1. Give name of grader.

2. Give manufacturer's name.

3. Give location of manufacturer.

4. How is the corn separated into different grades?

5. Into how many grades is the corn separated?

6. How many sieves has the grader?

7. What is the method of agitating the corn on the sieve?

8. What is the capacity of the grader? 
Part II. Test of Corn Grader. - Weigh out twentyfive pounds of corn. Adjust the grader properly for grading corn. Run the corn through the grader and separate into three grades, if possible. Weigh the amount of corn in the first grade and determine its per cent. Weigh and determine the per cent of both the corn that is too large and the corn that is too small.

Record data on following outline:

Table showing Grade of Corn as separated by the Corn Grader

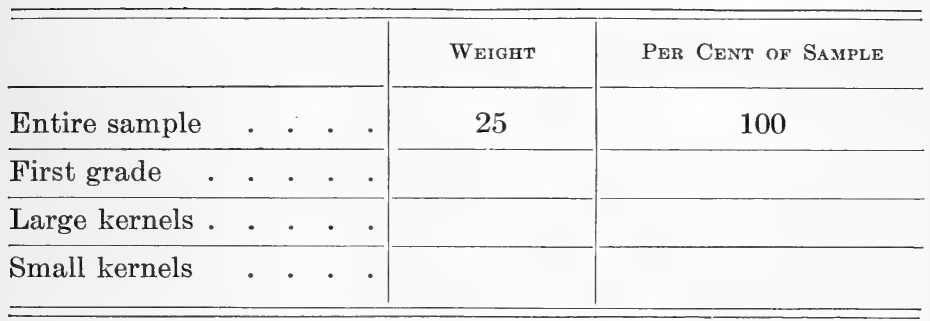




\section{EXERCISE 45}

\section{THE CORN PLANTER}

Object. - To study the structure of the corn planter, and become familiar with its different parts and their purpose.

Explanation. - The corn crop is the most valuable crop grown in the United States. More acres of land are planted to corn in the Central United States than to any other cultivated crop. It would be impossible to plant this vast acreage of corn without the aid of the corn planter. The corn planter, therefore, is absolutely necessary upon nearly all farms in the corn belt.

Equipment. - 1. A two-row corn planter.

2. A one hundred foot tape line.

Directions. - Make the necessary observations to answer . the following questions. Record the answers in the following outline form. 


\section{STUDENT'S NOTES AND REPORT \\ The Corn Planter}

1. Give name of planter.

2. Give the manufacturer's name.

3. Give the location of manufacturer.

4. What kind of furrow opener has the planter - stub or curved runner, single or double disk?

5. What kind of wheel has the planter - open, solid, or double?

6. Are the wheels high or low?

7. Has the planter a drill or full hill drop?

8. Has it an edge selection or flat plate?

9. Will the seed box tip over?

10. How many valves has each planter shankं?

11. Trace the path of the corn from the seed box to the ground.

12. What is the object of the upper valve? 
13. Of the lower valve?

14. Does the lower valve counteract the speed of the team?

15. Can the width of the row be varied?

16. What is its greatest width?

17. What is its least width?

18. How is the reel attached and driven?

19. How is the number of kernels in each hill determined?

20. Do the plates rotate continuously in accumulating a hill?

21. Do the plates revolve vertically or horizontally?

22. Has the planter sight feed?

23. Can the planter be arranged to drill the corn?

24. Adjust the planter for drilling and to drop one kernel every eighteen inches. After properly adjusting the planter for this rate of drop, measure off a stretch of one hundred feet on the bare ground and pull the planter over this distance to determine the accuracy of drop. 
25. If you were to buy a planter, what kind would you buy? What kind of wheels and furrow openers would you select? Give fully the reasons for your answer. 


\section{EXERCISE 46}

\section{ACCURACY OF DROP OF THE CORN PLANTER}

Object. - To test the accuracy with which the corn planter drops the kernels of corn.

Explanation. - Nearly every corn planter is equipped both to drill the corn in the row and to plant it in the hill. When the corn planter is set to drill the corn in rows, the distance apart at which the kernels are dropped may be varied by changing the plates in the hopper and by varying the size of the drive wheel that governs the speed of the planter plates. When planting in hills, the planter may be adjusted in the same way to drop from two to six or seven kernels in the hill. Since the yield of corn on a given area of ground is greatly influenced by the stand secured, it is very desirable to use a planter that will plant accurately at the proper rate. Before using the planter in the field it should be adjusted to plant at the rate desired and thoroughly tested to make sure that it is planting accurately.

Equipment. - 1. A two-row corn planter.

2. Four quarts of shelled corn.

Directions. - Adjust the corn planter with the proper plates to drop two kernels in a hill. Place a few handfuls of corn in the hopper. Jack up the planter so that the wheels turn free from the ground. Run the planter slowly by hand 
and count the number of kernels dropped in each hill until one hundred hills have been dropped.

Record in the accompanying outline form the number of hills in which no kernels were dropped, one kernel, two kernels, three kernels, four kernels, five or more kernels.

Repeat the count for another hundred hills and record results as before.

Adjust the corn planter to drop three kerneis in a hill. In the same manner as before count the number of kernels dropped in each hill until one hundred hills have been dropped.

Record in the outline form the number of hills in which no kernel was dropped, one kernel, two kernels, three kernels, four kernels, five or more kernels. Repeat the count for another hundred hills and record the results as before. 


\section{STUDENT'S NOTES AND REPORT}

Accuracy of Drop of Corn Planter

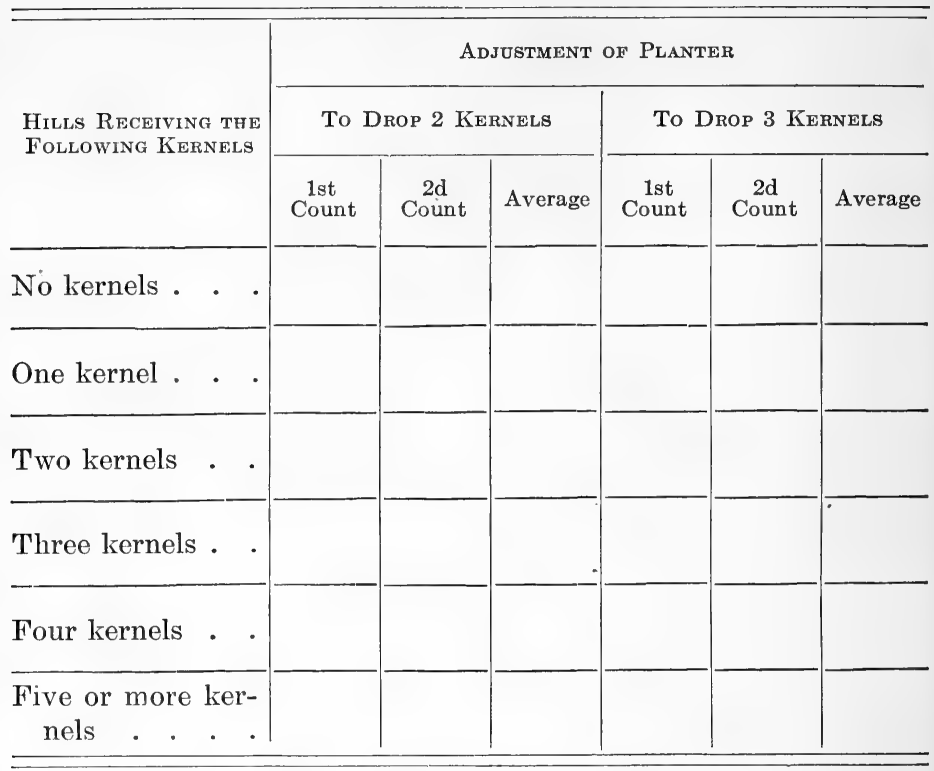




\section{EXERCISE 47}

\section{TREATMENT OF SEED OATS FOR SMUT}

Object. - To demonstrate a practical method of treating seed oats for smut.

Explanation. - Smut in grain is caused by a parasitic plant growing through the tissue of the grain plant. Smut usually. appears as a black, powdery mass of spores, and may destroy the entire head of grain. Smut is produced from smut spores as other plants are produced from seeds. Smut frequently appears in oats and often greatly reduces the yield.

A solution made of one pint of formaldehyde added to fifty gallons of water is effective in treating oat smut.

The smut spores become ripe soon after the oats head out and are then blown about through the field by the wind. Many of the smut spores cling to other heads and kernels. When the seed is planted the next year, the fungus grows up within the young seedling. At flowering time the smut becomes visible and the head develops into a mass of smut spores.

Equipment. - 1. One half bushel of oats.

2. 50 c.c. of 40 per cent solution of formaldehyde.

3. A four-gallon crock. 
4. Paper plates or blotters for making germination test.

5. A cotton sack.

Directions. - Reserve twenty grams of the sample for study and germination test. Pour four liters of water into the crock. Add to the water 30 c.c. of the formaldehyde solution. Put four pounds of oats into a cotton sack large enough to hold ten pounds, and submerge it in the prepared solution. Move the sack around in the solution so that all the grain may become thoroughly wet. Remove after thirty seconds. Empty the sack and spread the grain out on a clean surface to dry. Submerge another four-pound sample in a similar manner and remove after two minutes. Spread it out on a clean surface to dry. Submerge a third fourpound sample for five minutes and place it out to dry. Make a germination test of the untreated sample and each of the treated samples. Use one hundred grains of each for the germination test as shown in Ex. 39. Record the vitality of each sample on the outline form. Seed oats should be thoroughly treated, but not left in the solution long enough to injure their vitality.

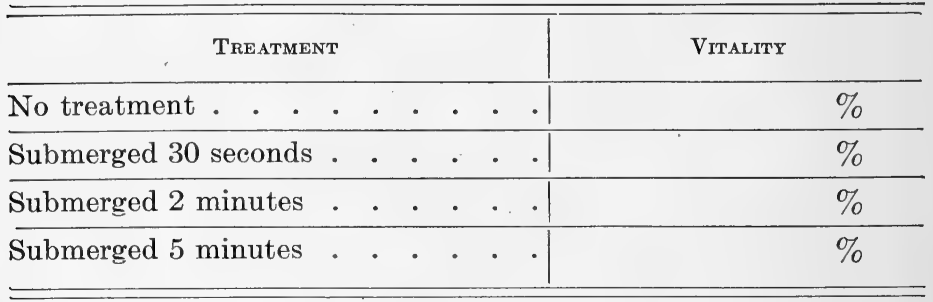

After oats are treated for smut they should not be put in bins or sacks that have smut in them. 
The loose smut of oats, the stinking smut of wheat, the covered smut of barley, and the sorghum grain smut may all be treated effectively in a similar manner. The loose smut of wheat cannot be successfully combated by the above treatment. 


\section{EXERCISE 48}

\section{THE IRISH· POTATO}

Object. - To become familiar with the structure of the potato and to determine the qualities that affect its value.

Explanation. - The potato is an underground enlargement of the potato plant. It is commonly called a tuber. The tuber serves as a means of storing reserve plant food to be used later in the development of new plants. The eye of the potato is a dormant bud from which the new plant develops. The interior of the potato is filled with starch and serves as food for the new plant. The potato is used as one of the principal foods of man. Its value for food is affected by its freedom from injury and disease, smoothness, depth of eyes, and size. A good potato should be smooth, free from disease, of medium size, and have medium shallow eyes.

Equipment. - 1. Twenty pounds of potatoes of various shapes and sizes, and if possible of different varieties.

2. Balance weighing to one half of one gram.

3. A paring knife.

Directions. - Weigh out fifteen pounds of potatoes and make a detailed study of them. Use the outline form "A Study of the Potato" to record the results of the examination.

Shape. - Make a study of the shape of the potatoes by 189 
separating the sample into the following classes: round, cylindrical, oval, flat oval. Count and record the number of potatoes in each group.

Size. - Separate the potatoes into groups of large, medium, and small size. Count and record the number in each group.

Color of Skin. - Separate the potatoes into the following groups: yellowish, white, pink, russet, red, and other colors. Count and record the number of potatoes in each group.

Texture of Skin. - Separate the sample into the following groups based upon the texture of the skin: corky, netted, medium smooth, very smooth. Count and record the number in each group.

Depth of Eyes. - Separate the sample into the following groups, based upon depth of eyes: deep, medium, and shallow. Count and record the number in each group.

Condition. - Make a study of condition by separating the sample of potatoes into the following groups: clean, broken or cracked, and diseased. Count and record the number of potatoes in each group.

Select from the sample five large, five small, and five very rough and knotty potatoes. Weigh each group of five separately and record weight. Peel the potatoes in each group, removing as nearly as possible the same thickness of peeling in each case. Weigh, and record the weight of the peeled potatoes of each group. Subtract these weights from the first weights to determine the weight of peeling in each group. Determine the per cent of waste in each group.

Record the data in the accompanying outline form. 


\section{STUDENT'S NOTES AND REPORT}

A Study of the Irish Potato

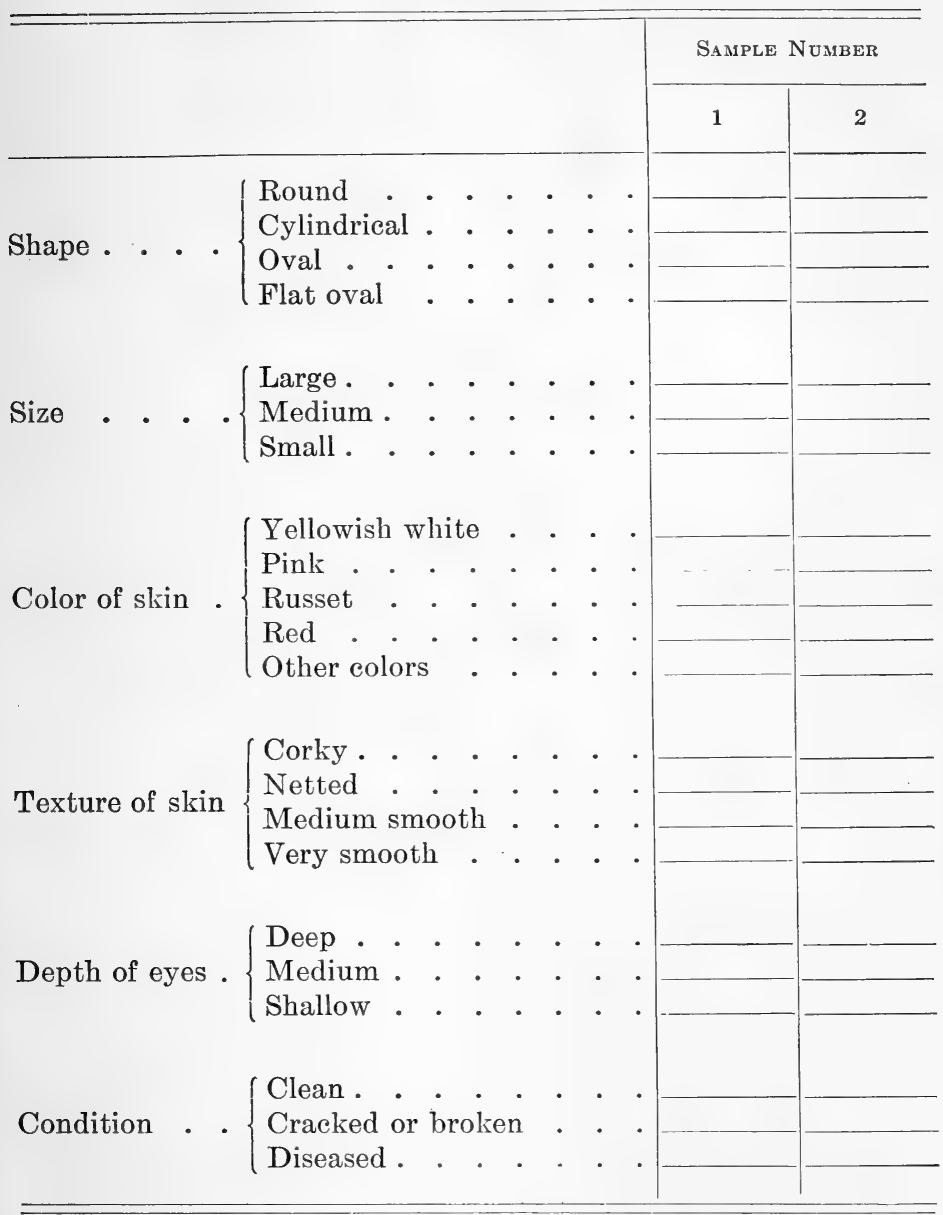

Date 


\section{STUDENT'S NOTES AND REPORT}

\begin{tabular}{|c|c|c|c|c|c|}
\hline Group No. & & $\begin{array}{c}\text { WEIGHT OF } \\
\text { WHOLE }\end{array}$ & $\begin{array}{l}\text { Weight of } \\
\text { PEELEd }\end{array}$ & $\begin{array}{c}\text { Weight of } \\
\text { PeEling }\end{array}$ & $\begin{array}{l}\text { Per Cent } \\
\text { of Waste }\end{array}$ \\
\hline Large potatoes & - $\quad$. & & & & \\
\hline Small potatoes. & - $\quad$. & & & & \\
\hline Rough potatoes & - $\quad$. & & & & \\
\hline
\end{tabular}




\section{EXERCISES 49 AND 50}

\section{PLANNING THE HOME GARDEN}

Object. - To plan the arrangement and succession of crops in the home garden.

Explanation. - It is practically impossible for the farmer to have fresh vegetables during the summer unless he produces them in his own garden. There should be a small plot of ground set aside on every farm for the home garden. A garden well planned and growing a succession of vegetable crops will be a great convenience in furnishing fresh vegetables in the summer time. The home garden should afford pleasure and reduce the cost of living expenses.

The garden should be large enough to make cultivation with horses possible. The rows will have to be further apart and more ground will be needed for the same amount of crops, but much hand labor will be saved. A home garden might well occupy a space of one half to one acre of land. Where this much space is not available the rows may be placed closer together, and hand cultivation resorted to. The site for the garden should be conveniently arranged close to the house, on a plot of land of good texture and fertility.

It is advisable to apply a dressing of well-rotted manure to the garden each year. Cultivation should be frequent to prevent the growth of weeds. 
Garden crops are more valuable than field crops considering the space they occupy, and the grower can afford to give them more cultivation.

The garden should be fenced with a woven wire fence to protect it from rabbits, chickens, and "live stock."

The home garden may include annual and perennial vegetable crops and small fruit crops. The following are some of the annual crops that may be grown successfully: radishes, lettuce, peas, beans, onions, carrots, parsley, turnips, tomatoes, cabbage, sweet corn, celery, and cucumbers. Radishes, lettuce, peas, and beans are often ready for use in early summer, and the space they occupied may be reseeded with other vegetables, as cucumbers, celery, and turnips.

Perennial plants, such as horseradish, rhubarb, asparagus, blackberries, raspberries, currants, and grapes, may well occupy a permanent place in the garden. If the entire garden is not occupied by the above crops, the remainder of it may well be planted with more sweet corn and potatoes.

Directions. - Take the measurements of your home garden. Plan what portion of it should be devoted to each of the crops given. Figure the area to be occupied by each crop. If the garden is not already properly planned, make such changes as you think advisable. Draw a plan for the garden and, show where all the crops are to be located. Estimate the amount of seed needed for each crop. Go to your seed dealer and ascertain the price required to purchase the seed. Give the quantity and approximate cost of each kind of seed to be used in the garden. 
STUDENT'S NOTES AND REPORT 
196 LABORATORY MANUAL OF AGRICULTURE

STUDENT'S NOTES AND REPORT 


\section{EXERCISE 51}

\section{PRUNING}

Object. - To study methods of pruning, and the benefits derived from removing undesirable branches from trees.

Explanation. - It is often necessary to remove branches from trees in order to promote their best development. There are two important objects to be secured by pruning. One is to beautify the tree by giving it a better shape; the other is to make it more fruitful or increase its vigor. Pruning may be performed at various times during the year, and the best time depends largely upon the purpose for which it is done. Pruning in the winter tends to promote growth of wood, while pruning during the growing season tends to promote the production of fruit buds. It is usually well to prune orchard trees late in the winter or early in the spring while they are in dormant condition. Pruning may be done successfully almost any time of year except when the buds are starting. Pruning is a means of thinning out undesirable branches. Very severe pruning tends toward the production of a new growth of wood and a light production of fruit. For the best results an orchard should be pruned a little every year. When a limb is cut off, it should be removed as near its main branch as possible, and parallel to it. The wound will heal much more rapidly if the limb is re- 
moved close to the main branch than if the stub is left longer. The healing of the wound takes place at the cambium layer. The hard wood itself at the center of the limb never heals, but is partly covered over by the growth of the cambium layer. When large limbs are removed, the wound is often covered with paint to protect it during the process of healing.

Equipment. - 1. Pruning shears.

2. Pruning saw.

3. Pruning knife.

Directions. - Go to a near-by orchard of mature apple trees. Other fruit trees may be chosen, or even forest trees may answer the purpose if orchard trees are not accessible. Select a tree in need of pruning. Remove all broken, injured, or diseased limbs. Remove limbs that are likely to rub or injure other portions of the tree. Remove all water sprouts. Remove a sufficient number of the least desirable limbs so that the light may penetrate to the center of the tree. 


\section{STUDENT'S NOTES AND REPORT}




\section{EXERCISES 52 AND 53}

\section{THE BABCOCK TEST ${ }^{1}$}

Object. - To determine the per cent of butter fat in milk. Explanation. - The value of a cow as a milk producer depends not only on the quantity of milk produced, but also on the per cent of butter fat in the milk. The amount of butter fat in milk may be determined by the Babcock test.

Equipment. - 1. One or more pint samples of milk.

2. A Babcock testing outfit.

Directions. - Bring the acid and milk to be used to a temperature of $70^{\circ} \mathrm{F}$. This can best be done by placing them in the hot-water bath. Mix the milk thoroughly by pouring it from one vessel to another no less than five times.

Take pipette between thumb and second and third fingers, leaving the index finger free, draw milk into pipette immediately after stirring and place index finger over the tip of pipette; now release the finger very slightly until top of the milk column is even with the mark of the pipette.

Hold the milk bottle on a slant and place the end of the pipette in the neck of the bottle, leaving an opening for air so that air bubbles cannot form and throw milk out of the neck;

1 Adapted from O. E. Reed in the Dairy Primer, Chapters in Elements of Agriculture, Extension Department, Kansas State Agricultural College. 
then release finger and allow the milk to flow into the bottle, blowing the last drop from the pipette. A second sample of the milk should be taken in the same way as a duplicate.

Fill acid measure to the mark (never draw acid into pipette). The acid is very strong and should be handled with the greatest caution. Water should be at hand to remove quickly any acid coming in contact with the hands or other parts of the body. Take the milk bottle by the neck between thumb and fingers of the left hand so that the bottle can be turned; now bring the lip of the acid measure to the mouth of the bottle and pour the acid into the bottle so that all of the milk will be washed from the neck into the bottle. Hold the bottle at a slant while doing this so that the acid will not fall directly on the milk and form pieces of charred curd.

Give the bottle a rotary motion in order to cause a gradual mixture of milk and acid; sudden mixing will cause large amounts of heat and gas and will throw the material out of the bottle.

After the bottle has been stirred thoroughly and the curd is dissolved, place the bottle in the Babcock tester and whirl five minutes.

Place the bottles in the water bath of $180^{\circ} \mathrm{F}$. for five minutes and fill with hot water to the neck.

Whirl for two minutes.

Place in water bath for five minutes and fill with hot water to within one half inch of the top of the bottlè.

Whirl for two minutes.

Place in water bath, $130^{\circ} \mathrm{F}$., for five minutes.

Measure the fat column by placing one point of the dividers at the bottom and the other at the top, then keeping dividers 
at this spread, place one point on the zero mark and note where the other point falls on the scale. The reading on the scale at this point indicates the per cent of butter fat in the milk. Record the per cent of butter fat of both the first and second determinations. Additional tests should be made as time will permit. 


\section{STUDENT'S NOTES AND REPORT}


204 LABORATORY MANUAL OF AGRICULTURE

STUDENT'S NOTES AND REPORT 


\section{EXERCISE 54}

\section{MIXING SPRAY MATERIALS}

Object. - To prepare Bordeaux mixture for spraying apples.

Explanation. - Apple trees are sprayed to destroy fungi or insects which may injure or completely destroy the crop if their growth and development are not checked. In order that spraying may be effective it is necessary to apply a substance that will destroy the fungi or insects without injury to the apple tree or fruit.

The spray material known as Bordeaux mixture has been found to be effective in destroying fungi such as apple scab, apple blotch, and bitter rot, usually without injury to the tree or fruit. Lime sulphur, another spray material, is less likely to injure some varieties of apples, but does not effectively destroy the apple blotch. Where the apple blotch is not present, lime sulphur may be used instead of Bordeaux mixture. Lead arsenate is effective in controlling the codling moth, one of the insects most destructive to the apple crop. A strong solution of lead arsenate will destroy the cankerworm and other insects that feed upon the foliage and fruit. A strong solution of lime sulphur is used to combat the San José scale.

A common formula for making Bordeaux mixture is : 
Three pounds of copper sulphate.

Four pounds of fresh lime.

Fifty gallons of water.

The proportion of lime is sometimes increased if there is danger of spray burn. The lime is slacked by pouring water over it, and the copper sulphate is dissolved in water. Both the copper sulphate solution and the lime solution should be diluted to twenty-five gallons and then poured together. The entire solution should be poured through a strainer to remove coarse material.

Lime sulphur can be purchased on the market as such. Commercial brands usually test $32^{\circ}$ or $33^{\circ}$ Baumé. Material of this strength should be diluted about thirty to thirtyfive times with water before using on trees that are in leaf.

Lead arsenate spray may be prepared by dissolving two to four pounds of lead arsenate in fifty gallons of spray material. Lead arsenate may be used in the same spray with Bordeaux mixture or lime sulphur. Spray burn sometimes results from the use of Bordeaux mixture in wet weather, and from the use of lime sulphur in dry weather. When both sprays are used together, one application will be effective in combating both the codling moth and fungous diseases. Spraying must be done at various periods to protect the apple crop successfully.

Equipment. - 1. Thirty grams of copper sulphate.

2. Fifty grams of fresh lime.

3. Two two-gallon crocks.

4. One four-gallon crock.

5. Ten grams of potassium ferrocyanide. 
6. Graduated cylinder, 100 c.c.

7. Balance weighing to one half gram.

Directions. - Dissolve thirty grams of copper sulphate in two liters of water, in a two-gallon crock. Slack forty grams of fresh lime by pouring water over it and mixing. Pour in water to bring the solution up to two liters. Pour the two solutions together into the large crock. The resulting solution is the Bordeaux mixture.

The Bordeaux mixture should be alkaline in reaction. Dissolve the ten grams of potassium ferrocyanide in 50 c.c. of water. Pour a drop of potassium ferrocyanide solution into the spray material. If it turns brown on striking the liquid, the reaction is acid, and more limewater must be added to make it alkaline. If the reaction is acid, add 50 c.c. of limewater and test again with a drop of potassium ferrocyanide solution. Continue adding limewater and testing until the solution no longer gives the brown color when potassium ferrocyanide is added. 
208 LABORATORY MANUAL OF AGRICULTURE STUDENT'S NOTES AND REPORT 


\section{EXERCISE 55}

\section{GRAFTING}

Object. - To study the principal simple methods of grafting. Explanation. - Grafting is the operation of inserting a small branch or twig (called a cion) into an incision of another branch (called the stock). The cion must bear one or more buds, and its cambium layer must be placed next to the cambium layer of the stock so that the wood of the two may unite and grow. The main object of grafting is to propagate plants that do not readily reproduce themselves in desired forms from the seed. There are several methods of grafting. Two important ones are root and top grafting. Root grafting is practiced with apples in starting young trees. The fruit produced from a seedling apple tree is uncertain in kind and value. One-year-old seedlings are used for the root stock. Twigs of the previous summer's growth taken from good apple trees are used for the cions. Top grafting is employed to change the character of fruit of an older tree by replacing the branches of the tree with small twigs of a desirable variety.

Equipment. - 1. Grafting knife.

2. Saw.

3. Grafting wax. ${ }^{1}$ 4. Ten one-year-old apple seedlings. ${ }^{2}$

${ }^{1}$ Grafting wax may be made by melting together four parts, by weight, of resin, two parts of beeswax, and one part of tallow. When thoroughly melted, pour the mixture into a pail of cold water. After it hardens it should be pulled and worked until it becomes tough. The hands should be greased with tallow when handling grafting wax.

${ }^{2}$ Apple seedlings may be secured from nurseries in lots of one hundred. 


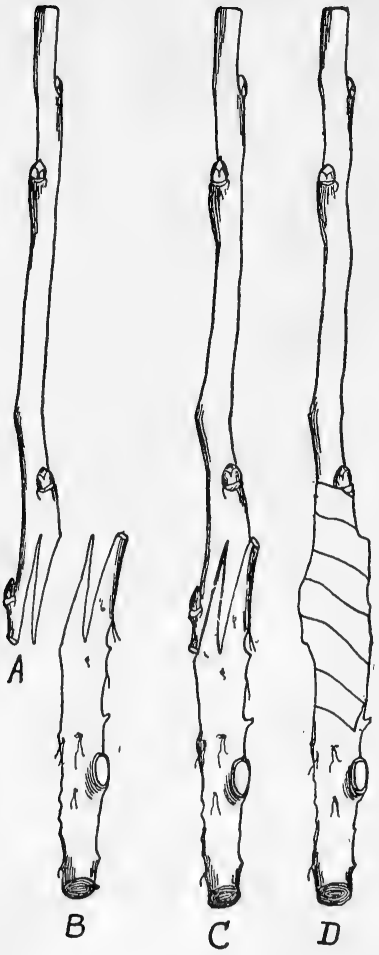

FIG. 12.-Root grafting. $A$, cion shaped ready for insertion ; $B$, portion of seedling root shaped to receive the cion; $C$, the cion and portion of root put together; $D$, the same as $C$, wrapped with grafting paper. (After Goff.)
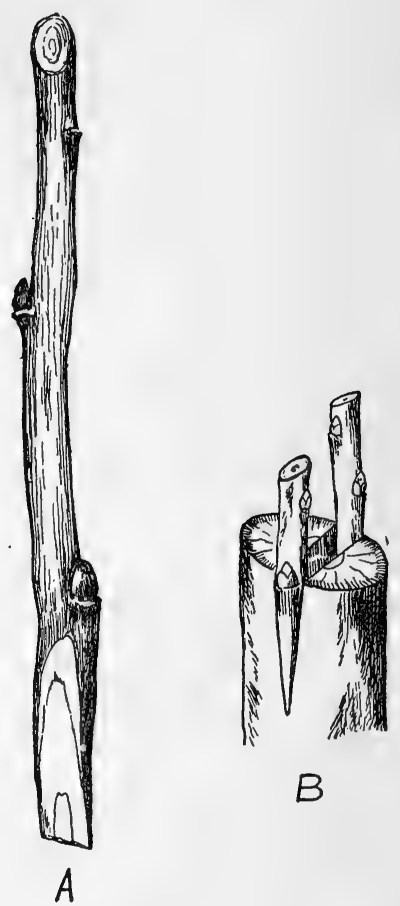

Fig. 13. - Cleft-grafting. $A$, cion shaped ready for insertion in cleft (after Bailey) ; $B$, cions inserted in cleft ready for waxing. (After Goff.) 
Directions for Root Grafting. - Select a proper root stock and cion for grafting. Cut both the stock and the cion across diagonally, so that the cut surface will extend from one to two inches. Make a vertical slit in each cut suriace and press the tongue of the cion into the cleft of the stock. (See illustration.) Wrap the graft firmly with a bandage and apply grafting wax over the bandage for protection.

Directions for Top Grafting. - Select an apple tree which is barren or produces an inferior variety of apples. Remove with a saw a branch that is one half inch to one inch in diameter. Make a split down the center of the stock. Prepare two cions four to five inches in length and wedgeshaped at the base. Place the cions in the split, one on each side, so that the cambium layer of the outside of each cion comes into exact contact with the cambium layer of the stock. Cover all the wounds carefully with grafting wax. 


\section{EXERCISES 56 AND 57 \\ GERMINATION TEST OF SEED CORN}

Object. - To test the vitality of seed corn.

Explanation. - If the field of corn examined in Exercise 2 shows a poor stand, the largest possible yield was not secured. A poor stand of corn may be due to a poorly prepared seed bed, but is very often due to the low vitality of the seed corn. Early in the winter corn usually contains an abnormally high per cent of moisture. If a severe freeze occurs while it is in this condition, the vitality is likely to be impaired or destroyed. If seed corn contains a high per cent of moisture at husking time, it should be properly dried out to keep it from molding, and placed under shelter to keep if from freezing.

A man experienced in corn selection may be able to determine with some accuracy by inspection whether or not corn will grow. But often an ear that will not grow has no outward indication of reduced vitality. It is impossible to determine definitely which ears of corn will not grow without making a germination test.

Equipment. - 1. One hundred ears of corn.

2. A germination tester or box as shown in Fig. 14 .

3. Sand.

Directions. - Lay the ears of corn that are to be tested in a long row, side by side, where they will be undisturbed 

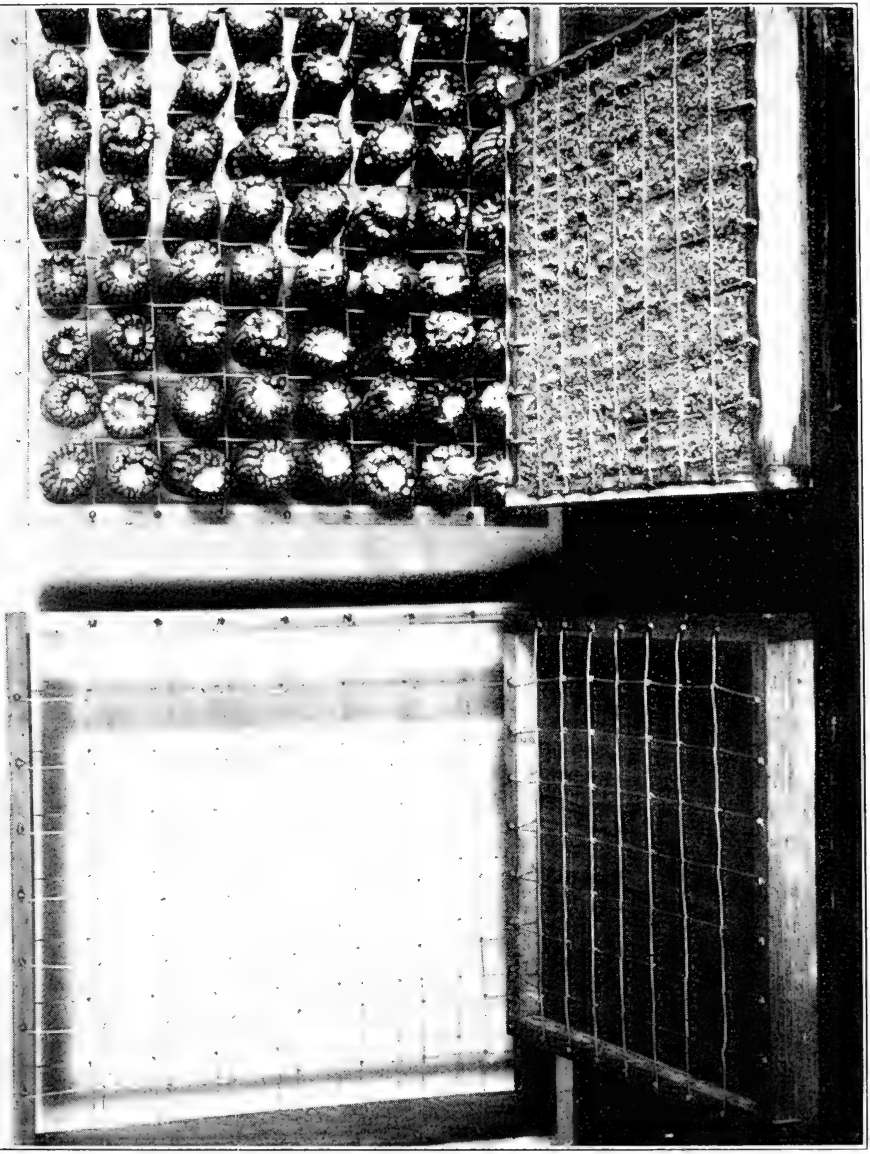

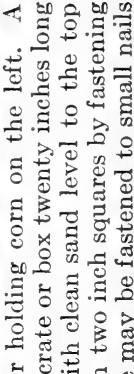

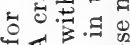

○ उ

过䓽

$=.0$.

उ

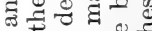

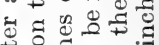

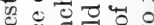

+

교용요

ह

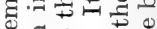

-

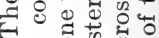

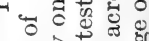

$\therefore$ त

से है

क $00 \%$

일됴

I士

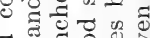

ठ

$D_{0 \rightarrow 3} D_{0}$

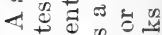

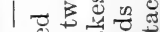

+

$\dot{s}$ 
until after the test is completed. Number the ears from one to one hundred. Commencing at the left end of the row, remove six kernels from each ear - two near the butt, two near the middle, and two near the tip. These kernels may be pulled out with the aid of a penknife and without injury to the kernels. Place the six kernels from ear No. 1 in the sand of the germinator tip downward in square No. 1. Place the six kernels from ear No. 2 in square No. 2 in a similar manner. Place the kernels from all other ears which are to be tested in a like manner in the germinating tester in squares assigned to them. Keep the germinating tester moist and at a temperature of from $70^{\circ}$ to $85^{\circ} \mathrm{F}$. In five or six days the test should be complete. If the temperature has been below $70^{\circ} \mathrm{F}$. much of the time, a longer period for the test will be required. Remove the kernels from the tester and count the number that germinated from each ear. Record on the squares of the diagram on the next page the number of kernels that germinated from each ear.

\section{QUESTIONS}

1. What per cent of ears shows perfect germination?

2. What per cent of the kernels tested shows perfect germination?

3. How many acres of corn will one hundred ears plant after the ears have been tipped, butted, and graded, assuming that one fourth of each ear is rejected for seed, if the rows are planted fortytwo inches apart and the kernels twenty-one inches apart in the row? (Use figures determined in Ex. 20 for size of ear.)

4. How many ears are necessary to plant sixty acres of corn?

5. How many bushels are necessary to plant sixty acres of corn, counting seventy pounds of ear corn to the bushel?

6. How much time is actuaily required to perform the work of the germination test for one hundred ears?

7. How much time is required to perform the work of the germination test for sixty acres? 


\section{STUDENT'S NOTES AND REPORT}

Diagram of Squares showing Record of Germination Number of tester.

Date of starting test

Date of completing test

Name of variety.

Source of seed

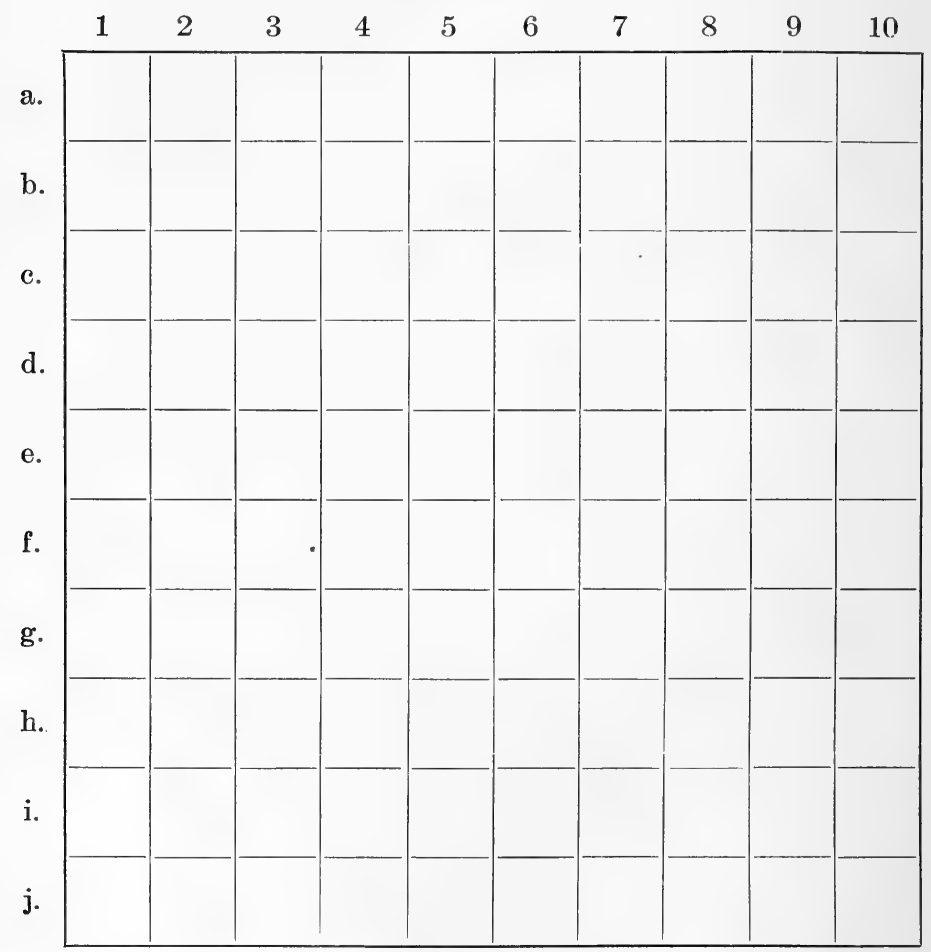




\section{STUDENT'S NOTES AND REPORT}




\section{EXERCISE 58}

\section{THE EARLY DEVELOPMENT OF THE BARLEY PLANT}

Object. - To study the germination of the barley kernel and the early growth and development of the plant.

Explanation. - The kernel of barley is not like the kernel of wheat, though it is somewhat similar. It is inclosed within a hull. The hull adheres to the kernel as in oats, and with it comprises the grain. The germ of the barley kernel occupies a small place at one end of the kernel, as in wheat and oats.

When the kernel of barley germinates, it usually sends out five temporary roots. These five roots help supply the small plant with food until the permanent root system develops.

Equipment. - 1. Plants of barley, one, two, three, and four weeks old, seeded one inch deep.

2. Plants of barley two and four weeks old, seeded three inches deep.

Directions. - Dig up a number of small barley plants for this study. Observe the same precautions in preparing the plants for study as were observed with wheat. (See Ex. 16.)

Make a study of plants one week old, two weeks old, three weeks old, and four weeks old, seeded one inch. Also make a study of plants two weeks old and four weeks old, seeded three inches. (In determining age of plant count time from 
date of seeding.) Make drawings of the plants at the different stages of growth and from the different depths of planting. Show in drawings the five temporary roots which develop first, and in other drawings the permanent roots which develop somewhat later, and are sent out in whorls from the nodes. Show how the distance between the temporary roots and the whorl of permanent roots depends upon the depth of planting. Show how the older plants, by sending out new stems, begin to tiller. Group the drawings so that they will appear well on the page. The drawings should include the root system, stems, and leaves and their arrangement. 
220 LABORATORY MANUAL OF AGRICULTURE

\section{STUDENT'S NOTES AND REPORT}




\section{STUDENT'S NOTES AND REPORT}




\section{EXERCISE 59}

\section{THE EARLY DEVELOPMENT OF THE OAT PLANT}

Object. - To study the germination of the oat kernel and the early growth and development of the plant.

Explanation. - The kernel of oats is not like the kernel of wheat, though it is somewhat similar. It is inclosed within a hull. The hull adheres to the oat kernel and with it comprises the oat grain. The germ of the oat kernel occupies a small place at one end of the kernel, as in wheat.

When the kernel of oats germinates, it sends out three temporary roots. These three roots help supply the small plant with food until the permanent root system develops.

Equipment. - 1. Plants of oats one, two, three, and four weeks old, seeded one inch deep.

2. Plants of oats two and four weeks old, seeded three inches deep.

Directions. - Dig up a number of small oat plants for this study. Observe the same precaution in preparing these plants for study as was observed with wheat.

Make a study of plants one week old, two weeks old, three weeks old, and four weeks old, seeded one inch deep. Also make a study of plants two weeks old and four weeks old, seeded three inches deep. (In determining age of plant count time from date of seeding.) 
Make drawings of the plants at the different stages of growth and from the different depths of planting. Show in drawings the three temporary roots that develop first, and in other drawings the permanent roots that develop somewhat later and are sent out in whorls from the nodes. Show how the distance between the temporary roots and the whorl of permanent roots depends upon the depth of planting. Show how the older plants begin to tiller by sending out new stems.

Group the drawings so that they will appear well on the page. The drawings should include the root system, stems, and leaves and their arrangement. 
224 LABORATORY MANUAL OF AGRICULTURE

STUDENT'S NOTES AND REPORT 
STUDENT'S NOTES AND REPORT 


\section{EXERCISE 60}

\section{JUDGING DRAFT HORSES}

Object. - To study the draft horse and observe those factors that affect its quality and worth.

Explanation. - The draft horse is used principally for hauling heavy loads. In order to perform its work successfully it must be large of frame, well muscled, and heavy in weight. It is not necessary for the draft horse to be a rapid mover, yet freedom of action and good movement, when associated with weight and good muscular development, are always desirable. In judging draft horses care should be taken not to mistake fat for muscle. It is often difficult to observe defects in a fat draft horse that would be perfectly evident in an animal of thin flesh.

Equipment. - A good draft horse.

Directions. - Examine the animal carefully and estimate the value of each point given in the accompanying score card. While judging the animal by the score card, have in mind an ideal draft horse. You can obtain an idea of an ideal draft horse from the best individuals seen at fairs or stock shows, and from pictures of prize-winning animals that appear in every good farm paper. With the picture of an ideal animal in mind compare each point of the animal you are scoring with 
the ideal. The standard score on the score card refers to an ideal animal. In judging each point record the number of points that the animal falls below the ideal. The accompanying photograph, Fig. 15, shows the location of the points described on the score card that should be observed in judging a draft horse.

General Appearance 19 Per Cent. - The height, weight, form, quality, and temperament are the most important factors to consider in the general appearance of the draft horse. Estimate the height of the horse. The height of a horse is taken by measuring from the ground to the top of the withers, and is usually expressed in hands. A hand is four inches. After recording the estimated height, measure the horse and record its actual height.

A draft horse must weigh 1600 pounds. If a draft horse weighs less than this and is of draft type, it is called a "wagon horse," or "chunk." The best draft horse weighs a ton or over.

The heavy weight of the draft horse should be due to its massiveness and great muscular development rather than to fat. Great weight is desirable in a draft horse because it holds him on the ground and enables him to secure a foothold when starting heavy loads.

Estimate the weight of the horse and record the estimate. If possible, take the horse to a scale and weigh it and record its actual weight.

In form the draft horse should be blocky, well proportioned, and symmetrical. It should have good quality, as indicated by clean bone, fine hair, and loose skin. The temperament should be energetic and the disposition good. 


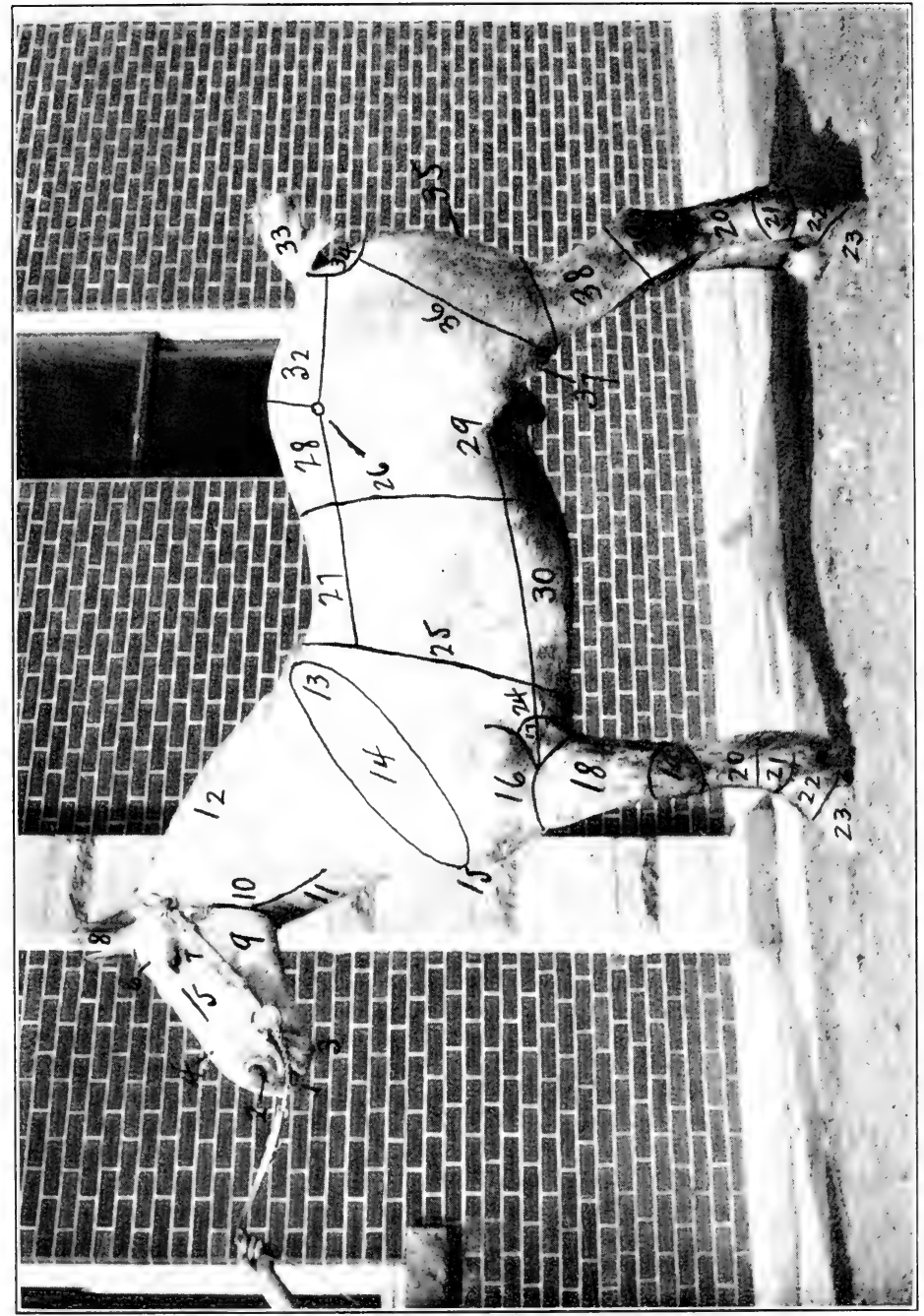

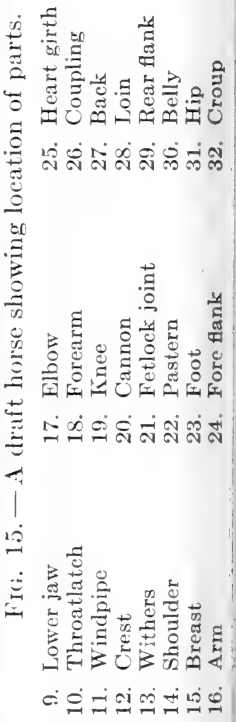

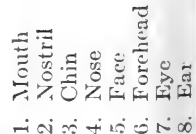


Head and Neck 9 Per Cent. - The head and neck of the draft horse should be of such form and shape as to give the horse a stylish and pleasing appearance. The face should be straight; the eyes large, clear, and bright; the ears erect and of medium size, and the neck well muscled and arched. Note the teeth and eyes to see that they are good.

Forequarters $24 \mathrm{Per}$ Cent. - The shoulder furnishes the surface against which the collar rests. It should be smooth and strong. If rough and uneven, continual pulling against the collar will develop sores and unsoundness. See that the shoulders are not sweenied. This is a sinking of the muscles of the shoulder, making it appear flat and bare of muscle. The slope of the shoulder should be about forty-five degrees as this affords the greatest comfort under the collar. The forearm should be clean and strongly muscled. The cannon should be short, wide, and clean. Examine the cannon for splints. Splints may occur on any part of the region and appear as hard, rough protrusions on the bone. Do not mistake the two small bones associated with the cannon for splints. These bones occur in the same location on both legs and may be recognized in this way. The pasterns should have an angle of about forty-five or fifty degrees when viewed from the side. This affords spring to the gait and tends to prevent foot and leg troubles.

The feet of the draft horse should be large, even sized, and sound. The foot should be attached to the leg so that the toe is straight ahead. If the horse toes in, it will "wing," or throw its feet out when it brings them forward. If the horse toes out, it will " paddle," or throw its feet in when it brings them forward. The toe should slope at an angle of 
about forty-five or fifty degrees, thus harmonizing with the slope of the pastern.

Body 9 Per Cent. - The chest should be deep and wide, and the ribs should be long and well sprung. This affords plenty of room for the development of the heart and lungs and thus indicates a good strong constitution. The back and loin
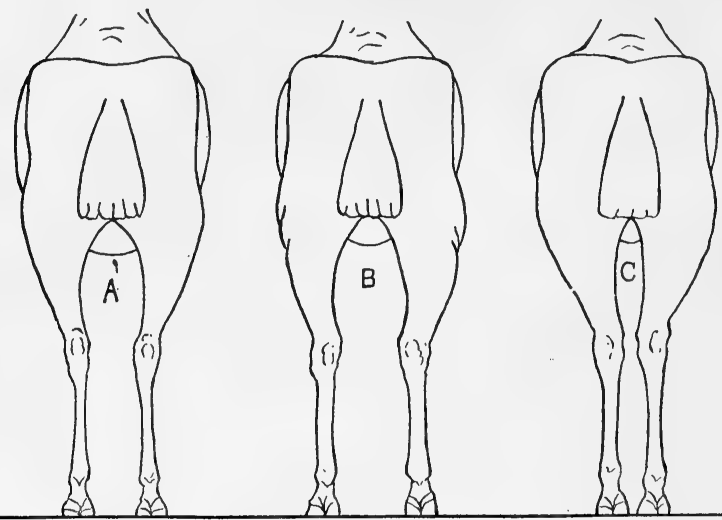

Frg. 16. - Rear view of hind legs of horses. A vertical line drawn downward from the point of the buttock should fall upon the center of the hock, cannon, pastern, and foot. Cut $A$ represents the right conformation. $B$ and $C$ are common defects. (After John A. Craig.)

should be straight, short, broad, thickly and strongly muscled. The underline should be low and flanks full.

Hindquarters 30 Per Cent. - The hindquarters of the draft horse should be heavy and well muscled, for it is in this part of the animal that the greatest force is exerted when pulling. The hips of the draft horse should be broad but smooth, and in proportion to the rest of the body. The croup should be level, wide, and fairly long. The quarters and thighs should be broad and heavily muscled. 
Examine the hock from the front of the horse and observe its outline. It should be large, clean, strong, and well set. See Figs. 16 and 17. Examine the hocks for bone spavins. This is the most common trouble of the hocks, and when
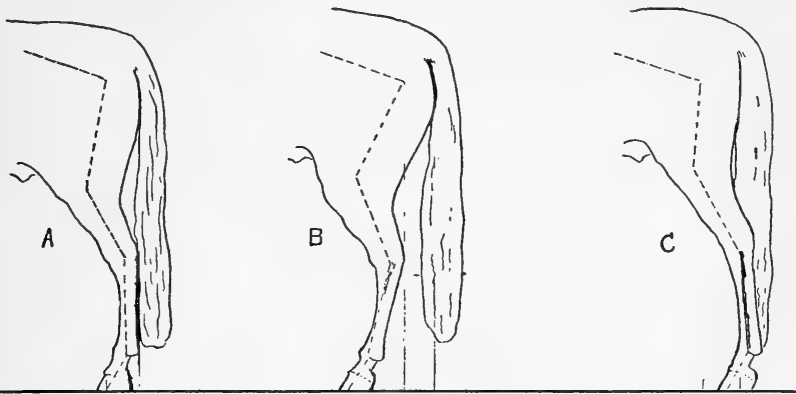

FIG. 17. - Side view of hind legs of horses. A vertical line drawn downward from the hip joint should fall upon the center of the foot and divide the gaskin in the middle; and a vertical line drawn from the point of the buttock should coincide with the angle of the hock and pastern joints. Cut $A$ represents the right conformation. $B$ and $C$ are common defects. (After John A. Craig.)

visible, appears as a bony enlargement on the lower inner side of the hock joint.

The fetlocks should be wide, strong, and clean, and the pasterns strong and springy. The feet should be large, even sized, and clean.

Action 9 Per Cent.-Walk the horse and observe its action. Its movement should be fast for a heavy horse, elastic, and regular, and the feet should move in a straight line.

Trot the horse and see that its movement is free, springy, straight, and balanced. See that it does not "wing" or "paddle." Examine the horse for unsoundness of wind after trotting. 


\section{SCORE CARD}

\section{Draft Horses}

\begin{tabular}{|c|c|c|c|c|c|}
\hline \multirow[b]{2}{*}{ Scale of Points } & \multirow[b]{2}{*}{$\begin{array}{c}\text { STAND- } \\
\text { ARD }\end{array}$} & \multicolumn{4}{|c|}{ Points Deficient } \\
\hline & & $\begin{array}{l}\text { Stu- } \\
\text { dent's } \\
\text { Score }\end{array}$ & $\begin{array}{l}\text { Cor- } \\
\text { rected } \\
\text { Score }\end{array}$ & $\begin{array}{l}\text { Stu- } \\
\text { dent's } \\
\text { Score }\end{array}$ & $\begin{array}{l}\text { Cor- } \\
\text { rected } \\
\text { Score }\end{array}$ \\
\hline $\begin{array}{l}\text { General Appearance }-19 \text { per cent } \\
\text { 1. Height, estimated, hands; actual, } \\
\text { hands . . . . . . . . . }\end{array}$ & & & & & \\
\hline $\begin{array}{l}\text { 2. Weight, over } 1600 \mathrm{lb} \text {, estimated, } \\
\begin{array}{l}\text { lb.; actual, } \\
\text { age. } . . \\
\text { lb., according to }\end{array}\end{array}$ & 6 & & & & \\
\hline $\begin{array}{l}\text { 3. Form, broad, massive, well propor- } \\
\text { tioned, blocky, symmetrical . . . }\end{array}$ & 4 & & & & \\
\hline $\begin{array}{l}\text { 4. Quality, refined; bone, clean, hard, } \\
\text { large, strong; tendons, clean, de- } \\
\text { fined; skin and hair fine.... }\end{array}$ & 6 & & & & \\
\hline $\begin{array}{l}\text { 5. Temperament, energetic; disposition, } \\
\text { good............... }\end{array}$ & 3 & & & & \\
\hline $\begin{array}{l}\text { Head and Neck }-9 \text { per cent } \\
\text { 6. Head, lean, proportionate size; pro- } \\
\text { file, straight } . . . \\
.\end{array}$ & 1 & & & & \\
\hline 7. Ears, medium size, well carried, alert & 1 & & & & \\
\hline 8. Forehead, broad, full . . . . . . & 1 & & & & \\
\hline 9. Eyes, full, bright, clear, same color & 2 & & & & \\
\hline 10. Lower jaw, angles wide, clean . . . & 1 & & & & \\
\hline $\begin{array}{l}\text { 11. Muzzle, neat; nostrils, large, open, } \\
\text { free from discharge; lips, thin, even, } \\
\text { firm . . . . . . . . . . }\end{array}$ & 1 & & & & \\
\hline $\begin{array}{l}\text { 12. Neck, well muscled, arched; throat- } \\
\text { Iatch, clean; windpipe, large . . } \\
\text { Carried forward }\end{array}$ & 2 & & & & \\
\hline
\end{tabular}




\section{Draft Horses - Continued}

\section{Brought forward}

$$
\text { Forequarters }-24 \text { per cent }
$$

13. Shoulders, moderately sloping, smooth, snug, extending into back . . .

14. Arm, short, strongly muscled, thrown back, well set

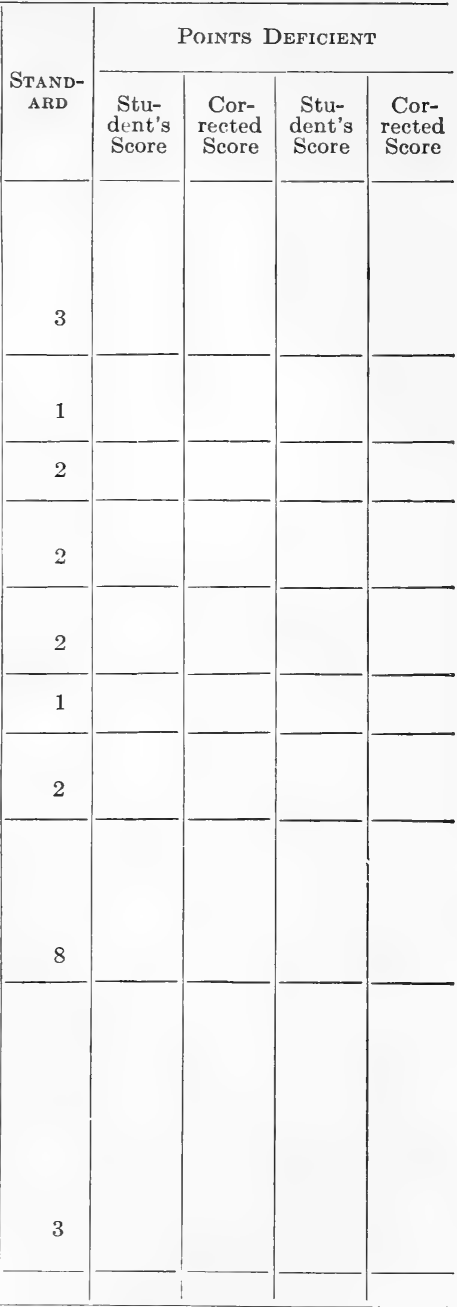

17. Cannons, short, wide, clean; tendons, defined, set back . . . . . .

18. Fetlocks, wide, straight, strong, clean

19. Pasterns, moderate length, sloping, strong, clean - .

20. Feet, large, even size, sound; horn, dense, waxy; sole, concave; bars, strong; frog, large, elastic; heel, wide, and one fourth to one half the lineal length of toe .....

21. Legs, viewed in front, a perpendicular line from the point of the shoulder should fall upon the center of the knee cannon, pastern, and foot. From the side, a perpendicular line dropping from the center of the elbow joint should fall upon the center of the knee and pastern joints and back of the hoof Carried forward 


\section{Draft Horses - Continued}

Brought forward

$$
\text { Body }-9 \text { per cent }
$$

22. Chest, deep, wide, large girth

23. Ribs, long, well sprung, close ; coupling, strong

24. Back, straight, broad, strongly muscled

25. Loins, wide, short, thickly muscled

26. Underline, low ; flanks, full

$$
\text { Hindquarters - } 30 \text { per cent }
$$

27. Hips, broad, smooth, level, well muscled

28. Croup, not markedly drooping, wide, heavily muscled.

29. Tail, stylishly set and carried . .

20. Quarters, deep, broad, heavily muscled; thighs, strong . . . . .

31. Gaskins, leng, wide, heavily muscled .

32. Hocks, large, clean, strong, wide, well set . . . . . . . . Carried forward

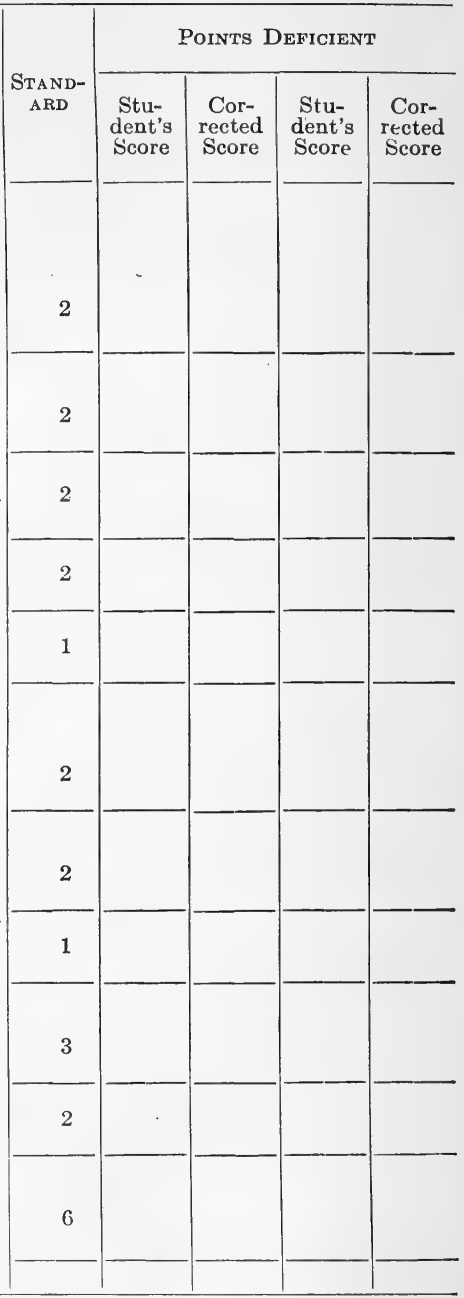




\section{Draft Horses - Continued}

\section{Brought forward}

33. Cannons, short, wide, clean; tendons, defined

34. Fetlocks, wide, straight, strong, clean .

35. Pasterns, moderately sloping, strong, clean . . . . . . . .

36. Feet, large, even size, sound; horn, dense, waxy; sole, concave; bars, strong; frog, large, elastic; heel, wide, and one fourth to one half the lineal length of toe . . . . .

37. Legs, viewed from behind, a perpendicular line from the point of the buttock should fall upon the center of the hock, cannon, pastern, and foot. From the side, a perpendicular line from the hip joint should fall upon the center of the foot and divide the gaskin in the middle, and a perpendicular line from the point of the buttock should run parallel with the line of the cannon

\section{Action - 9 per cent}

38. Walk, fast, elastic, regular, straight .

39. Trot, free, springy, balanced, straight .

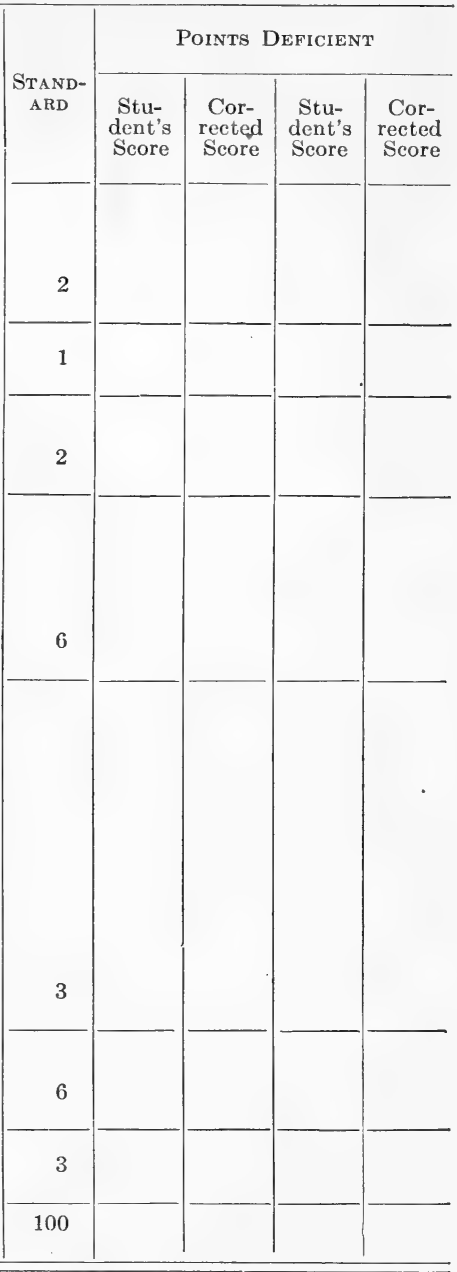




\section{EXERCISE 61}

\section{JUDGING LIGHT HORSES}

Object. - To study the light horse and observe those factors that affect its quality and worth.

Explanation. - There are three general types of light horses; namely, the coach or carriage horse, the saddle horse, and the roadster horse. The coach or carriage horse is distinguished by its plumpness, symmetry, and action. It is well muscled over all parts of the body. Its head is small, lean, and attractive; neck long and graceful; limbs clean, and body plump and round. It is valued for its graceful carriage and stylish action. In the roadster horse style and graceful movement have been sacrificed somewhat for speed and endurance. Besides having speed and endurance the roadster must be well mannered and safe. In conformation this type lacks the fullness and symmetry of the coach horse, is lighter in weight, and is more rangey in appearance.

In conformation the saddle horse is intermediate between the coach and roadster horse. It resembles the roadster more than the coach horse. The saddle horse is prized for its graceful movement and comfortable gait under the saddle.

Equipment. - A good driving or riding horse.

Directions. - Examine the animal carefully and estimate the value of each point given on the accompanying score 236 
card. Have in your mind a picture of the ideal light horse. An idea of a good light horse may be obtained by studying the pictures of the best animals as they appear in good farm papers, and by observing good light horses at fairs and stock shows. The standard score on the score card refers to an ideal animal. In judging each point record the number of points that the animal falls below the ideal. The accompanying photograph, Fig. 18, shows the location of the points described on the score card that should be observed in judging a light horse.

General Appearance 12 Per Cent. - In general appearance the light horse should have a smooth, symmetrical form and stylish appearance. The quality of the animal should be good, as shown by a firm, clean bone and fine skin and hair. In temperament it should be energetic and active, but gentle and kind in disposition.

Head and Neck 6 Per Cent. - The shape of the head and neck of the horse adds greatly to its appearance. It is chiefly from this standpoint that they are important. The head should be straight and thin, the features of the face distinct and broad enough between the eyes to give a pleasing appearance. The nostrils should be large and open; eyes large, bright, and indicating vigor ; ears erect and somewhat pointed, and neck well muscled, arched, and joined smoothly to the body.

Forequarters 23 Per Cent. - The shoulders should be long and oblique to give the action desired, and to add strength to the back and length to the underline. The forelegs should present a clean-cut appearance, should be broad, cordy, straight, and free from coarseness. The cannon should be 


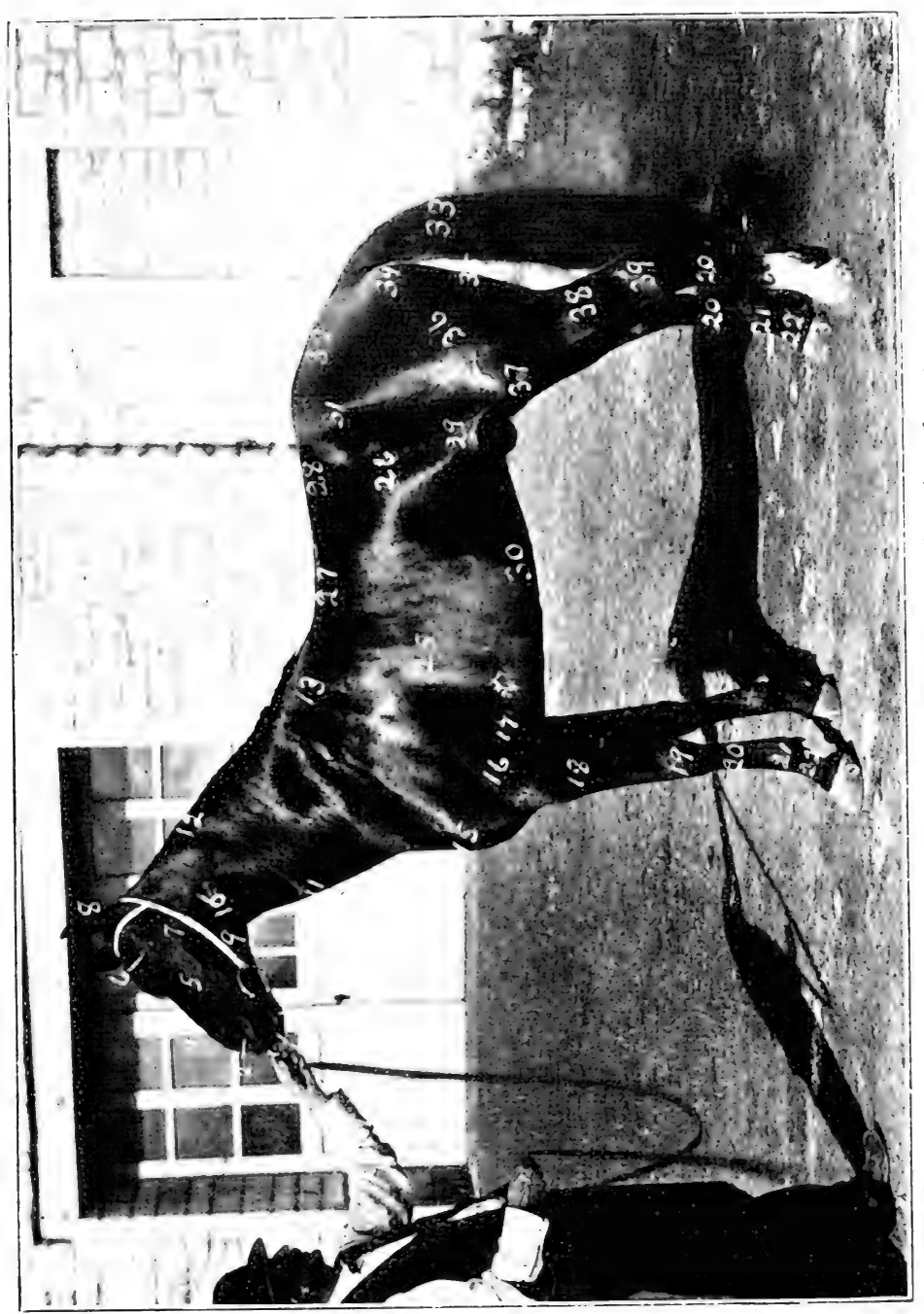

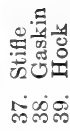

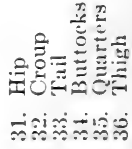

营营喝

은

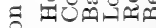

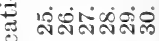

$\stackrel{0}{\circ}$

然

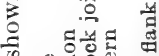

क

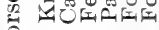

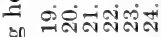

.

范

5 尊

4 开触

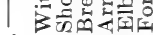

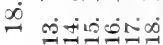

宓

Fis

\section{. \\ 过}

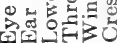

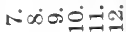

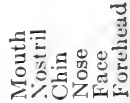


wide, showing very little shrinkage below the knee, as a broad support is necessary for the knee joint. A common-size driving horse should measure at least eight inches around the cannon at this joint. The pasterns should be strong and should slope at an angle of forty-five degrees with the ground. The feet should be of medium size and of good quality, the frog large, and the heel wide. Examine the feet and legs for unsoundness as in judging the draft horse.

Body 10 Per Cent. - The light horse should have a deep rather than a broad chest as it is not called upon for heavy work, and a broad chest would interfere with the free play of the shoulder, which is very desirable in this class of horses. The ribs should be well sprung, as horses with well-sprung ribs present a better appearance and are usually easier keepers. In proportion the body should be short above and long underneath, as this adds strength and gives the legs free play. The loin should be short, broad, and muscled.

Hindquarters 29 Per Cent. - The croup should be well muscled and long. Length of croup allows greater length of muscle in this region and insures greater speed. The hindquarters should be heavily muscled and when viewed from behind should show a heavy muscular development between the legs. The hind legs should be well carried; if bent too far forward they are likely to develop a curb, while if too straight, they are more subject to thoroughpins or spavins. The hock should be broad, allowing plenty of room for the attachment of muscles. The hock should be carefully examined for unsoundness. The hind cannon should be wide, short, and clean; the hind pasterns of medium size and length. 
The hind feet should be of medium size, and should have strong, wide heels and full fronts.

Action 20 Per Cent. - Walk the horse back and forth and observe the action. The step should be quick, elastic, and balanced. Trot the horse and notice its action when moving more rapidly. It should have free action, a rapid, straight, and regular movement, and if a coach horse, its action should be high. 


\section{SCORE CARD}

\section{Light Horses}

Scale of Points

General Appearance - 12 per cent

1. Form, symmetrical, smooth, stylish .

2. Quality, bone, clean, firm, and indicating sufficient substance; tendons, defined; hair and skin, fine . .

3. Temperament, lactive; kind disposition Head and Neck-6 per cent

4. Head, lean, straight .

5. Muzzle, fine; nostrils, large; lips, thin, even; teeth, sound .

6. Eyes, full, bright, clear, large

7. Forehead, broad, full

8. Ears, medium sized, pointed, well carried, and not far apart . . . .

9. Neck, muscled; crest, high; throatlatch, fine; windpipe, large

\section{Forequarters - 23 per cent}

10. Shoulders, long, smooth, with muscle oblique, extending into back . .

11. Arms, short, thrown forward

12. Forearms, muscled, long, wide

13. Knees, clean, wide, straight, deep, strongly supported .

14. Cannons, short, wide; sinews, large, set back

S1

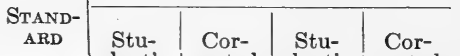
dent's Score

Score

dent's

Score

rected

Score

Carried forward 


\section{Light Horses - Continued}

\section{Brought forward}

15. Fetlocks, wide, straight

16. Pasterns, strong; angle with ground forty-five degrees . . . . . .

17. Feet, medium, even sized, straight; horn, dense ; frog, large, elastic ; bars, strong; sole, concave; heel, wide.

18. Legs, viewed in front, a perpendicular line from the point of the shoulder should fall upon the center of the knee,cannon, pastern, and foot. From the side, a perpendicular line dropping from the center of the elbow joint should fall upon the center of the knee and pastern joints and back of hoof

$$
\text { Body }-10 \text { per cent }
$$

19. Withers, muscled and well finished at top

20. Chest, deep, low; large girth

21. Ribs, long, sprung, close

22. Back, straight, short, broad, muscled

23. Loin, wide, short, thick

24. Underline, long: flank let down

$$
\text { Hindquarters - } 29 \text { per cent }
$$

25. Hips, smooth, wide, level . . . .

26. Croup, long, wide, muscular . . .

27. Tail, attached high, well carried Carried forward

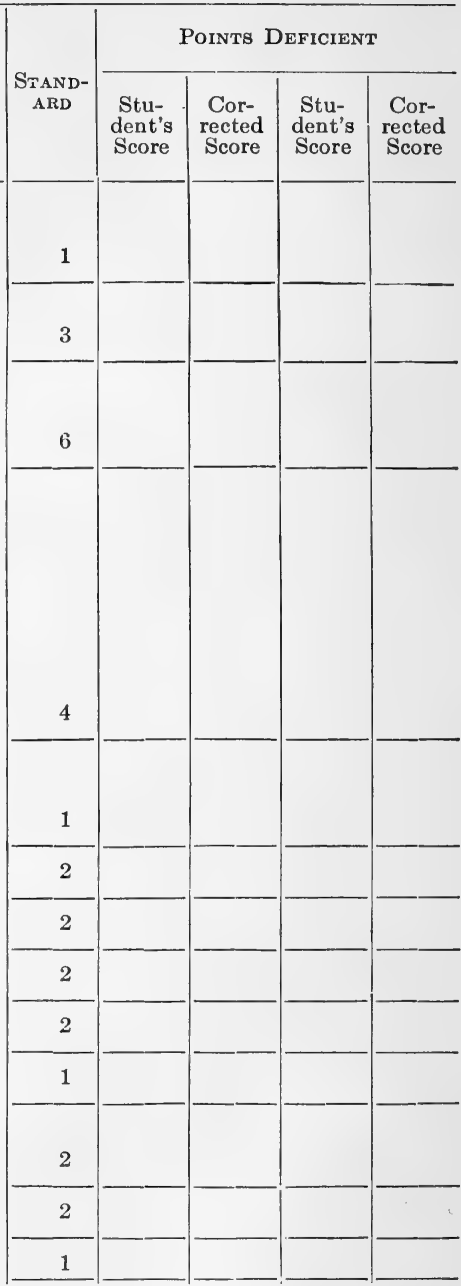

Carried forward 


\section{Light Honses - Continued}

\section{Scale of Points}

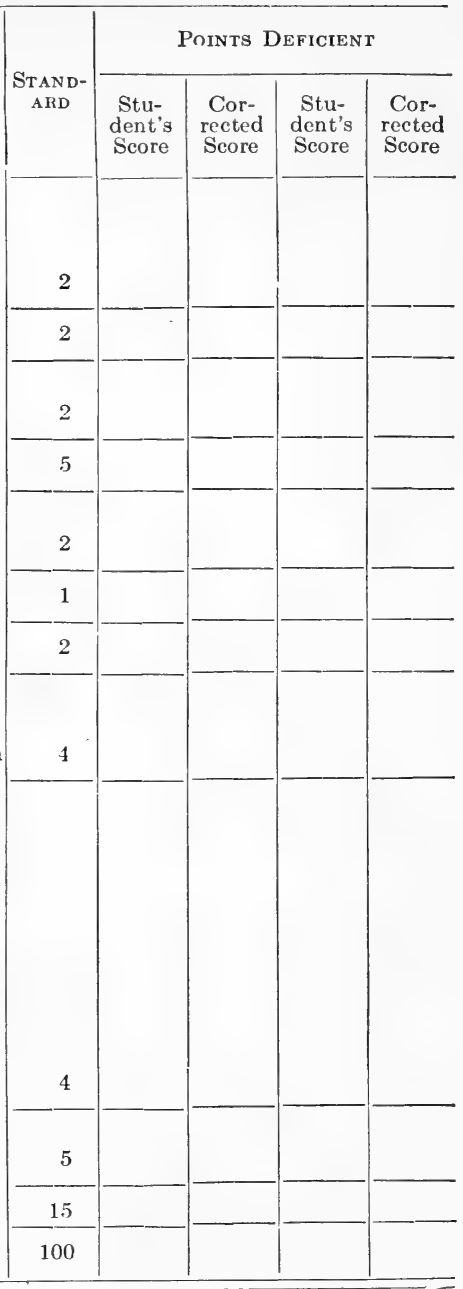

28. Thighs, long, muscular, spread; open angled

29. Quarters, heavily muscled, deep . .

30. Gaskin or lower thighs, long, wide, muscular . . . . . . .

31. Hocks, clearly defined, wide, straight .

32. Cannons, short, wide; sinews, large, set back . . . .

33. Fetlocks, wide, straight . . . .

34. Pasterns, strong, sloping . . . .

35. Feet, medium, even sized, straight: horn, dense ; frog, large, elastic ; bars, strong; sole, concave; heel, wide, high

36. Legs, viewed from behind, a perpendicular line from point of the buttock should fall upon the center of the hock, cannon, pastern, and foot. From the side, a perpendicular line from the hip joint should fall upon the center of the foot and divide the gaskin in the middle; and a perpendicular line from the point of the buttock should run parallel with the line of the cannon.

$$
\text { Action - } 20 \text { per cent }
$$

37. Walk, elastic, quick, balanced . .

38. Trot, rapid, straight, regular, high . 


\section{EXERCISE 62}

\section{COMPARATIVE JUDGING OF HORSES}

Object. - To place the animals of a class of horses according to their worth.

Explanation. - When a good horseman selects a valuable horse, he has in mind an ideal of the type of animal that he wants. He makes a careful study of all the points of the animal and chooses the individual that most nearly meets his ideal. If he is placing a class of horses, he makes a careful study of each individual in the class and places the best individual first. The other animals of the class are in a similar way placed in the order of their worth.

It is necessary for the beginner who wants to become proficient in the judging of horses to study the quality of the individuals of the class and to become familiar with the characteristics that affect value. After becoming familiar with each animal, he can then place them according to their merits.

Equipments. - A class of four good draft horses or a class of four good driving horses. All the animals of the class should be of about the same age and same condition of flesh. ${ }^{1}$

1 The instructor may use his own judgment in selecting a class of animals. Sometimes one class will be more easily available than the other. If it is impossible to obtain a class of four, the exercise can be conducted with two animals. 
Directions. - Number the animals from one to four and place them side by side. Examine thoroughly and systematically all the animals in the class. Keep in mind the relative value of the points discussed on the score card. After this thorough examination decide which animal is best. This can be done by balancing the good and bad points of one animal against those of another. When the best animal is selected, record its rank in the blank space opposite its number on the outline form of Student's Notes and Report. In like manner choose the second best animal in the class and record its rank in the space opposite its number. The third and fourth animals are to be placed and recorded in the same manner.

Discuss fully under "Student's Notes and Report" the good and bad points of each animal in the class. Discuss them in the order of your placing. Give in detail the reasons for placing each animal as you did. 


\section{STUDENT'S NOTES AND REPORT}

\begin{tabular}{|c|c|c|}
\hline $\begin{array}{c}\text { Order of Numbering } \\
\text { The Class }\end{array}$ & $\begin{array}{c}\text { Order of Student's } \\
\text { Placing }\end{array}$ & Correct Placing \\
\hline 1 & & \\
\hline 2 & & \\
\hline 3 & & \\
\hline
\end{tabular}


STUDENT'S NOTES AND REPORT

STUDENT'S NOTES AND REPORT 


\section{EXERCISE 63}

\section{JUDGING DAIRY CATTLE}

Object. - To study the dairy cow and observe those factors that affect her quality and worth.

Explanation. - A dairy cow is used primarily for the production of milk and butter fat. The most profitable dairy cow is the one that produces the maximum amount of milk and butter fat for a given amount of feed. Two methods are used in selecting profitable dairy cows. One method of selection is to consider the record of the animal and from this record to determine her ability to produce milk and butter fat. The other method of selection is to consider the form or conformation of the animal. The first method is the better because the actual record of the animal is considered. This method cannot always be employed because the record of the dairy cow is not always available. When the record of the cow is not available, the only means of determining her value is by studying her form and conformation. High milk production is usually associated with a definite form or conformation. The dairy cow is thin and muscular and in this respect differs from the beef animal. This condition is due not to her inability to utilize food economically, but to her tendency to convert the food consumed into milk rather than into body fat. 


\section{Equipment. - A good dairy cow.}

Directions. - Examine the animal carefully and estimate the value of each point given on the accompanying score card. While judging the animal by the score card, have in mind an ideal animal. You can obtain an idea of an ideal animal from the best individuals that you have seen at stock shows and fairs, or from pictures of the winners at the International Live Stock Show. With the picture of an ideal animal in mind compare each point of the animal you are scoring with the ideal.

The standard score on the score card refers to the ideal animal. In judging each point record the number of points that the animal falls below the ideal. The accompanying photograph, Fig. 19, shows the location of the points described on the score card that should be observed in judging a dairy cow.

The Head 8 Per Cent. - Examine the general appearance of the head and note the size of the muzzle. The muzzle should be broad, for this is usually associated with a good feeder. The face of the dairy cow should be of good length and free from extra flesh. A fleshy face is not associated with high milk production. The eyes should be large, mild, and quiet but not drowsy. A large milk production is not associated with a drowsy eye. The ears should be of medium size, fine textured, and well supplied on the inside with waxy secretion of yellow color. The waxy secretion yellow in color indicates vigor and general good health in the animal.

Forequarters 10 Per Cent. - The throat should be thin and clean-cut. The neck should be of medium length, thin, and free of flesh, in direct contrast to the beef animal. A short, 


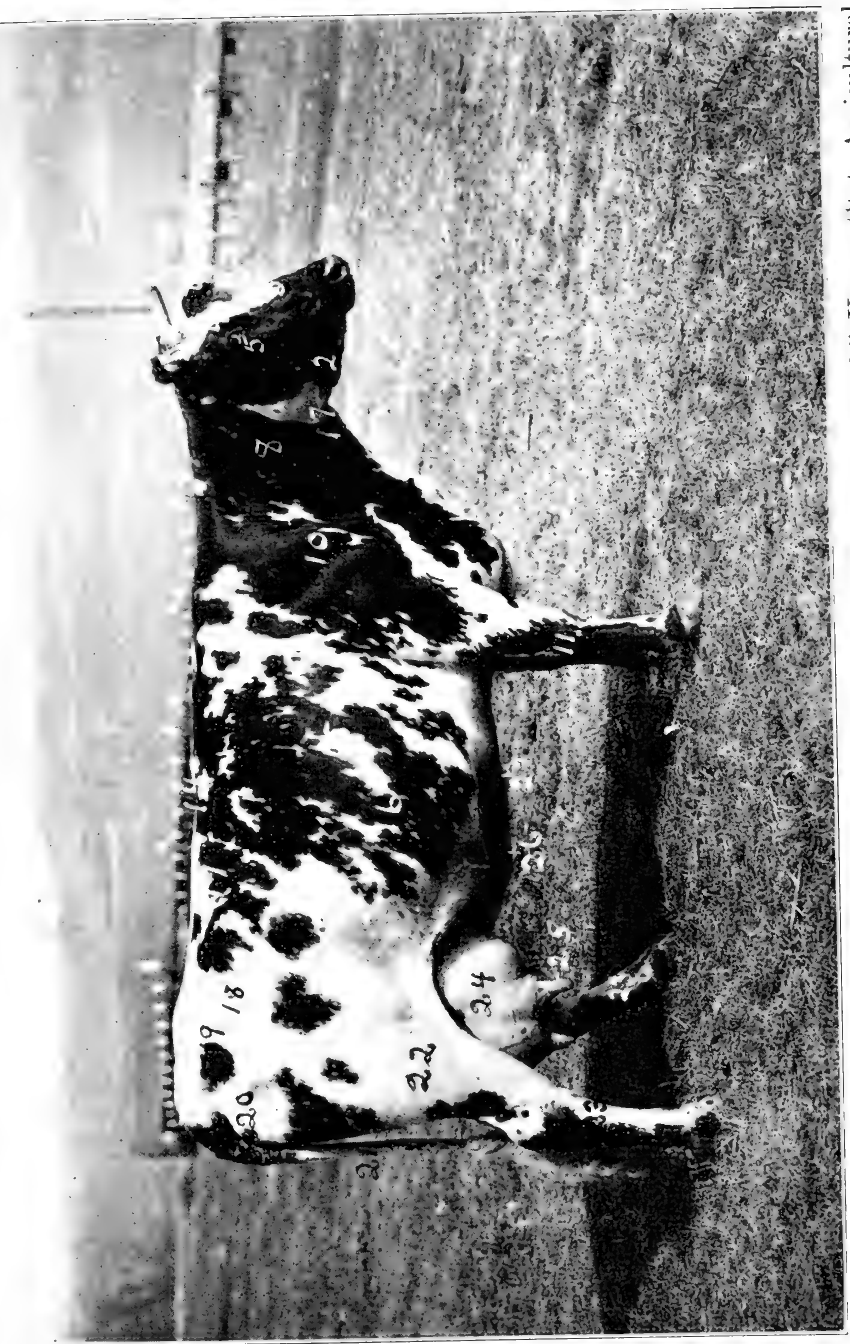

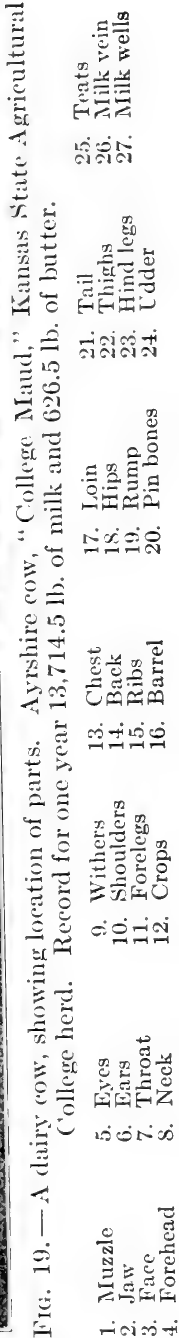


beefy neck does not denote high milk production. The neck should be joined smoothly to the shoulders, which should be sloping. It should be smooth and have a light brisket. The withers should be narrow and sharp, not broad and flat, as this indicates beefiness. The forelegs should be straight, clean, set well under the body, and well apart. Legs set too close together indicate lack of room for the development of lungs and heart, and therefore a poor constitution.

Body 25 Per Cent. - The chest of the dairy cow should be deep and roomy, and have a broad floor, as these characteristics all indicate more room for the heart and lungs, and consequently a strong constitution. The back should be straight and strong. A weak, sunken back is a common defect in dairy cows. It indicates insufficient strength to carry a heavy barrel. The vertebra or spinal processes along the spinal column should be prominent and open. The lateral nerves pass out between the vertebra, and plenty of room for these nerves is desirable. The barrel of the dairy cow is her storehouse for food. The dairy animal, to be profitable, must consume a large quantity of food and she must have a large barrel in which to store it. The ribs should be well sprung and wide apart, thus making a large barrel possible. The loin should be broad and strong, especially broad to avoid trouble at time of parturition.

Hindquarters 12 Per Cent. - The hips of the dairy cow should be prominent and wide apart, as this indicates both capacity in the barrel and room in the pelvic region. The rump should be long, and high at the tail head. A long rump is associated with plenty of room for udder attachment. 
The tail should be thin, tapering, and long, the tail bone extending at least to the hocks, as a long tail is associated with a high nervous development, much desired in a dairy cow. The hind legs should set well apart, especially at the hocks, thus allowing plenty of room for the development of the udder.

Mammary Development 30 Per Cent. - The udder is the most important part of the dairy cow. It should be attached high behind and carried well forward, thus affording the maximum amount of room for its development. It should be flexible, and when empty, drop into folds. A fleshy udder is not desirable, as there is not sufficient room for the secretory glands. The quarters should be even and not cut up. The teats should be wide apart, uniformly placed, and of convenient size, which qualities aid in milking and insure greater capacity in the udder. A thorough examination should be made to see that all teats are perfect. A stream of milk should be drawn from each teat. The milk veins should be large and twisting, and should extend well forward. The size of the milk veins indicates the amount of blood that can pass through the circulation to the udder. The milk wells or cavities where the milk veins pass into the body should be large and numerous. Examine the cow and determine the number of milk wells. Every cow has two milk wells, and some cows have as many as fourteen.

General Appearance 15 Per Cent. - The disposition of the dairy cow should be quiet and gentle, yet she should show indications of a high nervous development well under control, since this characteristic indicates milk production. Health and vigor will be determined by her wide-awake 
appearance and by the quality of her hair and hide. A strong constitution is shown by a deep, broad chest. Quality is indicated by a soft, thin, mellow hide. Determine this by gathering up a handful of hide over the last two or three ribs. The hair should be fine and the secretions oily and abundant, as this indicates a healthy condition.

Temperament, or the tendency to dairy performance, is indicated by the general appearance of the animal. She should give the impression of being an individual capable of converting food into milk. 


\section{THE SCORE CARD}

\section{Dairy Cattle - Cow}

\section{Scale of Points}

\section{Head -8 per cent}

1. Muzzle, broad

2. Jaw, strong, firmly joined

3. Face, medium length, clean

4. Forehead, broad between eyes, dishing

5. Eyes, large, full, mild, bright . . . .

6. Ears, medium size, fine texture, secretions oily and abundant, yellow color Forequarters - 10 per cent

7. Throat, clean .

8. Neck, long, spare, smoothly joined to shoulders, free from dewlap . . .

9. Withers, narrow, sharp

10. Shoulders, sloping, smooth, brisket, light

11. Forelegs, straight, clean, well set under body

\section{Body -25 per cent}

12. Crops, free from fleshiness . . .

13. Chest, deep, roomy ; floor, broad

14. Back, straight, strong, vertebra open .

15. Ribs, long, deep, sprung, wide apart .

16. Barrel, deep, long, capacious . . .

17. Loin, broad, strong Carried forward

\begin{tabular}{|c|c|c|c|c|}
\hline \multirow{2}{*}{$\begin{array}{c}\text { STAND- } \\
\text { ARD }\end{array}$} & \multicolumn{2}{|c|}{$\begin{array}{c}1 \\
\text { Points De- } \\
\text { Ficient }\end{array}$} & \multicolumn{2}{|c|}{$\begin{array}{l}2 \\
\text { PoINTS DE- } \\
\text { FICIENT }\end{array}$} \\
\hline & $\begin{array}{l}\text { Stu- } \\
\text { dent's } \\
\text { Score }\end{array}$ & $\begin{array}{l}\text { Cor- } \\
\text { rected } \\
\text { Score }\end{array}$ & $\begin{array}{l}\text { Stu- } \\
\text { dent's } \\
\text { Score }\end{array}$ & $\begin{array}{l}\text { Cor- } \\
\text { rected } \\
\text { Score }\end{array}$ \\
\hline 1 & & & & \\
\hline 1 & & & & \\
\hline 1 & & & & \\
\hline 1 & & & & \\
\hline 2. & & & & \\
\hline 2 & & & & \\
\hline 1 & & & & \\
\hline 2 & & & & \\
\hline 3 & & & & \\
\hline 3 & & & & \\
\hline 1 & & & & \\
\hline $1-$ & & & & \\
\hline 6 & & & & \\
\hline 3 & & & & \\
\hline 3 & & & & \\
\hline 10 & & & & \\
\hline 2 & & & & \\
\hline & & & & \\
\hline
\end{tabular}




\section{Dairy Cattle - Cow - Continued}

\section{Scale of Points \\ Hindquarters - 12 per cent}

18. Hips, prominent, wide apart . . . .

19. Rump, long, level, not sloping

20. Pin bones, wide apart .

21. Tail, neatly set on, long, tapering .

22. Thighs, spare, not fleshy . . . .

23. Hind legs, well apart, giving ample room for udder . . . . . . .

Mammary Development - 30 per cent

24. Udder, large, very flexible, attached high behind, earrying well forward: quarters, even, not cut up . . .

25. Teats, wide apart, uniformly placed, convenient size

26. Milk veins, large, tortuous, extending well forward

27. Milk wells, large

General Appearances - 15 per cent

28. Disposition, quiet, gentle

29. Health, thrifty, vigorous . . . .

30. Quality, free from coarseness throughout; skin, soft, pliable; secretions, abundant; hair, fine

31. Temperament, inherent tendency to dairy performance

Total

\begin{tabular}{|c|c|c|c|c|}
\hline \multirow{2}{*}{$\begin{array}{c}\text { STAND- } \\
\text { ARD }\end{array}$} & \multicolumn{2}{|c|}{$\begin{array}{l}1 \\
\text { Points De- } \\
\text { FICIENT }\end{array}$} & \multicolumn{2}{|c|}{$\begin{array}{l}2 \\
\text { PoINTS DE- } \\
\text { FICIENT }\end{array}$} \\
\hline & $\begin{array}{l}\text { Stu- } \\
\text { dent's } \\
\text { Score }\end{array}$ & $\begin{array}{l}\text { Cor- } \\
\text { rected } \\
\text { Score }\end{array}$ & $\begin{array}{l}\text { Stu- } \\
\text { dent's } \\
\text { Score }\end{array}$ & $\begin{array}{l}\text { Cor- } \\
\text { rected } \\
\text { Score }\end{array}$ \\
\hline 1 & & & & \\
\hline 4 & & & & \\
\hline 1 & & & & \\
\hline 1 & & & & \\
\hline 3 & & & & \\
\hline 2 & & & & \\
\hline 15 & & & & \\
\hline 5 & & & & \\
\hline 4 & & & & \\
\hline 6 & & & & \\
\hline 2 & & & & \\
\hline 3 & & & & \\
\hline 4 & & & & \\
\hline 6 & & & & \\
\hline 100 & & & & \\
\hline
\end{tabular}




\section{EXERCISE 64}

\section{JUDGING BEEF CATTLE}

Object. - To study the beef animal and observe those factors that affect its quality and worth.

Explanation. - The principal purpose of beef cattle is the production of meat. The beef animal that most nearly meets the demands of the butcher is the one that the farmer should produce. The animal that brings the highest price on the market is the one that will dress the highest per cent of salable meat and will have a maximum amount of this meat located in those parts of the body from which the most valuable cuts are secured.

\section{Equipment - 1. A good beef steer.}

Directions. - Examine the animal carefully and estimate the value of each point given on the accompanying score card. While judging the animal by the score card, have in mind an ideal animal. You can obtain an idea of an ideal animal from the best individuals that you have seen at stock shows and fairs, or from pictures of the winners at the International Live Stock Show. With the picture of an ideal animal in mind compare each point of the animal you are scoring with the ideal. The standard score on the score card refers to an ideal animal. In judging each point record the per cent that the animal falls below the ideal. The 
accompanying photograph, Fig. 20, shows the location of the points described on the score card that should be observed in judging a beef animal.

General Appearance 40 Per Cent. - The value of an animal as a meat producer depends upon its form, quality, condition, and weight. Form has reference to the shape of the animal. The shape of the animal should be such that it will carry the maximum amount of the most valuable cuts of meat. Quality is determined by the condition of the bone, hair, skin, and flesh. Good quality means that the animal has clean bone, soft, mellow skin, general refinement of features and appearance, and all parts of the body covered thickly and evenly with firm, mellow flesh. Condition refers to the finish of the animal. The animal is said to be finished when it is fat. A fat animal will produce a higher per cent of dressed meat, and the meat is more valuable because it is more tender and palatable.

In addition to these factors the weight of the animal for its age should also be considered. Estimate the weight of the animal before weighing and record your estimate on the blank in the score card. Take the animal to stock scales if possible and determine its actual weight.

Head and Neck 7 Per Cent. - Examine the general appearance of the head and neck. Note the size of muzzle; the muzzle should be broad, the mouth large, and the nostrils large and open, for these qualities denote a good feeder. The neck should be short, broad, and refined, and in correct proportion to the rest of the body.

Forequarters 9 Per Cent. - The shoulder should fit smoothly into the body without too much prominence of shoulder 
blades. The lower part of the shoulder should be smooth, well covered with flesh, and not too heavy. The forelegs should be short, standing well apart, and the foreflank should be full.

Body 30 Per Cent. - Observe the body from the side; it should present the general outlines of a rectangle. The top line should be straight from head to tail. The bottom line should be low, straight, and parallel to the top line. The chest should be deep and full, and the hind flank should be full and even with the underline.

Hindquarters 14 Per Cent. - Observe the animal from the rear. The hindquarters should be deep and as broad as the shoulders. The rump should be long and wide, and the tail head smooth. The twist should be deep and plump. The legs should be wide apart, straight, and short. 


\section{THE SCORE CARD}

Beef Cattle - Fat

Scale of Points

General Appearance - 40 per cent

1. Weight, estimated, lb. ; actual, lb., - according to age . . . .

2. Form, straight top and underline, deep, broad, low set, stylish, smooth, compact, symmetrical . . . .

3. Quality, fine, soft hair; loose, pliable skin of medium thickness; dense, clean, medium-sized bone . . . .

4. Condition, deep, even covering of firm, mellow flesh; free from patches, ties, lumps, and rolls; full cod and flank indicating finish

\section{Head and Neck -7 per cent}

5. Muzzle, broad; mouth, large; nostrils, large and open . . . . . . .

6. Eyes, large, clear, placid .

7. Face, short; jaw, strong

8. Forehead, broad, full

9. Ears, medium size; fine texture . .

10. Neck, short, thick, blending smoothly with shoulder; throat, clean with light dewlap

\section{Forequarters - 9 per cent}

11. Shoulder vein, full . . . . . .

12. Shoulders, smoothly covered, compact, snug, neat

\section{Carried forward}

\section{Points Deficient}

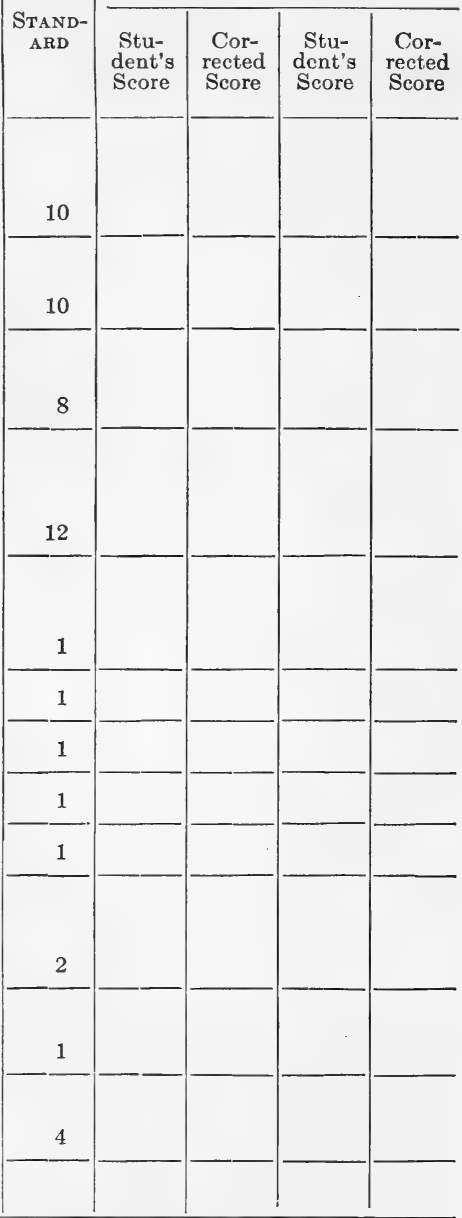


Beef. Cattle - Fat-Continued

Brought forward

13. Brisket, trim, neat; breast, full . .

14. Legs, wide apart, straight, short; arm, full; shank, wide . . . . . .

$$
\text { Body }-30 \text { per cent }
$$

15. Chest, full, deep, wide; girth, large; crops, full

16. Ribs, long, arched, thickly and smoothly fleshed

17. Back, broad, straight, thickly and smoothly fleshed . . . . . .

18. Loin, thick, broad

19. Flank, full, even with underline

$$
\text { Hindquarlers - } 14 \text { per cent }
$$

20. Hips, smooth

21. Rump, long, wide, level; tail head, smooth; pinbones, wide apart, not prominent

22. Thighs, deep, full

23. Twist, deep, plump

24. Legs, wide apart, straight, short; shanks, fine, smooth . . . . . . Total

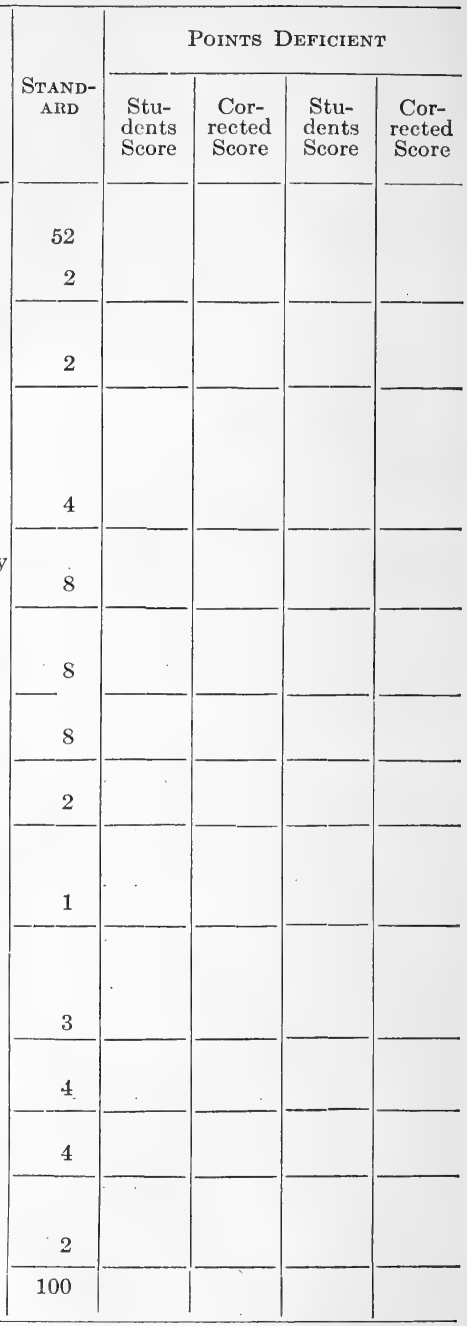




\section{EXERCISE 65}

\section{COMPARATIVE JUDGING OF CATTLE}

Object. - To place the animals of a class of cattle according to their worth.

Explanation. - When a stockman goes into a herd of cattle, or when a judge goes into a show ring, he has in mind the type of animal that he desires for his purpose. If the judge is placing a class of beef cattle, he examines the entire class, keeping in mind the ideal beef animal, and chooses that individual for first which most nearly meets this ideal. In the same way he places in the order of their merit the other animals of the class. In a similar manner the judge of dairy cattle, keeping in mind the ideal dairy cow, awards the places in the dairy cattle class.

It is necessary for the beginner who wants to become proficient in judging cattle to study the characteristics of the individuals of the class and to become familiar with the characteristics that affect value. After becoming familiar with each animal the beginner can place it according to its merits.

Equipment. - A class of four good dairy cows, or a class of four good beef steers, all the animals of the class to be of about the same age and same condition of flesh. ${ }^{1}$

${ }^{1}$ In selecting a class of animals for this exercise the instructor should be governed by the relative importance of the two classes of 263 
Directions. - Number the animals from one to four and place them side by side. Examine thoroughly and systematically all the animals in the class. Keep in mind the relative value of the points discussed in the score card. After this thorough examination decide which animal is best. This can be done by balancing the good and bad points of one animal against those of another.

When the best animal is selected, record its rank in the space opposite its number. In like manner choose the second-best animal of the class and record its rank in the space opposite its number. The third and fourth animals in the class are placed in the same manner. Record their placings.

Discuss fully under Student's Notes and Report the good and bad points of each animal in the class. Discuss them in the order of your placing. Give in detail the reasons for placing each animal as you did.

animals in the community. If the dairy industry is of greater importance, a dairy class should be selected If not, a beef class should be selected. 


\section{STUDENT'S NOTES AND REPORT}

\begin{tabular}{|c|c|c|}
\hline Order of Numbering & $\begin{array}{c}\text { Order of Student's } \\
\text { Placing }\end{array}$ & Correct Placing \\
\hline 1 & & \\
\hline 2 & & \\
\hline 3 & & \\
\hline 4 & & \\
\hline
\end{tabular}


266

LABORATORY MANUAL OF AGRICULTURE

STUDENT'S NOTES AND REPORT 
STUDENT'S NOTES AND REPORT 


\section{EXERCISE 66}

\section{JUDGING FAT HOGS}

Object. - To study the hog and observe those factors that affect its quality and worth.

Explanation. - There are two general classes of hogs, commonly sold on the market, the fat or lard hog and the bacon hog. The lard or fat hog is short legged, broad, and of medium length. It fattens easily and is used on the market for making lard, supplying hams and shoulders, and furnishing cheap side meat. The bacon hog is long, deep, and narrow in body, has long legs, and is used chiefly for the production of bacon.

The fat hog is best suited to the north central United States because of the abundance of corn in this region and the ability of the fat hog to fatten rapidly on this food. In some of the northern states of the United States and in Canada the bacon hog is generally produced.

The fat hog that is in greatest demand is the one that will dress the largest percentage of good salable meat. It supplies the demand for good hams and shoulders, and furnishes a large amount of lard.

Equipment. - A good fat hog.

Directions. - Examine the animal carefully and estimate the value of each point given on the accompanying score 268 


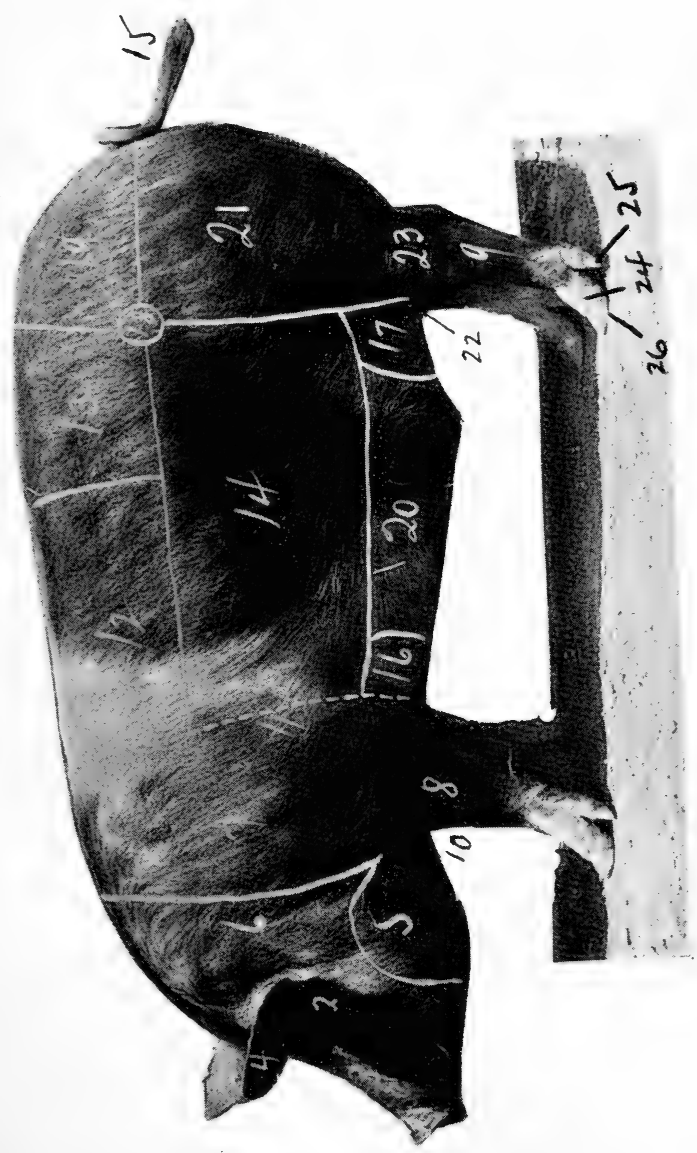

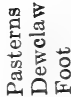

เిผ

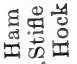

สิ ผี่

$\frac{1}{2}$
$\frac{\pi}{6}$
0

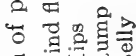

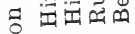

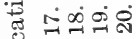

○

.

兘

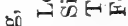

요

$+$

480.

$1 \frac{0}{\sigma}+$

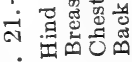

近

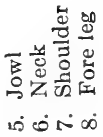

苛皆 - 
card. Have in your mind a picture of the ideal fat hog. An idea of an ideal hog may be obtained by studying pictures of winners at the International Live Stock Show or by observing good individual specimens. The standard score on the score card refers to an ideal animal. In judging each point record the number of points that the animal falls below the ideal. The accompanying photograph, Fig. 21, shows the location of the points described on the score card that should be observed in judging a fat hog.

General Appearance $30 \mathrm{Per}$ Cent. - The general appearance of the fat hog is determined by the weight, form, quality, and covering of the animal. The weight of the hog will vary with age. Record your estimate of the weight of the hog. If possible, weigh the hog and record its actual weight. The best weight at which to market the fat hog varies with the demand and the supply of the market. As a rule fat hogs weighing from 200 to 300 pounds are the most profitable for selling.

The fat hog should be compactly built, round ribbed, and deep chested. Good quality is indicated by smooth, fine hair, clean, strong bone, and a general appearance of refinement.

Head and Neck 8 Per Cent. - The head and neck of the fat hog have very little commercial value. In fact this portion of the animal is nearly all waste to the butcher. The head of the hog, however, shows character and feeding capacity. A broad head and a short neck are desirable because they are usually associated with feeding capacity, broad back, and heavy hams.

Forequarters 12 Per Cent. - The most important part of the 
forequarters of a fat hog is the shoulders, which should be level on top, well packed with flesh, and broad and deep. The breast should be full, as this indicates a vigorous constitution. The legs should be straight, short, and strong, with hard, clean bone.

Body 33 Per Cent. - The body is the most important part of the animal from the butcher's standpoint, for it is this part of the animal that supplies most of the dressed meat. The back should have a straight top line, although a gradual rise from both the neck and the tail to the center of the back usually renders the animal stronger and able to carry more flesh. The back should be broad and carry its width well forward and back. It should be evenly and thickly fleshed. The underline should run nearly parallel with the top line. Hindquarters 17 Per.Cent. - The hams are the most important part of the hindquarters. The ham should be wide, plump, full, and carry down well to the hock. The hind legs should be short, strong, and placed wide apart. 


\section{SCORE CARD}

\section{JUdGING FAt Hogs}

Scale of Points

General Appearance - 30 per cent

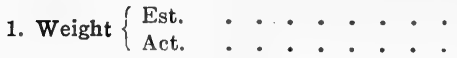

Score according to age . . . . .

2. Form, deep, broad, medium length ; smooth, compact, symmetrical, standing square on medium short $\operatorname{legs}$

3. Quality, hair, smooth and fine; bone, medium size, clean, strong; general appearance, smooth and refined .

4. Covering, finished, deep, even, mellow, free from lumps and wrinkles. .

\section{Head and Neck- 8 per cent}

5. Snout, medium length, not coarse . .

6. Eyes, not'sunken, clear, not obscured by wrinkles........

7. Face, short; cheeks, full . . . .

8. Ears, fine, medium size attached neatly

9. Jowl, full, firm, neat . . . . .

10. Neck, thick, short, smooth to shoulder

\section{Forequarters - 12 per cent}

11. Shoulders, broad, deep, smooth, compact, on top

12. Breast, full, smooth, neat .

13. Legs, straight, short, strong; bone, clean, hard; pasterns, short, strong, upright; feet, medium size Carried forward

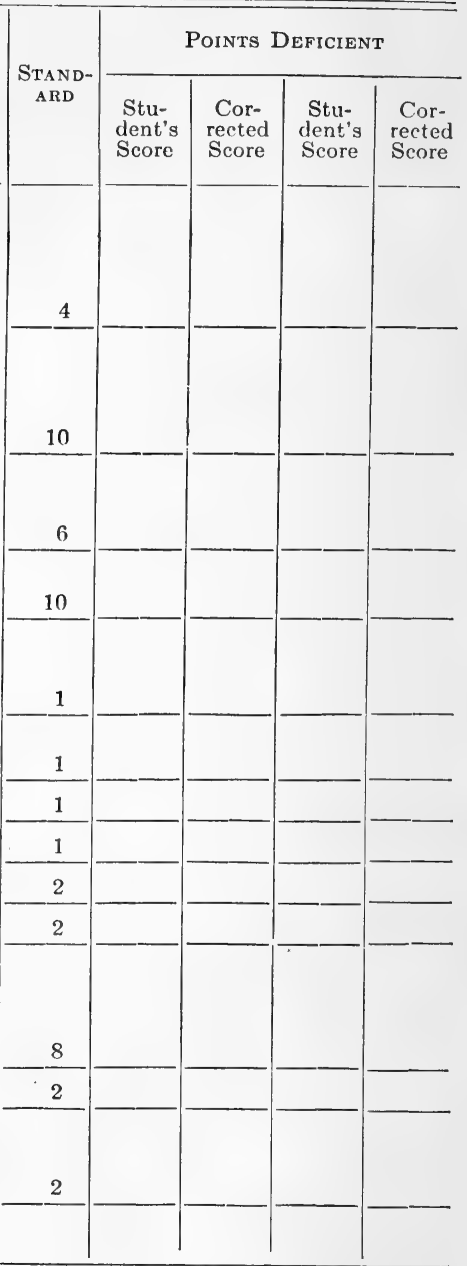




\section{Jodging FAt Hogs-Continued}

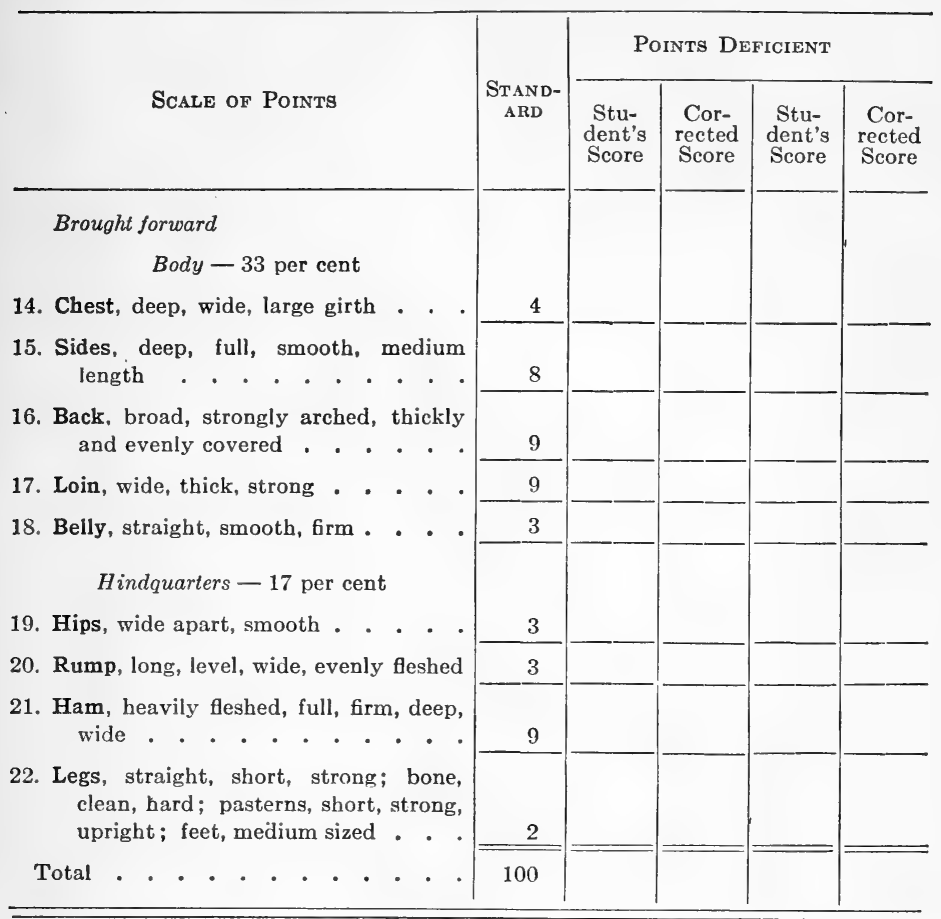




\section{EXERCISE 67}

\section{JUDGING MUTTON SHEEP}

Object. - To study the mutton sheep and observe those factors that affect its quality and worth.

Explanation. - Sheep may be divided into two general types based upon the purpose for which they are bred. One type is bred chiefly for the production of mutton and the other type principally for the production of wool. For mutton purposes the most desirable sheep to produce is the one that most nearly fills the market demands. The sheep that most nearly meets the market demand for mutton is the ideal described in the accompanying score card.

Equipment. - A good mutton sheep.

Directions. - Examine the animal carefully and estimate the value of each point given in the accompanying score card. Have in mind a clear understanding of the ideal mutton sheep. This may be gained by studying photographs of prize-winning sheep or by examining prize animals at fairs and stock shows. The standard score on the score card refers to the ideal animal. In judging each point record the number of points that the animal falls below the ideal. It is more difficult for beginners to judge sheep than any other class of live stock. On account of the length of the fleece it is difficult to determine by observation alone the form of the 
animal. It is necessary to handle every part of the sheep to determine its form. Therefore, sheep judging is done more with the hand than with the eye. To add to the difficulty of judging sheep by outside appearances nearly all showmen trim their sheep before placing them on exhibition. It is thus possible to cover up any weak points in the animal, and to make judging by any other method than that of handling absolutely impossible.

In handling sheep do not disturb or break the fleece. Hold the hand flat with the fingers together in a sloping manner. Press the hand over the fleece and feel the form in this manner. Do not stick the fingers into the fleece, it makes breaks and allows both dirt and water to enter. When studying the length of wool, place the two hands, palms downward, over the spot to be examined and separate the wool by slowly moving the hands apart while firmly pressing the wool. This spreads the fleece naturally and does not injure it in any way.

The accompanying photographs, Figs. 22 and 23, show the location of the points described on the score card that should be observed in judging a mutton sheep.

General Appearance 38 Per Cent. - Most mutton sheep are sold on the market while they are lambs, under one year of age. Lambs weighing in the neighborhood of eighty pounds usually sell at the highest price on the market. In general appearance the mutton sheep should present a fullness and smoothness of outline which indicates thick and evenly distributed flesh. The animal should show good quality, as indicated by a clean bone, silky fleece, and fine pink skin.

Head and Neck 7 Per Cent. - The head should show character and should be short and broad. The eyes should be 

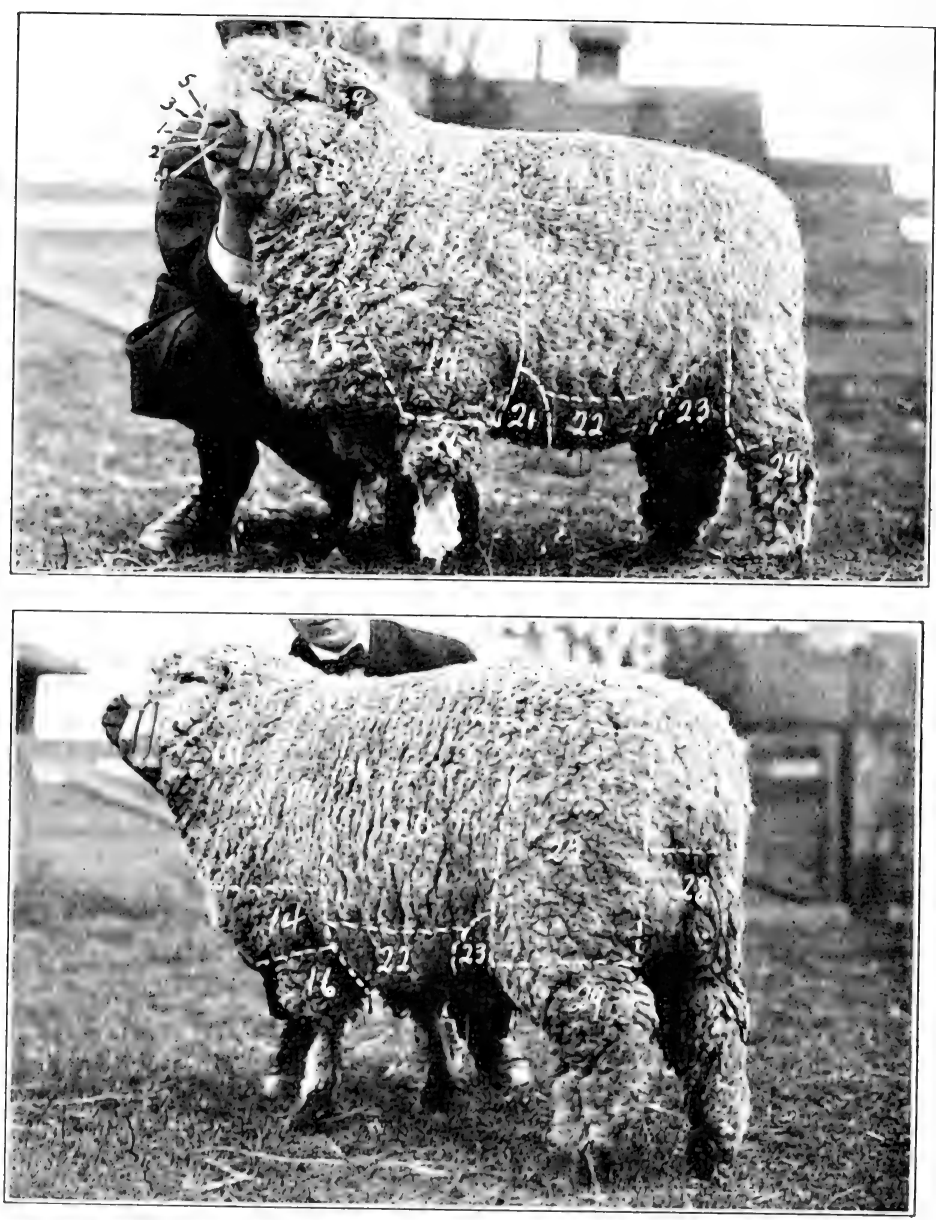

Figs. 22 and 23. - A mutron sheep, showing location of parts.
1. Muzzle
2. Mouth
3. Nostril
4. Lips
5. Nose
6. Face
7. Forehead
8. Eye

9. Ear

10. Neck

11. Shoulder vein

12. Top of shoulder

13. Shoulder

14. Chest

15. Brisket

16. Fore leg
17. Back
18. Loin
19. Hip
20. Ribs or side
21. Fore flank
22. Belly
23. Flank

21. Rump

2.). Leg of mutton or thigh

2t). Crop

27. Dock or tail

2S. Twist

29. Hind leg 
clean, bright, and placid. The muzzle should be broad and open, indicating feeding capacity. The neck should be thick, short, and set well into the shoulders.

Forequarters 7 Per Cent. - The shoulders should be compact on top, well covered with flesh, and of the required smoothness to give good form. The brisket should be neat and extend well forward. The breast should be wide and full, indicating health and a vigorous constitution.

Body 20 Per Cent. - The chest should be wide, deep, and full, and the ribs well sprung to give plenty of room for the development of the lungs, heart, and digestive system. The back should be broad, straight, of good length, and thickly fleshed, and the loin should also be thick and broad, for in this region is located some of the highest priced meat.

Hindquarters 16 Per Cent. - The leg of mutton, which represents over 40 per cent of the value of the mutton carcass, is located in the hindquarter. For this reason a good development of this portion of the animal is highly desirable from the butcher's standpoint. The rump should be long, level, and wide, thighs full and deep, twist plump, and legs straight, short, and strong.

Wool 12 Per Cent. - The wool should be of good length, dense, and evenly distributed over all parts of the body. A dense fleece is desirable because it produces more wool and affords greater protection to the sheep. The condition of the fleece should be good. It should be well supplied with yolk or oil, although too much is not desirable. It should be soft, light, and free from dirt and trash. The skin under the fleece should have a bright, pink color. A bluish tint is not desirable, as it indicates lack of vigor and health. 


\section{SCORE CARD}

\section{Mutton Sheep}

\begin{tabular}{|c|c|c|c|c|c|}
\hline \multirow[b]{2}{*}{ Scale of Points } & \multirow{2}{*}{$\begin{array}{l}\text { StAND- } \\
\text { ARD } \\
\text { ScORE }\end{array}$} & \multicolumn{4}{|c|}{ Points Deficient } \\
\hline & & $\begin{array}{l}\text { Stu- } \\
\text { dent's } \\
\text { Score }\end{array}$ & $\begin{array}{l}\text { Cor- } \\
\text { rected } \\
\text { Score }\end{array}$ & $\begin{array}{l}\text { Stu- } \\
\text { dent's } \\
\text { Score }\end{array}$ & $\begin{array}{l}\text { Cor- } \\
\text { rected } \\
\text { Score }\end{array}$ \\
\hline $\begin{array}{l}\text { Aeneral Appearance- }-38 \text { per cent } \\
\text { 1. Weight, score according to age . }\end{array}$ & 8 & & & & \\
\hline $\begin{array}{l}\text { 2. Form, long, level, deep, broad, low set, } \\
\text { stylish } \\
\text {. }\end{array}$ & 10 & & & & \\
\hline $\begin{array}{l}\text { 3. Quality, clean bone; silky hair; fine } \\
\text { pink skin; light in offal, yielding } \\
\text { high percentage of meat. . . . }\end{array}$ & 10 & & & & \\
\hline $\begin{array}{l}\text { 4. Condition, deep, even covering of firm } \\
\text { flesh, especially in regions of valuable } \\
\text { cuts. Points, indicating ripeness, are, } \\
\text { thick dock, back thickly covered } \\
\text { with flesh, thick neck, full purse, full } \\
\text { flank, breast. . . . . . . . . }\end{array}$ & 10 & & & & \\
\hline $\begin{array}{c}\text { Head and Neck }-7 \text { per cent } \\
\text { 5. Muzzle, fine; mouth, large; lips, thin; } \\
\text { nostrils, large and open. } . .\end{array}$ & 1 & & & & \\
\hline 6. Eyes, large, clear, placid . . . . . & 1 & & & & \\
\hline 7. Face, short, features clean-cut & 1 & & & & \\
\hline 8. Forehead, broad, full . . . . . & 1 & & & & \\
\hline 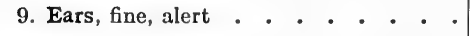 & 1 & & & & \\
\hline 10. Neck, thick, short, free from folds & 2 & & & & \\
\hline $\begin{array}{l}\text { Forequarters }-7 \text { per cent } \\
\text { 11. Shoulders, covered with flesh, compact } \\
\text { on top, snug } . . \\
.\end{array}$ & 5 & & & & \\
\hline $\begin{array}{l}\text { 12. Brisket, neat, proportionate; breast, } \\
\text { wide . . . . . . . . . }\end{array}$ & 1 & & & & \\
\hline Carried forward & & & & & \\
\hline
\end{tabular}




\section{Motton Sheep - Continued}

Scale of Points

Brought forward

13. Legs, straight, short, wide apart, strong; forearm, full ; shank, smooth, fine . . . . . . . .

$$
\text { Body }-20 \text { per cent }
$$

14. Chest, wide, deep, full . . . . .

15. Ribs, well sprung, long

16. Back, broad, straight, long, thickly

17. Loin, thick, broad, long . . . .

$$
\text { Hindquarters - } 16 \text { per cent }
$$

18. Hips, far apart, level, smooth . .

19. Rump, long, level, wide to tail-head .

20. Thighs, full, deep, wide

21. Twist, plump, deep

22. Legs, straight, short, strong; shank, fine, smooth

$$
\text { Wool - } 12 \text { per cent }
$$

23. Quantity, long, dense, even . . .

24. Quality, fine, pure; crimp, close, regu-

\begin{tabular}{|c|c|c|c|c|}
\hline \multirow{2}{*}{$\begin{array}{c}\text { Stand- } \\
\text { ARD } \\
\text { ScORE }\end{array}$} & \multicolumn{4}{|c|}{ Points Deficient } \\
\hline & $\begin{array}{l}\text { Stu- } \\
\text { dent's } \\
\text { Score }\end{array}$ & $\begin{array}{l}\text { Cor- } \\
\text { rected } \\
\text { Score }\end{array}$ & $\begin{array}{l}\text { Stu- } \\
\text { dent's } \\
\text { Score }\end{array}$ & $\begin{array}{l}\text { Cor- } \\
\text { rected } \\
\text { Score }\end{array}$ \\
\hline 1 & & & & \\
\hline 4 & & & & \\
\hline 4 & & & & \\
\hline 6 & & & & \\
\hline 6 & & & & \\
\hline 2 & & & & \\
\hline 4 & & & & \\
\hline 4 & & & & \\
\hline 5 & & & & \\
\hline 1 & & & & \\
\hline 4 & & & & \\
\hline 4 & & & & \\
\hline 4 & & & & \\
\hline 100 & & & & \\
\hline
\end{tabular}
lar, even

25. Condition 


\section{EXERCISES 68 AND 69}

\section{JUDGING A FARM ${ }^{1}$}

Object. - To study a farm and become familiar with the factors that affect its value.

Explanation. - The farm is the place of business and the manufacturing plant of the farmer. The farmer is a manufacturer as truly as the man who builds stoves from iron or the man who produces iron from the ore. As the manufacturer of stoves uses iron as raw material and produces stoves as the finished product, so the farmer uses the elements of nature, and manure or fertilizer, the plant food of the soil, as raw material, and from these produces grain and hay as finished products. He may carry the process of manufacture one step farther and by feeding the grain and hay to cattle, produce beef or milk as the finished product. The farm, therefore, is a manufacturing plant and should be as well suited to the type of farming that the farmer wishes to pursue as the shop that the manufacturer builds is suited to his business.

The farm, however, is more, or should be more, than a manufacturing plant merely. It should furnish a pleasant and healthful home for the farmer and his family. Thus, in judging a farm, both the advantages of the place for the

${ }^{1}$ Adapted from G. W. Warren's score card for judging farms. 
type of farming to be pursued and the desirability of the farm as a place to live must be considered.

Directions. - Go to a near-by farm and make a thorough examination of the place. Keep in mind the purpose for which the farm is being used, whether grain farming, dairying, fruit farming, general farming, etc. Make a journey over the fields, noting their shape, topography, character of the soil, drainage, and condition of the fences. After thoroughly examining the fields, return to the farmstead and observe the improvements, house, barn, orchards, water supply, etc.

After the farm has been thoroughly examined fill in the score of the different points on the accompanying score card. In scoring designate the condition of each point by marking with E., V.G., G., F., P., V.P., standing for excellent, very good, good, fair, poor, or very poor. The figures in the standard score give the relative importance of the different points that appear on the score card for a farm used for general farming. The distribution of points would be different in specialized farming. For instance, for truck farms all points that have to do with ease of tillage would be given a higher rating, while fertility would be of less importance.

Size 2 Per Cent. - The farm should not be too small. There are many farm operations that require two or more men for economical work, and a small farm requires as much machinery as a larger one. The fields should be long enough to be easily tilled, which is impossible on too small a farm. On the other hand, the farm should not be larger than it is possible to handle with the equipment and labor available.

Fields 6 Per Cent. - The fields should be of good shape. 
If they must be fenced, a square field is the most economical. They should be of sufficient size to till easily and should be arranged as near the barns or feed lots as possible.

Topography 6 Per Cent.- The farm should be level enough to make tillage easy and to prevent loss of fertility by washing and the loss of soil by erosion. The fields should be rolling enough to furnish good, natural drainage.

Fertility 12 Per Cent. - The soil should be in as high a state of natural fertility as possible. A soil in a low state of natural fertility cannot be made productive without the extensive use of expensive fertilizers.

Physical Properties of the Soil 12 Per Cent.- The physical properties of the soil are as important as the soil's fertility. They determine the ease and earliness at which the soil can be worked.

Drainage 5 Per Cent.-The soil should be well drained, either naturally or artificially. It is unprofitable to farm poorly drained land.

Condition 5 Per Cent.-Condition refers to waste land, weeds, stone, stumps, etc. It is generally cheaper to buy a farm in good condition than to improve one in this respect.

Climate. - While not given a score, climate should be considered in judging a farm, especially when topography or proximity to water influences the climate of different farms in the community.

Healthfulness 4 Per Cent. - From a personal standpoint the healthfulness of the farm might be the most important fact to consider, and even from an economical standpoint it is an important factor.

Location 25 Per Cent.- The location of the farm is undoubt- 
edly the most important factor influencing its value. The distance to railways and markets influences greatly the cost of producing farm products and is the most important factor in determining the kind of farming to be practiced on the farm. Many kinds of farming, such as gardening and fruit growing, are possible if the farm is located a great distance from markets and railroads. The labor supply, the neighbors, the conveniences, such as telephone, trolleys, and rural mail routes, should be observed in considering the location of the farm. The distance to school, church, grange, etc., should also be considered.

Taxes 1 Per Cent. - Taxes should be considered, for some farms admirably located near cities may be less desirable on account of the high tax rate.

Water Supply 4 Per Cent.- Running streams always add to the value of a farm. If running water is not present, the farm should have good wells.

Improvements 18 Per Cent. - The house, barns, and other buildings should be suitable to the farm. Too extensive buildings or too poor or too small buildings are not desirable. The condition of the fences and their arrangement should be considered. Good orchards and vineyards are an asset to a farm. 


\section{SCORE CARD FOR FARMS}

\section{NAME OF FARM}

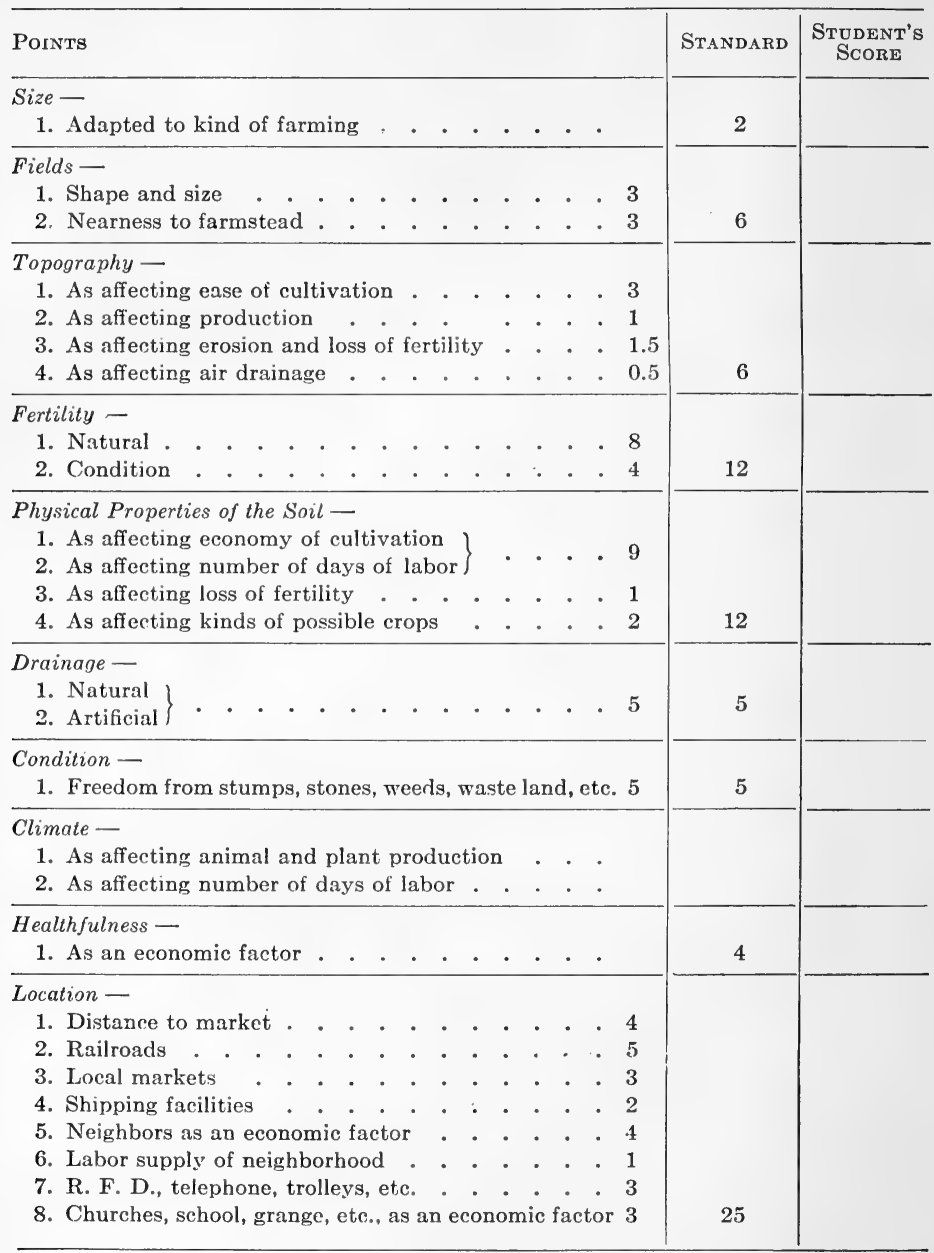




\section{Score Card for FARMs - Continued}

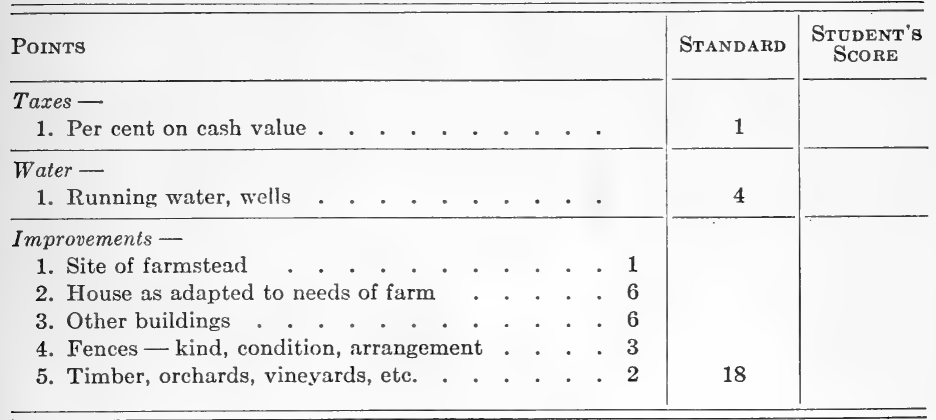

Total acres,

Acres tillable,

Per cent pasture,

Acres, pasture not tillable,

Acres, woods,

Acres, roads, waste, etc.,

Estimated total value of.

Tillable area,

Pasture,

Woods,

Barns,

Houses,

Total,

Average value per acre,

Price asked,

Is the farm worth the price asked? 
What is the probable increase in land value of this farm?

Give the striking desirable features of the farm.

Give the striking undesirable features of the farm. 


\section{EXERCISE 70}

\section{PLANNING THE HOME FARM}

Object. - To study the shape and arrangement of the fields of a farm in order to suggest ways for improvement.

Explanation. - The cost of operating a farm is greatly influenced by the way in which the fields are laid out and arranged. On some farms, due to poor arrangement of the fields, it is often necessary to haul the crops produced a much greater distance to the barn or feed lot than would be necessary if the fields were more systematically arranged. The cost of fencing or cultivating fields poorly shaped and arranged is often greater than would be necessary with a better arrangement.

In laying out the fields of a farm there are a number of factors that should be observed :

1. The fields should be arranged so that long stretches of land may be cultivated without turning. It is always cheaper to cultivate long rows than short ones. Therefore, if the farm is small, the fields should be long and narrow.

2. The roadways to the fields should be arranged to permit easy and direct access to all parts of the farm.

3. The buildings should be so located that the haul to the fields will be as short as possible. The ideal arrangement on a large farm is to have the buildings centrally located. 
4. The fields should be arranged to provide for a good rotation of crops.

5. The fields should be arranged to reduce the cost of fencing to the minimum. As far as possible, the fences should run straight and at right angles to each other. A farm that has straight fences, roads, and fields presents a neat appearance.

Equipment. - A foot rule divided into one-sixteenth inch divisions.

Directions. - Make a drawing showing the plan of your home farm. Show the arrangement of fields, the position of the barns, feed lots, orchards, etc. If there are any wood lots on the farm, show their location and size; show also the position of any waste lands, streams, etc. Show all fences, lanes, and roads on the place. Indicate on the map the crop that was on each field last year. Indicate also the crop that will be on the field next year.

Make a careful study of the arrangement of the farm to see if the fields could be more conveniently arranged or changed in shape so that the expense for fencing would be less. Redraw the plan of the farm, making all changes that you think would better the farm in any way. 


\section{STUDENT'S NOTES AND REPORT}




\section{EXERCISE 71}

\section{THE ARRANGEMENT OF FARM BUILDINGS AND PLANTINGS}

Object.- To study the arrangement of the buildings and plantings of a farm.

Explanation. - The buildings and plantings around the farm home are usually located in what is called the farmyard. The farmyard affords a setting for the buildings, provides access to the highway, well, and outbuildings, and provides space for various kinds of work. Everything about the yard should be convenient, the grades should be easy, the surface should be smooth and easy to mow, the walks should be pleasant, and the drives smooth and clean.

The plantings around the farm buildings should be plain and simple. The trees and shrubs, to look best, should not be set in rows, but should be bunched around the sides of the yard and at the rear. It is usually advisable to have the center of the yard open to the front to afford a good view of the road from the house. The large plantings, such as trees, should be at the rear of the buildings and at the sides of the yard, where they will furnish shade and a background for the house without obstructing the view. Care should be taken not to overcrowd the house with trees. Shrubs should be planted plentifully, but always in groups or clumps, and 
not as scattering plants. Common shrubs growing wild in fields are often more attractive to plant than uncommon shrubs that come from the nurseries. The flower gardens and vegetable gardens should be at one side or in the rear of the house. It is often desirable to plant low-growing plants against the foundation of the house.

The barns and other outbuildings should be conveniently located at one side or in the rear of the house and should be connected by as few walks as will serve the needs of those using them.

In general appearance the place should look simple, large, and generous, and should have a free, countrylike appearance. All parts of the place, and especially the yard, should have good care.

Equipment. - A foot rule with one-sixteenth inch subdivisions.

Directions. - Make a drawing of a farm site, showing the size and location of the yard, garden, orchard, feed lots, roads, lawns, etc. Show the location of the house, barn, well, and all outbuildings. Show the location of all trees and shrubs used in the plantings around the yard. Make a list of the trees and shrubs you know that would be suitable for planting in the farmyard. 


\section{STUDENT'S NOTES AND REPORT}


294 LABORATORY MANUAL OF AGRICULTURE STUDENT'S NOTES AND REPORT 


\section{EXERCISE 72}

\section{THE GEOGRAPHICAL DISTRIBUTION OF CORN}

Object. - To study the geographical distribution of corn over the United States.

Explanation. - The most important farm crops are usually produced where the conditions of environment are most favorable to their growth and development. The Corn Belt of the United States lies in the Central States in the valleys of the Mississippi River and its tributaries. Nearly all the states produce corn, but three fourths of the corn crop of the United States is produced in less than ten states, which are known as the Corn Belt.

Equipment. - Yearbook of the United States Department of Agriculture.

Directions. - Record in tabular form the total and acre yield of corn for each state in the United States. On the accompanying map show the distribution of corn by placing a star in each state for each $10,000,000$ bushels of corn produced. For each state producing less than 10,000,000 bushels record on the map the amount produced. 
296 LABORATORY MANUAL OF AGRICULTURE STUDENT'S NOTES AND REPORT 
STUDENT'S NOTES AND REPORT 


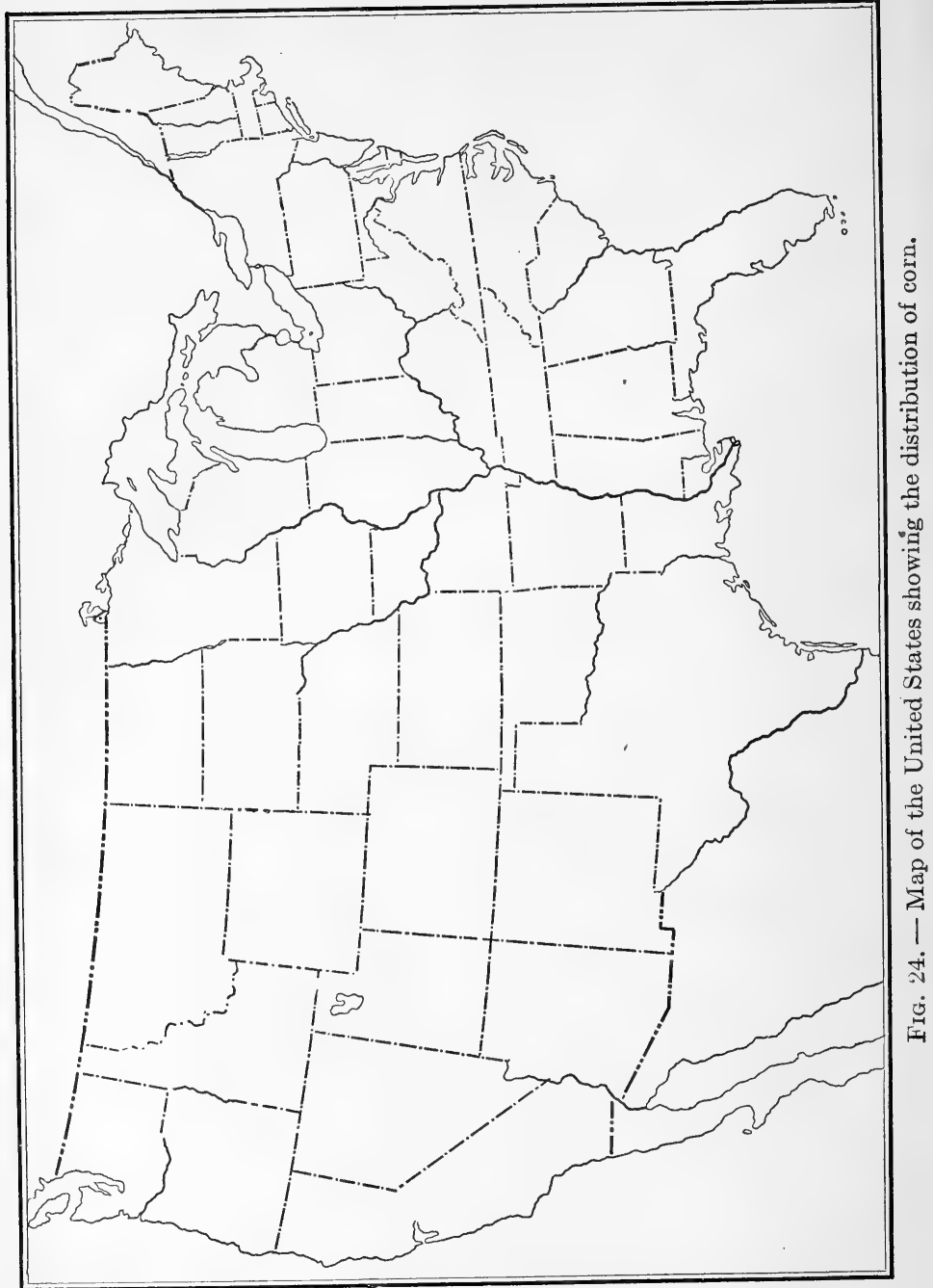




\section{EXERCISE 73}

\section{THE GEOGRAPHICAL DISTRIBUTION OF WHEAT}

Object. - To study the geographical distribution of wheat over the United States.

Explanation. - Wheat is adapted to growth in warm, temperate, and cool climates, and on various types of soils. Because of its general adaptation, it is widely distributed over the United States.

Equipment. - Yearbook of the United States Department of Agriculture.

Directions. - Record in tabular form the total and acre yield of wheat for each state in the United States. On the accompanying map indicate the distribution of wheat by placing a star in each state for each $5,000,000$ bushels of wheat produced. For each state producing less than 5,000,000 bushels record on the map the number of bushels produced. 
300 LABORATORY MANUAL OF AGRICULTURE STUDENT'S NOTES AND REPORT 
STUDENT'S NOTES AND REPORT

\section{STUDENT'S NOTES AND REPORT}




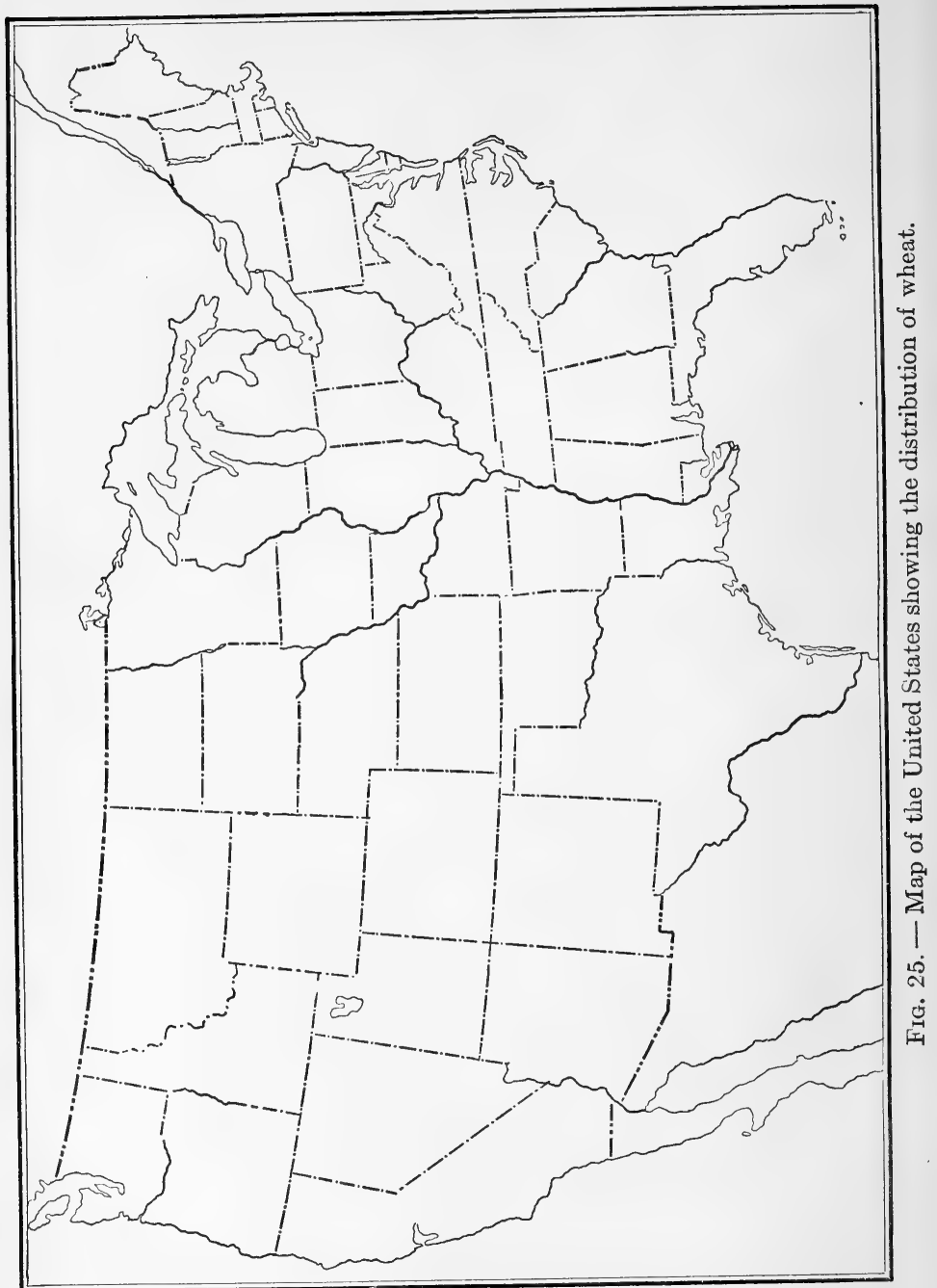




\section{EXERCISE 74}

\section{THE GEOGRAPHICAL DISTRIBUTION OF OATS}

Object. - To study the geographical distribution of oats over the United States.

Explanation. - Oats will grow in practically all localities in which wheat will grow. When grown in the same districts with wheat, it is usually grown in rotation with wheat and other crops. It reaches its highest development on the better lands and in a climate which is medium, moist, and cool. Of all the grains it ranks next to corn in number of bushels produced in the United States.

Equipment. - Yearbook of the United States Department of Agriculture.

Directions. - Record in tabular form the total and acre yield of oats for each state in the United States. On the accompanying map indicate the distribution of oats by placing a star in each state for each 5,000,000 bushels of oats produced. For each state producing less than 5,000,000 bushels record on the map the amount produced. 
304

LABORATORY MANUAL OF AGRICULTURE

STUDENT'S NOTES AND REPORT 


\section{STUDENT'S NOTES AND REPORT}




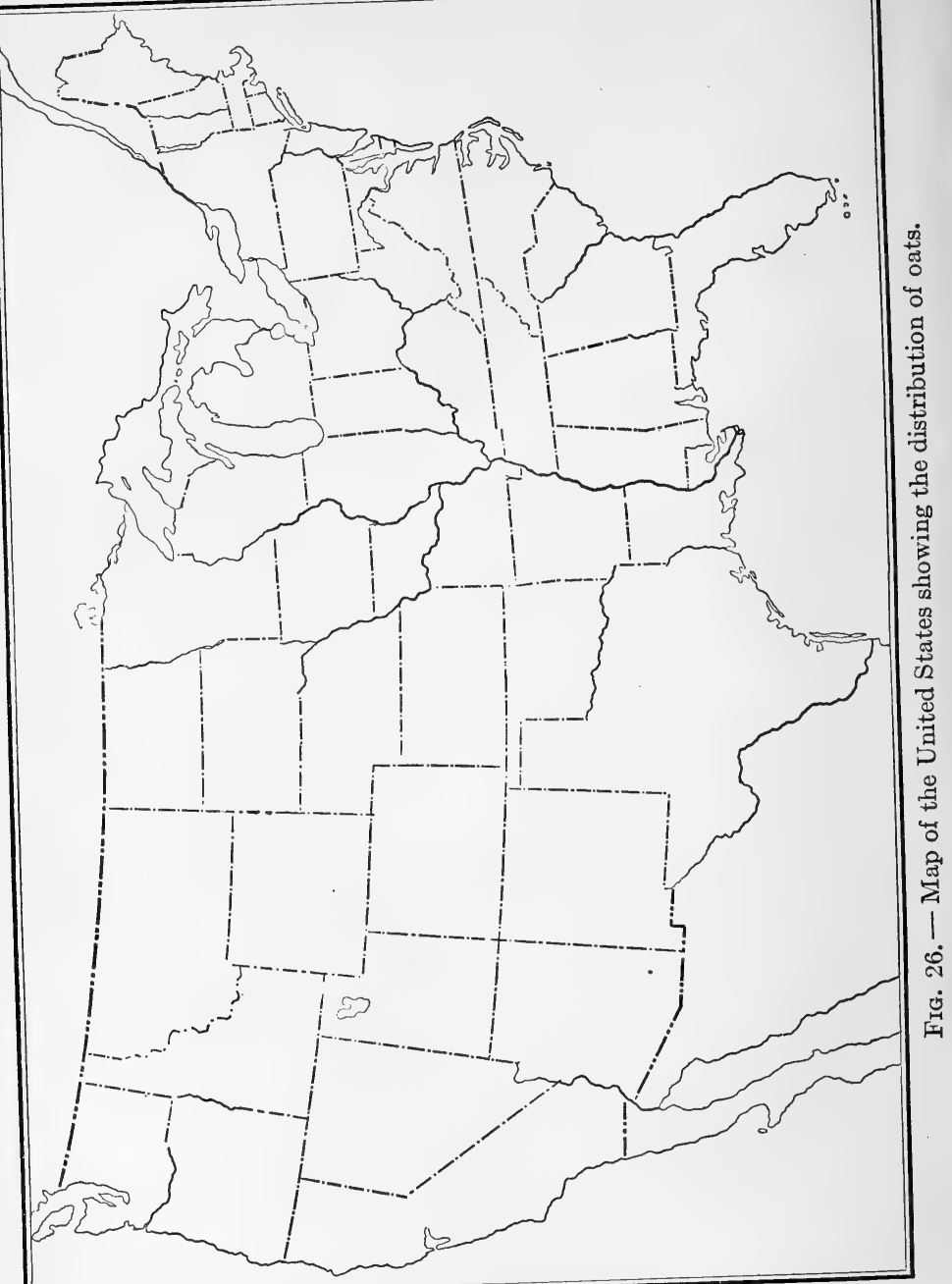




\section{EXERCISE 75}

\section{THE GEOGRAPHICAL DISTRIBUTION OF POTATOES}

Object. - To study the geographical distribution of potatoes over the United States.

Explanation. - Potatoes are generally grown throughout the United States, but the localities in which they develop best are restricted. Maximum yields are usually produced on a well-drained, sandy loam soil that contains an abundance of humus.

Equipment. - Yearbook of the United States Department of Agriculture.

Directions. - Record in tabular form the total and acre yield of potatoes for each state in the United States. On the accompanying map show the distribution of potatoes by placing a star in each state for each 5,000,000 bushels of potatoes produced. For each state producing less than $5,000,000$ bushels record on the map the amount produced. 


\section{STUDENT'S NOTES AND REPORT}




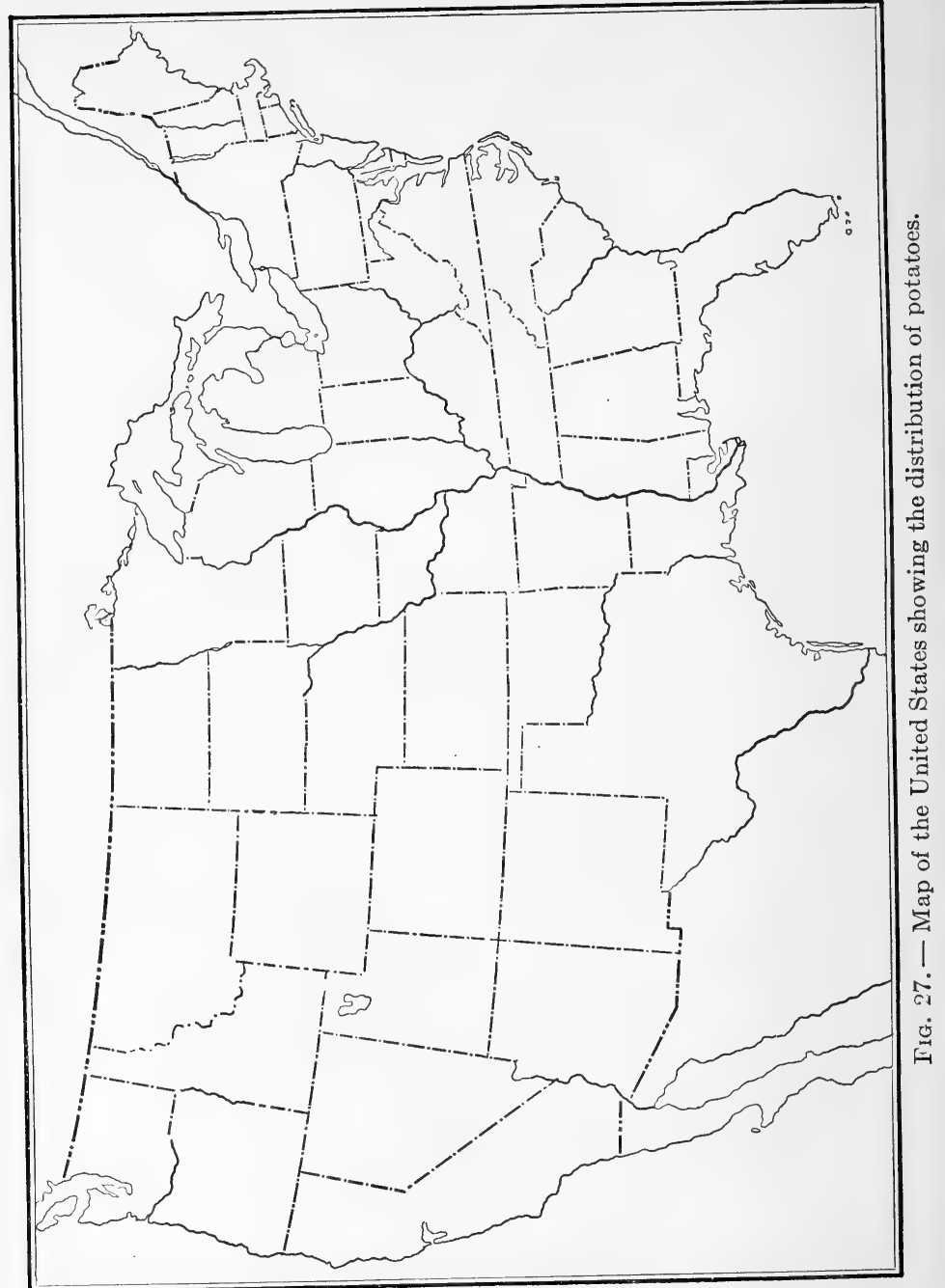




\section{EXERCISE 76}

\section{TREE IDENTIFICATION}

Object. - To study trees and become familiar with their general form, method of branching, shape and arrangement of leaves, and character of bark.

Explanation. - There are many kinds of trees, presenting a great variety of shapes and individual characteristics. The form of trees differs; some grow tall and slender, while others are spreading and grow close to the ground. The number of branches and their arrangement vary greatly. The shape, size, and arrangement of leaves are individual characteristics and may be used in distinguishing different kinds of trees. Botanical classification is based largely upon the method of reproduction, and upon the kind and character of the seed vessels and seed coverings.

Directions. - Go to the city park or a near-by.woods and make a list of as many trees growing there as you can identify. Select a typical elm, maple, and ash, and make a drawing of each. The drawing should show the outline form of the tree and the arrangement of the branches. What is the difference in the shape of these trees? What is the principal difference in the arrangement of the branches? 
Select a twig one foot to eighteen inches long from each of these trees and make a drawing of each, showing the shape of the leaves and their arrangement on the twigs.

Describe the difference in the shape of the leaves and in their arrangement. 
STUDENT'S NOTES AND REPORT 
314 LABORATORY MANUAL OF AGRICULTURE

\section{STUDENT'S NOTES AND REPORT}




\section{EXERCISE 77}

\section{STARTING PLANTS BY CUTTINGS}

Object. - To prepare cuttings for setting in pots and in the nursery.

Explanation. - A cutting is a small portion of a plant removed from the parent and placed under proper conditions for favorable growth. Cuttings may be made from many hard wood and herbaceous plants. Wood cuttings should be collected in the fall and stored in a cellar during the winter, where they will partly heal over. Herbaceous cuttings may be taken directly from the green plant and placed in the starting box.

Equipment. - 1. Twigs of grape and willow or cottonwood which have been stored in the cellar during the winter.

2. Plants of geranium or wandering jew.

3. A starting box two by three feet, one foot deep.

Directions. - Fill the starting box with sand and wet it thoroughly. Use the twigs or branches of grapevines and willow or cottonwood that were collected and stored in Ex. 15. Remove all but two buds on the top part of the plant. Make holes in the sand with a sharp stick or lead pencil about three inches apart. Insert the twigs in the holes and press the sand firmly about them.

Obtain small slips or branches of the geranium or wandering 
jew. They should be from one to three inches long. Remove some of the leaves. This will reduce the amount of moisture lost by transpiration while the roots are becoming established. Place the slip in the sand one to two inches deep, as in the case of the wood cuttings. If possible, the bottom of the box should be kept at a higher temperature than the air above. Keep the sand well watered. The hard wood cuttings may be transferred to the nursery and the herbaceous plants to pots after their root systems are established. 


\section{EXERCISE 78}

\section{POTTING PLANTS}

Object. - To study and practice methods of potting plants.

Explanation. - Small seedlings or cuttings are often potted in the greenhouse previous to setting in the soil out of doors. Flowering plants and ferns are often left in the pot for an indefinite length of time. The process of potting a plant is quite simple, and can be properly accomplished with a little thought and practice. The plant should be well placed in the center of the pot neither too deep nor too high. The size of the pot should correspond to the size of the plant. When the plant becomes too large for the pot, it should be repotted. The bottom of the pot should be open to allow drainage, and the soil should contain sufficient fine gravel and sand to insure perfect drainage.

Equipment. - 1. Ten three-inch flower pots.

2. Ten geranium plants four weeks old, from cuttings.

3. A loam soil.

4. Small amounts of gravel and sand.

Directions. - Prepare the soil for potting by mixing together three parts of loam, one part of thoroughly rotted manure, and one part of sand. Fill the pot with gravel to a depth of one half inch. Sprinkle over the gravel a sufficient 
depth of the prepared soil so that the plant will have the proper position in the pot when its roots just touch the soil. Remove a plant from the starting box and place it in position in the pot. Spread the roots of the plant out well and sprinkle prepared soil between them. Press the soil firmly about the roots and stem. Fill the pot with soil to within one half inch of the top. Add water slowly until it starts to run from the drain at the bottom of the pot. Place the pot in the laboratory window or in some other convenient place where it will have sufficient light and heat for growth. Water the plant at frequent intervals to keep it in good growing condition. Pot each plant in a similar manner. 


\section{STUDENT'S NOTES AND REPORT}




\section{EXERCISE 79}

\section{THE DAIRY HERD RECORD ${ }^{1}$}

Object.-To keep a record of the production of milk and butter fat of a herd of dairy cows.

Explanation. - It is impossible to determine the value of a dairy cow for milk or butter fat production without keeping a record of her products. The products of the dairy cow are usually sold from the farm in one of the following ways: first, as milk, either retail or wholesale; second, as cream to creameries or to retail trade; third, as butter sold direct from the farm. In keeping records of the cows the disposition made of the milk should be considered and the profits figured on these terms. When whole milk is sold, the milk record of each cow should be kept. When the milk is separated and the cream sold on the butter-fat basis, a record should be kept of the pounds of butter fat produced by each cow. When the butter is sold direct from the farm, it is equally important to know the record of each cow.

Equipment. - Spring balance scales weighing to one fourth pound.

Directions. - Let each student who can do so keep a record of the dairy cows on his home farm for one month.

${ }^{1}$ Adapted from O. E. Reed, A Dairy Primer, Chapters in Elements of Agriculture, Kansas State Agricultural College, Manhattan, Kansas. 
Rule a sheet of paper as the accompanying milk record sheet in "Student's Notes and Report" 1 is ruled. Tack the milk record sheet on the wall in the barn, near the cows. Suspend the pair of spring balance scales from the ceiling near the milk sheet. Fasten a lead pencil to a spring and attach it to the wall near the milk sheet. Keep a record of the milk of each cow for one month. (To determine the value of a cow for milk production, a complete record must be kept of the mi'k produced from the time she freshens until she is dry.) A test of each cow's milk for butter fat should be made at the beginning and end of the month. To secure a sample of the milk for testing, take a small quantity (about three tablespoonfuls) of the milk of each cow from each milking for two days. The milk should be thoroughly mixed before sampling. Place the milk from each cow in a separate bottle and label. Test each sample for butter fat by means of the Babcock test (Ex. 52).

Figure up the total amount of milk given by each cow during the month. Determine the value of the milk sold from each cow during the month. If whole milk is sold, figure the value in pounds or gallons. A gallon of milk weighs 8.66 pounds. If cream is sold, figure the value of the butter fat from each cow. Get the market price of whole milk and the market price of butter fat in your community and figure in which way it would be the most profitable to sell your milk.

${ }^{1} \mathrm{~A}$ milk record sheet ean undoubtedly be obtained without cost from your State Agricultural College or Experiment Station. 


\section{STUDENT'S NOTES AND REPORT}

\section{Milk Record Sheet}

Milk Record

For the Month Ending.........191

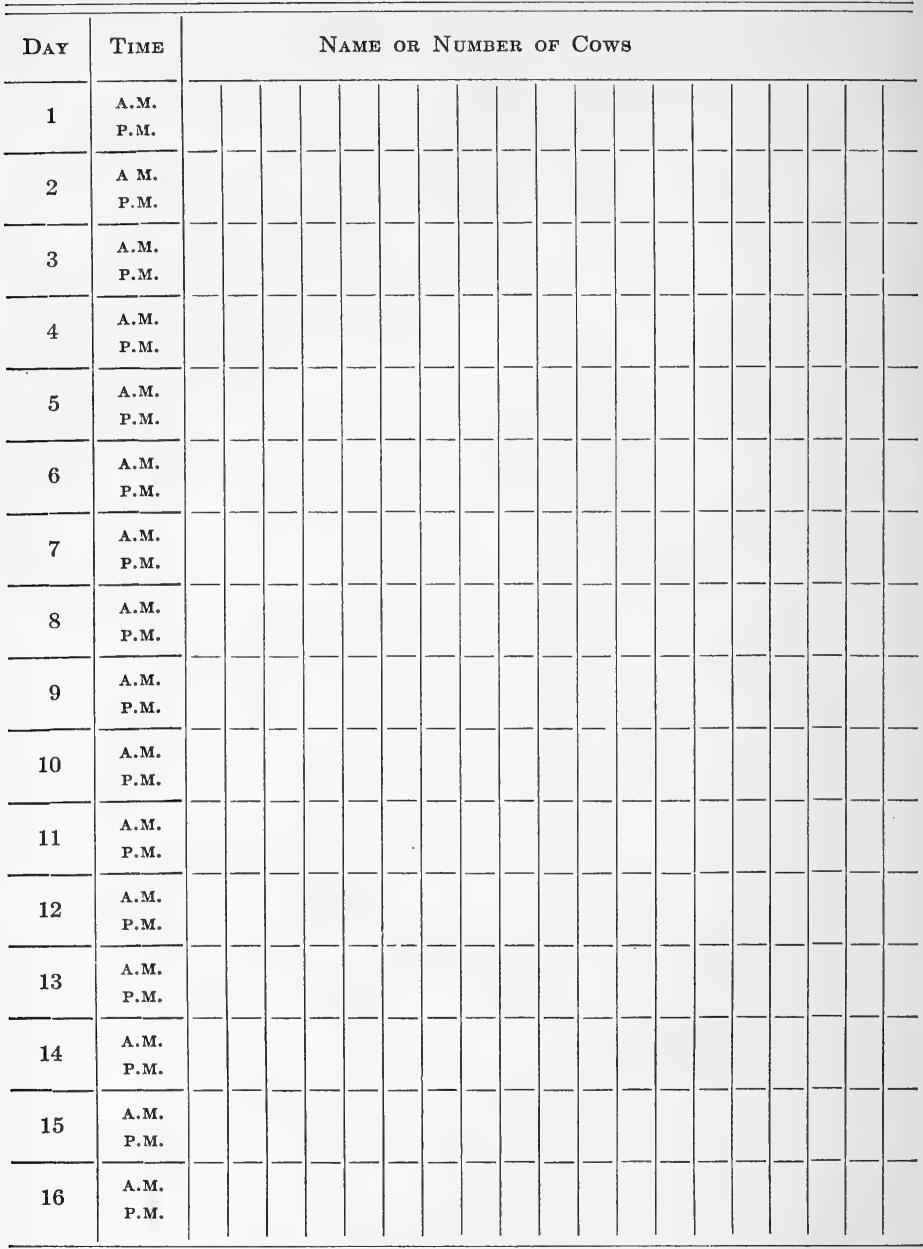




\section{Milk Record Sheet-Continued}

MiLk Record

For the Month Ending..........191

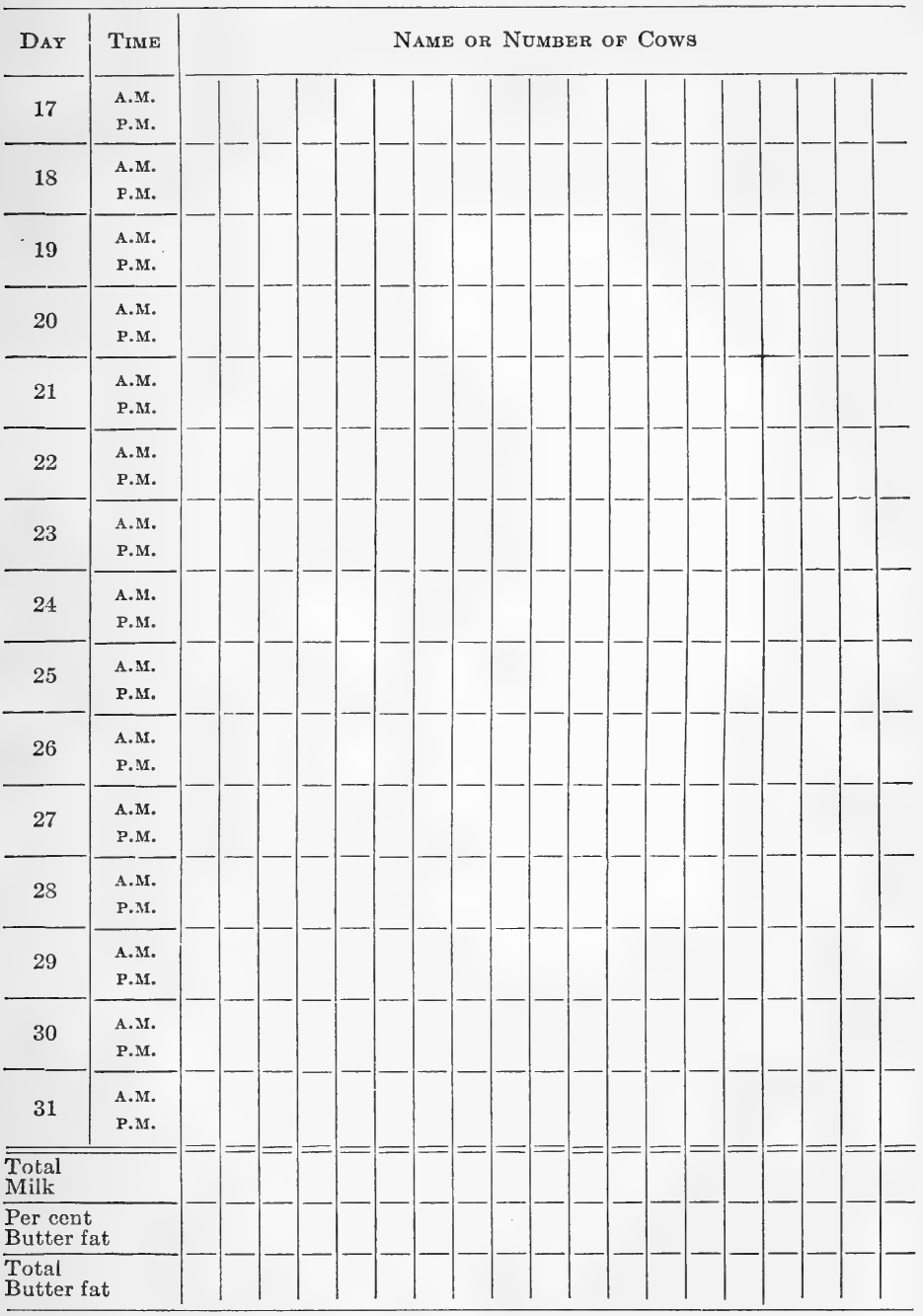




\section{EXERCISE 80}

\section{A STUDY OF THE EGG ${ }^{1}$}

Object. - To study the egg and become familiar with its parts.

Explanation. - In structure the egg consists of three principal parts : the shell, white, and yolk. The eggshell is a structure composed principally of lime for the purpose of protecting the egg. Just under the shell are two thin, tough membranes that serve further to protect the egg and prevent its drying out too rapidly. Near the larger end of the egg is usually found an air space. This air space is comparatively small when the egg is fresh, but becomes larger as the egg grows older, due to the drying out and shrinking of the white and yolk of the egg. The size of the air space serves as a means of determining the age of the egg. The air space is for the purpose of furnishing a ready supply of fresh air to the young developing chick. The air space lies between the outer and inner membranes.

The white of the egg consists of three important parts: the outer, thicker albumen; the inner, thinner albumen; and the chalaza. The albumen supplies in liquid form the food by which the chick grows within the shell. The chalaza consists of white cords of denser albumen that adhere to the

${ }^{1}$ Adapted from J. E. Rice in the Cornell Rural School Leaflet, Vol. I, No. 2. 
side of the yolk toward either end. These cords serve to keep the yolk suspended properly within the albumen.

The yolk of the egg consists of three parts: the germ spot, light yolk, and dark yolk. The germ spot appears as a light-colored spot usually found on the upper surface of the yolk. It is from this germ that the young chick develops.

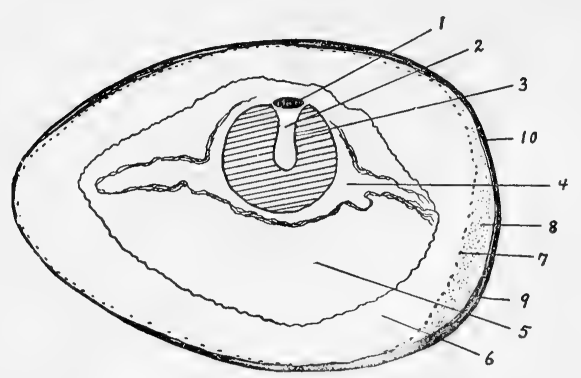

FIG. 28. - Sections of an egg. 1, germ spot;

2 , light yolk; 3 , dark yolk; 4, chalaza;

5 , the inner, thinner white or albumen;

6 , the outer, thicher white or albumen;

7 , inner membrane; 8 , air space; 9 , outer membrane; 10 , shell.

There is a tendency for the yolk to float at the surface of the egg. It is therefore necessary to turn frequently eggs that are to be used for hatching. If the egg is not turned frequently, the yolk will rise until the germ comes in contact with the shell membrane. It will then become dry by evaporation and adhere to the membrane. If the egg is then turned, the germ will be killed. Figure 28 shows a cross section of an egg.

Equipment. - 1. Two eggs, one light and one dark, for each member of the class.

2. Two saucers for each member of the class.

3. A sauce pan.

4. Some means of boiling an egg. ${ }^{1}$

5. A knife.

${ }^{1}$ If the eggs cannot be boiled at school, have each student bring a boiled egg from home. 
6. An egg tester which may be made from a box large enough to hold a small lighted lamp. In the box opposite the lamp cut a hole slightly smaller than the egg.

Directions. - Examine several eggs in the egg tester by holding them in the hole of the egg tester and looking through the egg toward the light. The egg tester must be used in a darkened room. Observe the size of the air space. The size of the air space gives some indication of the age of the egg. A spoiled egg does not look clear and distinct as a fresh egg does.

Break a fresh, uncooked egg in a saucer by separating the shell in the middle. Observe the germ on the upper surface of the yolk. Note the chalaza and the transparent watery appearance of the albumen. Examine the shell and observe the air space and the two outer membranes best seen at the air space. Note the pigment of the shell which gives the egg its color.

Boil an egg hard. Crack the large end of the egg and remove the shell piece by piece. Observe the air space and the two outer membranes. Cut the egg lengthwise and make a drawing of the longitudinal section showing:

1. The air space.

2. The two outer membranes.

3. The three layers of the white.

4. The white yolk and the dark yolk.

5. The germ. 


\section{EXERCISE 81}

\section{A STUDY OF THE RICE HEAD}

Object. - To examine the head of rice and become famil-

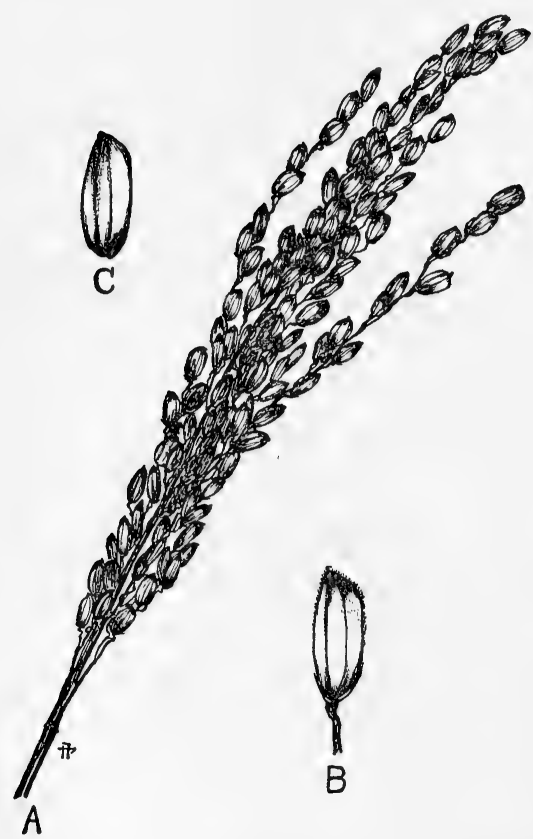

Fig. 29. - $A$, a head of rice; $B$, a single spikelet; $C$, the kernel of rice with glumes and palea removed. iar with the shape and arrangement of its different parts.

Explanation. - The head of rice is commonly called a panicle. It is composed of a branching stem with spikelets attached. Each spikelet contains but one kernel. The kernel is inclosed within a flowering glume on one side and the palea on the other. The flowering glume incloses about two thirds of the kernel. The outer glumes in rice do not cover the flowering glumes, but are small 
projections at the base of the kernel. The kernel is flatoval in shape with lines or small depressions running from top to bottom. The spikelets are placed singly at various intervals along the branches. Figure 29 shows the rice head. Equipment. - Heads of rice for each member of the class.

Directions. - Make a drawing of the entire head of rice. Remove a spikelet and make a drawing of it. Draw the outer glumes; a single flowering glume; and the palea. Make a drawing of the kernel showing the broad or side view, one showing the germ side, and one showing the cross section. Make all drawings at least four times natural size, except the one of the panicle. Make them in careful detail and show all the different parts. 
STUDENT'S NOTES AND REPORT 


\section{EXERCISE 82}

\section{TREE PLANTING}

Object. - To observe the conditions which are necessary for the successful transplanting of trees and shrubs.

Explanation. - Trees are usually started in the nursery, where at small cost special attention may be given them during their early development. Desirable shade trees often may be obtained along the creek bank or in the wood lot. Small trees may be safely transplanted after they have made two or three years' successful growth in the nursery. Trees may be reset either in the fall or in the spring. Spring planting is usually more successful. They should be transplanted when they are in a dormant stage just before the buds begin to swell.

There are three distinct steps in tree transplanting. They are: removing the tree from the soil, preparing the tree for resetting and transferring it to its new location, and replacing it in the soil.

In removing the tree from the soil care should be taken not to injure the roots. In preparing it for transplanting, the top should be cut back. This will reduce the leaf surface and amount of transpiration as the plant begins to grow. If this is not done, the tree may be stunted or perhaps may even die while the root system is becoming established. All 
injured limbs or injured roots should be removed with a sharp knife. The roots should not be allowed to become dry through exposure to the sun during the transfer to the new location.

The hole for resetting must be sufficiently large to accommodate the roots without crowding them. After the tree has been properly adjusted in its new location, loose soil should be worked in carefully about its roots. The soil should be compacted about the roots so that they will more readily s $^{+}$art. The soil on the surface should be left loose to serve as a mulch.

Equipment. - A good shade tree.

2. Spade.

3. Pruning knife.

Directions. - Select a desirable tree from the nursery or wood lot. It is best to use a tree two or three years old. Dig around it and remove it from the soil, injuring as few roots as possible. Keep the roots covered while transferring it to its new location. Cut the top back and remove all undesirable branches. Dig a hole sufficiently large to accommodate all the roots. Adjust the tree properly and fill in between the roots with loose soil. Compact the soil firmly about the roots. Water the tree when you have the hole about two thirds full of dirt. Fill the hole level to the top with loose soil. 


\title{
APPENDIX
}

\author{
SECTION I
}

\section{EQUIPMENT ${ }^{1}$}

Amodnt Necessary for a Class of Ten Students

1 Babcock testing outfit $(c)$.

1 balance, torsion, weighing to $\frac{1}{10}$ gram $(b)$.

1 balance, spring $(a)$.

1 basket, $\frac{1}{2}$ bushel $(a)$.

6 beakers, 500 c.c. (b).

1 burner, alcohol or gas $(b)$.

1 crock, 4-gallon $(a)$.

2 crocks, 2-gallon $(a)$.

1 The letter in parenthesis following the items of equipment refers to the place where the equipment may be secured :

(a) Local dealer. (b) Chemical Supply Houses. (c) Creamery Package Manufacturing Co., Chicago, Ill. (d) Central Scientific Co., Chicago, Ill. (e) The authors of this Manual will supply a limited number of sets of type samples of grain for secondary school work at a price sufficient to cover cost of material and packing. (See suggestions to teachers.) ( $f$ ) Bausch \& Lomb Optical Co., Rochester, N.Y. $(g)$ E. and T. Fairbanks \& Co., St. Johnsbury, Vt. (h) Apple seedlings can usually be purchased in lots of 100 from nurseries at very small cost.

Note. - The following are a few reliable chemical supply houses : E. H. Sargent \& Co., Chicago, Ill.; Bausch \& Lomb Optical Co., Rochester, N.Y.; Eimer \& Amend, New York City, N.Y. 
4 cylinders, evaporation $(d)$.

6 cylinders, percolation, with rack and supply tank $(d)$.

1 cylinder, graduated 100 c.c. (b).

10 forceps $(b)$.

4 glass plates, 3 inches square $(a)$.

1 grain, set of type samples of $(e)$.

1 knife, long-bladed $(a)$.

6 jars, Mason, 1 quart (a).

10 lenses, hand $(a)$.

1 microscope, magnifying to low power $(f)$.

6 microscope slides $(f)$.

1 oilcloth, 18 inches square $(a)$.

1 pan, galvanized iron $5 \times 14$ inches, 3 inches deep $(a)$.

12 pans, tin, 6 inches in diameter (pie pans) $(a)$.

50 plates, paper $(a)$.

2 pots, flower, 6 inches in diameter $(a)$.

10 pots, flower, 3 inches in diameter $(a)$.

1 pruning shears $(a)$.

1 pruning saw $(a)$.

1 pruning knife $(a)$.

1 rule, foot, division $\frac{1}{16}$ inch $(a)$.

1 sieve, for sifting soil, 12 meshes to inch (a).

1 saucepan, 2 quarts (a).

20 saucers (a).

1 scales, weighing $100 \mathrm{lb}$., accurate to $\frac{1}{4}$ pound (a).

1 shears $(a)$.

1 soil auger, 3 feet in length $(a)$.

1 string, ball $(a)$.

1 tape line, 100 feet in length $(a)$.

4 test tubes, large size $(b)$.

11 thermometers, chemical $(b)$.

4 tubes, glass, 3 feet long, 1 inch in diameter $(b)$.

6 wash pans $(a)$.

1 weight-per-bushel tester $(g)$. 


\section{SUPPLIES}

The most of which ean be provided by the teacher or secured at a small cost.

100 apple seedlings, one year old $(h)$.

2 boxes $2 \times 3$ feet and 1 foot deep (starting boxes).

1 box, large, for storing cutting and grafting material.

1 pound beeswax.

5 yards cheese cloth.

30 grams copper sulphate.

1 corn tester, for germinating seed corn.

24 eggs.

1 egg tester, for candling eggs.

Grain in the following amounts :

1 pound alfalfa seed.

4 pounds beans.

Barley -

4 ten-pound lots of different samples of barley.

1 bundle of barley heads.

1 pound clover seed.

1 pound sweet corn.

Field corn -

12 ten-ear samples.

4 ten-pound lots of different samples of shelled corn.

$\frac{1}{2}$ bushel of shelled corn.

Cowpeas -

2 six-pound lots of different samples.

1 pound grass seed (timothy, orchard grass, or redtop). Oats -

4 ten-pound lots of different samples of oats.

$\frac{1}{2}$ bushel of oats.

A bundle of oat heads.

Rye-

4 ten-pound lots of different samples of rye.

A bundle of rye heads.

Sorghum -

4 ten-pound lots of different samples of sorghum.

Heads of milo, kafir, and sweet sorghum. 
Wheat -

4 ten-pound samples of different lots of wheat.

A bundle of wheat heads

1 bushel of uncleaned wheat.

2 pints milk, different samples.

1 plant, geranium to use for cuttings.

1 bushel sand for germination.

Soil. - Three bushels each of the following kinds of air-dry soil: gravel, sand, loam, and clay.

1 tube rack for holding capillary soil tubes.

18 inches rubber tubing, $\frac{1}{4}$ inch inside diameter. 


\section{APPENDIX}

\section{SECTION II}

\section{SUGGESTIONS TO TEACHERS}

The laboratory work of this manual is outlined to meet the needs of secondary schools giving a year's instructional work in agriculture. It is impossible to give satisfactory instruction in agriculture without practical demonstrations, which can only be given in the field and laboratory. In planning this laboratory manual the authors have assumed that five periods a week will be devoted to the subject of agriculture: three to be used for classroom and lecture work and two periods of one and one half or two hours' duration to be spent in the laboratory and field. Since it is occasionally necessary to make short trips and excursions during the laboratory period, it will be found most satisfactory to devote the last periods in the afternoon to this work. If this is done, it will be possible to make longer trips than could be made if the work occurred at some other time of the day.

Suggestions concerning Equipment. - The list of equipment given in Section 1 of the Appendix gives in detail all apparatus and supplies required to carry out successfully the exercises given in the manual. Very few schools will find it necessary to purchase this entire list of equipment, for most schools are well equipped to teach laboratory work in botany, ehemistry, and physics. Ordinarily the same microscope, balances, scales, and much of the glassware that are used for botany, chemistry, and physics may also be used in agriculture, to avoid the expense of duplication.

Soils. - There are a number of exercises in soils that demand special equipment. It is to the best interest of the work to provide this equipment when possible. Where funds are limited, less ex- 
pensive equipment may be substituted. Student lamp chimneys may be used to replace glass tubes in Ex. 8 and 14. Tin cans with perforated bottoms may be used to replace the percolator equipment in Ex. 9. The same cans may also be used in Ex. 11. Solid-bottom quart tin cans may be used to replace the equipment called for in Ex. 10. In Ex. 13 four-gallon crocks may be used to replace the soil cylinders. If crocks are used to replace the evaporation cylinders, the soil must be saturated with water by applying water at the top before the mulches are added.

Four types of soil are needed in the laboratory: gravel, sand, loam, and clay. The gravel and sand may be obtained along streams, or if no stream is convenient, it can be secured as concrete sand from local lumber dealers. The concrete sand should be sifted through a sieve twelve meshes to the linear inch. The coarser material will furnish gravel and the finer material sand. Loam and clay can usually be obtained near the school. All the soils should be thoroughly air dry, pulverized, and sifted before they are used.

Crops. - The laboratory exercises in crops require head samples and seeds of a number of the common cereals and legumes. It will be necessary for the instructor to secure samples of heads of the grains to be studied. This can best be done by collecting the material in the field. If field samples have not been secured, it may be possible to obtain them from stacks or barns where this material has been stored. Samples of threshed and shelled grain may be obtained from local mills and elevators. Some of the more uncommon grains and seeds can be secured from seed houses.

Type Samples. - It is impossible successfully to study types and classes of grain without using a standard for comparison. It may be possible for schools to obtain type samples of grains from their state agricultural experiment stations. The authors of this manual, realizing the difficulty that many schools will have in obtaining suitable type samples, have arranged to supply this material at a cost of 50 cents per case of six samples or $\$ 3.50$ for an entire set of 48 samples. (This price does not include postage or express.) These samples will be put up in glass-front cases, properly labeled, and will include type samples of wheat, oats, rye, barley, legumes, and grass seeds. 
Farm Machinery. - A number of farm implements will be used as equipment in the exercises of this manual. This machinery can be borrowed from local implement dealers. If it is not convenient to bring this machinery to the school grounds or laboratory, the class should be taken to the implement house for the work. If there are several implement dealers in the town, the class should be taken to the different dealers for the different exercises.

Live Stock. - A very limited amount of work on live stock is outlined in the manual. Where live stock is of special interest, more time should be devoted to this phase of the work. In communities where dairying is important several exercises should be devoted to judging dairy cattle. The animals used for class judging can undoubtedly be secured from farmers or live-stock owners in the community. Good live stock for school purposes can be obtained in nearly every place.

Field Lessons. - Field lessons can be made the most valuable part of the work in agriculture, but to accomplish this the instructor must carefully plan the work. The instructor must be familiar with everything to be observed and studied on the trip. In Ex. 68 and 69 , on judging a farm, the farm chosen for the field trip should be located as near the school as possible. The first day should be spent studying the farm in the field and the second day used in discussing the good and poor points of the farm and completing the score card.

Home Garden. - For the exercise on the home garden, Ex. 49 and 50, the first day should be devoted to, drawing the plan of the garden, spacing and arranging the crops. The second day should be used to figure the area devoted to each crop and the cost for seed as determined by prices secured from seed dealers.

Extra Exercises. - A few more exercises appear in the manual than it is possible to give in a year's work in agriculture. This will allow some choice of exercises by the instructor. Where equipment is not available to perform a regular exercise, an extra exercise may be substituted. Of the extra exercises 76 is adapted for the fall, while 77 and 78 are suited for spring. Where Ex. 78 is used, it should follow one month after Ex. 77.

A Final Word to the Teacher. - Nearly every exercise in this manual is of such length that all the time possible for the laboratory 
period will be required to complete the work successfully. It will, therefore, be necessary for the teacher to have all material at hand to start the work promptly at the beginning of the period. The instructor should plan for each laboratory period far in advance. This is absolutely necessary in the case of Ex. 16, 17, 18, 58, and 59, for which material must be prepared four weeks in advance of the class period. 
THE following pages contain advertisements of a few of the Macmillan books on kindred subjects 



\section{Cyclopedia of American Agriculture}

\section{Edited By L. H. BAILEY}

Director of the College of Agriculture and Professor of Rural Economy, Cornell University.

With Ioo full-page plates and more than 2000 illuse trations in the text; four volumes; the set, $\$ 20.00$ net; half morocco, $\$ 32.00$ net; carriage extra

Volume I - Farms Volume III - Animals

Volume II - Crops Volume IV - The Farm and the Community

"Indispensable to public and reference libraries ... . readily comprehensible to any person of average education." - The Nation.

"The completest existing thesaurus of up-to-date facts and opinions on modern agricultural methods. It is safe to say that many years must pass before it can be surpassed in comprehensiveness, accuracy, practical value, and mechanical excellence. It ought to be in every library in the country." - Record-Herald, Chicago.

\section{Cyclopedia of American Horticulture}

\section{Edited By L. H. BAILEY}

With over 2800 original engravings; four volumes; the set, \$20.00 net; half morocco, \$32.00 net; carriage extra

"This really monumental performance will take rank as a standard in its class. Illustrations and text are admirable. . . . Our own conviction is that while the future may bring forth amplified editions of the work, it will prohably never be superseded. Recognizing its importance, the publishers have given it faultless form. The typography leaves nothing to be desired, the paper is calculated to stand wear and tear, and the work is at once handsomely and attractively bound." - Nern York Daily Tribune.

PUBLISHED BY

\section{THE MACMILLAN COMPANY}

64-66 Fifth Avenue, New York 


\section{BOOKS ON AGRICULTURE}

\section{ON SELECTION OF LAND, Etc.}

Thomas F. Hunt's How to Choose a Farm

E. W. Hilgard's Soils: Their Formation and Relations to Climate and Plant Growth

Isaac P. Roberts's The Farmstead

\$I 75 net

400 net

I 50 net

ON TILLAGE, Etc.

F. H. King's The Soil • • • • • • • I 50 net

Isaac P. Roberts's The Fertility of the Land . . . I 50 net

Elwood Mead's Irrigation Institutions • • • • 125 net

F. H. King's Irrigation and Drainage . . . . I I 50 net

William E. Smythe's The Conquest of Arid America . I 50 net

Edward B. Voorhees's Fertilizers . . . . . I 25 net

Edward B. Voorhees's Forage Crops . . . . I 50 net

H. Snyder's Chemistry of Plant and Animal Life . . I 25 net

H. Snyder's Soil and Fertilizers. Third edition . . I 25 net

L. H. Bailey's Principles of Agriculture . • • . $\quad$ I 25 net

W. C. Welborn's Elements of Agriculture, Southern and

Western • • • • • • • 75 net

J. F. Duggar's Agriculture for Southern Schools . . 75 net

G. F. Warren's Elements of Agriculture . . . . I Io net

T. L. Lyon and E. O. Fippin's The Principles of Soil Management

Hilgard \& Osterhout's Agriculture for Schools on the Pacific Slope

J. A. Widtsoe's Dry Farming . . . . .

I 75 net

I oo net

I 50 net

\section{ON GARDEN-MAKING}

L. H. Bailey's Manual of Gardening • • • • 200 net

L. H. Bailey's Vegetable-Gardening . . . . I 50 net

L. H. Bailey's Horticulturist's Rule Book . . . 75 net

L. H. Bailey's Forcing Book . • • • • • 125 net

A. French's How to Grow Vegetables . • • • I 75 net

ON FRUIT-GROWING, Etc.

L. H. Bailey's Nursery Book • • • • • . I 50 net

L. H. Bailey's Fruit-Growing . . . . . . I 50 net

L. H. Bailey's The Pruning Book . . . . . I 50 net

F. W. Card's Bush Fruits . . . . . . I 50 net

J. T. Bealby's Fruit Ranching in British Columbia . I 50 net

\section{ON THE CARE OF LIVE STOCK}

D. E. Lyon's How to Keep Bees for Profit

Nelson S. Mayo's The Diseases of Animals

W. H. Jordan's The Feeding of Animals

I. P. Roberts's The Horse

George C. Watson's Farm Poultry .

C. S. Valentine's How to Keep Hens for Profit ${ }^{-}$

O. Kellner's The Scientific Feeding of Animals (trans.)

M. H. Reynolds's Veterinary Studies for Agricultural Stu-

I 50 net

I 50 net

I 50 net

I 25 net

I 25 net

I 50 net

I 90 net dents

I 75 net 


\section{BOOKS ON AGRICULTURE-Continued}

\section{ON DAIRY WORK}

Henry H. Wing's Milk and its Products . . . \$I 50 net

C. M. Aikman's Milk

W. D. Frost's Laboratory Guide in Elementary Bacteriology

I. P. Sheldon's The Farm and the Dairy
Chr. Barthel's Methods Used in the Examination of Milk and Dairy Products

I 25 net

I oo net

I 60 net

I oo net

I 90 net

\section{ON PLANT DISEASES, Etc.}

George Massee's Diseases of Cultivated Plants and Trees

J. G. Lipman's Bacteria in Relation to Country Life .

E. C. Lodeman's The Spraying of Plants

H. M. Ward's Disease in Plants (English)

A. S. Packard's A Text-book on Entomology . . . . 450 net

\section{ON PRODUCTION OF NEW PLANTS}

L. H. Bailey's Plant-Breeding . . . . . 125 net

L. H. Bailey's The Survival of the Unlike . . . 2 oo net

L. H. Bailey's The Evolution of Our Native Fruits • 2 oo net

W. S. Harwood's New Creations in Plant Life . . I 75 net

\section{ON ECONOMICS AND ORGANIZATION}

J. B. Green's Law for the American Farmer . . . I 50 net

J. McLennan's Manual of Practical Farming . . . I 50 net

L. H. Bailey's The State and the Farmer . . . I 25 net

Henry C. Taylor's Agricultural Economics - . . $\quad$ I 25 net

I. P. Roberts's The Farmer's Business Handbook . . I 25 net

George T. Fairchild's Rural Wealth and Welfare . . I 25 net

S. E. Sparling's Business Organization . • . . $\quad$ I 25 net

In the Citizen's Library. Includes a chapter on Farming

Kate V. St. Maur's A Self-supporting Home . . . $\quad$ I 75 net

Kate V. St. Maur's The Earth's Bounty . • . . I 75 net

G. F. Warren and K. C. Livermore's Exercises in Farm

Management

H. N. Ogden's Rural Hygiene . . . . .

80 net

I 50 net

\section{ON EVERYTHING AGRICULTURAL}

L. H. Bailey's Cyclopedia of American Agriculture :

Vol. I. Farms, Climates, and Soils.

Vol. II. Farm Crops.

Vol. III. Farm Animals.

Vol. IV. The Farm and the Community.

Complete in four royal 8vo volumes, with over 2000 illustrations.

Price of sets : cloth, $\$ 20$ net; half morocco, $\$ 32$ net.

For further information as to any of the above, address the publishers.

\section{THE MACMILLAN COMPANY}

\section{Publishers




\section{ELEMENTS OF AGRICULTURE}

\section{By G. F. WARREN}

Professor of Farm Management and Farm Crops, New York State College of Agriculture, at Cornell University

Cloth, r2mo. 434 pages. \$I.Io net

Upon the appearance of this volume, Mr. W. J. Spillman of the United States Department of Agriculture, Washington, D. C., wrote as follows :

"I wish to congratulate you upon this book. It is a type of book which has been much needed. We have had a large number of good books recently that were not up to high school grade. Dr. Warren's book will evidently make an excellent text for high school work in agriculture. It is comprehensive and at the same time intensive, considering the scope which it must necessarily cover. The subjects are well chosen and are excellently treated. I predict great usefulness for this book."

This prediction has been confirmed not only by the words of hundreds of teachers who have used the book and found it eminently satisfactory, but by the fact that it is now used in more than one thousand schools and the number is rapidly increasing. 
ОСТ $18 \quad 1912$ 
- 


. 






\section{LIBRARY OF CONGRESS

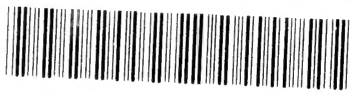 00027733554}

